
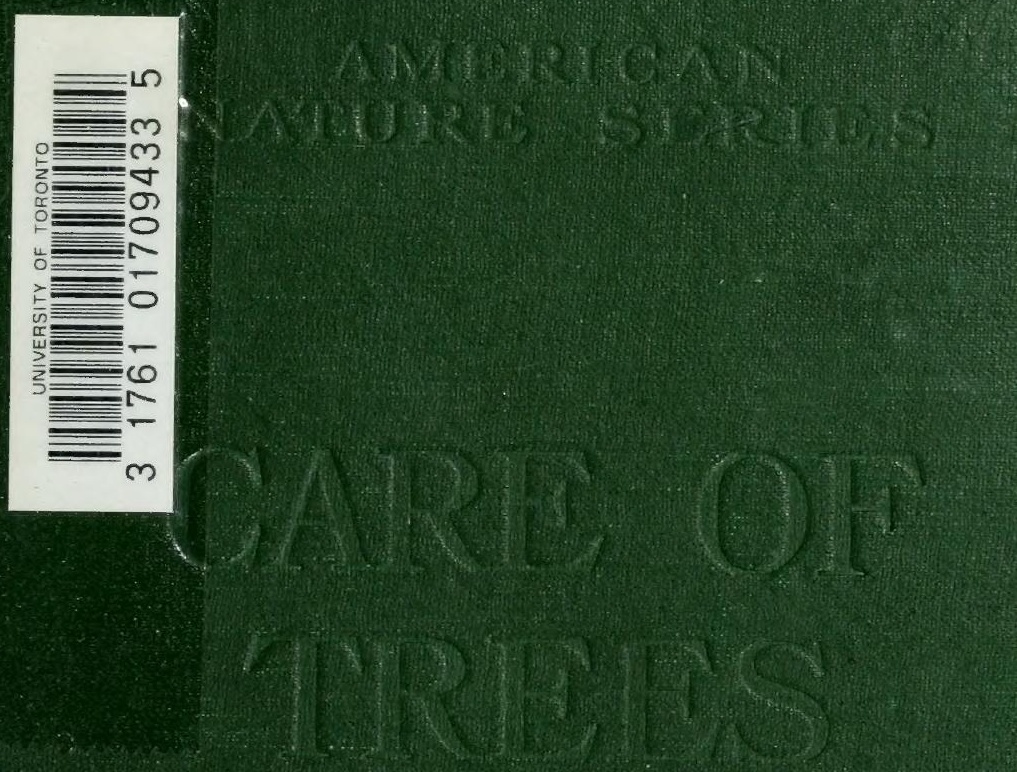

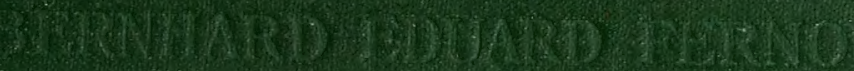




50 



\section{THE CARE OF TREES IN LAWN, STREET AND PARK}






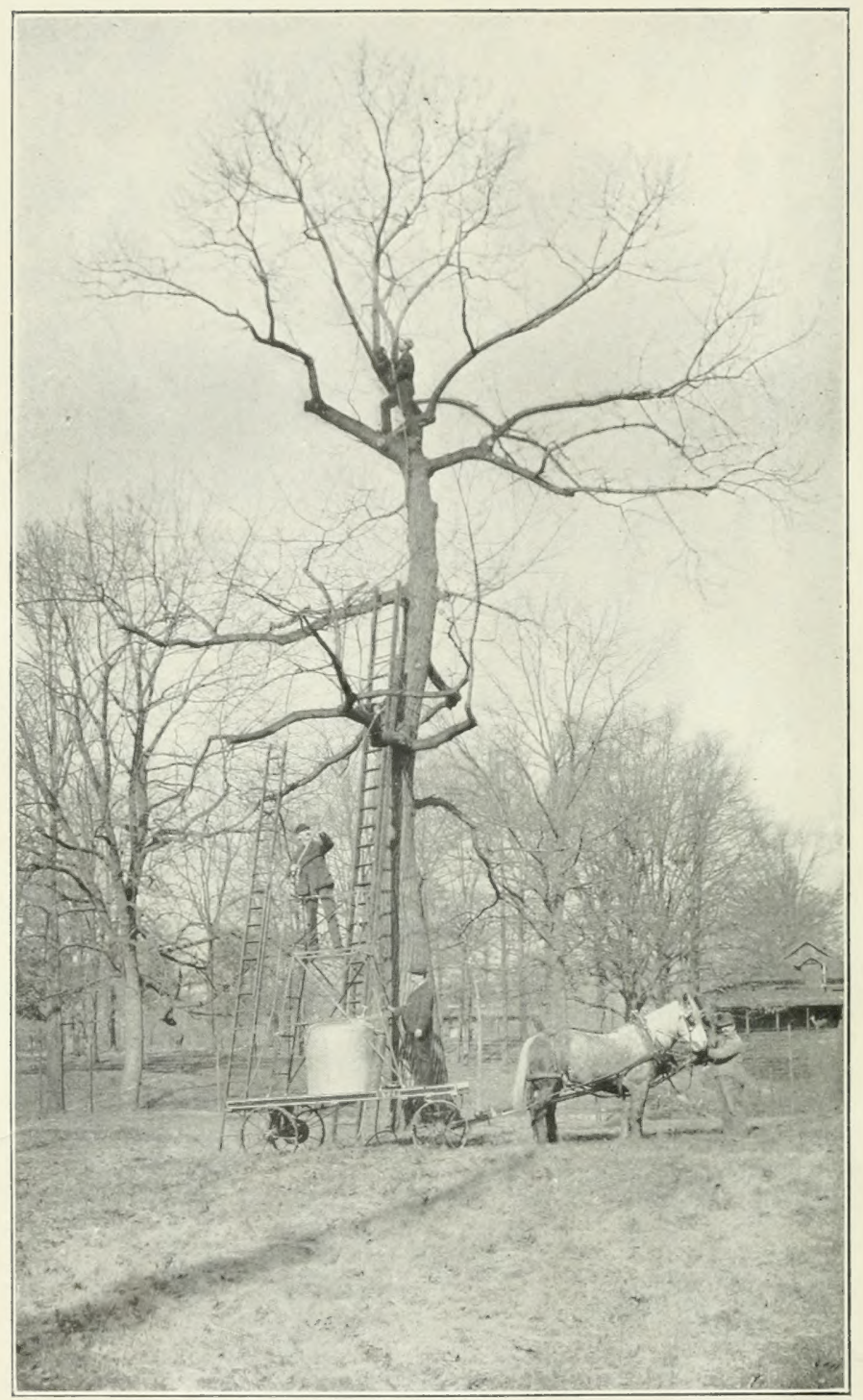

Power spraying outfit operating in a city. 


\section{American 円ature Sertes}

Group IV. Working with Nature

\section{THE CARE OF TREES}

IN LAWN, STREET AND PARK

WITH A LIST OF TREES AND SHRUBS

FOR DECORATIVE USE

BY

BERNHARD E. FERNOW

DEAN OF THE FACULTY OF FORESTRY,

UNIVERSITY OF TORONTO

\section{ILLUSTRATED}
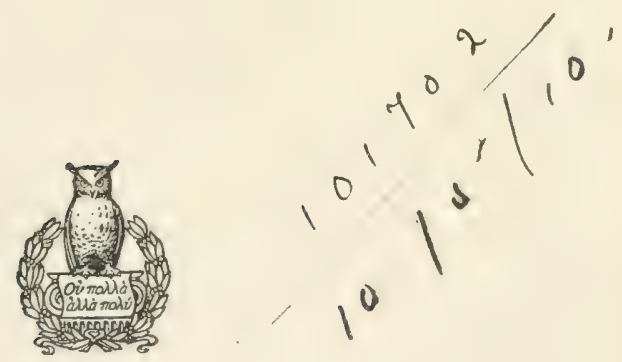

NEW YORK

HENRY HOLT AND COMPANY

I9IO 


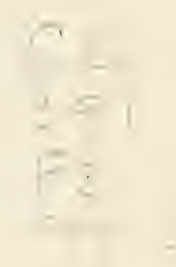

Copyright, Igro

BY

HENRY HOLT AND COMPANY

Published, April, 1910. 
TO MY VENERABLE FRIEND

DR. WILLIAM SAUNDERS

WHO HAS DEVOTED A LIFETIME IN ADVANCING KNOWLEDGE OF TREE GROWTH IN CANADA, BOTH IN ITS USEFUL

AND ORNAMENTAL AS P ECTS 



\section{PREFACE}

This volume is an accident, as it were, so far as its authorship goes. The author being a forester by profession, and, therefore, concerned with the utilitarian use of trees rather than with their ornamental employment, the subjectmatter of this volume might be considered foreign to his training. A forester, however, must be familiar with tree life in all its phases, so as to have judgment regarding the requirements of trees in health and disease and the proper care of them under all circumstances. Nevertheless, it was only an accident that induced the writer to devote time to the compilation of the present volume. A request by a tree owner for expert advice in the care of his lawn trees disclosed the fact that apparently no satisfactory, comprehensive treatment of the subject for amateur planters of trees was in existence, whatever might be said of the literature for specialists. This induced the writer to attempt to set down, as briefly as possible, what every tree owner should know of the care of trees.

The fact that the writer had for many years lived in Washington, D. C., and had taken a special interest in studying the composition of its many parks - indeed being for some time in charge of Soldiers' Home Park, also acting on a commission on the reconstruction of Central Park, New York - these experiences with ornamental tree-growth may entitle him to claim the necessary judgment in selecting from the vast amount of information that exists on this 
subject, that which would be most uscful to those readers for whom the book is intended, namely; the practical lovers and owners of trees.

Special acknowledgment is due to Dr. N. L. Britton under whose supervision the drawings of exotic tree species - and only such have been illustrated - were made. It is due to him to explain, that in the captions under these illustrations, contrary to the usage of Dr. Britton and many other botanists, species names derived from patronymics have been capitalized to conform with the mode of notation applied in the text, which is the mode still in use in most nurserymen's catalogues.

The author acknowledges his indebtedness to a large number of publications, too many to cite, from which he has extracted information, especially the many bulletins of Experiment Stations on combating insects and fungi. He claims originality mainly in the manner of presentation, and hopes that he has performed a useful service.

B. E. F.

Toronto, March, I9Io. 


\section{CONTENTS}

CHAPTER

PAGE

I. INTRODUCTORY . . . . . . . . . . . I

I. CHARACTERISTICS, STRLCTLRE AND LIFE ()F TREES - . . - . - . - . - - 5

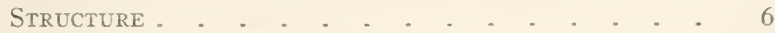

Growth AND Form DEVElopMent . . . . . 8

Physiological Points - - . - . . - . . . I7

Ecological Points - . . . . - . - . . $2 \mathrm{I}$

Recuperative Capacity - . - . - . - 26

III. DISFASE AND DFATH ()F TREIS. (GENER.ILITIES 20)

OLd AGE - . . . . . . . . . . . . 30

General Cause of Disease - . . . . . . 32

FLNGLS DISE.ISES . . . . . . . . . . . . . . . . . . . . . . . . .

INSECT DAMAGE - . - . . - . . . 44

IV. DIAGNOSING DISEASES - . . . . . . . 5 I

INSECT DAMAGE - . . - . - . - . - 53

Fungus ANd Bacterial Diseases - . . - . 55

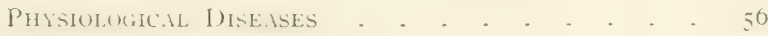

Effect of Soll Conditions - . - . - . 57

Atmospherical INfluences - . . - . . 63

Obxoxious Gases . . . . . . . . . . . . 68

Electric Currents - . - - - - - . . . 71

Light Conditions - . - . - . . . . 73

MEChanical InJuRIES - . . . . . . . . 74

V. CONTROL OF PHYSIOLOGICAL DISEASES AND

TREATMENT OF MECHANICAL INJURIES.-

GENERAL CARE OF TREES . . . . . . 76

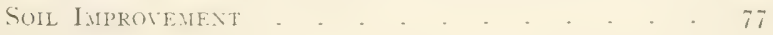

Fertilizing - - . - . - . - . - . - 79

Pornts in Grimivg . . . . . . . . . . So

Pruning and Trimimg - . . . . . . 83

Manjer of Operation - . . . . . . . . 87

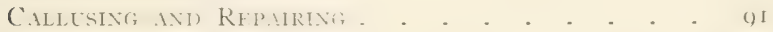

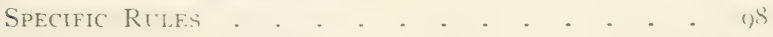

Pruning For Balance. - . . . . . . . . $9 \mathrm{~S}$ 
CHAPTER

PAGE

PRUNING FOR FORM - . . . . . . . . . IOO

Pruning Street Trees - . . . . . - . . IOM

PRUNING FOR FLOWERS . . . . . . . . . . IIO

REPAIRING DAMAGE - - - . - . . . . . III

Treatment of Street Trees - . . . . . . . II6

CARE of THE AGED - . - . . . . . . . . . III

QUACK MEdICINES - . . . . . . . . . . . 123

VI. CONTROL OF PARASITES . . . . . . . . 124

Fungus Parasites - . . . . . . . . . . . 124

Insect Parasites - . . . . . . . . . . . . 128

Civic Cooperation - . . . . . . . . . . . I3I

General Methods of Procedure - . . . . 133

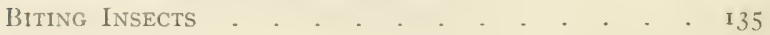

SUCKING INSECTS . . . . . . . . . . . IfI

Mechanical Destruction of Insects . . . . . 144

BORERS AND BARK-BEETLES . . . . . . . 146

ROOT DESTROYERS . . . . . . . . . . I 48

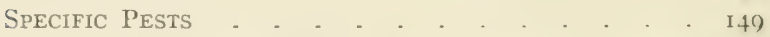

VII. CARE IN PLANTING TREES . . . . . . . . I6S

VII. ESTHETIC FORESTRY OR WOODLAND PARK

MANAGEMENT _ . . . . . . . . . . IS5

IX. CARE IN THE CHOICE OF PLANT IIATERIAL - I97

General Considerations . . . . . . . . mgh

List of Trees Desirable for Shade and Ornament 206

List OF SHRUBS - . . . . . . . . . 322

Selected Lists of Plant Material for Special

PURposes . . . . . . . . . . . . . 364

BRIEF LIST OF BOOKS ON COGNATE SUBJECTS - . 375

INDEX - . . . . . . . . . . . . . . 377 


\section{THE CARE OF TREES}

\section{CHAPTER I}

\section{INTRODUCTORY}

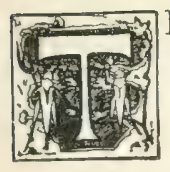

HIS book is not a sentimental effusion on the beauty and need of trees, but a compilation of information such as the owner of trees may be in search of.

Throughout our entire continent, especially in its more settled parts, and most of all in its cities, there has never before been such widespread interest as is now manifested in trees and tree-planting for shade and ornament. Although this kind of tree-planting has been quite assiduously practised in past generations, and although as a result we are the heirs of stately elms and oaks and maples, the necessity of greater care for this inheritance has only of late been fully realized. As a consequence, the "Tree Warden" and "City Forester" have become recognized institutions, and the statutes of several states for the protection of planted trees bear testimony to the popular sentiment, and to the conception that the care of public shade trees is a public duty.

Although with this awakened interest there has come forward a large amount of information regarding the care of trees, in the form of bulletins and essays, these generally confine themselves to some particular phase of the subject; a collective and more comprehensive manual, so far as the writer knows, is still lacking. It is to supply this gap that 
the present book has been written. Naturally the book does not bring much, if any, new knowledge; it is mainly a compilation of the well-known facts which bear upon the subject, selected, however, with the experience of a lifetime spent in the study of trees.

Believing that only a knowledge of relationships, principles and reasons enables one to apply prescriptions intelligently, and that a knowledge of the nature of trees is necessary in order to care for them properly, it has been the endeavor to broaden in this direction, without, however, becoming too technical. Technical language has been employed as little as possible and technical minutice, which, though interesting and valuable, may in the ordinary routine be dispensed with, have been as much as possible aroided.

The attempt to make the relationships clear to laymen has necessitated their presentation from various points of view in the different chapters, and this has led to repetitions; but, while such repetitions may be censured by the literary critic, the author believes that they serve the useful purpose of impressing the essentials upon the reader, and of making him familiar with the subject.

The care of shade and ornamental trees is an entirely different matter from the care of forests. It is unfortunate that the distinction has not always been clearly perceived. The object of forestry is the substance of the tree: only when the tree is cut and its wood utilized, is the object of the forester attained: he grows trees, not to be preserved, but to be hariested. Hence to call the tree-wardens of towns and cities "foresters" is a misnomer. The tree that satisfies the forester is most unsatisfactory to the landscape gardener or street tree planter, and vice versa. The latter arboriculturists are after shade or beauty of form, hence their treatment of trees is entirely different from that of the 


\section{Introductory}

forester, although, to secure the object in either case, the nature and life history of trees must be understood. On the other hand, no more fitting title, no better description of the duties of those who are set to care for our roadside trees or our city trees in street and park could be invented than that of "tree-warden," a most expressive, dignified, and honorable designation.

To the owner of trees who appreciates the value of his property and who realizes that it is an investment which can be duplicated only in time and by time, it is not necessary to point out that it is worth his while to take care of it. No millionaire can replace the ancieni spreading oak or the shapely old elm in his lawn by any amount of expenditure: these are the heirlooms of hundreds of years, and years alone can replace them. The Massachusetts courts adjudging the value of shade trees in damage as from S $50_{5}$ to $\$ 200$ hardly come up to the full appreciation of their full worth. Even though it is possible to transplant fullgrown old trees, it cannot be done with assurance of success, or at least not without interference with the natural form of the crown; in any case such transplants are a hazard.

On the other hand, trees in place may be rendered almost imperishable by proper care and attention.

To bring about this result requires some knowledge of the nature of trees, and also of the ills that may befall them. It is only through such knowledge that we are able to guard against the diseases and dangers which destroy prematurely so many valuable specimens on our lawns, and in our streets and parks.

Many of the fine remnants of former forest glory or of old-time planting which arlorn the grounds of our wealthy citizens and of our more humble home makers go to pieces, gradually, unobserved, and unnecessarily, because of neglect 
and carclessness; a little care at the proper time would have saved the investment which cannot be duplicated in the owner's lifetime.

In almost every small and large town in the C'nited States there has been a remarkable activity in the planting of street trees during the last fifty years; but for the lack of care the majority, perhaps, of these trees have become cripples, doomerl sooner or later to an untimely death. The public usually recognizes only the foliage and the shade, and fails to observe the insidious work of fungi, induced through breakages and bad pruning, and overlooks the unsightly scars and wounds and stubs which bring about this premature decline and death - all for lack of care.

To make owners of shade and ornamental trees more sensible to the care and attention which their property demands, to give them not only more interest but also specific advice, a "first aid" toward a knowledge of what this care should be, and to assist tree-wardens in caring for their charges with more circumspection, this book is written.

It is hoped that the perusal of these pages will enable any interested owner of trees to make himself intelligent as to the nature of trees, to help himself in most cases in their care, to aroid foolish practices advised by the quacks, and to superintend intelligently the execution of professional advice. For this purpose it is necessary first to have some knowledge of the life of trees and of their behavior in normal conditions, for then only will it be possible to recognize abnormal conditions, to diagnose disease, and understand the rationale in the use of the remedies.

It must, however, never be forgotten that the judgment of an cxperienced man is sometimes necessary to diagnose the case correctly, and to prescribe for it. 


\section{CHAPTER II}

\section{CHARACTERISTICS, STRUCTURE, AND LIFE OF TREES}

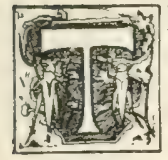

HE woody plants, trees, shrubs, and some vines, differ from all other plants in at least two directions: namely, in their persistent life, with only temporary rest periods in growth, a characteristic which indicates differences in structure from that of annuals - and in their clevation in height above the rest of regetation, which implies, besides difference in structure, difference in performing the functions of life.

Trees as a rule show these two characteristics of height and persistency of life in a most pronounced degrce. In addition, they differ from shrubs and vines by their form; namely, a single stem, rising from the ground, - the bole or trunk, - which develops more strongly than the branches, into which it divides in characteristic fashion, and which in their aggregate may be differentiated as the crown. These characteristics of form, longevity, and height make trees the most prominent and one of the most important, and most inieresting features in the living vegetable world.

To be able to care for trees, to diagnose diseases or abnormal conditions and to apply remedies judiciously, it is necessary to know and understand something of the structure, and of the life requirements of a healthy tree in normal condition. Indeed, we may say that only to the extent that this primary knowledge is possessed, can a rational treatment of trees be expected. 
Structure. 'That a trec, like crery other living thing, is composed of tissues marle up) of minute cells varying in shape, size, and thickness of cell-wall, is probably well

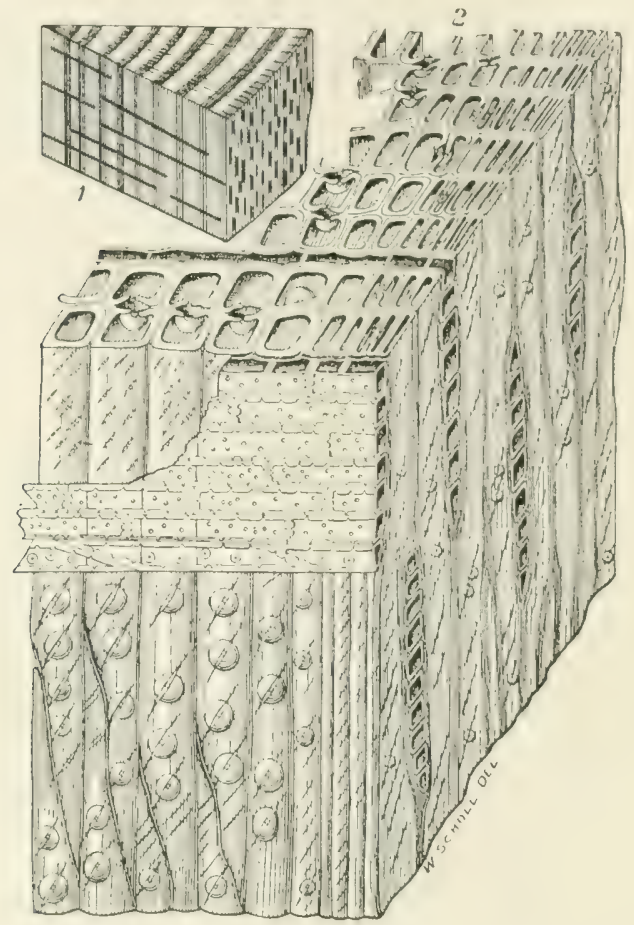

FIG. I. - Cell structure of a tree. (I) Appearance of a section of spruce wood, natural size; (2) Cell structure of same, magrified roo times (after Hartig, from Department of Agriculture, Forestry Division Bulletin, No. 10).

known to evervbody. But that the bulk of the bole of the tree is really not living but dead tissue, composed of cell cases without living contents, is perhaps less well known. While partially active in conducting water, most of the wood is merely supporting tissue. It is for this reason 


\section{Cell Structure}

that a tree may have its heart riddled and eaten out by fungi without losing in anything but firmness and stability.

Cell Structure. The living tissuc of the bole lies on the outside of the wood, between bark and wood, - a narrow layer of a few cells, called the cambium, enveloping the dead wood. This layer, by division and growth of the cells forming it, makes the new rood of the year, the "annual ring," which again dies for the most part, soon after it is formed, only the outermost cell tissues, the cambium cells, remain fully alive, i.e., capable of growth and subdivision.'

Injury to this portion is, therefore, directly of consequence to the welfare of the tree.

Besides the cambium layer, there are two other points at which persistently living cells are concentrated; namely, the tips of the roots or fibrils, and the tips of the shoots, the so-called growing points or buds. From the buds the shoots and leaves develop, the latter remaining living for only a few months, or, in the case of the needles of coniferous trees, for a few years.

It is, then, after all only one year's product that really lives, in the full sense of the word, and this living portion encloses a mass of tissues which have lost their life, although they may be still of service to the tree in conducting and storing water or food, in giving stability, or in other ways.

The outer bark also dies, new bark being formed on the inside next the cambium; and, as the growth of the annual ring of wood and bark on the inside proceeds, the outer dead portions of bark must give way under the pressure of the interior growth. In most cases these dead portions of bark break in characteristic form into fissures, ridges, plates, or scales, which may sooner or later loosen and be slougherl off.

${ }_{1}$ This is not entirely true, for certain tissues like the pith rays may be still considered as living. 


\section{Characteristics, Structure, Life of Trees}

This thick or outer bark is, therefore, of no direct use in the life of the tree, though indirectly it may be of use in protecting the living tissue underneath against heat and cold, against drying out and against mechanical injury. The scraping of bark, so often foolishly practised, is, therefore, in most cases either useless, or even, as it reduces the protection, injurious. Its only, yet doubtful, usefulness may be found in curtailing the chance for insects to hide their egges or cocoons; and, under certain abnormal conditions, when the tree is "bark bound," the operation of barking or slitting the bark may then be found useful in removing pressure, although other means of overcoming the trouble are probably better.

Growth and Form Development. Except in the trees of the palm tribe (which do not increase much in diameter, but start from the seed in nearly full size of girth) the growth of the trce in thickness takes place by division and growth of the cambium cells, annually adding a cone-like envelope over the whole body of the previous years; in cross section these annual envelopes appear as "annual rings." Hence the age of a tree can be determined from the number of rings, if it is cut low enough to include the first year's growth. Only under rare conditions does the tree, in countries with a definite growing season, fail to make this annual growth, or does it make apparently two or more such rings.

The growth in height or in length of branches and in the spreading of the crown is secured by addition of new shoots, which are developed from the buds. These shoots grow in length only during the season in which they are formed, then become rigid, and in these, no more growth in length but only in thickness is experiencer in subsequent seasons. The end-bud, which usually terminates the year's shoot, if not lost by frost or drouth during the winter (and in some 


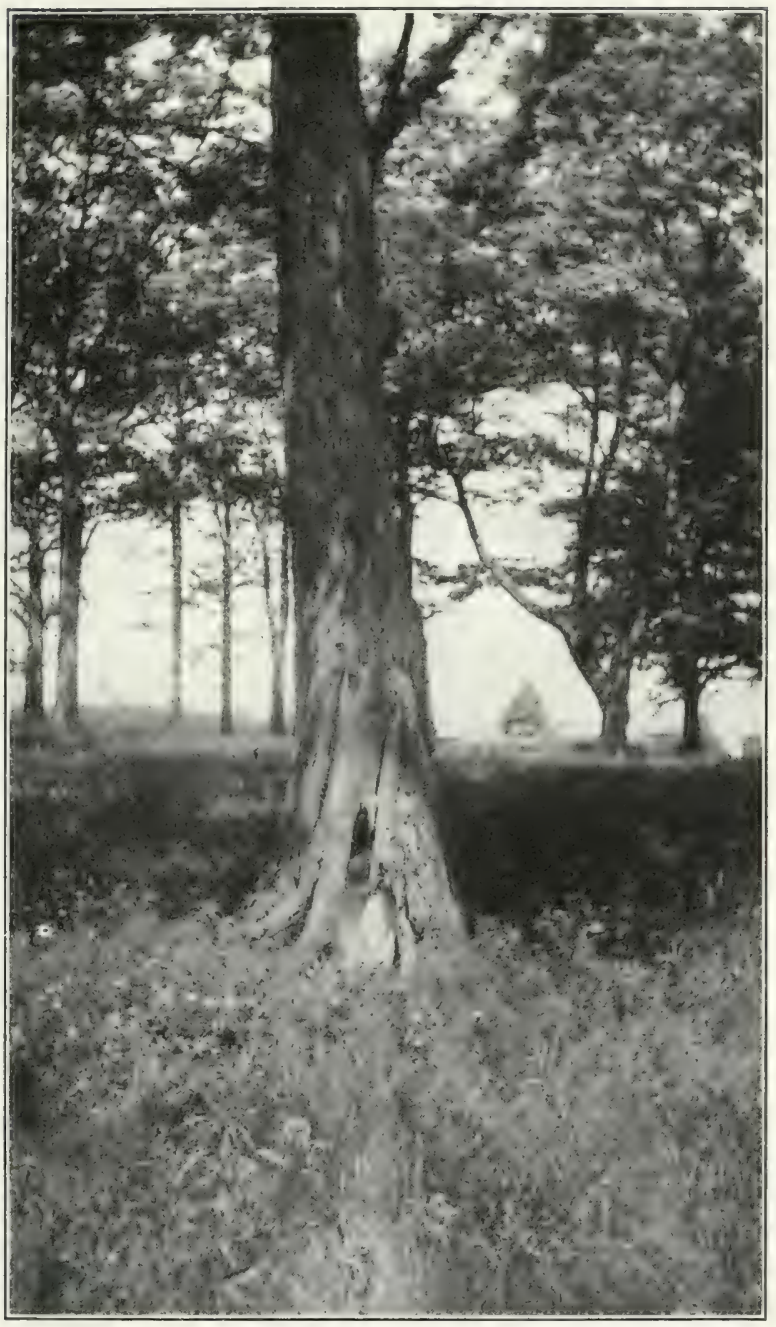

FIG. 2. - A tree, completely hollow at the base, but with the crown alive and fully developed. 


\section{Io Characteristics, Structure, Life of Trees}

species it is recrularly so lost), or else a sirle-burl near the tip, restumes the activity in the next season and lengthens the

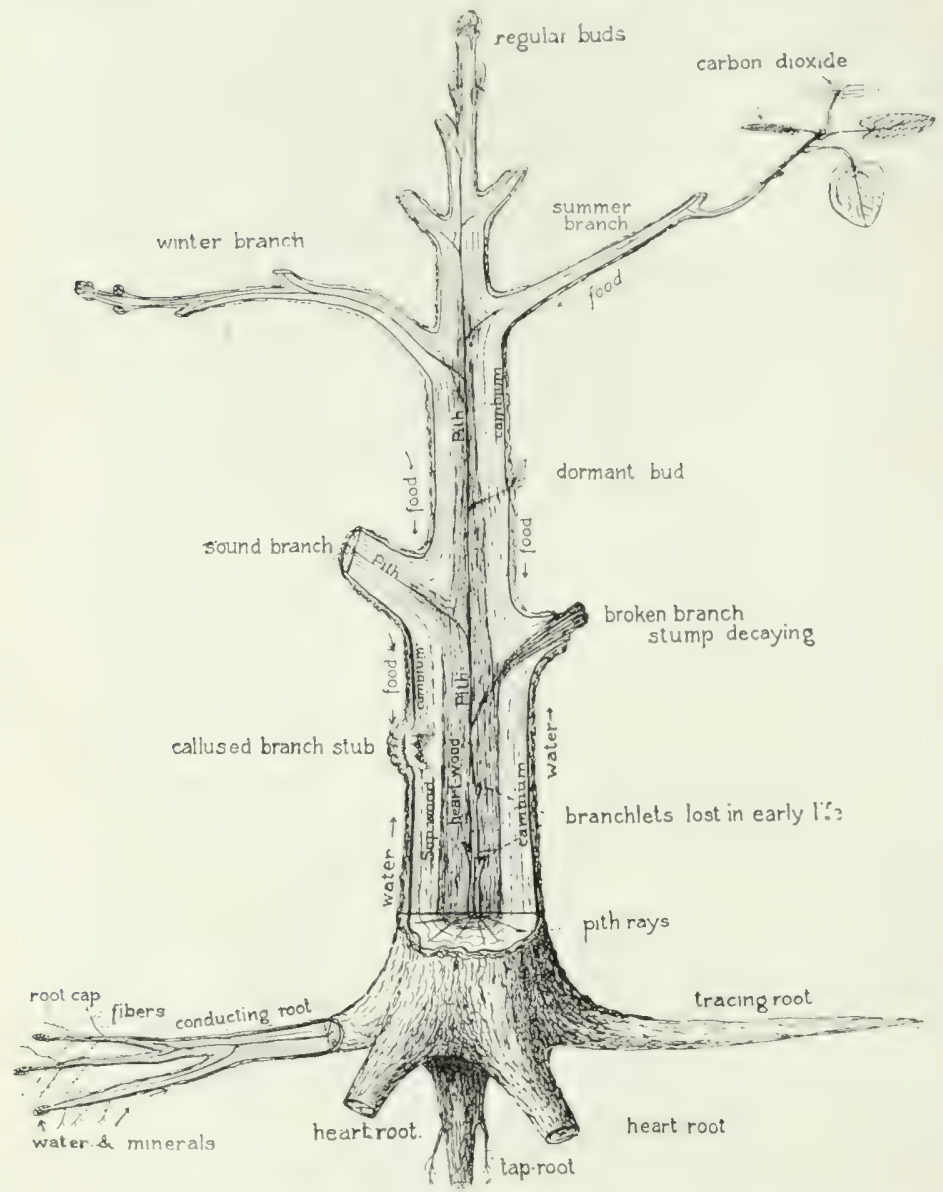

FIG. 3. - Diagrammatic view of the various parts and functions of a tree.

twig, forming at the sime time the leaves, and possibly flowers.

In this way, from scason to season, story after story is built up: cach twig, lengthening by additions and also gain- 
ing in diameter by additions, grows into a branch; new branchlets start from buds along the length of the mother shoot, the daughter shoots forming side branches, and by repeated ramifications, gradually from year to year, the crown is built up, characteristic in form and following well-known laws, typical for each species.

One important fact to be observed in this process of building up a crown is, that not all the buds which are formed on the twig develop into shoots; some remain undeveloped or dormant as buds, some are frozen, some dried up, some eaten or broken off; and even of the shoots which have been developed not all grow into limbs or branches: many are lost sooner or later by causes similar to those which destroy the buds, and by the withdrawal of light and food, as the upper portions of the crown develop and cut off from the less favorably placed portions the necessaries of life. Just as in the animal world the struggle for existence necessitates
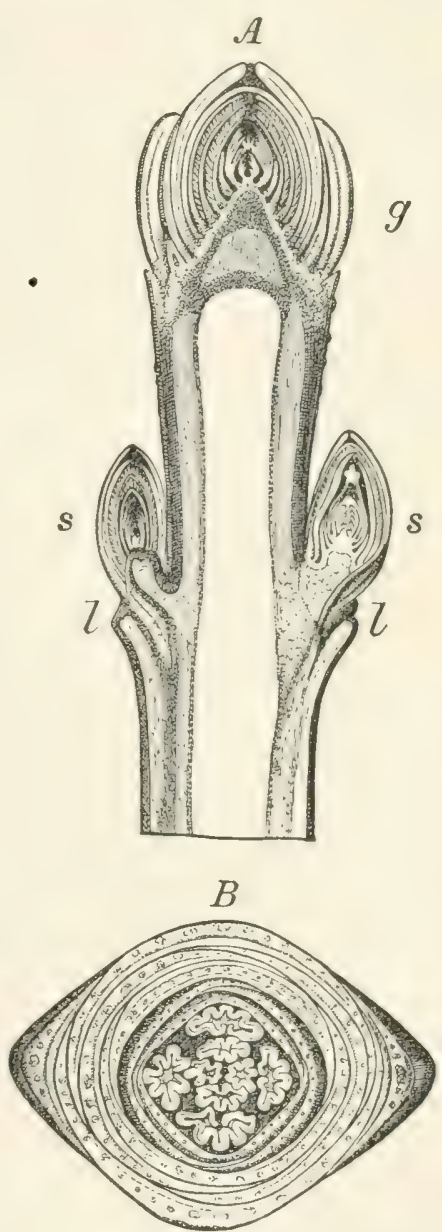

Fig. 4. - Bud Structure (Maple), $A$, longitudinal section through branch lip; $g$, end bud; $s$, lateral buds; $l$, scars of leaves of last season. $B$, cross section through bud, showing folded leaves in center and scales surrounding them. 


\section{I2 Characteristics, Structure, Life of Trees}

violent death and diminution in numbers, more or less proportionate to food supply and new births, in order to keep an equilibrium, so in the forest a constant diminution of individuals takes place as the stand grows up and the individual trees expand, competing for the limiterl air space and root space.

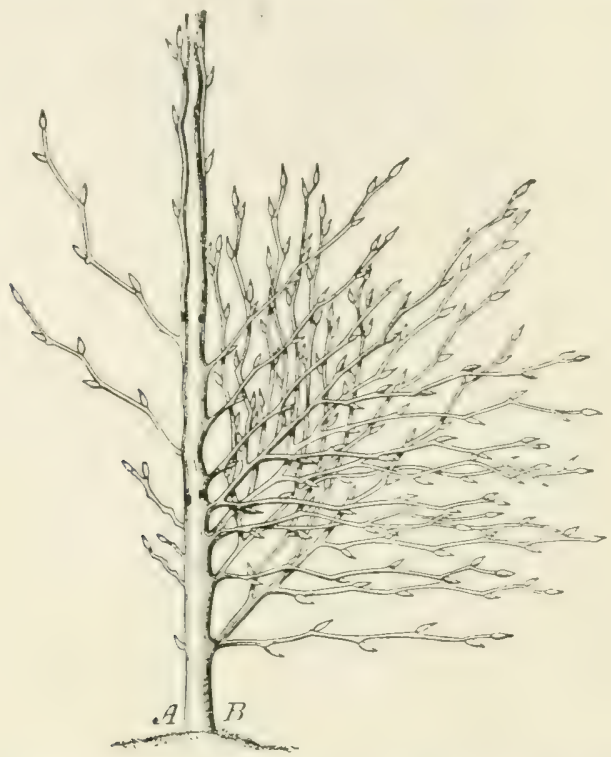

FIG. 4a.-Theoretical $(B)$ and actual (A) development of buds. (From Department of Agriculture, Forestry for Farmers, after Müller.)

So also in the individual tree there exists a competition for light and water between the many buds, twiss. and branches, and sooner or later some must succumb as their number increases and the supplies become relatively lesis.

As a result, in the full grown tree rarely more than eight or ten generations of branches can be counted, - the surrivals of this competition; the rest having been killed out, and being annually killed out, by the necessity of household 
economy. If this were not so, if all the buds formed and all the branches developed in mathematical order, very different forms from those with which we are acquainted would result.

This observation of the natural pruning of buds and twigs - withdrawal of water and light killing them and wind storms breaking them off - which takes place annually, especially as the trees grow older, is important in taking care of trees. It teaches that not all dying or dead branchlets, which we find on the normally developed tree, indicate any disease or abnormal condition. It teaches that pruning is not an unnatural but a necessary operation which, if neglected and not systematically directed by man, will be done by nature in a haphazard manner without reference to the wishes of man as to form. We learn from this that with the expanding crown some parts, the less favorably lighted ones, as for instance the interior or the lowest portions in a conifer, must eventually be lost, and, if we remove them in time, we have it in our fower to direct the development of the tree in form, favoring in the competition those parts, which we desire to preserve or develop.

Another fact in the development of the crown, which from different points of view interests the forester perhaps more than the tree-warden is, that every regularly formed branch or limb has its origin, its base, in the very center of the trunk or branch from which it arises, its pith or central portion being in direct connection with the pith of

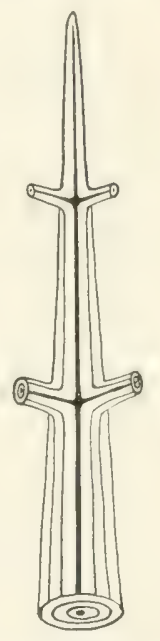

FIG. 5.-Diagram showing the connection of all branches with the pith. the bole or mother branch. The growth of wood which takes place annually on the bole or mother branch envelops 


\section{I4 Characteristics, Structure, Life of Trees}

the base of the daughter branch more and more, while the latter itself is also growing in diameter.

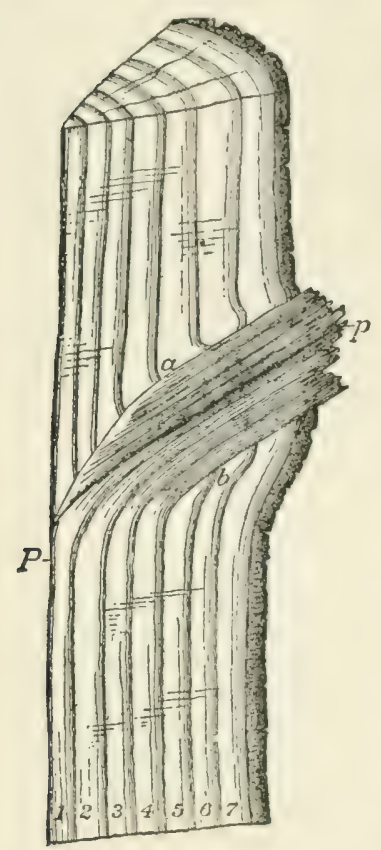

Fig. 6. - Method of formation of a knot. Seven amnual layers of wood; $a, b$, basal parts of a limb, which lived four years, then died and broke off near the stem. This leaves a "sound" knot to the left of $a$, the branch stub to the right forming a "dead" knot soon to be covered by the growing stem. (From Department of Agriculture, Forestry Bulletin, No. IO).

or pith of the branch or bole, which forms a direct and continuous communication through the entire tree from the method of branch formation, because he knows that, owing to it, every branch or limb which once existed will produce a "knot" in the lumber, although this lumber may be sawed from an apparently branchless bole. As long as the limb remained alive, this will be a "sound" knot; after the limb has died, it will be a "loose" knot (in conifers), or a decayed knot, leaving a blemish or hole in the board. The forester, therefore, attempts to grow his trees so as to kill out most limbs as early as possible in order to reduce the size and number of knots and thus secure a branchless bole.

When, however, a branch is broken or cut off, a dormant bud may derelop into a branch. Such dormant buds are connected with the pith by a fine trace of pithy material not large enough to be noted as an imperfection.

There is an interest in this structural peculiarity which concerns the tree-warden. The center

The forester is interested in this 


\section{Growth and Form Development}

tips of the roots to the tips of the crown with all its ramification of branches, consists of very loose, thin-walled cell tissues; hence it affords an easy pathway for the growth of the mycelium of wood-destroying fungi. It is along this line of least resistance that the most rapid progress of rot is made, and hence there is need for particular attention to the branch wounds where the fungus enters.

The root system develops in a manner somewhat similar to the crown, lengthening and ramifying by annual additions and increasing in diameter by division and growth of cambium cells. There are, however, differences in development, due, no doubt, to the difference of the medium in which the roots live. The soil offering more resistance than the air, the

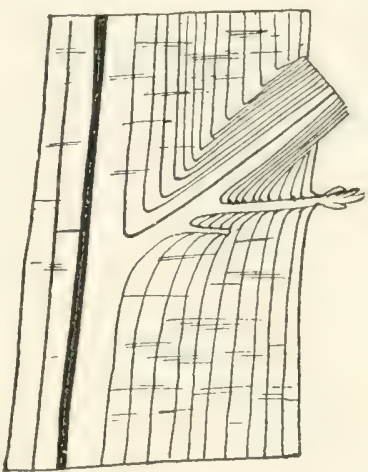

FIG. 7. - Method of formation of adventitious branches from the growth of dormant buds. ramifications are less regular. Instead of having more or less systematically arranged buds from which new roots may form, irregular growing points may arise on any part of the root where the bark is not too resistant, thus producing the new growth. The root system is therefore less regular, less symmetrical than the crown system. Nevertheless, as we recognize typical forms of crowns like that of the conical conifer, the spreading oak, the rase-shaped elm, so there are typical root systems, which fact has more bearing upon the form of ornamental and shade trees, than is usually recognized.

Although the root systems of most trees are very adaptive, there is a limit to the adaptation, and, as the trees grow older, the difficulty of adaptation grow's greater, and shows 


\section{Characteristics, Structure, Life of Trees}

itself in change of form of crown, or in lack of vigor. An entirely different shape from the expected may develop.

There are three types of root systems: the tap-root, the heart-root, and the tracing-root; in some species the type is and remains very pronounced, in others a change and adaptation is more easily effected.

The tap-root, perpendicular like the bole of a conifer and penetrating deep into the ground, is adapted to deep soils, and the difficulty of maintaining a hickory, a walnut, a fir, or some of the pines in a soil which is shallow-due to rocks or impenetrable layers, or groundwater close to the surface - is often due to the inability of adaptation of their tap-root systems.

The oak, also a tap-root tree, adapts itself more readily than those mentioned, splits up its tap-root into several strong heart-roots, and develops a considerable quantity of surface or tracing-roots, but then the short, stubby stature and rapid tapering of the tree above ground shows that it is not in its natural condition. Elm, ash, and linden behave in a similar manner, hickory and walnut resent curtailment of their tap-root more strenuously, and hence are difficult to transplant or to grow on shallow soils. The spruce, on the other hand, is one of the trees, which, with a typical tracingroot system, developing horizontally in the upper soil strata, can occupy the shallow soils without effect on its form derelopment. So can willows, poplars, and birches, while beech and maple with a regular heart-root system made up of several strong roots descending obliquely into the ground, stand between the two types first mentioned, both in requirement for soil depth, and in adaptability.

IVith the recognition of these characteristics in root development we shall not expect the same species of trees to produce the same form and remain alike under all 


\section{Physiological Points}

conditions. To this very important relation which exists between root and crown development we shall refer again further on.

Instead of leares, the youngest parts, i.e., the tips of the roots, are beset with fine hairs; delicate structures which serve the purpose of taking up water. The root-hairs live only a rery short time, hardly through the season, being ever replaced by new hairs near the tip, which constantly pushes into new soil. The tips of the roots, therefore, are the most important part of this organ for the life functions of the tree.

Physiological Points. The may now take a brief glimpse into the household affairs of the tree, - the manner in which it lives.

The essential fact which must be realized is, that the leaves and buds at one end, and the tips and youngest parts of the roots at the other end, with the cambium layer connecting the two, are the living tissues, and hence the main factors in the houschold. The tips and youngest ends of the roots or rootlets, densely beset with little hairs, are the mechanism which takes up the water and minerals from the soil. These are conducted through the roots by way of the cambium and the younger wood and bark to the leaves. The leaves in turn take up carbonic acid from the air, decompose it in their green parts (chlorophyll) under the influence of light, and combine it with the minerals and water into food materials which can be used in building up the body of the tree. This process is called assimilation. The food materials, manufactured in the leaves, wander through the veins and stalk: of the leaves inio the cambium and the youngest rood and bark of the stem and root, where they are used in new growth during the season. making the annual ring, or else are stored esjecially in the pith rays) 


\section{I8 Characteristics, Structure, Life of Trees}

for next year's growth all the way down to the root tips. The stored material is then used the following spring to form leaves and shoots and new rootlets.

The whole mechanism of the tree can le compared to a sytsem of water works - water being the most important factor in the life of the plant - the root tips being the pumps or valves taking up water with minerals in solution from the soil. The roots and stem and branches are the conducting pipes; the leaves are the engines where the power is applied which sets the current in motion: namely, heat, light, wind, and other causes of transjiration (evaporation).

In the leaves, which may also be regarded as the stomach of the plant, the raw food is digested and assimilated into a form in which it may be used by the plant, and thence it is carried by osmosis ${ }^{1}$ to places where it is needed.

It stands to reason that the amount of foliage which is active under the influence of light, determines the amount of assimilated food material which will be at the disposal of the tree and hence the amount of growth. The leaves and their healthy function are, therefore, of the highest importance to the tree; but just as important is the number of root tips capable of securing water and the necessary minerals.

For best results the amount of active foliage and of active rootlets must be in direct proportion; and, indeed, there is such a close relation between the two, that if for some reason the normal amount of active leaf surface is reduced, as by insect injury, a corresponding amount of rootlets may die because not fed, unless a surplus of stored material is available. Even more surcly, if the root system is in any way curtailed, as for instance when a cut for a street is made,

1 Osmosis is the name for the process by which liquids are diffused through membranes. 


\section{Physiological Points}

or the ground lowered, or if the roots fail to be supplied with sufficient water, the foliage and with it the whole crown will suffer in proportion.

Generally speaking, each side of the crown is in more or less direct relation with the same side of the root system, the roots living on one side feeding the foliage on that side, and vice iersa. There is, in other words, more or less direct reciprocity between branch and roots. Hence, if a root on one side of a tree is cut through, a branch on or near that side may die or suffer. As the shoots lengthen each year, so the roots lengthen; and since only the roungest root tips remain active in taking up water, it stands to reason that they must be fed in order to renew themselves, and to perform their function.

Anything that prevents the descent of food material from the leaves, as when by partial or total girdling ${ }^{1}$ of the tree the conducting tissue is reduced, will therefore starre and eventually kill the root srstem, partially or entirely. Conversely, if the root cannot furnish enough water to the leaves, these must wither and die, and finally the whole tree will succumb. Again, if any of the needed minerals are deficient in the soil, this fact will be indicated by at least some abnormal derelopment in the foliage, changes of color, size, form, etc. The interdependence, then, of roots and leaves is complete, an important fact in diagnosing abnormal conditions of either.

Normally, the leaves elaborate the food materials during the summer in sufficient quantity to supply all the material of the present year's growth, and, in addition, also accumulate a surplus, which wanders out of the leaves before their fall, and is stored in the wood to be used for next spring's

1 Girdling is the cutting through the cambium layer, or taking off a ring of bark around a tree. 
growth of buds and foliage. Hence a deficiency in food elaboration or defoliation in one year may, according to the time when it occurs, influence the growth and health of that and the next year; or the unfarorable seasion of one year may not show its effects until the following season.

Besides food, a tree, like an animal, needs air or oxygen for respiration. The importance of this fact is perhaps very imperfectly realized by the uninitiated. Fet not only the leaves but also the twigs, branches and bole, and eren the roots have breathing pores in the developed fissures of the bark, for the purpose of conducting air into the interior.

That the roots must breathe is often forgotten, as when trees are planted too deep, or when ground is filled in on top of them. Many a tree is lost by this ignorance. The more compact the soil and the deeper the cover, the surer and quicker the result; the tree dying from suffocation. The same result is induced by flooding, or even a very rainy season may, on compact soil, so reduce the aëration of the roots as to kill them. Trees growing in swamps have adapted themselves gradually to the difficulty of root respiration, and the ground around trees grown in such conditions may be filled up without the same detriment that would come to trees not so adapted.

Whenever there is a change made in the surroundings. especially in soil and in light conditions, there must take place an adaptation of the root system to the change. The tree, however, can make this adaptation only gradually, hence any contemplated change in the environment must be made by degrees or else the tree will suffer.

It appears from the brief description of the houschold economy of the tree, that the requisites for tree life are, like that of other plants, first of all, at the root:- 


\section{Ecological Points}

II ater, available in such a way that it can be absorbed by the roots; this depending upon physical and chemical conditions of the soil.

IInerals, of certain kinds, in available form but only in small quantities, such as are found in almost all soils.

Air, for respiration.

The amount required of these supplies varies with different species and with their gradual adaptation to existing conditions, also with the conditions at the other end, namely; the environment of the foliage.

Here the indispensable air for respiration and carbon supply is almost invariably present, but in addition there are required:-

Certain conditions of the air as regards temperature and humidity in order to produce the so-called transpiration, i.c., er'aporation of water from the leaf surface. This produces a stream of water flowing from the roots through the young wood, the carrier of minerals upward and of assimilated food materials downward as needed.

In addition there is necessary:

Light of certain intensity to produce the chemical action in the leaves by which the food materials are digested or assimilated.

Ecological Points. This relation and adaptation of the plant to its surroundings has been called its ecology.

Some of these conditions of environment are unalterable in any locality and situation; climate in general and the seasons being, of course, uncontrollable by man.

The adaptation of species to given climates has been accomplished during ages in such a manner as to assign to them fields of distribution within which they are found by nature, i.e., within which they can perform their lifs functions satisfactorily. This process of adaptation is 


\section{Characteristics, Structure, Life of Trees}

unquestionably still going on, species increasing their field of distribution, and also changing their functions to meet changes in climate, or clse succumbing and dying out through inability to adapt themselves. But this is a matter of long-continued evolution and rery gradual change, in which thousands of individuals succumb while a few selected ones are adapted. Artificial acclimatization, therefore, is probably not, at least practically, within the means of man, as far as the long-lived arborescent forms are concerned, whatever may be accomplished with annuals, or even with shrubs, which send out new shoots from the root-stock annually. But transfer from one locality to another where the tree is not native has been practised successfully, the assumption being that the climate of the new location was farorable to the exotic newcomer. Whether or not such transfer may be successfully made is in general a matter of trial, climate being too complicated a matter to permit ready comparison and prediction of the adaptation of the plant to its new surroundings. We have only a few points for basing a judgment as to the probability of success. It is, for instance, not likely that a tropical species or one of southern warm latitudes will, as a rule, adapt itself to a northern climate. Species from moist climates are apt to succumb in dry ones. The nearer in temperature and moisture the climate is to that of the native habitat, the greater the likelihood of success in transplanting a species.

Cases are known when the new environment has proved even more farorable to the derelopment of exotics than to that of its native flora, as in the case of European species in California and in other parts of this continent. On the other hand, while a species so transferred may be able to live in the new surroundings it may develop differently from its habit in its native country. Again, some species have 


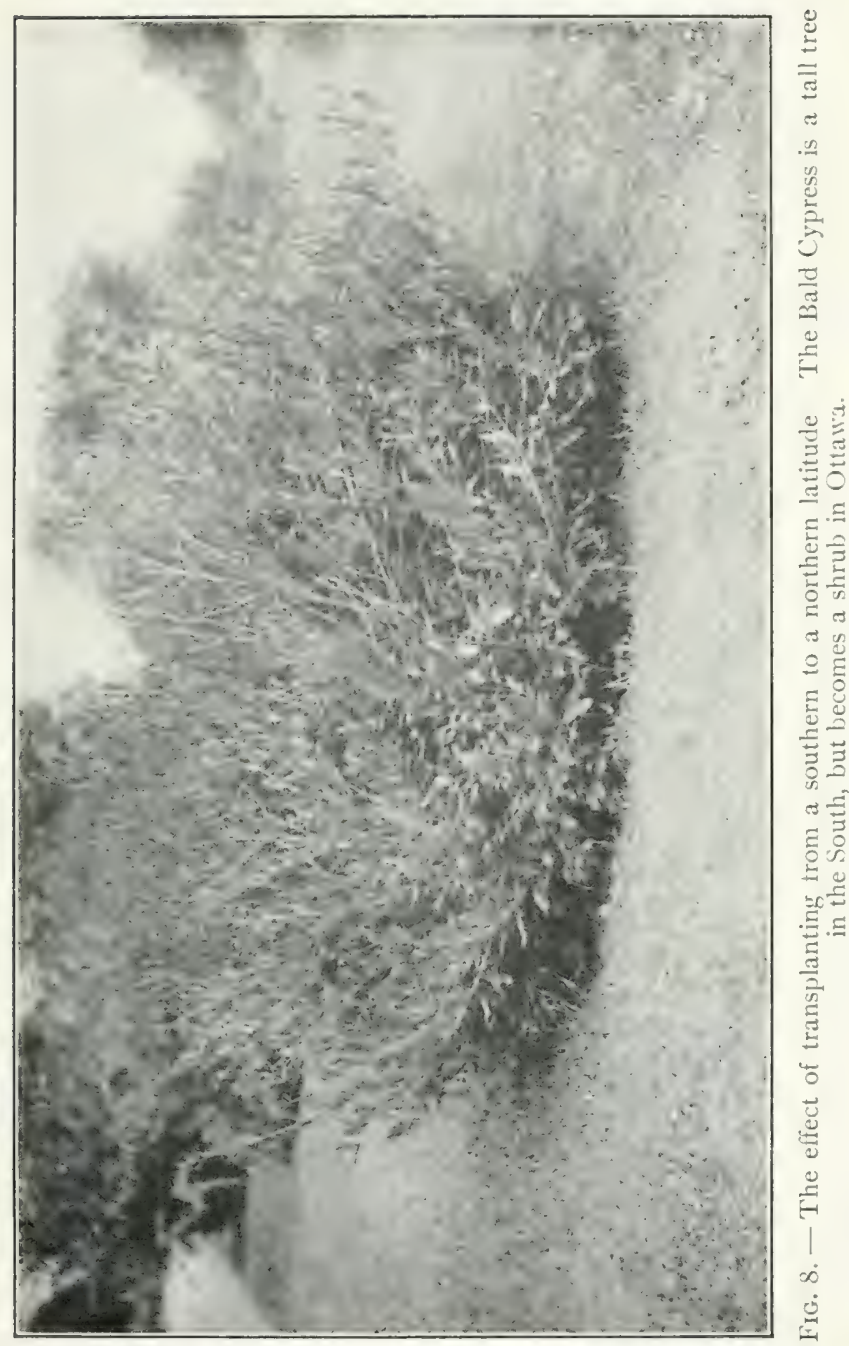




\section{Characteristics, Structure, Life of Trees}

such a wide range of distribution, through such a variety of climates, that the success depends upon the choice of the locality from which the plant has been derived or from which the seed has been secured, for the seed preserves all the characteristics of its mother plant. I case in point is the I)ouglas Fir, ranging from British Columbia to New Mexicc. Plants of this sfecies, when brought from the humirl, mild Pacific Coast do not thrive in the drier, severer climate of the Eastern States; but if grown from seed collected in the dry Rockies, they will succeed.

It must also be kept in mind that there is considerable variation of climate experienced locally within narrow limits, as for instance, in going from the foot to the top of a mountain, or with change of aspect, and with different exposure to winds. Hence the tree in one place may find satisfactory environment, when in close neighborhoorl, but in a different situation, it may not: the south side of a town is warmer, the northwest colder, but healthier, the southeast most equable, and so on.

While, therefore, the fact that different species of trees are by nature adapted to certain climatic conditions must influence the choice of trees for planting in a given locality, and while the natural adaptation of species to deep or shallow, wet or dry soils is also a matter to be considered in the selection of plant material, we know that soils at least can be adapted to support any tree species and also that the light conditions can, to some extent, be made favorable to the needs of the species adapted to the climate.

There is one condition of soil which is most favorable to all tree species, namely, a deep, moderately loose, sandy loam, which permits satisfactory aëration and furnishes an even water supply. When we speak of trees arlapted to other, dricr or wetter, more compact or looser, 


\section{Ecological Points}

soils, we mean that they can still prosper under less favorable conditions, if necessary; yet they would do best on the soil as described, which is, therefore, the nurseryman's choice.

As regards light supply to the foliage, we have, of course, no means of increasing or modifying it in general, yet in group planting, park planting, street planting, and even in pruning, the knowledge that different species require different light intensity for their best development is essential; for here proper adaptation to light conditions, and artificial changes in light conditions can be practised. All trees thrive ultimately best in full enjoyment of light and then derelop their characteristic form, as we see it in single trees on the lawn; but, if placed in close neighborhood of each other, the fact will soon appear that one species is "stronger" than another; that means the one spreads its branches and kills out those of its neighbor by its shade.

In other words, the foliage of one species requires more light to perform its work than that of another. This fact is exhibited in the individual tree itself. The interior of the crown in those which need much light, like the birch or aspen, thins out, is empty of foliage, because of the shade which the exterior exercises; it loses its lower branches sooner on account of the shading by the upper, or else the lower reach out farther to escape suppression. On the other hand, the tolerant or shade-enduring kinds, like beech and sugar maple, are characterized by compact and dense crowns: their foliage even in the dark interior of the crown can perform its office. And so a relative scale can be made with reference to light requirements from the most lightneeding to the most shade-enduring. Birch, aspen, willow, poplar, and pine are examples of those more sensitive to the withdrawal of light; beech, sugar maple, holly, spruce, 


\section{Characteristics, Structure, Life of Trees}

fir, and hemlock are examples of those which can endure considerable shade.

The practical importance of this fact is exemplified in almost every fark or yard where groups are planted, either by the failure of the designer to group, trees with reference to their characteristics, or by failure of the manager to correct in time such changes of relationship, and by allowing the "stronger" to damage or kill out the "weaker."

The knowledge that this strength or weakness is merely" in the light requirements can be used, first, in restraining the stronger by proper pruning, if the two are to be kept together; second, if it becomes necessary to plant between existing groups, in choosing a species capable of bearing the shade of its neighbors; and finally, in pruning individuals of the light-needing kind so as to give more light to the interior of the crown, making it fuller and more compact by the development of dormant buds.

Recuperative Capacity. There is one other feature in the economy of the tree, important to the tree-warden, by which it differs from the animal household (with exceptions), namely, its ability to replace lost parts. This is due to the fact that it produces and keeps alive many more buds or growing points than it can develop in a scason. As we have seen, only a few of the many bucls formed each season grow into shoots and make leares; the majority die, are killer by insects, or dry out, while a number remain living but undereloped, keeping dormant until neederl.

Let a tree be defoliated again and again by insects in a single season and the dormant buds will replace the lost foliage as long as there are stored food materials at hand to feed them; let a twig or branch be cut off, and screral dormant buds near the cut base will vie with each other to replace it; cut off the whole tree and with most deciduous- 


\section{Recuperative Capacity}

leaved trees the stump, if not too old, will have dormant buds still alive below the bark to force themselves through and make sprouts to replace the lost bole; or else the cambium layer may form new, so-called adventitious buds for the same purpose.

Lost roots too can be replaced, if conditions are favorable, through adventitious buds, a fact of importance in transplanting trees, when usually a part of the root system cannot be taken up, and must be replaced by the tree in its new position.

Upon this observation of the replacement of lost parts the practice of pruning is based: the tree pruner, by lopping off branches and thereby changing conditions of nutrition, produces at will new branches, and influences direction, character, and amount of development.

Tree surgery becomes, therefore, next to securing favorable soil conditions, the most important factor in the care of trees, for it enables us to remove diseased, malformed, undesirable parts without fear of harm to remaining portions and with the possibility of restoring to symmetry and vigor a dilapidated and sickly tree ruin.

With old age, to be sure, this capacity for replacement may be lost in the older parts, and it must also be kept in mind that different species are more or less vigorous in developing dormant buds.

The essential points, then, of tree life to be kept in view in the care of trees are:-

I. The living portion of the tree is found in the cambium layer directly under the bark and in the tips of branches (buds) and roots.

2. Root tips and foliage are in direct communication with each other and interdependent, relying on each other for food. 


\section{Characteristics, Structure, Life of Trees}

3. Water, mincrals, and air in sufficient quantity at the roots are the principal needs of trees, and especially the aëration of the roots is of importance, while light in varying amounts is required by the foliage for proper function.

4. Trees have the capacity of replacing lost parts. 


\section{CHAPTER III}

\section{DISEASE AND DEATH OF TREES-GENERALI- TIES}

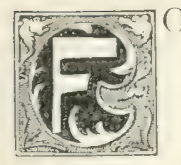

OR normal development trees require, as we have seen, light, heat, water, air, and nutritive elements in certain amounts. If any of these conditions or elements are temporarily deficient (or sometimes when in excess) the normal functions are interferer with, and the tree may be ailing, although not necessarily sick, for it may recover its normal condition as soon as the deficiency is corrected.

We speak of disease only when live parts fail to perform their normal functions and begin to die before their time, that is to say, when buds, rootlets, or cambium die at any time, and leaves change color, become dry, and fall before the end of the season.

Since, as we have seen, the living parts of the tree lying on its periphery rejurenate themselves every year by the formation of new shoots, buds, camlium and rootlets, there can be actually no natural death from old age in the same sense as in animals. Even death from internal causes as a direct result of disease, at least sudden death, is rare.

Trees die mostly as a result of unfarnrable external conditions, which inierfere with their nutrition, and which are generally capatile of control. As a ruke, they succumb so gradually that they actually die by inches; it may take many years before all life is gone, and hence there is time for recuperative measures. 


\section{Disease and Death of Trees - Generalities}

()ften it is dillicult even for the expert to determine the exact cause of final death. The cause frepuently lies hidden under sround, or is only to be discovered in a complication of various conditions, operative at difierent times.

Finally, howerer, it is mostly interference with normal mutrition and esfecially deficiency in water-supply that is the ultimate cause of death.

Old Age. Since the truly living jortion of the tree is annually renewed, it follows that when we speak of the length of the natural life of trees, we can mean only that period of time during which the tree without human aid may, as a rule, successfully resist unfarorable external influences of soil, climate, or attacks of parasites, and may repair mechanical injuries.

Although we do not know in trees the decline which characterizes the old age of animals, yet we lind that, as in animals, extreme youth as well as extreme oll age predisposes the tree to diseases, and that serious conseduences and fatal results are more apt to follow the attacks of enemies in the rounger and in the older stages than in middle life.

One reason for the greater danger to olrl trees seems to be in their mode of growth. Since trees lengihen their shoots as well as their roots by additions, the distance between the place of supply and of consumption of water constantly increases. Finally the forces at work can not readily pump the water against gravily and friction from the ever farther removed root tips to the utmost twigs in sufficient quantity to satisfy the demands of a drouthy season. The twigs rlie back again and again, and thus a limit to height growth is set. At least this is the theory of the writer, and no better one has as yet been presented.

But there is also opportunity griven for fungi to enter 


\section{Old Age}

through the dead twigs as well as through the larger branches, broken off by the winds; the danger of damage from wind, snow, and ice pressure increasing with the growth in lengt'in which adds to the leverage. Rot, riddling the bole (which is really dead matter) and eating out the heart of the giant, does not really kill, but after ycurs of work the stability of the bole is undermined and eventually the tree succumbs to a windstorm; broken, it may be, in full leaf and, as far as the living parts are concerned, in full health. Just as wild animals are said to die mostly from violence, so trees in nature break down under the violence of windstorms rather more often than they succumb to natural deat'i cr disease.

When this time of insufficiency of water-supply and hence endangered old age will arrive, depends on a variety of conditions. Difference in wood structure and hence in conductivity for water may make long-lived and short-lived $s_{1}^{\text {recies; }}$ deep soil and ready water-supply for the roots and farorable climatic conditions, increase height growth, and may also possibly lengthen, or, as may be, shorten the life of the individual.

Again, some species, or some varieties or even some individuals of a given species may be found to resist damage more readily than others, or else be more predisposed and liable to disease. Some are more adaptive to a change in the environment, while others quickly resent such changes, especially as regards water-supply at the roots or transpiration at the foliage.

Diseases in trees are usually more or less localized, spreading gradually, and in the absence of a nervous system, seconclary complications in other organs, as they occur in the animal body, are not generally observable. One portion of the tree may remain perfectly normal and healthy while another portion may be diseased or even dead. 


\section{Disease and Death of Trees - Generalities}

Nevertheless, since difierent parts are interdependent for their nutrition, any interference in feeding arrangements will be more or less felt, at least in all growing parts which organically belong together. It is, therefore, usually, one side of the crown, in sympathy with the same side of the root system, which is diseased or dead, while the other side may remain alive and even vigorous.

This fact, together with the ability of trees to replace lost parts, makes it possible to resuscitate and restore quite dilapidated specimens by surgery and proper treatment, and to prolong their life almost indefinitely.

General Causes of Disease. There are two general causes of disease, namely, unfarorable environment and parasitic organisms (which, however, should really be considered a part of the environment). Under the influence of these two we may group for diagnosis and treatment four classes of troubles to which trees are exposed, namely: physiological diseases which are produced by generally unfarorable conditions of growth in atmosphere, climate, or season, and soil; mechanical injuries, which destroy living parts or else weaken the dead wood of the body; attacks of fungi and other plants; and attacks of insects.

Usually several of these causes work together or are even interdependent, and it is not always easy to tell which is the primary, which the secondary, cause of the diseased or abnormal condition. This difficulty of diagnosis is especially experienced when there are no i'isible signs of insect or fungus pests present and when the trouble seems not localized but exhibits itself in general debility or sickly appearance.

Fungus attacks are usually secondary results of mechanical injuries, and insect pests become in most cases fatal only when other debilitating causes are at work simultaneously. 


\section{General Causes of Disease}

Shade trees in city streets are especially subject to many adverse conditions, which make the attack of fungi and insects much more dangerous than it would be in the virgin forest. Injuries from gnawing horses, abrasions from passing rehicles and other agencies give entrance to fungi, reduce the feeding area and the rigor of the tree; parements and macadamized roads reduce the water-supply and the supply of air to the roots; excarations for buildings, sewers, water-, gas-, and steam-pipes destroy parts of the root system; grarlings do the same, and earth fillings change the water and air supply; gas leakage at the root and other obnoxious gases at the foliage interfere with the health and vigor; inattention to the wounds and broken limbs invite fungus attacks; and electric wires introduce the danger of electric discharges. All these untoward conditions of the environment together with the mechanical injuries, if not fatal in themselves, tend to reduce the vigor of the tree and make it more susceptible to the attacks of parasites.

The first concern of the tree doctor, therefore, is to secure a favorable environment, - sanitary surroundings for his charges, which will keep them in rigorous condition and enable them to fight off their enemies in the plant and animal world. The conditions in the atmosphere are only very partially controllable; drouthy and wet seasons and the ills of frost and lightning have to be endured without much, if any, chance of counteracting their unfavorable influences. But the medium in which the roots perform their function, the soil, is much more readily influenced, and here, therefore, lies the main activity for securing farorable conditions. As we shall see more fully later, the regulation of the watersupply to the roots and a sufficiency of air or oxygen for their respiration, and, to a minor degree, a satisfactory amount of available mineral material are the means of 


\section{Disease and Death of Trees - Generalities}

keeping trees in vigorous constitution and of aroiding physiological diseases.

Not only are certain species adapted to certain climatic conditions and hence may not be transferred into a different locality with assurance of success, but even the individuals of the same species are adapted to the special features of their nearer surroundings of local climate as well as of soil, and resent change, or at least must re-adajt themselves if mored into new surroundings. To some extent, eren the seed itself inherits this adaptation; hence the young plants of Pacific Coast conifers, grown from seed derived from the mild, moist climate of their habitat, may suffer from frost and drouth in the Eastern States, while plants of the same species, derived from the rigorous, dry, alpine climate of Colorado, will be hardy.

In transplanted trees this difference in derivation of the plants and the difficulty of adaptation may sometimes account for their ailing condition, and may result in their death.

The seasons will naturally influence the condition and disposition to disease of the tree: a period of drouth, for instance, may kill feeding roots, leaves and branches, and at the same time open the door for fungi to enter; a period of wet, rainy and cloudy weather may have the same effect, by depriving roots and leaves of their respiration; a severe cold spell in the spring may kill foliage and twigs, and especially "kill back" immature young wood of the previous season, such as forms when a moist fall follows a dry summer. Attacks of fungi may or may not be of moment according to the season and the condition in which the tree is found by these parasites.

Mechanical injuries, by which the truly living parts are exposed to the air, are perhaps the most prolific cause of trouble and disease. 


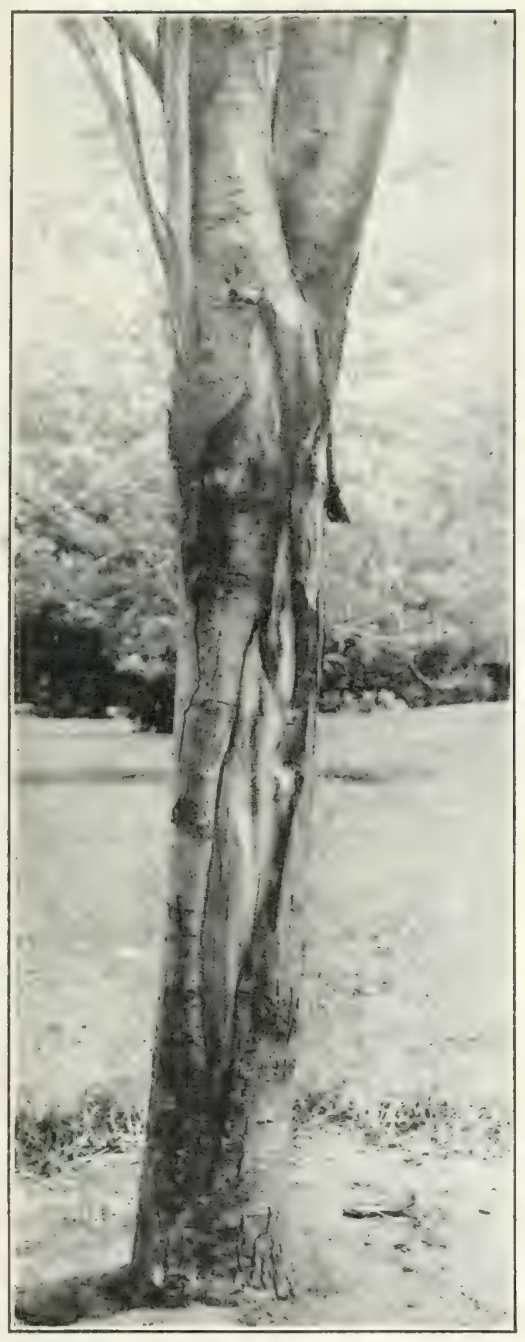

$\mathrm{F} I(;)$

u. - A "sun-scalded" silver maple still alive, giving chance for fungus to enter.

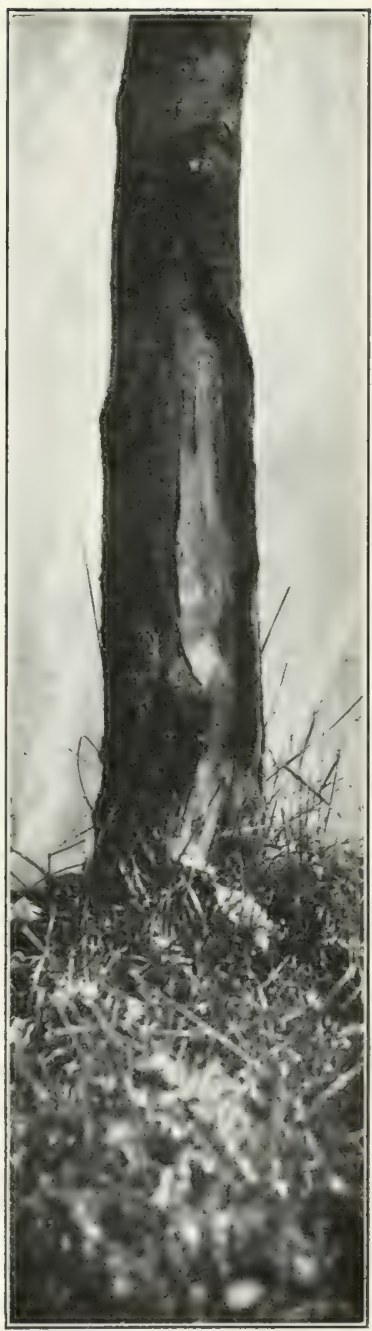

b. - The bark torn off from onehalf of the bole. Immediate attention by tree wax and wrapping has kept the tree in full growth. 
A tough skin or epidermis protects the leaves and young shoots, and a corky bark the living portion of the older parts of the tree, and prevents, or at least impedes, access of insects and fungi to the tender living tissues. But there are innumerable opportunities of breaking through this protective cover and exposing the delicate tissues below. Ninute punctures are marle by insects; hailstones tear off portions of leaves, profuce contusions on the young twigs and lacerate the bark; windstorms tear off foliage and twigs and break branches; frost and sun-scald split and kill portions of the bark, and lightning may rend the bole to the very heart. In addition, careless man and gnawing animals inflict wounds, small or large.

The result is, first of all, an interference with the normal functions of the tree: certain areas of conducting tissue or, in the leaves, of assimilating tissue are destroyed, and by so much the equilibrium of the whole system is disturbed in its nutrition; and secondly, a way is opened for fungi to attack the living or supporting tissue.

The recuperative power of trees is so great that almost any wound, if properly assisted, can be healed by the process of callusing, described on pages $9 \mathrm{r}-98$. All that the tree doctor can do, or needs to do, in most cases, is to see that this healing process is performed promptly and without interference. The sooner the injury is looked after the better, so that the secondary evils of fungus infection may be prevented.

Fungus Diseases. Any portion of a tree which has been mechanically injured, so as to expose the living tissues of the wood, is subject to the attacks of fungi, although sometimes attarks may occur without such injury. There are fungi which live on trees as saprophytes, using the tree merely as a location; others which feed on the tree, 


\section{Fungus Diseases}

sapping its life, - true parasites; others again are in some stages of development parasitic, and in other stages only saprophytic.

There are fungi living on leaves, others living on the roots, others on the bark, and again others living on the wool of the tree, producing its decomposition, or what is commonly known as rot.

The young plants or seedlings are exposed to a large number of fungus enemies, which do not trouble them in later life, but we shall here only discuss those occurring in older trees.

Of the many interesting phenomena in the life history of the fungi one of the most important is that many not only pass, like the insects, through different phases or forms of derelopment, but in these different phases live on different "hosts," as the plants are called on which they feed.

The well-known rust of wheat lives in one phase of its development in the ground, as many others do, and in another on the barberry bush; some fungi, active on the juniper tree, are found in different stages of development on apple and other trees. A rust which attacks the needles of pines is dependent for its development on ragweed or groundsel (Sencio). Lately a new pest attacking our white pine has been introduced from Germany, and this passes one stage of its development on currant bushes.

The presence of a certain plant may, therefore, be a cause of the spread of the disease on another, and the removal of the host plant as well as of the infected trees or parts of them is often the only means of getting rid of the trouble. In so far as specific enemies exist on given species, if an epidemic has set in, it may become practically necessary to replace the species by another in order to avoid the spread or renewal of the trouble.

The fungi which attack the foliage usually destroy only 


\section{Disease and Death of Trees - Generalities}

portions of the leaf surface and thus simply reduce the assimilating area and lessen the feeding capacity of the tree; thereby the growth of the tree is diminished in proportion to the leaf area destroyed. Since the leares fall and are renewed the next scason, the trouble can be continued only by a new infection; in other words, only one season's growth and function is involved.

There are, however, a few fungi which not only reduce the assimilating leaf area but even cause the premature fall of the entire leaves, and these fungi are, of course, the more injurious.

The most common leaf fungi are those producing the spot diseases, the foliage being corered by spots varying in color, size, and shape, which mark the destroyed tissue. Sometimes the destroyed tissue dries out, becomes brown, and breaks out under action of rain and wind, the leaves remaining perforated as by shot.

Another class of fungi produce the so-called powdery and other mildew's, recognized by a whitish or else black spiderweb-like growth on the surface (the fruit-bodies), which becomes powdery.

While the spot diseases and mildews affect mainly the broad-leaved trees - maples, chestnuts, oaks, and many others - the rusts, characterized by collections of yellowish red, somewhat powdery fruit bodies are more frequent on conifers. These attack also stems and branches, causing peculiar swellings or knots and blister-like patches.

Here also belengs the disease known as juniper apple, which appears on the red cerlar with a fruit body of slimy or gelatinous, yellow or brown, conical masses.

On the whole, all these fungi are of minor importance and, if the trees are otherwise kept in vigorous condition, their damage is in most cases readily repaired. 


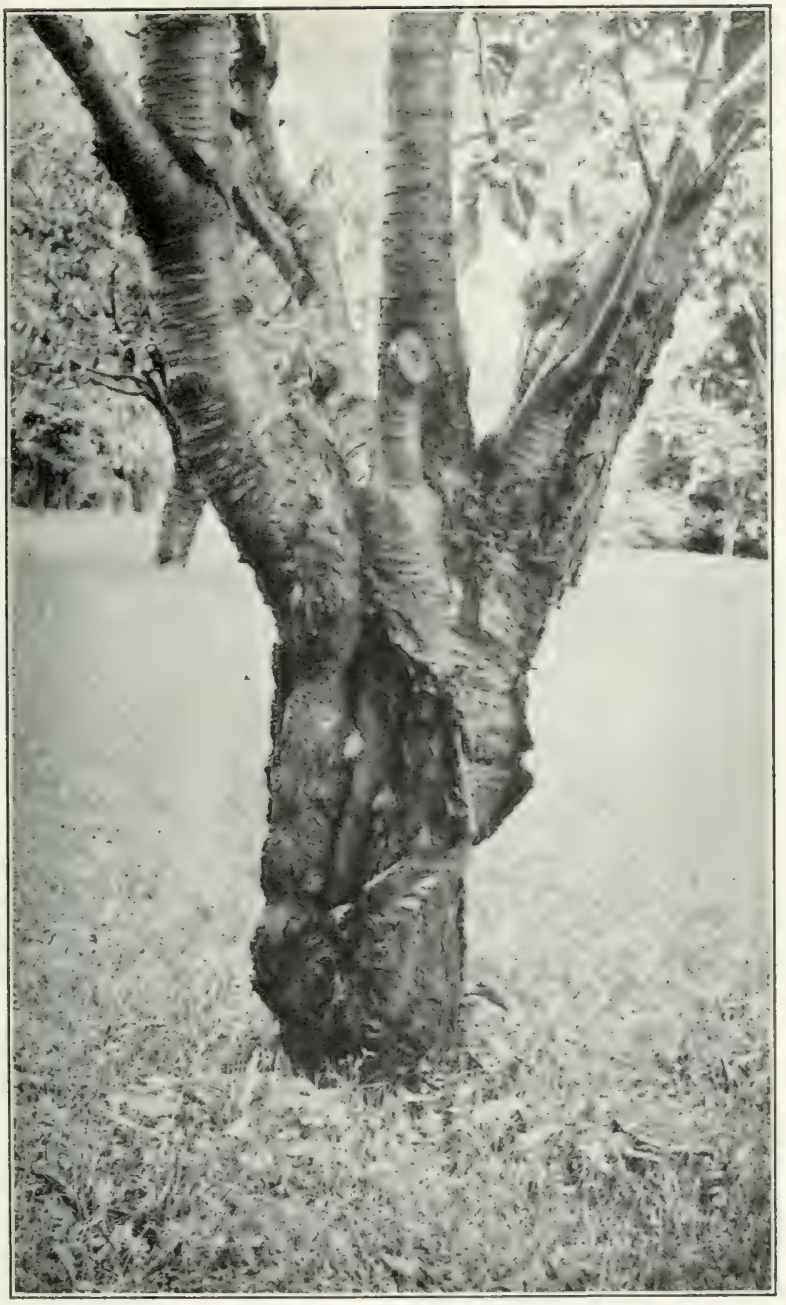

FIG. I0. - A cankerous cherry tree, the two white spots on the wound being fruit bodies of the fungus. 


\section{Disease and Death of Trees - Generalities}

The "black" fungi, which attack the bark, find entrance through small wounds made by hailstones, insects, or breakages. Working between bark and wook in the bast or bark portions of the cambium and into the wood, they destroy living tisisue, and, if the in jury is extensive in younger trees and twigs, they become dried out and killed.

These bark-fungi are found especially on conifers, pine, spruce, fir, etc. Their presence is ustlally not discovered until a number of pin-sized, white, black, bright rexl, or yellowish pustules or spots - the fruit-borlies of the fungus - appear on the outside of the dead bark.

In deciduous-leared trees the same class of fungi produce malformations known as canker. (On small areas of irreorular shape the bark is killerl, and in the attempt to heal the damage by callusiner each season, and at the same time in the continuance from year to year of the fungus growth, all kinds of curious shapes of the wound are produced. Small fruit-bodies, white with minute red spots, appearing on the dead bark of the margin of the wound are the indications of the fungus causing these malformations.

Similar to this disease is the black-knot of the plum and cherry trees, a fungus producing swellings of irregular shape.

By reducing the water-supply, especially in dry years, these bark-infesting fungi cause sometimes the partial or entire death of twigs and branches.

Various fungi working on young trees and on foliage give rise to swellings of the leaves like boils, and to the curious deformations known as "witch's broom." 'Timely removal of these arrests the progress of the disease.

The condition and age of the tree determine, to a large extent, how far these fungus attacks may be detrimental.

The rot fungi, which produce the decay of wood, are the 
most common and the most insidious, since their mycelium penetrates deeply into the body of the tree out of reach. Since the trunk of the tree, the rood, is mostly dead tissue,
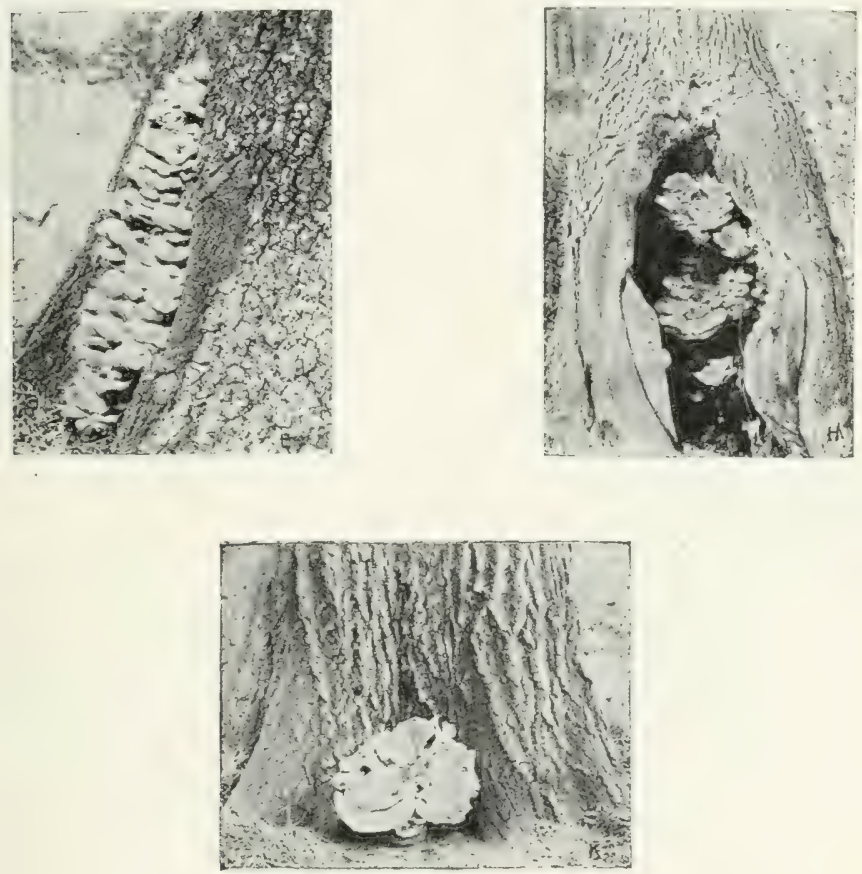

FIG. II. - Three species of rot fungi. When these fruit-bodies appear at the base or on the wounds of a tree, the interior is usually all decayed, and help comes too late. (After Murrill, from Corneli University Bulletin, No. 205.)

they do not impair to any great extent the living portion. Yet they are not mere saprophytes, for they really feed on the wood, absorbing cell-walls and cell contents, and to some extent impair its functions in the conduction of water. But their main damage lies in destroying the firmness of 


\section{Disease and Death of Trees - Generalities}

the wood body. While the tree can go on rotting for years, to all appearances without detriment, its stability is undermined, and finally a windstorm may lay it low in full leaf and otherwise in full health.

These fungi gain entrance to the wood through wounds made by broken or badly pruned branches, by broken bark or through injured, exposed roots.

On the ragged surface of a broken branch stump, and even on a well-pruned but unprotected wound, dust and

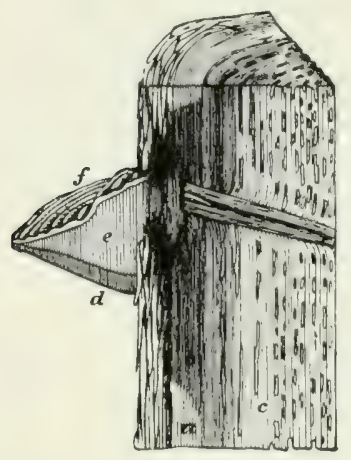

FIG. I2. - "Shelf" fungus or: the stem of a pine. $a$, sound wood; b, resinous "light" wood; c, partly decayed wood or punk; $d$, layer of living spore tul,es; $c$, o!d filled up spore tubes; $f$, fluterl upper surface of the fruiting body of the fungus, which gets its food through a great number of fine threads (the mycelium), its vegetative tissue penetrating the wood and causing its decay. (Department of Agriculture, Division of Forestry Bulletin, No. IO.) water collect and form a seed bed on which the fungus spores - corresponding to the seeds of other plants, minute or microscopic, easily scattered by the winds can locate and sprout. These grow into the wood by rootlike $h y$ pho, which bore through and between cell-walls, branching multifariously and forming a mass of white meshes penetrating the wood in all directions - the so-called mycelium. This draws its sustenance from the tree, ciestroying cell-walls and absorbing cell contents. As a consequence the wood dries, shrinks, cracks, turns reddish brown, or else becomes syong! and vellowish white. The mechanical destruction proceeds as the $\mathrm{my}$ celium proceeds.

Finally, sometimes after years, the mycelium forms a fruit-body on the outside of the tree, the readily recognized toadstool making its presence 


\section{Fungus Diseases}

known to the uninitiated long after the mischief has been done.

On the roots, besides the rot fungi, there are found others which attack the living parts and hence become directly a damage to the life function of the tree.

While here too, as a rule, an injury or weakened condition invites the fungus attack, there are fungi which appear to attack perfectly healthy and uninjured roots. Thus the southern root rot which infests a large number of tree species, kills the roots so extensively as to produce a sudden wilting of the leaves and subsequent death of the tree. Poorly drained and poorly aërated soils seem to favor its development.

The honey mushroom also kills young trees and weakens or stunts the growth of older trees which finally; if a dry, hot season occurs, may dry up for lack of water-supply. Its mycelium grows not only in, but alongside the roots through the ground, within a few inches of the surface and thus spreads from tree to tree, increasing the area infested.

Some few plants other than fungi may be found as parasites on branches and bole; they are mischievous, although rarely of importance unless extraordinarily dereloped. Among these are various species of mistletoe, which occasion objectionable burl-like malformations, due merely to the mechanical obstructions to the wood growth which their roots, imbedded in the cambium laver of the host, produce. The dying of the branch above this burl may be the consequence. The trouble is spread by the seeds of the mistletoe, which are corered with a sticky substance and are carried by birds to other branches and trees; hence its spread, at least, can be prevented by removing the affected branches.

In addition to the parasitic fungi and other parasitic plants, there will be found on all trees epiphytes, i.e., 


\section{Disease and Death of Trees - Generalities}

plants which do not feed on the host plint, but use it simply as support, such as mosses and lichens, orchicls and various climbers, like the Virginia creeper. As a rule, these are of little conserguence; yet if in excess may become troublesome.

The excessive derclopment of mosses and lichens on the bark is a sign either of a very humirl atmosphere, of very wet soil, or of very slow growth of the tree. In the latter case, the outer bark is sloughed off very slowly, thus giving time for the epiphyte to develop. Usually there is no damage to be anticipated from the epiphytes, but, if excessively dense, the cover of lichen and moss may become injurious by closing the breathing pores of the bark, and had better be removed.

Creepers are usually harmless, but may become nbjectionable on young trees and young parts, like wires or artificial ligatures, if the pressure with which they resist the expansion of the body of the host plant becomes so great as to retard or prevent the supply of formative materials to the portions below the constricted part. In such cases the lower portion will be retarded in its diameter growth.

Insect Damage. A host of insects belonging to the orders of beetles, moths, butterflies, gall-flies, saw-flies, plant and bark-lice, are parasitic on all parts of trees, feeding on leaves, twigs, cambium, roots, and wood.

Sometimes it is the imago, the beetle, that does the mischief, but mostly it is the larva, the grub or caterpillar, which is to be feared. Some live and feed on the exterior of the plant, especially those which depredate the foliage, others are internal feeders, living during some stage of their development within some part of the host plant. Such are the gall-insects and leaf-miners, which lay their eggs in the soft tissues of leaves, leaf-stalks, or fruit, where the larva develops and feeds. The larra of the bark-beetles feed 


\section{Insect Damage}

on the soft cambium layer underneath the bark; the stemborers hollow out twigs or make their abode in the trunks, feeding on the wood itself.

Some do little or practically no damage; indeed, in the majority of cases only when an extraordinary development of an insect pest in any one season takes place, or when repeated invasions have to be endured, or when other accessory unfavorable conditions occur, need any apprehension for the life of the tree be felt. Such unusual developments of insect pests seem to take place periodically, when, due to specially farorable seasons or otherwise, the pest is farored, while natural enemies are reduced or less favored.

The leaf-eaters of certain species are especially liable to this periodic excessive multiplication.

If the defoliation is only partial and occurs at a time of the year when the foliage can still be replaced by the development of the dormant buds, outside of the temporary unsightliness, only a reduction in the season's growth is the result. But, if tie defoliation is complete, and, as happens with some species if leaf eaters, more than one generation is dereloped in a wason, repeating the destruction of the foliage as new lives are formed and thereby preventing the assimilation of food materials, the tree may be weakened even to death. At least a repetition of the defoliation for two or possibly three seasons, according to the vigor and age of the tree, will be fatal.

The new foliage, formed in the same season after the first defoliation, is apt to be smaller in size or abnormal in form and thinner, hence less effective. Sometimes, however, when a large number of buds have been destroyed, unusually large and abnormally formed secondary leaves arise from the few remaining buds. In either case the nutrition of the tree is interfered with. 


\section{Disease and Death of Trees - Generalities}

While some insects are general feeders, i.e, attacking all kinds or at least a number of tree species, insects, eren more than fungi, are partial in selecting their hosts, i.e., given species of insects attack giren species of trees. Besides, they differ much more in their life habits than fungi, hence they may not be dealt with as a whole, like the fungi, but it becomes more needful to know them specilically by name, appearance, and habit, with their life history, in order to apply judiciously measures for their reduction. Moreover, there are a number of enemies of the obnoxious insects found in the insect world, and it becomes necessiry to distinguish between friend and foe, in orter not to rimenty the natural enemies of the pest.

We can here refer speci. ally unis is the nute romonon pests of ornamental and siluse nes? lesting fie ne mun-

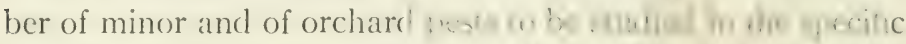
literature. Fuller descriptwon, will tw townt in Limeger

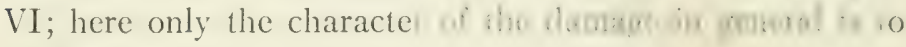
be discussed.

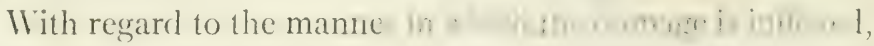
we can classify the injurious imects intr: : fers grouple, ach

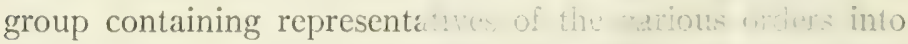
which insects are scientificuily classined. Ithese grours may be called leaf-eaters, froi mu: suckers, gall-insects, bark-lic not-iben and borers.

The character of the da , li- il muy ise inreetold, namely, destruction of substance, occasioned by leaf-eaters, bark-beetles or borers; loss of saj) occasioned by plant-lice; and formation of abnormal excrescences or galls, to which the plant is stimulated by various insects. All three kinds of clamage or any two may be occasioned by the same pest.

The leaf-eaters are mostly caterpillars of butterflies and especially of moths, which in feeding on the foliage generally 


\section{Insect Damage}

destroy the entire leaf. But the larvie of beetles also, and some of the bectles themselves are destructive in this manner.

The leaf-miners, which sketetonize leaves, eating only the softer jortions in patches, also come from different families. Some of these, like the elm-leaf beetle and the larchminer, make such extensive inroads, that the result is very much like the eating of the whole leaf. Others make only small, blotch-like mines or short tracks on upper or lower, or both sides of the leaves, destroying small areas of the soft tissues. These, as a rule, lo little damage. Nevertheless it is wise to reduce them by burning up the fallen leaves, in which they usually hibernate.

Another set, the leaf rollers, also coming from difierent families, roll the leaves together in various ways to make shelter for the caterpillars, folding the edlges and sewing them together with sillien threads, or spinning them, as in the case of needles of conifers, into a web). These distortions and occultations of the foliage would generally be of little consecpuence, but the insect, here sheltered, usually is destructive to the bukls and young shoots, and, if the leares in the web) are eaten, as is done by some, the damage may become considerable.

While the leaf insects so far mentioned feed on the foliage by eating it, there are a few, like the plant-lice and leafhoppers, which stick the sap by piercing the succulent leaves and leaf stems or even twigs, causing the leaves to crumple or roll, or producing gall-like swellings. Usually these leaf-suckers do not do much damage unless unusually abundant. There are, howerer, some bark-lice which do much more damage by puncturing the bark of twigs.

To this group belong also various scale-insects, which, adhering to the small limbs, sap their life and cause them 


\section{Disease and Death of Trees - Generalities}

to dry up, and even large branches and entire trees can be killed by these scale-insects if they are abundant.

I very large number of insects coming from sereral of the various orders, inhabit the foliage and smaller twigs in their egg and larval stage and produce what is known as galls, peculiar swellings, tumors, or malformations, often highly colored. Especially the family of gall-tlics, numbering some hundreds of species, inhabit larely the oaks, producing all sorts of leaf-galls. Among these are the galls of commerce from which ink and gallic acid are manufactured. The damage is too small to deserve much attention, but where excessive, the leares should be gathered while green and burned, to get rid of the deformation.

These swellings or malformations of twigs, burls and shoots are often accompanied by a shortening of the annual growth and a crowding of the foliage, forming what is known on willows as the "willow rosette" and on pines or on spruces as the "pine-apple."

'The sari-flies, similar to the gall-flies, lay their exgs in the tissues of the leaf, but as they live in colonies and hare often two broods in a season and their larva feed roraciously, they are more injurious than the gall-flies and may, as in the case of the larch and the pine saw-flies, cause widespread haroc. The conifers suffer especially from these pests.

With the family of beetles known as atevils we come to the stem-boring insects. For, although some feed on the foliage and puncture the bark, their worms or srubs inhabit not only the fruit but also the young twigs; the beetle with its long cylindrical snout perforating the bark and depositing an egog in the hole, the larva developing from it, burrowing beneath the bark, loosening it from the wood or boring into the stem and destroying the wood.

Bark-beetles, the "grubs" of which live under the b:11" 
especially of coniferous trees, and feed on the soft cambium layer, are usually secondary troubles, after the vigor of the tree has been undermined by defoliation, by fire, or by other causes. They rarely attack vigorous and healthy trees; sometimes, however, when a pest is excessively abundant, healthy trees may be attacked and succumb, especially young specimens. Since the larvie of these beetles destroy the cambium, their damage becomes easily very serious, leading to the death of the tree. And as their presence is not readily detected before the mischief is done they are most difficult to deal with.

Not less insidious and difficult to combat are the woodborers and wood-wasps which burrow in the wood, or hollow out the pith of twigs. Although they are mostly less injurious to the tree, being usually few in number and working as they do in dead wood, yet when they attack the smaller branches and young trees they may cause undesirable loss. Even in the bole of older trees they may, if very numerous, undermine the vitality of the tree by reducing the conducting tissue so as to eventually cause the death of the less rigorous individuals. Moreover, these boring insects may produce mechanical injuries which furnish an entrance for fungus growth and thereby lead to more serious trouble.

The roots suffer also from a number of insects. Some of them destroy the youngest root tips mechanically, as is done by the mole-cricket and the larva of the June bug, while wireworms and other bectle larve, and a few caterpillars and root-lice living underground, feed on them, and others again burrow in them. The damage is usually of moment only in young trees and is, of course to be found in the loss of feeding apparatus.

There should perhaps here be added, since the question occasionally arises, a few remarks on "how to kill a tree." 


\section{Disease and Death of Trees - Generalities}

It is casy enough to get ricl of any tree hy culting it, or by merely girdling, and, if it is a "sil) -wood" tree, by sawing through the sajp-woot, thereby cutting off water-supply. from the foliage and food-supply from the root. While this works positively with conifers and many broad leaf trees, there are some of the latter, which have such vigorous sprouting habit from the root that something more must be done to kill the root-stock. Remoral i.s, of course, again the most eflective but expensive method. With some, cutting through the root strands will expedite death; but others are so fersistent that still another means must be added. The most effective of these and least destructive to other regetation, is the thorough drenching of the rootstock with kerosene which closes the breathing pores and chokes out life. 


\section{CHAPTER IV}

\section{DIAGNOSING OF DISEASES}

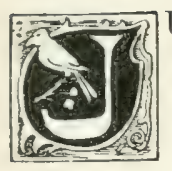

UST as the physician finds his greatest difficulty in determining the cause of illness, so the tree doctor, although knowing the diseases to which trees are liable and knowing the remedies, may still find trouble in diagnosing the true cause of the evident abnormal condition. Here it is that experience and judgment come in, yet sometimes eren an expert remains doubtful. Nevertheless, hy careful cxamination, in many cases even the less experienced can determine what ails the tree.

Usually, if anything is the matter in any living part of the tree, the foliage gives the first indication, and furnishes the most readily available symptoms for diagnosis.

Hence our examination begins with the foliage, to see whether it shows any diverence from normal conditions in size, quantity, form, or color. With a conception of what the normal foliage ought to be, we ascertain whether the leaves of the indivilual under examination are smaller than usual, or thinner, whether the foliage as a whole appears slim, whether the leaves are wholly or partially discolored, whether they are mechanically injured, eaten, crumpled, or otherwise misshapen, spotted, wilted, or dead.

If no local cause, as from fungi or insects, can be ascertained as surely responsible, we look next for indications on twigs, branches and bole as accounting for sickly appearance of the foliage or death of branchlets. Mechanical 
injuries to the cambium and young wood, caused by insects or other agencies, and the robbery by sucking insects like the scale and bark-lice, affect the feerling processes of the tree and may be the reason for the abnormal condition of the foliage.

If only certain portions of the foliage show abnormality, it is almost certain that a localized cause will be found such as a colony of insects, a partial destruction of food-conducting tissue, a particular root injury. If, on the other hand, the whole crown is affected, the cause must be more general and may be found in general conditions of nutrition. Then it becomes necessary to examine the soil, to see whether in any way conjectures as to the conditions at the root may be formed, accounting for the indications in the cromn.

Here, in the root region, matters become more complicated because hidden from direct observation, and yet here lies probably the most fertile source of trouble.

As so often in an old man head and feet become feeble simultaneously, so in the tree, when the top gives out, there is usually something wrong at the root, and that means generally at the very extremities, - the root-tips. The distance from root-tip to branch-tip), from pump and power plant to feeding extremities, increasing continuously, makes naturally the life processes more and more difficult to perform at the extremities, and if any other cause of discomfort is added, the result may be fatal.

As on the leaves and bole, so on the roots, there are predatory insects and fungi active and the roots are liable to mechanical injuries with the same results. But, in addition, there are essential conditions in the soil, the medium in which the roots live, which can change to a much greater extent than can those of the air, the medium of the upper portions of the tree. As we have alrearly seen, these changes 
involve the water-supply; the supply of oxygen, and the supply of nutritive elements.

The most common symptom of unfavorable soil conditions is found in the paling or etiolation of the leaves, which become prematurely yellow, wilting and falling before the end of the season; while in other cases the leaves and buds are reduced in size. Branch-tips, especially of horizontal branches, are killed back, and the top of the crown dries and dies, giving rise to the so-called staghead; or else watersprouts, slender, long, wisp-like shoots out of the regular order, are formed. Excessive growth of moss and lichen may also be an accompanying symptom.

If the tree has been vigorous before, and has only recently shown signs of weakness, we must note especially any changes lately made in the soil conditions, which may account for change in its vigor; such as the cutting down or filling up of ground, making ditches, laying gas-pipes, draining or flooding, cultivating or sorlding, performances which are apt to interfere with the root system, altering its environment, and hence the amount of active root growth.

If none of these investigations give a clue, we must then inquire into the weather conditions and the history of the preceding two, three, or four seasons, as well as into surroundings generally, and we must ascertain what has been the previous treatment of the patient.

Thus circumspect investigation and observation and historical evidence must be brought together to diagnose the more complicated cases, while in other cases the initiated may be able at once to determine the cause of the abnormal condition. The novice will have to examine with more care, especially to avcid the mistake of recognizing as the primary cause what is only secondary.

Insect Damage. The most obvious damage is that done 
by the leaf-eating insects. 'Th: only trouble is, that when the damage has become apparent, it is either too late, or very difficult, for that season at least, to combat them. Since in these cases preventive measures alone are elficacious, it is desirable to secure, in due time, evilence of the frobable appearance of large numbers of these pests, or che, as a matter of precaution, to apply preventive measures (spraying poisons) even without that evidence.

In the German forest administrations, trial collections of the hibernating insects are made every spring to determine whether necessity for preventive measures exists. Cocoons, caterpillars, and beetles are collected from under the bark of stems and from under the moss and rubbish at the foot of the trees, and an estimate of their probable number is made.

In parks, similar precautions can be practised to adrantage, and the collection, instead of being a trial one, may be one directly destructive of the pest.

Observation of other signs, which, however, require the eye of the practised entomologist or dendrologist, leads to a recognition of the impending danger.

The number of insects observed in previous seasons may also be used as an indication of what to expect in the following year, since insect pests are ajt to srow from year to year until a climax is reached and their prouress checked by natural enemies or by an untoward season.

In city streets, where only certain species of trees are planted and the same species lines street after street, the (levelopment of insects depending on that species is naturally farored: a city of elms is also a city of elm-bectles. Hence, one may expect here a yearly incursion, and preventive measures should be taken as systematically as strect cleaning, or as any other regular public function is performerl. 


\section{Fungus and Bacterial Diseases}

If the timely examination of insect conditions has been neglected, then the diagnosis will be made when the damage has begun or has progressed to some degree. The insect can be observed at work, the culprit captured and its name or character determined. With the leaf-eaters this is usually readily accomplished, but the sucking insects whose damage is not at once apparent, as well as the barkbeetles and borers are discovered by close observation only.

The small round entrance holes in the bark of conifers, accompanied by resinous exudation, and finally the loosening of patches of bark where the cambium has been destroyed give evidence of the presence of bark-beetles. The presence of borers is indicated by the entrance holes, usually near the base of the tree, and by the excreta or finely divided wood particles, ziood-flour, found at the base of the tree.

Fungus and Bacterial Diseases. The fungus diseases of the foliage make themselves known by the partial discoloration of the leaves, usually in spots of various colors, and by the fowdery aggregations of fruit-bodies, silky, smutty, or otherwise. Sometimes also the foliage wilts or dries up.

As there is only one practicable remedy for all these fungi, namely, spraying with poisons, it is not necessary to be familiar with the different kinds, beyond recognizing their existence. The same can be said of the rot fungi, which practically behave alike, and are treated alike. Discoloration of the wood in wounds, and whitish or yellowish mycelia strands breaking through the tissues, and finally the fruit-body proclaim the presence of rot fungi. The dying of portions of the crown on account of reduced water conduction may also be due to these fungi. 
The existence of the root rot which produces stunted growth and erentually death, may be determined by close observation in finding a whitish, yellowish, or dark brown growth of loosely interwoven, hair-like mycelium threads on the root surface and in decaying tissues, or in the soil itself. This mycelium will also be found between wood and bark in whitish leather sheets, and will grow into the bark at the base of the tree above ground, finally producing here and on exposed roots the readily recognized fruitbody.

There is at least one insidious disease, known to be due to bacteria, a disease peculiar to North America, and familiar under the name of fire-blight, which attacks the trees of the apple family, and especially the pears and quinces, but also the mountain-ash, service-berry, and hawthorn. It is evidenced by the browning and subsequent blackening, first of the leaves and finally of young twigs and shoots, starting at the tips and progressing downward until even the larger branches may be infected. The bark of the diseased branches cracks, and a thick, blackish, gummy fluid exudes, the bark later drying up and shrinking. The discase may even descend into the trunk, then resembling sun-scalt.

Curiously enough, healthy, vigorous, well-fed, and well cultivated trees are more liable to this malady than less thrifty ones, new succulent growth favoring the disease. There is but one remedy, namely, to cut out and burn the affected parts well below the discolored portions. This should be done during winter or spring, or in the fall after the trees hare stopped forming wood. Checking the amount of moisture in the soil, as, for example, by the growth of grass or clover, will reduce the succulent growth and prevent the disease.

Physiological Diseases. Whenever local causes of the 


\section{Effect of Soil Conditions}

diseases of foliage are present, such as those produced by insects or fungi, the diagnosis is comparatively easy and the remedy rcadily suggested; but in the absence of such local disturbances, when the erident abnormality of the foliage is due to more remote causes, the difficulty is greater. As long as fungus growth or insect depredations on bark, wood and root, can be discovered as likely to have produced the disturbance in the condition of the foliage, eren a layman may find the causc; but to diagnose the so-called physiological diseases which are due either to permanent changes, or to some unusual temporary conditions in the environment, the services of an expert may be required.

Changes in the conditions to which the tree was originally adapted may take place in the soil or in the light supply (when neighbors are removed or are crowding), or they may simply be in the weather conditions of the particular season, or, in many cases, the combined conditions of soil and season effect the sickness.

Indeed, whenever the conditions of nutrition are interfered with, the foliage will soon give eridence of it. And in this connection, the soil conditions, especially the mechanical conditions which influence water and air supply, are of the greatest importance, as these are the ones which can be more or less controlled.

Effect of Soil Conditions. It must not be orcrlooked that a soil changes in its stucture and thereby in its capacity for water conduction and aëration by the compacting of raindrops, by frost, and in many other ways, so that the same soil which was originally satisfactory to tree growth, may in time become less so. Not only soils exposed directly to rains, but also those under sod, or even under sidewalks, become constantly more and more compacted, and hence a gradual change in their permeability to water and air takes 
place, until in an unfarorable season this reduction of water and air becomes fatal.

Moreover, as the root sistem expands it enters new regions and possibly less farorable strata than it occupied before. Therefore, whenever direct visible causes are absent, an cxamination of the soil condition.; especially those of water supply and aëration, furnishes in most cases the basis for the diagnosis of disease. Excess or deficiency of water, and deficiency of air at the root produce very similar results in the appearance of the tree above ground.

Pale or yellowish foliage, undersized leaves, short annual shoots, or long spindling ones poorly foliaged, and finally the dying of branch tips are the results of a compact heary soil. Especially is this true in a cool wet season, when, owing to the excess of water in the soil, air (or oxygen) is excluded from the roots, and their respiration rendered imperfect.

In newly planted trees, especially in compact soils, these same symptoms, followed by death, often appear as a consequence of too (leep planting. The aëration of the roots and lower portions of the tree being thereby precluded, alcoholic fermentation of the cells sets in, and the waterconducting function of the cambium and young wood is impeded, as becomes evident from the sickly yellow appearance of the foliage. If the soil is not corrected, in a year or in a few years the tree succumbs. Some species, however, such as willows, poplars, elms, and basswood, may under these conditions form new superficial roots from the bole and thus help themselves.

A surplus of water in the soil, besirles unfarorably influencing aëration and thereby producing the symptoms mentioned, may also produce a kind of dropsy, if weather conditions are favorable to rapid transpiration or if light conditions in 


\section{Effect of Soil Conditions}

the foliage have been changerl: an excess of water will cause an excess of cambial activity, and this may cause the bark, especially on young twigs, to burst open in spots, from a few inches to a foot, exposing the wood. This is found rery frequently on currant bushes, but occurs also in oak, horse-chestnut, and beech. To correct this and some other similar conditions, the expert surgeon applies a blood-letting process, making a longitudinal cut through the bark, whereby the pressure is relieved; such a wound soon heals. In other trees, like the silver maple, the excessive growth slough.s off the old bark, rapidly exposing the younger bark. This may be followed up by sun-scald - the drying and breaking open of the bark - with the consequences usual to mechanical injuries.

A great number of malformations in young shoots, foliage and fruit are also attributable to excess of water-supply at the root.

A very common result of the change in the relation of consumption to supply of water, as for example, when a tree is severely pruncd, or in the case of mere excess of water at the root, is the formation of so-called water-sprouts, or suckers, - very vigorous thin long shoots, which arise form dormant buds out of regular order along the branches and bole, particularly near cut branches. These may or may not be injurious. They interfere, however, with the symmetrical development of the crown, and they are injurious when they rob the main branches of water and cause their drying out. They should therefore be removed, and at the same time the water-supply at the roots regulated.

Thus, while excess of water on compact soil becomes injurious through the impeded aëration of the root system, deficiency of water in a drouthy season produces similar results by the failure to supply the stream of transpiration 
from the foliage, the newly formed rootlets dying in the dry soil. This results in premature yellowing of leaves on single branches, a shortening of the year's shoot and the drying out first of portions of the bark and finally of entire branches.

In light sandy soils this deficiency of water at the root may be due to orer-drainage, or, in compact soils, to the packing and caking of the surface layers, preventing aëration as well as the penetration of water. This hindrance to penetration, especially in paved and asphalted streets, grows more and more pronounced from year to year, and hence premature loss of vigor is the conseruence unless assistance is given at the root.

Since trees get their water-supply from great depths, the drouth must be very protracted before the effect is felt, except in shallow soils, on rocky ledges, etc. Yet, in our country, there occur seasons, when the drouth is so severe and protracted that eren well-established specimens of native trees, such as Rock Maple, and IThite Pine, have their leaves badly scorched. The leaves then do not fall, but become brown and dry, and remain hanging on the twigs. A very similar appearance of foliage in early spring, especially in conifers and other evergreens, such as Rhododendrons and Buxus, is due to winter drouth. This is experienced usually when, with the ground still frozen, a sudden rise of temperature occurs and dry winds prevail which overtax the transpiration current from the leares. This "burning" of the leaves is chiefly confined to that side of the tree which is exposed to the prevailing winds.

In fruit trees there are quite a number of other symptoms due to deficiency of water which do not concern us here.

Different species make different requirements on watersupply, some adapting themselves to deficiency or excess 


\section{Effect of Soil Conditions}

more readily than others. These latter, like the Swamp Oak, Bald Cypress and Mlder, especially when they have once adapted themselves to swampy life are at a great disadvantage if the conditions are suddenly changerl. It is, therefore, possible that in newly planted trees any ailment is merely due to change from one set of conditions to another, to which the tree is not as yet adapted. Thus a tree moved from a shady position to one of more intense light will suffer for a time until the foliage is adapterl to the new environment.

In passing it is interesting to note that even a physically moist or wet soil may be physiologically dry, that is to say, the water may not be arailable to the rootlets. This is the case in swamps where the water is saturated with humic acids from the decay of regetable matter, these acids having a greater attraction for the water than the rootlets can exercise. Here we see quite frequently the disease called staghead, which consists in the drying of the top due to deficient water-supply at the root.

It is, therefore, necessary to be cautious in the attempt to diagnose and correct water conditions.

The death of the top, top dryness or staghead, is gradual, the lower branches remaining green, their annual shoots, however, becoming shorter. It is a result of drouthy conditions at the root, which may be caused in various ways, other than the one just cited. In forests and parks, by cutting out or burning the undergrowth and by serere trimming, the sun is given access to the ground. As a consequence the decomposition of the litter and humus which covers the soil proceeds more rapidly, while at the same time on account of the increased light supply the foliage becomes more active. Stimulated by the increased food elaboration, all the benefited trees at first grow more vigorously and their 
foliage is greatly increased, but finally, after a year or more, a disproportion of supply and demand arises, and, as the lower branches appropriate a greater share of the water and minerals from the soil, the upper ones are starverl and die.

We will see later that electric discharges may also cause this stagheaded condition.

Although water is the most important contribution of the soil to tree growth, - most soils containing sufficient quantities of the needful mineral nutritive elementsyet, sometimes a deficiency of the latter in available form may account for sickly appearance of the foliage. Hence the chemical constituents of the soil should also be examined.

If the premature yellowing of the leaves and other abnormal appearances do not find any other explanation, they may be due to deficiency in iron, magnesium, potash, lime, phosphoric acid or nitrogen, and the application of appropriate fertilizers will correct the evil.

The deficiency most likcly to occur is in nitrogen, of which trees require a relatively large amount. The absence of nitrogen in sufficient quantity is indicated by the etiolation of the foliage, which assumes a yellowish or even a whitish appearance.

It will have appeared from the foregoing statement that, while the foliage gives sure indications that something is wrong, it is not so easy to decide what is wrong. Different causes may produce the same abnormal appearance and the same behavior in foliage and twigs; just as the paleness of the human patient may be due to various causes.

The abnormality may be primarily due not to local, but to more remote causes, which affect the whole physiology of the tree, and often the secondary evils, which, to the 


\section{Atmospherical Influences}

uninitiated, appear as the true source of the disease, are mercly the result of the unfavorable physiological conditions of the tree.

Hence in diagnosing, one should never be satisfied to stop short of an examination of the condition of the patient in all directions.

Atmospherical Influences. The conditions of the atmosphere naturally also influence the functions of the tree, but are mostly not under control. Here, too, species vary in their requirements and in their capacity for adaptation. Here even more than with reference to soil conditions (which are under control) it is necessary to make sure of the natural adaptation of the tree to its surroundings. And, we reiterate, it is not only the species that need consideration, but the individual itself, when transplanted from one set of conditions to another. For, the individual tree as it grows up from the seed has the capacity of adjusting itself to its environment, but when suddenly transplanted into other surroundings it cannot do so at once. Hence it may be ailing for some time until it gradually adjusts itself, or else it may succumb to the unaccustomed conditions, either directly or by physiological discase, or indirectly by falling a prey to parasites in its enfeebled state.

If, in planting, species or specimens have been chosen which are adapted neither to the conditions of humidity or drouth, nor to the temperature changes of the atmosphere common in their new home, they will suffer, and perhaps die, and should be replaced by those which are better suited to the environment. Theoretically, it may be possible to help such exotics by regulating the soil conditions, and to mitigate climatic conditions by screens and other protection; but practically this is usually too troublesome.

Soil and atmosphere are in such interdependence as far 
as the life functions of a tree are concerned, that the influences of the one may be counteracted or increased by the influence of the other: drouthy conditions of the atmosphere may be met by irrigation at the root; cloudy weather may counteract deficiency of water at the root; a warm soil may start growth so early in the season that frost will do clamage, which otherwise would have been harmless. These relations involve complications which may bafile even an expert's diagnosis as to the true cause of physiological clisease.

The humidity and temperature of the atmosphere are conditions of moment, especially in frost phenomena, but the soil plays in these no subordinate rôle. Indeed, many frost phenomena are more dependent on soil conditions than on temperature. Stiff, clayey soils are, as a rule more liable to frost than light soils, and a soil producing over-luxuriant growth is apt to expose the imperfectly ripened wood to damage by early frosts in the fall.

There are three seasons in which frost may occur with differing effects, namely, the fall or early frosts, the winter cold, and the spring or late frosts.

The early frosts occurring in the fall at the end of the growing season will be felt especially by ihose leaves which have not been shed, and by the tips of the shoots which have not perfected their growth. Damp locations seem to induce this late growth, or at least do not seem to mature the wood as well, and they are also more liable to fall frosts than drier regions, hence draining may reduce the frost danger.

In certain positions the danger from frost is greater than in others, and, if this is due to cold air settling in a given place, say a group of trees, it may be corrected by opening up the group) and thus creating a draft for the cold air to draw off. Conifers may suffer especially in such "frost holes." 


\section{Atmospherical Influences}

The proper treatment for trees whose shoots have been frost-killed, is to head them back severely to sound wood in order to get rid of the injured, and to supplant it by active, healthy growth. This pruning is best done shortly before the foliage starts, when the extent of the injury can be better noticed. Trees or branches thus injured by fall frosts may sometimes leaf out and bloom in spring, but they soon sticcumb for lack of sufficient water-supply through the injured parts.

The loss of foliage with the approach of winter, which is a natural physiological process, is more or less connected with changes in temperature conditions, and hence in some years may occur earlier, in others later than usual, without being a sign of sickness. Besides leares, certain species, like Elm, Linden, Black Locust, Poplar, Willow, Oak, Bald Cypress, and many others shed more or less regularly whole branchlets, from one to ten years old, and more. This phenomenon may also be considered pathological, although it occurs quite frequently, and sometimes regularly and systematically. Neither the cause nor the remedy is known. This shedding of branchlets is entirely different from the loss of the tips by frost, regularly experienced by some species like Linden, Elm, and Sycamore, and by exotics which find the summer too short to finish their growth. This habitual freezing back can be prevented by defoliating the branchlets before growth ceases, when the wood will harden before the frosts come.

In other species such loss of the young twigs occurs only under special conditions, namely, when the young wood has not been matured in time. This is apt to happen when a late and warm moist fall follow's a dry summer, inducing belated growth which does not harden but remains succulent and is nipped more or less severely by the early frost.s. 
Late pruning in summer will produce such late growth and is, therefore, to be avoided.

The late or spring frosts will injure mainly the new tender growth of leaves and flowers, and the opening buds. A temperature from two to even seven degrees above freezing point may suffice to do the damage. Southern, eastern, and southeastern exposures are especially dangerous, for in these sun-warmed situations regetation awakens in early spring and the tender foliage falls readily a victim to the late frost.

Shade, or any other method of keeping the soil cool and retarding the activity of roots and buds is the only means of counteracting these frosts. In most cases they have to be endured, or aroided by selecting late budding species and varieties.

Winter cold, as a rule, does not do much damage, yet occasionally very severe and persistent cold, causing frost to penetrate the soil to a great depth, may become detrimental, injuring or even killing trees and shrubs. This is especially true when the preceding season has been unfarorable, or for other reasons the plants have had their vitality impaired. Soil conditions and situation have considerable influence on the occurrence of winter killing, just as they have on early and late frost.; high, dry ground and exposed places being especially subject to this damage. Even native species are by no means exempt. The loss may be only in buds, or in twigs, but, if the roots are killed, the entire plant may succumb. During the severe winter of 1903-rgot, Red Maple, Butternut, and White Pine in the State of New York were killed outright, and a long list of trees and shrubs were partially killed. The loss of part of the root system may exhibit itself, as in any other case of reduced water-supply, in the loss of part of the crown 
and a thinning of the top, or in under-derelopment of the foliage, the latter being smaller, assuming a pendulous position and early fall coloring.

The best preventive, where this kind of loss is anticipated, consists of pruning and mulching well, in order to restore the proper balance between root and crown.

IV inter cold will, of course, affect the young and immature twigs in the same way as do the late frosts.

In smooth-barked trees, such as the Beech and Horsechestnut, and in special situations, the bark of branches and young trees cracks in patches, and the cambium and the young wood underneath are killed. If such lesions are extensive they may lead to the death of branch or tree. This injury generally takes place on the southwest side and toward the end of winter when rapid temperature changes are more common; a few warm days stimulate the cambium on the south side to premature activity; freezing weather following, these active areas are killed, the young wood cells and cambium shrinking away from them and the bark cracking and drying out. Often not until summer does the bark split and reveal the damage below.

Such frost phenomena as the killing of the bark appear in very variable form, such as small frost boils, or smaller or larger frost plate's, the dead bark splitting off from the live margins and rolling back, exposing the dead wood, which then is either gradually covered up by a callus from the marginal cambium, or else becomes infested by fungi.

The worst form of these frost injuries is the malformation known as canker, in which fungus parasites also take part. Wet, cool localities seem to predispose trees to this disease, but severe pruning and manuring in the spring may produce the same effect; this curiously enough, seems to appear as an individual peculiarity which can be transmitterl by 
grafting. Drainage of soil and more careful pruning will reduce the discase. The cankcrous parts should be cut out to the living cambium and covered with hot tar, at the same time the exposed side should be partially protected by brush or boards, until the cambium orergrows the wound. Similar results, i.c., the bursting in longitudinal cracks and killing of the bark and of underlying wood portions, are produced by the so-called sun-scald, which is also especially observed on the south and southwest sides of such smooth-barked trees as Beech, Apple, Pear, and also of the soft-wooded Basswood, Horse-chestnut, Chestnut, Ash, Plane tree, Birch, and Willow. It is an open question whether this is not due in part, at least, to frost, in conjunction with the sun. Protection of the exposed side by boards or straw, or still better by a neighboring shady tree, will avoid the trouble.

When the fall of a winter temperature is very sudden and very low (below zero) frost splits, due to uneven shrinkage of the wood in the interior, are produced in a variety of trees; especially in those with distinct heart-wood, the sapwood shrinking more than the heart-rood, a longitudinal split results. These cracks usually close up during warm weather, a callus orergrowing the wound forms a ridge and the dlamage consists only in this malformation, unless fungi and insects gain access. Such frost splits occur very frequently in northern latitudes, even in the forest, and on very cold day's with a noise resembling a gunshot.

Obnoxious Gases. Finally, special conditions of the atmosphere which become more and more potent in our cities, namely, the smoke and olher poisonous gase's emanating from factories, must be considered as causes of disease. The merely mechanical black coating of coal particles and soot which settle on the foliage will only slightly reduce the 


\section{Obnoxious Gases}

function of the leaves, while a still more serious injury comes from the sulphurous acid which accompanies the smoke of most coals, and poisons the foliage. A small amount of this acid taken up by the leaves suffices to do the mischief.

In most cases, howerer, the movement of the air, and the chemical change of sulphurous acid into innocuous sulpluric acid produced by contact with the humid air, prevent the worst effect; but, if conditions are farorable, the smoke of a brick yard, for instance, may suffice to kill the foliage. Even the smoke from locomotives may become injurious in moist climates, or in certain locations, such as in narrow valleys, when it remains stationary for some time. We may mention such smoke-resistant trees as Sycamore, Poplar, Ash, Alder, Maple, and Elm.

The duration of the poisonous condition of the air rather than the concentration of the poison is of moment. The first visible signs of poisoning are characteristic pale spots on the blades of leaves, which turn brown, while the reins of the leaves remain green; the normal water movement in the leaves is interrupted and the green tissues are disorganized, the tips and margins of the leaves being first affected and drying up. The effect is similar to that of drouth and sunburn. If the trouble continues, the entire leaf becomes yellow or brown, except in the case of conifers, when the leaf turns red. Finally the leaf rolls up and drops. The drier the air, the higher the temperature and the more intense the light, in other words, the more active the foliage, the more quickly are these effects produced. The effect is therefore greater in the day and less at night. The poison does not penetrate the tree, but remains in the foliage, and hence the effect is only that of defoliation in general, namely, reduction or loss of food material. 
Chlorine gas, developed by the burning of coal in smelters and in certain soda factories, as well as soluble metallic oxides from various manufactures, have similar effects.

Only the systematic suppression of the smoke nuisance, which several cities, notably St. Louis, have begun, and the enforcement of factory laws (such as are operative in most European communities) to prevent the escape into the air of poisonous substances, will remove this cause of disease for which there is no remedy.

The escape of illuminating gas produces similar effects. To injure foliage a large amount of this gas is required, such as the continuous vitiation of the air, which often takes place in the neighborhood of gas works or of natural gas wells. The effect is usually the dying of portions of leaves, the tips and margins especially turning brown and dry; sometimes the entire leaf becomes dry and withered, hanging, however, tightly to the branch.

More frequently still does the escape of gas into the soil from leaky pipes do harm. Indeed, when we read that in I905 the gas companies of Massachusetts experienced a loss of ten per cent. of the gas actually produced, we must conclude that gas leaks are a much more frequent cause of damage to trees in streets and parks than is usually supposed.

It is probably the sulphuretted hydrogen, which, taken up by the roots, acts as a poison. The result of gas poisoning may be only a partial or local dying of parts, namely, of those directly affected by the leak; but it may also cause death of the whole tree.

The presence of the gas is detected by the odor when the ground is turned, and by a blue coloration of the roots or of the sap-wood, ascertained by boring or chipping. This gas kills the roots, and, as a consecfuence, discoloration and 
premature dropping of leaves and dying of branches occur above the affected root. A characteristic outward sign for diagnosis is the darkening and rapid loosening and falling of the bark, similar to what occurs in the case of kerosene poisoning.

If the leak is a sudden one and the gas escapes in a large quantity, a tree in full foliage may suddenly have its leaves droop and turn brown; these hanging on, however, till winter winds tear them off; such trees die in short order. In some cases trees have been known to have been killed by gas in a single night.

If, however, the leak is slow and small, only a single root and its corresponding crown parts may be killed, but, if the leak continues and the gas spreads in the soil - which in loose soils may go on rapidly for a thousand feet or more, - general debility develops and the whole tree gradually succumbs. There is practically no recovery for a tree once severely poisoned in this way, for the soil is saturated with gas, the roots are killed, and it is practically impossible to renew the soil.

Watering, which has been proposed as a remedy, does not seem to counteract the poison. If detected in time, renewal of the soil, root pruning, and severe cutting back may restore the patient.

Electric Currents. The appearance of trees killed by gas is very much the same as that of those killed by lightning or electric currents, the foliage dying and remaining hanging on the tree. This takes place not necessarily only on trees which show the lightning stroke along the trunk, but also as a result of general electric conditions of the atmosphere, or of a discharge through the whole tree, without any apparent actual mechanical injury.

If the stroke follow's a vertical line along one side of the 
bole there may not be any more consequences than accompany any ordinary or frost-split wound which may be healed by callusing, but when it follows a spiral course, killing cambium on all sides of the tree, the result is like that of girdling.

Very lately it has been discovered and experimentally demonstrated 'that electric shocks of low tension occurring during thunder-storms, especially in winter, are the frequent cause of the phenomenon described above as staghead, the leader and upper portions of the crown for from five to ten feet or more being killed while the rest of the tree remains uninjured.

Every tree owner should look out for the wire stringer, who not only disfigures the tree by chopping off branches, regardless of consequences, but introduces the danger of electrocution. Trees and branches, beating against electric wires in winter storms, wear off the insulation and thus establish short circuits, which under certain weather conditions as, for example, in a thunder-storm, may bring about the total destruction of a long-cherished old trec.

According to the latest investigations ${ }^{2}$ there is a difference in the effects of direct currents which are used chicfly in operating electric railroads, and of alternating currents of the electric light plants, which, although carrying a higher current, appear to be less disastrous.

In moist or wet weather, when the tree is covered with a film of water, the current causes, at the point of contact, an injury to the tree, which provides favorable conditions for leakage through the film of water, grounding the current and burning the limb, partially or entirely killing the cambium

1 See Forestry Quarterly, Feb., I904.

2 "Injuries to Shade trees from Electricity." Bulletin No. 91, Mass. Agr. College. 


\section{Light Conditions}

at point of contact, and drying out the limb above. With alternating currents the damage seems usually confined to this local destruction at or near the point of contact as a result of the heat created. With direct currents, in addition to these local burnings, clectric effects are sometimes noted at a distance, the escaping current girdling trees at the base, and killing the cambium without the characteristic burning at point of contact or at point of discharge. This appears to happen only when the positive current is not as usually carried by the feed-wire, but by the rail, and leakage through imperfect rail-connection occurs. In an observed case the damage was done when the trees were four feet from the rail, the moisture conditions of soil and bark being evidently most favoralble for electric discharge.

The only help) is, of course, to string the wires outside of the tree line, or at least to prevent contaci, keeping in mind that winds will sway the branches and that allowance must be made for this.

No authentic cases of injury or death, due to the mere effect of the light of arc lamps, are on record.

Light Conditiens. Where trees are planted close together, standing in groups or clumps, there is apt to be an uneven distribution of light, some trees or some parts of trees being deprived by their neighbors of a sufficiency in that respect. The light is necessary, as we have seen, for the leaf to perform its functions in assimilating food. Deficiency in this respect may show itself in ctiolation, the leaves becoming small and elongated, and the leaf-stalks and branchlets thin and slender. Finally, when the shade becomes too dense, the shaded portions die. 'This very important observation is utilized by the forester in securing branchless boles by the natural trimming that takes place in dense growths. 
It stands to reason that the stronger and more shadeenduring species, having also a denser crown, will retard the development and kill out the light-needing varieties that may have been planted under its shade. The sensitiveness to withdrawal of light increases with deficiency of soil moisture. Pruning back of the stronger will give the weaker a chance for development.

Care is necessary, however, with some species, especially conifers, in not opening up too rapidly, so that the foliage may gradually adapt itself to the new light conditions.

Wherever there are trees planted in groups or as close neighbors this relative shade endurance becomes one of the most important factors in influencing the form development of the tree, and where light-needing species are in competition with shade-enduring, the former are likely to lose the battle.

Mechanical Injuries. Finally, if none of the causes of disease so far discussed can be adduced as occasioning abnormal conditions, we must look for mechanical injuries.

As we have seen, mechanical injuries to the bark and wood, by whatever agency inflicted, are first of all injurious by admitting destructive fungi. In addition, the bark, branch, or bole being broken or torn off in places, much of the underlying cambium and young wood is killed and rendered inactive in conducting water and food materials. As a consequence, some parts of the crown and of the root system are underfed and suffer in proportion to the extent of the injury, until the wound is healed and closed up. Usually, such injuries are one-sided and it is, therefore, a particular branch or one side of the tree which shows the influence of the under-feeding in the foliage or in dying portions. More regarding the nature and physiological 


\section{Mechanical Injuries}

influence of these injuries will be found in the discussion of their repair in the next chapter.

It will ha e become clear that the diagnosis of diseases in trees, although by no means as complicated as in the animal, nevertheless requires considerable knowledge and judgment. 


\section{CHAPTER V}

CONTROL OF PHYSIOLOGICAL DISEASES AND TREATMENT OF MECHANICAL INJURIES - GENERAL CARE OF TREES

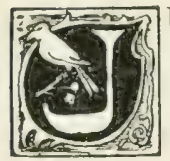

UST as in all other cases, the ills to which trees are exposed are best met with the prescription of the old adage: "An ounce of prevention is worth a pound of cure."

Just as the physician insists upon sanitary conditions, as a means of preventing disease, so the tree doctor should insist upon securing the most farorable conditions of growth for his charges. These may be achieved by looking after soil conditions, mainly with reference to air and water-supply; by providing a satisfactory amount of light, and, above all, by timely and judicious surgery-pruning, by which the consumption of supplies from the root can be regulated sometimes more easily than the supply in the soil itself.

These two means, then, regulation of foliage development by pruning and soil improvement, are compensating and should usually go hand in hand. Timely attention to these requirements will prevent many of the troubles to which trees are liable, and, when trouble has come, half the battle is won, if these conditions of favorable nutrition are established and the tree has been kept in rigor to fight off the disease.

W'e shall devote this chapter, therefore, entirely to the discussion of proper care in scil conditions and in pruning, 


\section{Soil Improvement}

whereby physiological diseases are prevented or cured, and mechanical injuries rendered harmless. Too much stress cannot be laicl upon the need of such care. Tree owners do not seem to realize that, after the plantation is made, it still refuires attention; that most trees deteriorate or dic because they are unterfer and allowed to dry up). Suffeicnt water-supply is the most important mans of maintaining healthy tree growth.

Soil Improvement. The most natural conditions for tree growth are found in the rirgin forest: a soil continuously sharled, practically free from grass and weerls, covered with a heary mulch of decaying foliage and of humus, which prevents evaporation and keeps the soil granular, easily penetrable to water and air, and well supplied with food materials.

Street trees and lawn trees are not growing under natural conditions. In the one case the parement keeps much of the water from penetrating, while in the case of the lawn, the grass competes severely with the tree for water, and the natural mulch of foliage is raked off every year, and thus food materials and soil protection are removed and much moisture is allowed to evaporate.

Such trees are, therefore, more or less on starration rations; they show almost always that they are underfed, or else suffer in their respiration, and, if any other contributive cause for unhealthy condition is added, they rearlily succumb, especially as they grow older and the difficulties of securing their water-supply increase with age.

In lawns, therefore, and in strects, where practicable, the sod should be taken up from time to time, or the soil stirred so as to secure better aëration, and a clressing of hardwood ashes, of garden mole or of well rotted stable manure applied, and possibly a mulch of spent bark shav- 
ings or leaves should be adderl. If this is done in the fall the tree will be invigorated with new life, the winter moisture will penetrate, and new rootlets will form in larger numbers, for root activity continues long after the fall of leaves. In the spring the sod may be re-established, although badly starved trees will be benefited by keeping them mulched for a few seasons. The mulch should not be too thick, just enough to prevent the pattering rain from compacting the soil, and to prevent eraporation from it; this may be attaincd by a cover not hearic $r$ than one-half to one inch. Nor should the mulch be allowed to become compacted itself, so as to impede frec penetration of water and air.

There is not much value in making this application close around the stem; it is under the trough of the outer foliage, under the ambitus of the crown, that the main feeding rootlets are located, and here the treatment will most benefit the patient.

On shallow and very compact clay soils this treatment should be frequently repeated, and possibly at the same time some sand or garden mold should be worked into the soil, or else an application of lime, marl, or gy psum may be made, which has the eflect of granulating a stifi soil, making it porous and thus improring its water-conducting capacity. The application of slacked lime, as free as possible from magnesia, should be made during the winter in small repeated doses at the rate of about one to three pounds per hundred square feet.

Watering, where practicable, will, of course, overcome the effects of drouth; but it must be kept in mind that a surplus of water may become injurious by reducing aëration. Often, the mere loosening of the soil is sufficient to correct the deficiency in water-supply: the loose surface 
soil acts precisely like a mulch, the capillaries having been destroyed. Hence no water can rise from below into the surface layer, and thus loss of water by evaporation is prerented. In applying water to the surface, therefore, the compracting of the soil by the water must be avoided, and this is best done by applying the water through ditches or holes near the tree, by sub-surface watering.

Where, due to soil and topographic conditions, continued excess of moisture is cxperienced, ancl aëration thus imjected, the drainage must be improved. Lsually it is better simply to lower the water table than to attempt thorough draining. An open or covered ditch properly lucated at some distance will do the work. Such ditches may be filled up with rublble and then be again corererl and sorkleci.

It is, however, advisable to be very cautious in attempting the regulation of the water-supply by drainage, for not only do species vary in their water requirements, but the individual trees, having once adapted themselves to a wet situation, may resent any sudklen change of condition. Time must, therefore, be allowed the tree to adapt itself, by changing the water level gradually, while at the same time the process of adaptation may be assisted by judicious pruning.

Fertilizing. 'Troubles due to deficiency' in mineral salts in the soil are of rare occurrence, since most soils contain sulicient quantities of the needful minerals of which trees require only small amounts, their bodies being mainly built up from the carbon of the air. The only mineral likely to be deficient is nitrogen, the lack of which would produce a yellow or cren whitish appearance of foliage. In nature this mineral is provided by the decay of fallen leaves, in which the nitrogen-gathering bacteria work. So the practice of raking off the leaves in parks is one way of starring trees. 
A nitrogenous furtilizer, or an occasional dressing with hardwood ashes, which contain the required minerals in most accessible form, is to be recommended wherever the vigor of the tree is impaired. A dressing of ten pounds of ashes per hundred square feet, costing ferhaps twenty cents, will be found very ample.

Although in most cases hardwood ashes are as good a fertilizer as need be, for very impoverished soils the following mixture will be found serviceable and should be applied in early spring before the leaves unfold, namely, one pound of nitrate of soda, five pounds cotton-seed meal, two pounds acid phosphate, two pounds muriate of potash, the whole mixed together just before using; che pound of this mixture costing, if prepared in puantity. less than two cents per pound, will suffice for a hundred square fect. This is also an excellent top dressing for lawns.

The growing of a crop of clover, alfalfa, lupine, or some other similar crop and plowing it under while green, is also an excellent means of recuperating imporerished soil both physically and chemically, and at the same time improring its aëration.

While lawns are benefited by sheep, cow, and horse manure, and some flowering shrubs respond to treatment. with a compost made of bone dust and manure, or better still, with leaf-mold, the physical improvement of the soil for water conduction by stirring and mulching, as advised in the preceding pages, is usually all sufficient for arborescent growth.

Points in Grading. One of the most common mistakes causing the loss of many old trees, is the filling up of ground over the roots in grarling operations. by which water and still more surely the necessary air is excluded. This careless burying of the roots shows inexcusable ignorance 


\section{Points in Grading}

of the requirements of tree life, for if the corer is of sufficient depth, say two feet or more, and especially if of compact soil, it wiil usually quickly and surely kill the tree.

No less ignorance is exhibited by those who, when such filling is to be done, leave an unfilled depression or space directly around the bole, perhaps walling it up with brick and covering with wire netting or filling with rubble. In doing this the notion is to admit rain water, and perhaps also air, to the roots. But, while undoubtedly the admission of water and air is facilitated by this derice, the need of water and air is much less near the bole where only conlucting roots are located, than on or towards the ambitus of the crown, where the feeding rootlets lie and the respiration is most actively needed. Filling around the bole is, to be sure, undesirable as it not only clogs respiration in that part of the bole, but, with some species, induces the formation of suckers, which weaken the tree. Hence the precaution of keeping the base of the bole free is a good one, but it does not compensate for the filling over the feeding rootlets.

There are three ways of meeting the trouble, if there is a strong desire to save the trees instead of remoring and replacing them by others. Where practicable, the filling should be done so as to leare depressions with gentle slopes towards the feeding area of the root system; or better still, the filling should be done gradually, taking if possible several years, and after first thoroughly stirring and fertilizing the ground around the roots, so that the tree may make new feeding roots towards the surface.

Or, where deep fillings have to be made and valuable trees are to be saved, the following device may be employed. After the ground has been stirred and fertilized as suggested, an air chamber may be established by covering the ground 
with rubble or broken stone before putting down earth and sod, keeping the space around the bole open and in addition introducing through the filled ground aërating pipes which connect the air chamber with the outer air.

In any case, trees so treated should be at the same time severely pruned, since some of the feeding roots are bound to die and it is necessary to establish an equilibrium between root system and crown system. Otherwise nature will do the pruning and perhaps not in the manner desired.

Different species vary in their sensitiveness to the withdrawal of air and, as we have seen before, trees which have grown up in swampy conditions make provision in other ways to meet their requirements for air, and may therefore be corered to a considerable extent with impunity. In general it will be found that the trees naturally growing in the swamp will stand filling best.

The depth and character of the soil used for cover will naturally also have to be considered, since with a loose soil and a moderate depth the respiration may not be materially interfered with, while a thinner layer of clay would be detrimental.

In most cases, howerer, the safer way is either to avoid the grading or to replace with new trees.

Whenerer it becomes necessary in grading, making of streets, laying of conduits, etc., to cut into and destroy part of the root system, a corresponding amount of the crown system should be removed by proper pruning, keeping in mind the fact that the side on which the roots are destroyed is the one that needs to be most severely pruned.

The aëration and watering of street trees is a most difficult question, especially where macadam or other solid parement is used. It is, therefore, necessary in the first place to choose species which are frugal in that respect. Here again, species 


\section{Pruning and Trimming}

growing naturally in the swamp promise well. In addition, a certain space, say one and one-half by two yards, should, if practicable, be left unpaved around the base of the tree, and this space should be kept open, stirred and fertilized from time to time. Where this is not practicable, a smaller space left unpaved may be covered by a grill or iron grating, supported on wooken peess driven in the grount. Such grills are found in Paris, lierlin, and London (see page IIg), and permit of watering the trees. This treatment is, to be sure, applicable only with new plantings, when the trees will adapt themselves to the conditions. Where old established trees are concernerl, it is doubtful whether they can be permanently maintained when a tight pavement is placed over their roots.

Pruning and Trimming. Next in importance to attention to soil conditions, there is nothing of more value for aroiding and correcting trouble in tree economy than properly applied surgery.

There is competition everywhere in the living world, and not only do the individual trees compete with each other for root and air space, water and light, but each leaf, each bud, each shoot competes with it.s neighbor, although only a limited number can develop.

As we have seen, trees prune themselves, i.e., some of the buds and branchlets die every year and are broken off by the wind. This natural pruning is the result of the struggle for existence, i.e., fir food and light supply, between the buds or branchlets, and an arljustment in the economy of the tree, keeping the balance between income and expenditure. By reslucing the number of mouths to be feel the remaining are better fed. There is, therefore, not necessarily any apprehension to be had if some twigs and branches die in response to the perfectly normal neerl of arljusting 
consumption to nutrition and light supply. On the contrary, by anticipating this natural process through timely artificial pruning and trimming, still further ad vantage can be secured; for, by interfering carly and limiting the competition, the vitality of the remaining branches is increased, so that pruning acts very much like soil improvement.

The common practice in pruning is to cut out the dead wood; the proper practice is to prune in time so as to aroid as much as possible the making of dead wood.

By judicious and ststematic trimming (heading in), both the form and the health of the trees are improverl, and in

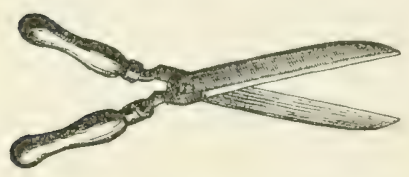

Fig. I3. - Hedge shears for pruning. fruit trees even the fruit-bearing can be influenced, - but this is an art by itself. Such trimming should be done annually or biennially, when only small changes at a time are made, the branchlets cut are small, and the tree economy is only slightly disturbed. The branch system being kept shortened, the roots are much more likely to suffice in supplying the needed water even in drouthy seasons, while enough (lormant buds will develop to fill out the crown as much as is needful.

Thus by timely and systematic attention we can produce just such forms and conditions in a tree as we desire, instead of learing it to the accident of natural development.

Indeed, in such lightineeding species as the Sycamore or Silver Maple, which are apt to thin out in the interior of their crown, the crown may be considerably improved and the foliage corer thickened by such cutting back of branches and consequent formation of new branchlets, which fill out the otherwise thin crown. Inother advantage of cutting "or heading back" the annual shoots in rapid srowing 
trees with sprawling branch systems, as in the case of the Soft Maple, is to make the crown more compact and thereby to increase its resistance to wind breakage.

Unless this operation is judiciously performed there is danger of spoiling the natural form and making the crown formal and undesirable.

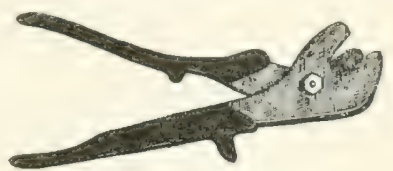

FIG. I4. - Levin's patent pruning shears.

Whenever twigs or branches are dying without a visible cause, it is in many, if not in most cases a sion that tire rout and branch systems are not in equilibrium, and it is

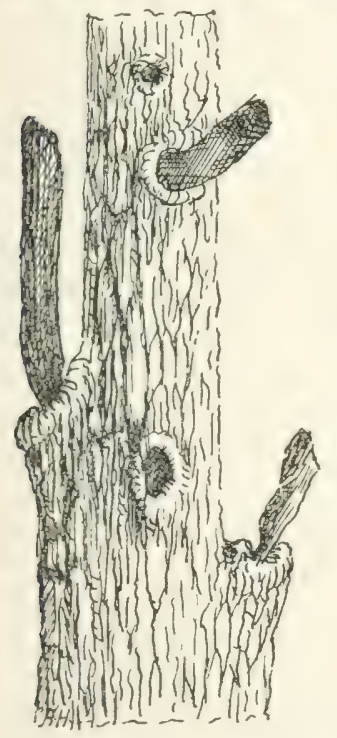

FIG. I5.-Broken branches which have not been pruned, liable to introduce rot. proper to remove not only the dead wood, but also some of the green wood, in order to give the root system opportunity to do its work more easily.

How severely this surgery may be applied depends on the condition of the individual, the species, and the age. Some species, even when quite old, respond more readily to the treatment than others, and they may be cut back severely into old parts and yet rehabilitate themselves. Others, like the ash, do not respond so readily and lose, as does also the oak in very old age, the power of replacement by dormant buds. Perhaps it may be a law that all those that sprout readily from the stump, such as the oak (when young), chestnut, basswood, and majle, also respond readily to the pruning knife. 
Besides the trimming for form and equilibrium, all broken branches must be at once pruned in proper manner, to prevent location of fungus spores, for, as we have seen, branch stumps are the most prolific causes for the beginning of rot.

The rules for proper pruning, although simple and based

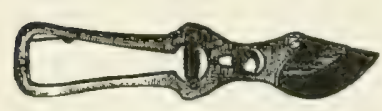

FIG. I6. - Solid steel pruning shears. on a knowledge of tree physiology, seem most generally unknown or overlooked, because the operation is left to ignorant workmen. There is probably more loss of tree life due to unskilful pruning than to any other cause.

Nothing can more pithily and impressively express the public attitude still prevailing to a large extent on this subject than Lowell's words in a letter directed to the President of Harvard University in 1863 , a letter containing so much common sense on tree management that we quote fully from it.

"Something ought to be done about the trees in the college yard. . . They remind me always of a young author's first volume of poems. There are too many of ' $\mathrm{cm}$ and too many of one kind. If they were not planted in such formal rows, they would typify wery well John Bull's notion of "our democracy' where every tree is its neighbor's enemy and all turn out scrubs in the end, because none can develop fairly. ... I think Hesiod (who knew something of country matters) was clearly right in his 'half heing better than the whole, and nowhere more so than in the matter of trees. . . Ne want to learn that one fine tree is worth more than any mob of second-rate ones. We want to take a leaf out of Chaucer's book and understand that in a stately grove every tree must 'stand well from his fellow apart.'. . . 


\section{Manner of Operation}

Nor should the pruning as now be trusted to men who get all they cut off, and whose whole notion of pruning, accordingly, is 'ax and it shall be given unto you.' Do pray take this matter into your hands - for you know how to love a tree - and give us a modern instance of a wise saw."

Manner of Opera'ion. lie may distinguish between trimming or heading in, which refers to cutting back or shortening of twigs and small branchlets with shear or knife, and pruning proper, which refers to operations with axe and saw in removing larger branches. It is in these latter operations that care is most needful, in order to avoid secondary damage from fungus disease.

The tocls must be sharp; the saw with wide set for laige branches; the cut must be made smooth. When cutting heavy long branches there is danger of the weight of the branch breaking it off before the cut is completed, splitting, splintering, and tearing off bark. To avoid this, two cuts should be made, the cne at some distance, - two or three feet from the base of the branch, to relieve the leverage, the other, which is the final one, or near the final onc, at the base; in both cases first sawing a kerf or

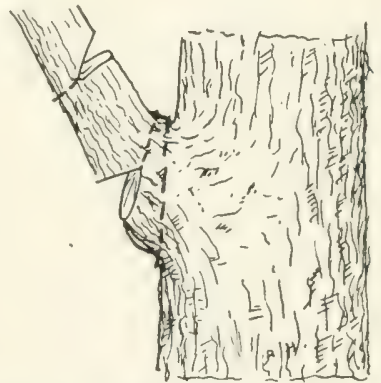

FIG. I7. - Methor of removing a heavy branch without splitting and tearing the bark on the under side, the lower notch being made first.

notching from below half way through the branch, and then sawing or notching from above, in order to avoid splitting and tearing off bark on the lower side.

With very large branches or tops to be removed, mechanical appliances, such as chains and ropes, varying with conditions to suit the case, for the purpose of avoiding 
damage will readily suggest themselies. A rope or hook ladder will often be a desirable addition to the outfit.

Where saw or axe cannot readily be used, a chisel and mallet may be substituted. In any case, a smooth surface must be secured, not a hacked and lacerated wound.

Alizily cut close at the very base of the branch to be amputated, with a cut as nearly parallel to and even with the outline of the main axis (branch or trunk) as possible,
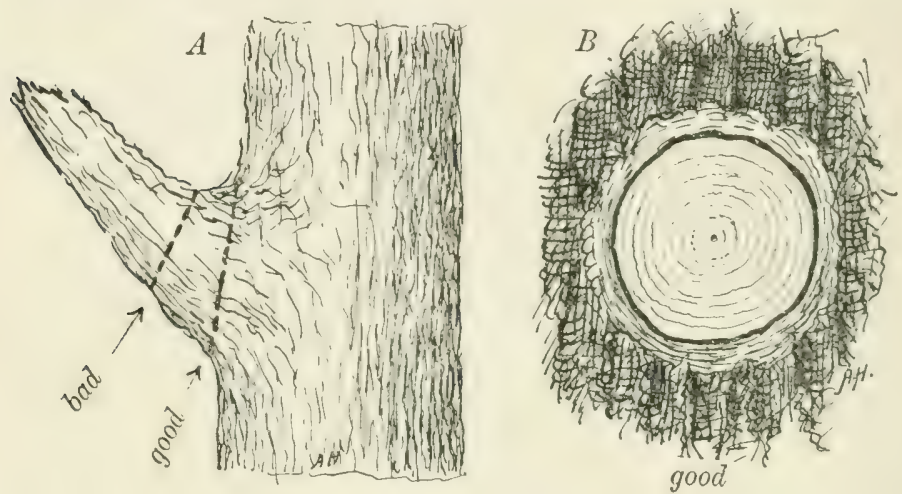

FIG. IS. - Good and had pruning. A, side view of good and bad branch pruning; $B$, front view of a well pruned branch.

leaving no portion or stub of the amputated dead branch on the trunk. Many older branches as well as younger, have at their base a swelling bulge, sometimes called a "shoulder"; this must be cut into and remored in order to satisfy the requirement of close cutting, in spite of the fact that the wound is thereby greatly enlarged.

The object of cutting close and parallel to the remaining axis is to expedite the closing of the wound by the callus or wound woot formed from the cambium at the margin, which, as we will presently see, is more realily formed when the cut is made as prescribed. Great care must be 


\section{Manner of Operation}

taken not to loosen or separate the bark from the wood at the margin of the wound, or to crush the cambium in this region.

All wounds must be smoothed and then hearily dressed with an antiseptic, impenetrable corer, in order to keep out water, and with it, bacteria and fungi. Common lead paint answers this purpose best, being antiseptic as well as lastingly impenetrable to water. By making it as nearly

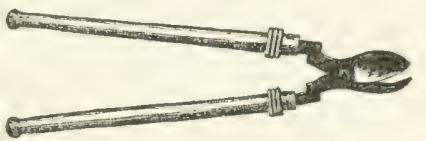

FIG. I9. - Topping shears. as possible the same color as the bark the unsightliness is reduced. Coal tar is also recommended, but aside from its unsightly color it sometimes damages the cambium at the edges, and is not as easily handled as learl paint.

Be sure to make the coating thorough, possibly applying two or three coats. This coating or dressing does not influence the healing process in any way, but is merely a mechanical device to licep out water and fungus spores. Therefore, every cranny should be filled, especially the lower edge, which collects water more easily. If cracks appear, the coating must be renewed so as to fill them and keep out the surface waters.

With the observation of these few simple rules, any intelligent man can do the ordinary pruning without doing damage.

As to the time of pruning, there are advantages and disadvantages in every season, although the operation may be performed at any time with safety, provided it is properly executed. During the early growing season, when the bark peels easily, there is greater danger of injuring the tree mechanically by bruising the bark; so it is better to defer the pruning until fall, winter, or very early spring. In 
summer the leares are also a hindrance to the work, and, besides, a certain amount of foud in leaves and young parts would be lost to the tree, endanerering the life of a proportionate number of rootlets, or at least unnecessarily reducing the reserve stores. Lisht trimming, however, may usually be done in summer with impunity.

For pruning into live parts it is better to wait until the foliage has withered, when the food contents of the leares

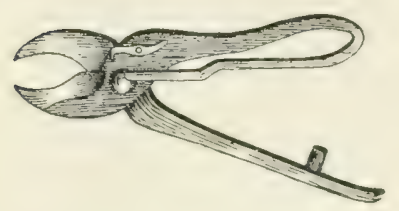

FIG. 20. - English shears. have been withdrawn into the trunk and become available for the unfolding of the next year's buds.

The cold winter makes pruning an uncomfortable operation, and the results are therefore hazardous and less efficient. It is, in addition, physiologically undesirable, except on mild days, as, owing to the uneven expansion of bark and wood under the influence of frost, the wood is apt to shrink away from the bark, and a considerable portion of the cambium may be killed, rendering the healing process more difficult.

For the choice of early spring (March or April) it is said that then the healing process of the wounds sets in at once, or at least sooner than when made in the fall, and the danger of fungus infection is reduced.

But as a matter of fact it is generally believed that the season has not any appreciable influence on the healing of the wound, provided the pruning is properly done, which means also proper protection of the wound. Large wounds especially are best made in fall or early winter (October, November, and December in the Northern States) rather than in spring. In winter the bark atheres firmly and the wood is dry so that the paint or tar can be more readily 


\section{Callusing and Repairing}

applied, while in spring the oozing sap of many species will prevent the paint from sticking or the tar from penetrating. If pruned in the fall, the wound wood begins to form in the early spring and is well adranced before the fungus spores begin to fly. The comparative absence of fungus spores in late fall and the fact that the form of the tree is better visible when the foliage has left it also favors this season

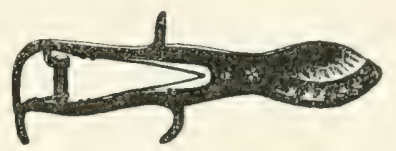

FIG. 2I. - Malleable pruning shears.

as compared with the summer. Orly those species, which, like the maples and birches, are apt to bleed freely even late in the autumn and early in spring, are best pruned in winter or late summer, although the bleeding is in the main detrimental only because it prevents the paint from adhering.

Callusing and Repairing. We will now briefly look at the healing process, a knowledge of which will be useful to the pruner and will assist his judgment, especially as to where and how to locate most advantageously the cut in trimming, pruning, and repairing.

When, in the natural order of things, a leaf falls, or a piece of bark is sloughed off, as is so conspicuously done in the sycamore, this loss of parts

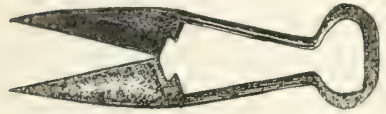

FIG. 22. - Sheep shearing shears. has been gradually prepared for and the wound is already covered securely by a cork layer, or a temporary covering has at least been provided for by the formation of gum or resin, before this final voluntary loss occurs. IThen an involuntary physical injury, as the tearing off of a piece of live bark or the breaking of a branch, takes place, a similar process of providing a covering of the wound 
sets in, hut this takes time, and meanwhile the exposert fart is subject to inimical influences, drying out, or givings access to parasites.

Of course, only so far as living tissues are touched or exposed is there any real injury, hence scraping or breaking off the dead outer bark does no direct harm and the cutting off of dead branches in the dead parts produces no further results. It hen live tissues have been injured, a certain area of the wounded and exposed live tisiues dries out and dies before the healing process has begun, and it is only by the growth of neighboring live tissue that a corering can be gradually established. In other words, the cut surfice or wound consisting of deal tissues cannot heal over as a llesh wound cloes. but the narrow ring of cambium cells at th: margin of the wound, being relieved from the pressure of the bark, subdivides and grows rajpilly; and an excessive growth of wood cells and bark cells takes place, forming the so-called callus or wound wood, and this protrudes from the old bark over the wound. like a thick mass boiling over from the rim of a vessel. Year after year it increases in mass, and finally covers up) the surface mechanically, leaving only a scar where the margins meet; and in time even this may ranish. The wound, then, is not really healed; merely a mechanical corer or cap is established, not organically connected with the surface of the wound, and, if properly cut, it comes off like the cover of a box.

In conifers, especially in young trees, usually an exudation of resin first corers the wound, jreventing loss of water and entrance of fungi, but the callus itself forms more slowly, and in older trees both processes of resin and callus formation may become fecble or fail altogether, so that careful attention to the wounds is necessary.

The growth of the callus, like all other growth, takes 
place, of course, during the growing season only, and is due to division and enlargement of cambium cells into wood, cork, or bark cells. Since these cells preferably divide vertically or lengthwise, and since the assimilated foot materials required in their growth are carried from the foliage downward, the upper edges and the sides of the wound usually close more rapidly than the lower edges.

For the same reasons, a branch stub protruding from the trunk or larger branch heals more slowly, for here the cells must divide horizontally or crosswise, which they do with difficulty; moreover, the cells, being out of the direct path between root and foliage, have to derive

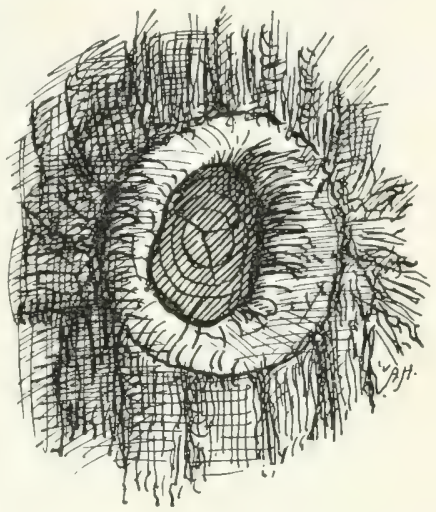
their food materials circui- Fig. 23.- - Satisfactory growth of the tously from a neighboring callus over a pruned branch.

branch, and are apt to find them less in quantity and less readily available than if a direct supply from the foliage of its own lost portion could have been har. Hence a vertical wound, running up or down the trunk or branch, is much less dangerous and more quickly corered than a much smaller wound running around the bole or branch, and similarly, the wound made by the loss of a branch at its very base is more rapidly closed than when cut or broken above the base and across the liameter. Branch stubs are, therefore, apt to die back and to decay most readily; because longer exposed to the action of rot fungi without any vital process counteracting these fungi.

In the case of small branchlets or twigs, which have been 


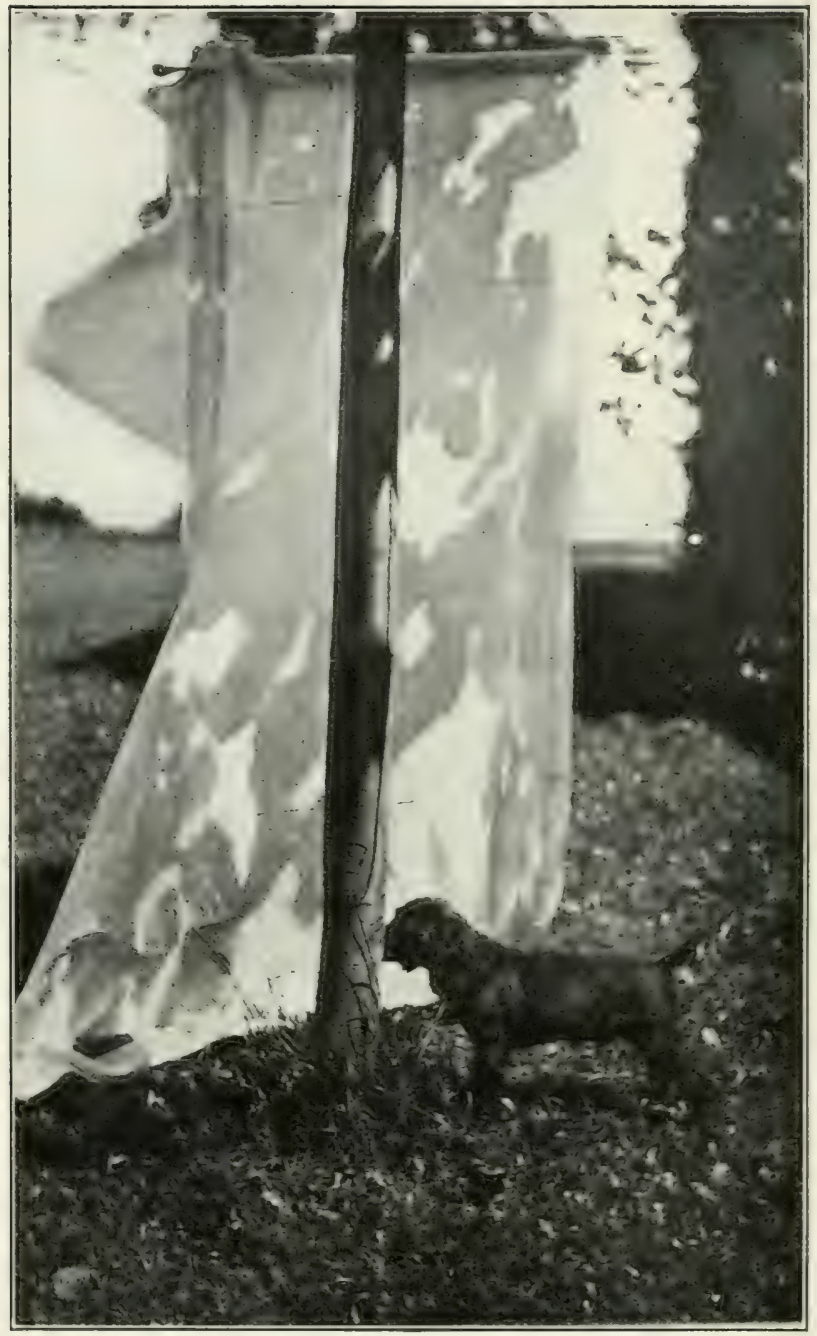

FIG. 24. - Callusing proceeding from the sides, not the top or base of the wound. 


\section{Callusing and Repairing}

trimmed back, if the wound is not covered at once with wax - which keeps it moist and the cambium layer at the circumference active, so that it can form a callus under the wax - the twig dries out and dies back for a shorter or longer syac:. The cambium below the dead yortion will, of contres. sect to re air the damage and its activity will make itelf aptirent in a bulge of the bark, and when the dead stump has broken off, the callus will proceed, as described above, to cover the ragged wound.

Nore frequently and preferably, a bud below the dead pcrticn will start into life and grow into a shoot; the shoot will tend to take the direction of the mother branch and by its growth at the base will expedite the sloughing off of the dead portion; in this way the wound is corered more rapilly and comIletely than by the ordinary callusing process. Thus in a

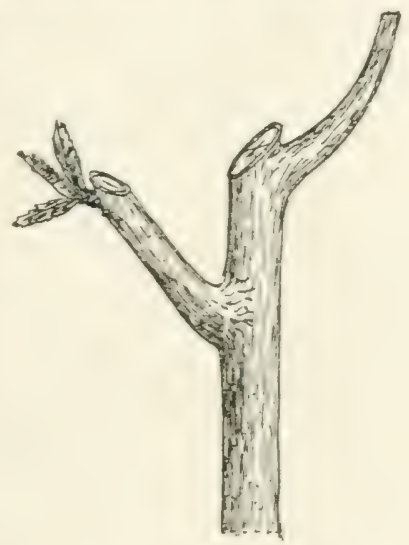

FIG. 25. - A bud below the termind! hra:c lo starting intw a tive growth to spylant the fosi linb. short time its existence is only to be inferred by a crosk in the branch; and eventually cren this cruok may be outgrown.

Hence in trimming back. care should be talien to cut near to a strong bud or branch. and yet not near enough to have the burl it-clf dry out or be injuret. What hould be the distance of the bux from the weun l deerend on a variety of conditions, which intuence the ratidity and inten-ity of the drying out of the stub. If cut in ine arince, shord: before or after the activity of the bul has bestun, the cat 
may be mate quite close to the but; if earlier, it will be safur to leate a stuh) of a quarter $(1)$ a half inch in length. ()r the stub may be left an inch or more at lirst cutting, and

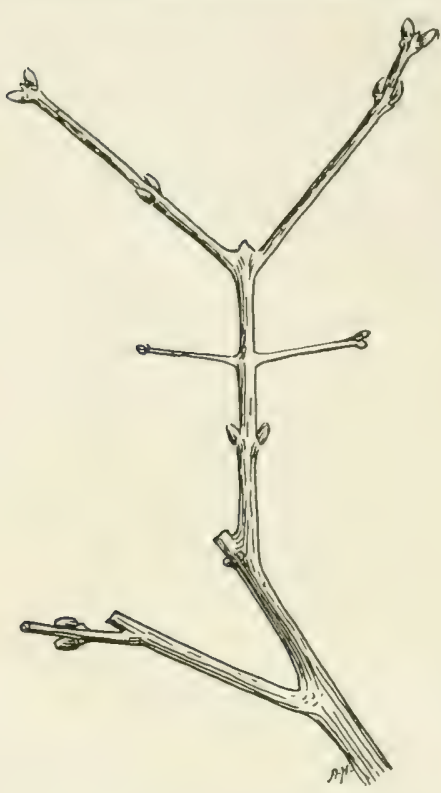

FIG. 26. - Correct method of trimming, a stub being left one-quarter (1) one-half an inch above the next lower bud or branchlet.

after the bud has started, the stub may be cut back to near the base of the new shoot.

The rapidity with which wounds, especially large ones, are covered up by callus formation depends on various conditions. Different species behave differently in this respect, but finally the general vigor of the plant, its age and its condition of nutrition, i.e., the amount of food materials it can elaborate, determine the rate of progress. The size and number of the wounds, their smoothness or roughness, their location on the bole, whether or not a strimp has been improperly. left and what its length is all these facts have an influence; indeed, conditions are so variable that it is impossible to give definite rules, save in a given case, as to how severe the pruning may be. If, however, the wounds have been properly dressed and ke $p t$ cozered against water and fungi, it does not matter how long it may take them to close, although the danger of the deterioration of the antiseptic covering naturally increases with time.

Small wounds are covered relatively much more quickly 


\section{Callusing and Repairing}

than large ones. The proper practice is, therefore, to prune in time, so as to avoid the cutting of large branches.

In order to secure a satisfactory proportion between the amount of food material used in making callus, and the supply, it is best not to make too many large wounds at once, and, if possible, no wounds larger than four to six inches in diameter. Three medium-sized branches of from three to four inches in diameter may be safely removed in any one year, even from old trees, and the wounds will heal in from three to six years, while young

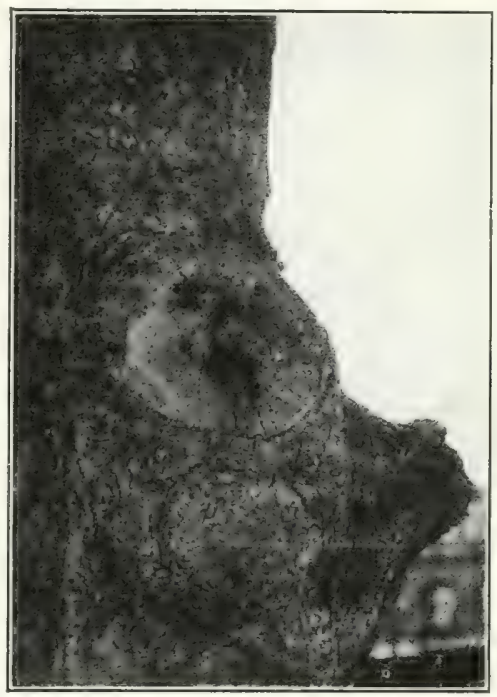

FIG. 27. - An example of proper pruning but with the wound !efi undressed. vigorous trees will elaborate enough food material to take care of a larger number.

The wounds on young trees and in the younger portions of the trees heal more readily than those on old trees and

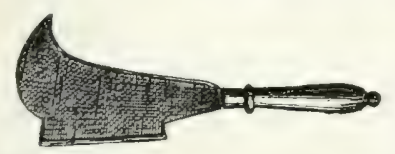

FIG. 28. - Importe 1 bill hook. those near the base, removed from the food-elaborating foliage. In very old trees which are underfed, the callusing process may go on with exceeding slowness or may even be entirely suppressed. Wounds on the lower side, shedding water more readily, are less dangerous than those on the upper side of limbs.

In general, the fewer and the smaller in extent the wounds 
and the more they lie in the length direction of the stem, the more readily are they covered; $i$.e, the more live cambium borders them sideways, the more active the foliage above the wound, and the more directly the repairing cambium is fed.

The severity with which a tree may be pruned depends, then, mainly on its capacity to cover the wounds in a reasonable time; and since this is a result of food elaboration, it depends on the growth conditions of the tree. Therefore, the tree surgeon, like the surgeon in the hospital, must consider the condition of the patient. The pruning may be executed in the most careful and approved manner, and yet the result may be disastrous if the vitality of the tree is not equal to the task of repair. If the pruning were accompanied by attention to the vigor of the tree in improving its chances for nutrition, results would more often be satisfactory. Hence, if you prune hearily, do what you would expect to do with a human being that has an operation to undergo; make it comfortable and keep) it well fed in order to invigorate its constitution.

Specific Rules. Pruning of ornamental and shade trees is practised, then,

(I) to remove superfluous and injurious parts,

(2) to keep the trees within manageable shaje and limits,

(3) to train the tree to desirable form,

(4) to modify the vigor of the tree.

Pruning for Balance. The lirst pruning is to be done at the time of planting, when it is needful to restore the balance between the branch system and the root system, the latter often having been curtailed in the operation of transplanting the tree. First, all injured roots need attention. Broken ones must be cut with a sharp), smooth draw cut, in such a manner that the face is on the lower side, so that from it 


\section{Pruning for Balance}

new fibrils may form in the natural direction. Bruised roots, if too much lacerated to promise ready healing, are also better removed, since they may otherwise become starting points for rot. If they cannot be dispensed with without too much loss to the tree their treatment may follow the prescription for treating wounds in general (see page 89 ).

Next comes the trimming back of the head to balance

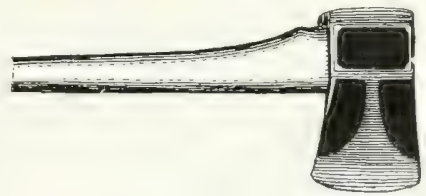

FIG. 20. - Pruning axe. with the root system, keeping in mind in the choice of parts to be removed the height from the ground at which it is desired to start the crown.

Injured or misshapen parts are, of course, the first to be subjected to the knife. Next a heading in of the tips of spindling branches may suffice, with due reference to desirable shape of the crown. Finally, if this seems insufficient, whole branches may be entirely removed by cutting them out close to the stem. When it seems undesirable to use the knife, the balance may be attained by breaking out buds, and this is the preferable method, especially in conifers, as the knife is apt to spoil their form.

If, in the planted tree, balance between the root system and crown system has been disturbed, as may be occasioned

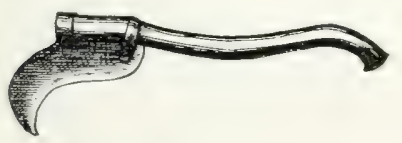

FIG. 30. - Brush axe. by the loss of roots through grading, the same operation of balancing the crown is needed, always keeping in mind that the tree will, unaided, restore the balance, but without reference to its appearance; hence it is desirable to anticipate the natural process.

The need of pruning for balance when part of the root 
system is killed by winter cold has been discussed on page 67 , where injuries by frost are described.

Pruning for Form. The removal of dead and broken branches and the smoothing and proper dressing of badly made wounds is, of course, the first concern of the pruner.

The removal of green branches has usually for its object the regulation of the form, in order to faror invigoration,

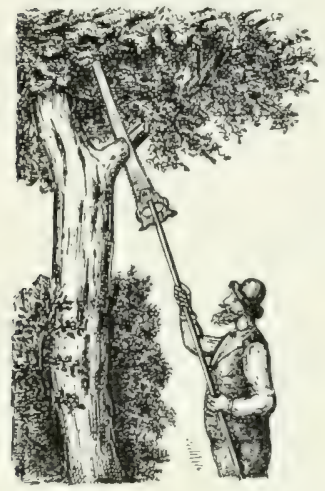

FIG. 3I. - "Lightning" double edged pruning saw. or new formation in other parts. Every branch or twig cut produces a change in the development of other branches or twigs, because these now enjoy different light, food, and watersupply. The skilful pruner keeps in mind, therefore, what new development will be induced by cutting away branches, and cuts accordingly, either to strengthen a weaker member by removal of a stronger, or to help a stronger one by subduing superfluous feeders, faroring either the leaders by the removal of side branches, or inducing the spread and compacting of the crown by heading back the leaders. And, in pruning for form, he keeps in mind that the heading in of young shoots tends to develop dormant buds; that the tendency of most species is to develop the upuermost buds rather than those at the base of the shoot; that heary pruning at the top tends to invigorate and produce better development of the lower portions, and vice versa.

Of superfluous parts to be removed are the water-sprouts or suckers, for, as their very name indicates, they are robbing other branches of food materials. Water-sprouts are branchlets, arising from adventitious buds out of regular 


\section{Pruning for Form}

orther, allone the trunl and branches, whenerer the equilib)rium in feeding comblitions is disturbed and hat wo be ad justed, as, for instance, when the tree has been heavily pruned, or when soil or light conditions have been changed. Although they are not necessarily a detriment, it is evident that they interfere with the development of the regular crown and are therefore best removed. It appears that water-sprouts are less likely to form if the pruning is done after midsummer, when a re-

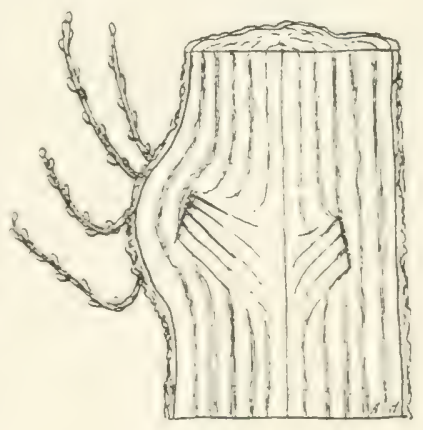

FiG. 32. - An example of correct l,runing. we!! heale!. l,ut with water-sprouts developing.

arljustment of feerling conditions without this expedient seems to take place.

In setting new trees, or in the case of plant material which has not been trained in the nursery to form its head at a desirable heisht from the ground, this should be attended to first. This heirht depends upon the species and the object for which the planting is done. In specimen trees, and especially tress of high stature, and decidedly in conifers, the crown shoulit reach dewn almost to the ground. In shade and street trees it is desirable to keep it from ten to fifteen feet above ground.

In street trees and in ornamental plantings, where several kinds of trees stand close to each other, the pruning knife may be used to adrantage in preventing an undue expansion of cromn. If this is rlone at regular and not too long intervals, interference between neighboring trees and the consequent intluence on tach other's form may be aroided and the operation be kept within the limits of a slight trimming back. 
In planted groups of several species, the fact (referred to on pages 25 and 7.3 ) must be kept in mind that the different species vary in regard to the amount of light which they repuire for normal development. Some, such as the Beech, Maple,

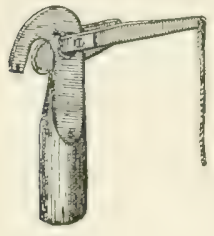

Fig. 33. - "Telegraph" tree pruner. and Holly, are very shade-enduring and at the same time they themselves make a dense shade; if associated with such light-needing species as the Tulip tree, the Ash, Walnut, Cherry, and many others, the latter will be at a great disadvantage: the shady species crowding them, suppressing their branches, and possibly shading out the entire tree, unless the shaders are kept within bounds. T'he pruner must study these relationships, must protect the weaker, and must give them at least a free upper crown, if he desires to keep the groujes in harmonious development. I little observation will soon show which trees are relatively weaker in their shade endurance.

The most difficult task of the pruner, because requiring the most judgment, a sense of fitness, and a clear conception of the results of his pruning, is that of training trees to desirable outline. This refers, of course, to single trexs on the lawn, where the form and outline of the crown are the important features.

The "natural," symmetrical form, typical of the particular species, is, to be sure, the ideal

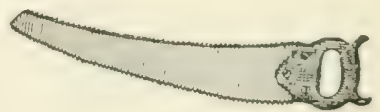

FIG. 34. - "Paragon" double edged pruning saw. one to be attempted in general. But it is by no means. certain that the inclividual tree will, if left alone, develep) this form. Not only do conditions of the soil, which influence the root development, find expression in the shape of the crown, leading to irregular and sometimes undesirable 


\section{Pruning for Form}

shape, but accidents, like breakages of branches, disturb the normal development and call for the correcting hand of man. Some species, as, for example, the Silver Maple, the Sycamore, and poplars, have a straggling habit, developing so irregularly, that their long branches are apt to be broken by the winds. By judicious pruning this habit can be counteracted, and the crown be made more compact and wind-resistant.

Too often old neglected trees have lost their beauty by neglect in earlier pruning, and it may tax the ingenuity and goor judgment of the tree doctor to restore them to desirable shape in order to save the time which their replacement would require. Lsually in such cases general repairing and invigorating of the dilapislated cripples are also involved.

As regards the form in which to trim a tree, it is necessary to know, not only that the various species exhibit various forms typical of themselves, but also that their form varies with age, the young tree being different in form from the middle-aged, and this again differing

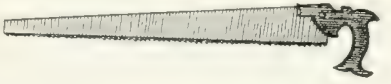

FIG. 35.-Plain one edged pruning saw.

from the old tree. It is, therefore, impossible to give general rules; only study and observation in the field can develop the eye which recognizes typical form.

There are, however, two very clearly distinguishable types, namely, that of the conifers, and that of most of the broad-leaved trees.

The conifer type is characterized by the prramidal shape of the crown, the main axis developing more rapidly than the branches, and these besetting the bole to its base. This beautifully symmetrical pyramid, which is especially typical of spruces and firs, lasts from twenty to forty years and 
sometimes even longer. Then the lower branches begin to die, and, when the tree has reached its full height, this loss of lower branches proceeds more rapidly; and a period of unsightliness must be passerl through. Meanwhile, the branches of the upper crown lengthen and the crown broadens, the old trees of most sjecies having a very different shape from the younger ones.

It is, of course, desirable to retain the pyramidal form of the conifers as long as jossible, to trim as little as possible,

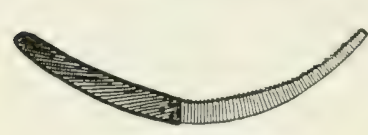

Fig. 36.-California bow shaped pruning saw. and then always to a strong lower bud, which will then apparently continue the limb as if from an end-bud. The pruning of lower branches, the peculiar beauty of the conifers, should be deferred until it becomes absolutely necessary.

In conifers, bud pruning is adrantageously practised to preserve perfect shape and prevent undue spreading. This is done by clipping off the center-buds from any shoot that 1 rojects beyond proper limits. This method will also tend to improve and compact the form of such looser crown structures as the upright junipers.

Should a leader be damaged or broken, cut it back, learing a short stub) above some strong branch, and tie the latter up (by using the stub) as nearly as may be into vertical position, when it will by and by assume the leadership and eventually supplant the lost one.

In the broad-leared trees the tendency with most species is to lose the jurenile form, in which the main axis is prominent, sooner than in conifers; the branches develop more stoutly and the crown spreads earlier, unless by crowding in the forest or in planted sroups, this spread is prevented and the shaft forced to grow upward. 
In the development from youth to old age there can be recognized at least four stages of development, in which the form varies.

In $186+$ a Frenchman, M. A. Des Cars, jublished a booklet on the methods of pruning trees, ${ }^{1}$ which is still essentially correct. It was written for foresters, with a view to secure the production of good timber rather than for use in ornamental trees. The author develops what he considers the proper form for

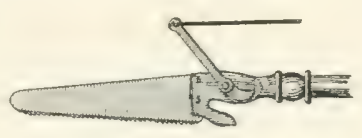

FIG. 37.- "Little Giant" pruner and saw combined. trees, especially oak trees, in the different stages of their development. He also derises what he calls a dendroscope, a piece of thin carclboard, in which a hole has been cut of the shape which the outline of the tree crown is to assume. A fine wire, stretched from base to top of the whole, serves as a guide in adjusting the dendroscope opposite the bole of the tree in front of the eye. By this little device the pruner is aided in determining what branches to remove in order to secure the desired symmetrical form. While we would hardly recommend any strict adherence to the directions given on this point by Des Cars, we reproduce for their suggestiveness the summary of his conclusions, together with the dendroscope and the examples of how to shape a given tree. The use of this device is self-erident.

I. Young Tree. The length of the branchless trunk should equal one-third of the entire height of the tree. The head should be elongated, oroid in form, with the center of gravity sufficiently low to keep the tree upright. The lower branches, shortened to prevent excessive derelopment of the

${ }^{1}$ A Treatise on Pruning Forest and Ornamental Trees, by A. Des Cars. Translated from the Seventh French Edition, with an Introduction by Chas. S. Sargent, Boston, 1884 . 
leader, should afford sufficient leaf surface to elaborate the sap necessary to insure rapid growth.

2. Midde-Aged Tree. The trunk should equal about two-fifths of the entire height of the tree. The head should be a shorter ovoid than that recommended for trees of the first class. A rertical branch upright on the trunk, or any part of the trunk, should if necessary be made to replace the original leader; all other vertical branches should be shortened to encourage the growth of the leader. If a single branch cannot be converted into a leader, a regular well-balanced head may be made with several branches. As the tree grows some of the lower branches should be removed to increase the length of the trunk. Not more than three or four branches should be remored in any one year. The amputation of a branch should be carefully performed; the cut should be made perfectly smooth and rounded, to coincide with the form of the trunk, thus bringing its whole circumference into direct communication with the leaves by means of the layer of living cells. These distribute the descending sap, which alone forms the new wood destined in time to corer orer the wound. Wounds made in this manner heal in a short time; but, to preserve them from external influences which induce decay, they should be covered as soon as made with a coat of coal-tar. All dead or dying branches, and all stumps of branches, should be cut ofi, and the wounds treated in the same manner.

3. Old Tree. The length of the trunk should nearly equal one-half the entire height of the tree. All decayed portions of the tree should be carefully removed. A few of the lower branches may be removed or shortened.

4. Veteran. The tree having ceased to grow the head gradually becomes flat-topped. Such lower branches as might, by their too great size, injure younger trees growins 

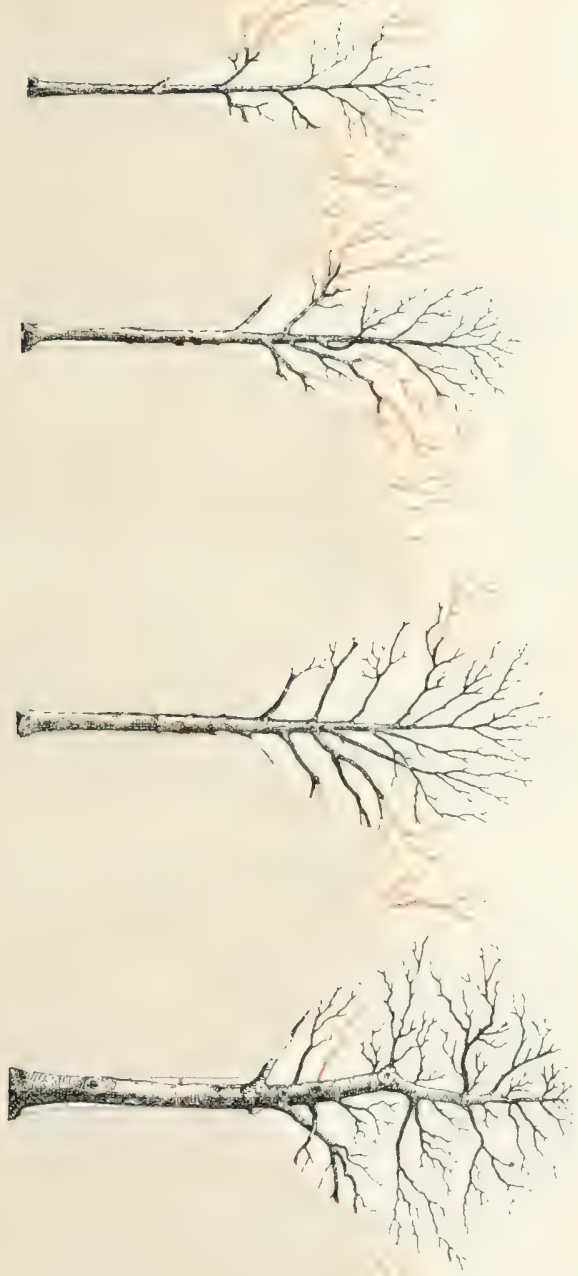



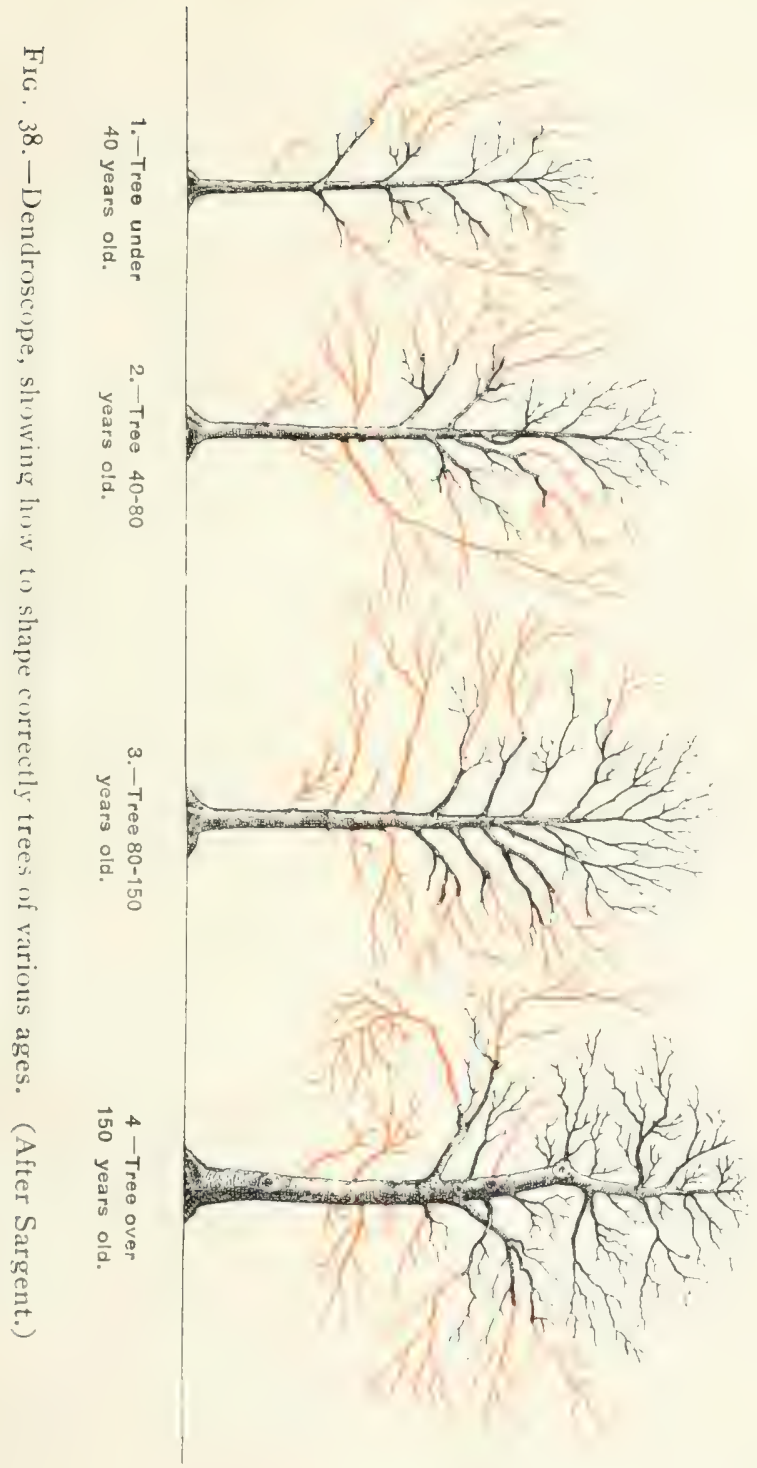



in the vicinity should be removed. Very old trees should be treated in the manner recommended for those of the third class, although requiring greater care and judgment in their management.

In the following brief instructions as to procedure in pruning a tree to form, we also follow the advice of Des Cars.

First select a rigorous leader, if no natural one exists, i.c., a branch which is to become (or remain) the main axis; any almost vertical branch near the top may be taken. The original leader may be discarded if not desirable, and a lateral branch substituted, which will soon straighten up, if the growth of the new leader is stimulated in this (as shown before) by tying it into upright position with withes attached to the base of the original leader or of some other branch. If there is no serviceable leader to

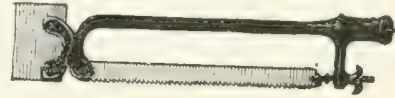

FIG. 39. - Combined pruning saw and chisel. be found, two or three or more branches should be preserved to form a compact head. A forking leader is rather to be discouraged, but the forking of branchlets at their ends is to be encouraged by removing all branchlets which assume a vertical growth, for these forks give to the tree a more natural appearance, and by dividing the flow of sap prevent the growth of too vigorous shoots, which might in time develop into supplementary leaders to the injury to the tree. Altogether, the development of the unnaturally strong growth of any individual branch, especially at the expense of the leader and in an undesirable direction (drooping or recurved), is to be checked by shortening.

The operation of pruning should begin at the top of the tree, both for the sake of the safety of the operator and the better opportunity of controlling the shape. After establishing the leader or leaders, the main branches are short- 
ened, especially those inclined to compete with the leaders or to assume a vertical position. In shortening these, the cut should be made at the point at which they begin to assume upright positions, and, if possible, just above some secondary ascending branch or branches, and these in turn should also be shortened, just above one of their secondary branches, as shown in the accompanying schematic figure. In other words, the upper branch is the one preferably to be removed. Care must be taken to leave enough branchlets to insure sufficient food elaboration for feeding the main branch. This is especially essential in old trees. The branches left are significantly called "sap lifters." By their development they will gradually outgrow and straighten the angles made by the removal of their competitors.

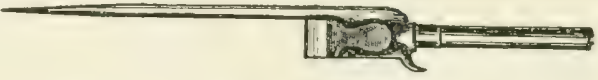

FIG. 40. - "Victor" tree-pruner.

The illustration taken from Des Cars will suffice, without further explanation, to show how properly pruned trees may appear, according to his notion.

Tools. The tools to be used in pruning are of importance. The axe is not a serviceable tool and should be used only in the rough work, such as the first cutting back of branches which are afterward to be taken off by the saw. A fine-toothed, narrow-bladed, stiff saw is in most cases the best tool. Various bow-shaped saws are in the market, but they have little advantage over the straight blade in skilful hands. Stiffness is, however, an important quality, and a thin blade stretched in a steel frame answers best. A double-edged pruning saw on a long handle can be used to advantage only for medium-high work. Extension ladders and closer approach to the work are necessary on larger 


\section{Pruning Street Trees}

trees. The use of climbing irons should be avoided, as well as other methods which would damage the bark. A heary pruning cleaver for medium-sized twigs and pruning knives and shears of rarious shapes for the smaller twigs are useful. For the latter, a long handled chisel with a guide (Victor Pruner) in practised hands, is an excellent tool. Chisel and hammer may sometimes be needed to smooth cut surfaces and to cut out rotten wood. For small branches, up to threequarter inch diameter, the cutting shear tree-pruners either with or without pole and rope are serviceable, various forms being on the market. The main point to look out for is that the cutting edges pass close past each other and that

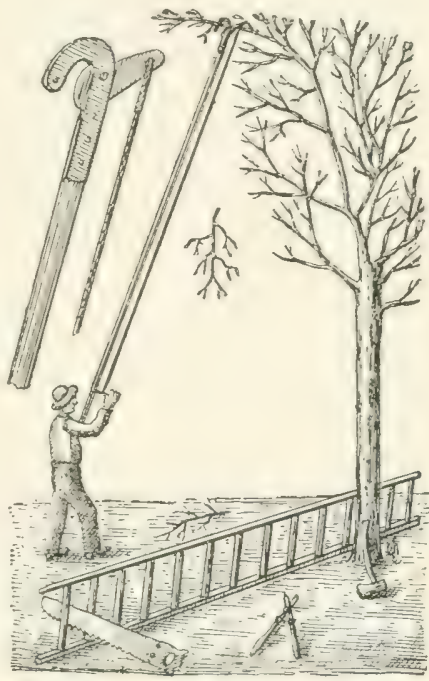

FIG. fI. - "IVaters" " tree-pruners. they can readily be kept in such relation, that the spring opening the blades be sufficiently strong, and yet not too strong, that the grips are not closing up too closely, and that the tool be kept sharp. Common sheep shears answer for light trimming as well as any other more fanciful tool.

Pruning Street Trees. The pruning of street trees should begin early, while the tree is still young, so as gradually to secure the proper form - a well-defined main shaft and a symmetrical crown of branches starting well above the heads of the passers-by. If this trimming is done within a few years after planting and is repeated regularly every two or three years, the necessity of removing heary branches, 
which in city streets is always connected with difficulties, can be avoided; moreover, the "heading back" of heary branches mars the symmetry and beauty of the tree and can only be considered a remedy for the neglect of earlier trimming.

When pruning becomes necessary in order to reduce the crowding of neighbors, it is better to cut out entire branches

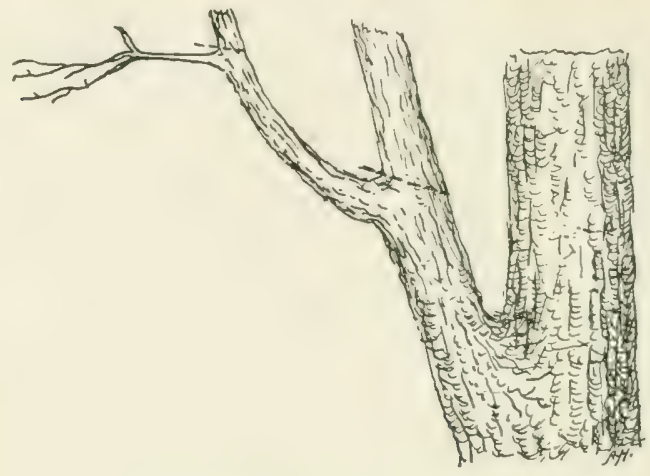

FIG. 42. - Methods of correct pruning.

than to trim back the ends, since this only stimulates the production of new shoots, which soon close up again. ".1 skilful operator will remove one-third or more of the branches of a thickly set tree in such a manner that the ordinary observer will not perceive that any pruning has been done, the tree looking as natural in its ramifications as if it had not been disturbed."

Pruning for Flowers. Pruning is also resorted to for the purpose of stimulating flowering and fruiting. This is a special subject of the orchardist, which we can touch only as far as flowering ornamental trees or shrubs are concerned. When flowers are the object for which the tree or shrub is planted, the pruner must have knowledge of the flowering 
habit of the tree or shrub, namely, whether it bears flowers on the old woorl or on the new wood of the season. Most early bloomers develop their flower buds in the preceding year: the flowers are, therefore, borne on the old wood. It is erident that by heading back the last year's growth, the bloom will be diminished. Such species, therefore (like Amelanchier, Aesculus, Catalpa, Cercis, Crataegus, Halesia, Magnolia, Prunus, Pyrus, Robinia, also pear and peach), should be pruned after the flowers are past, and then merely by thinning out weakly, misplaced, and imperfect shoots, and shortening specially long ones. On the other hand, species which bear their flowers on the new wrod of the season in which they bloom (generally later bloomers) should be severely headed back in the fall or spring, if it is desired to increase the bloom.

Gencrally speaking, severe pruning and heading back at the top tends to reduce flowering and to increase production of wood, since thereby the water-supply is relatively increased. Hence, to stimulate flower production, the pruning should be rather light and repeated annually. For the same reason, a dry season and root pruning, which decreases water-supply, stimulates flowering.

Repairing Damage. Besides attention to the newly-made wounds in the operation of pruning, there is frequently neerled a helping hand in mending neglected wounds and in repairing damage due to various mutilations of the bole, and to breakages by wind.

In walking through the streets and parks of American cities and even through private preserves, the observant tree lover often comes to the conclusion that the American is either blind or sees beauty in disease, for malformations due to rot and neglect are common everywhere.

While the adage "never too late to mend" may often 
practically be untenable, there are nevertheless many cases of neglect where a skilful surgeon can at least improve matters.

All stumps left from improper pruning or from breakage:s of branches should, of course, be removed, and the newly made wound.s, as well as neglected old branch wounds, properly treated. If the rot has penetrated into the trunk, it is well to gouge out as much rotten woorl as prssible, then apply an antiseptic, such as the Bordeaux mixture or perI haps carbolineum (a mixture of heary coal-tar oils), which especially if applied hot, will not only kill the fungus my-

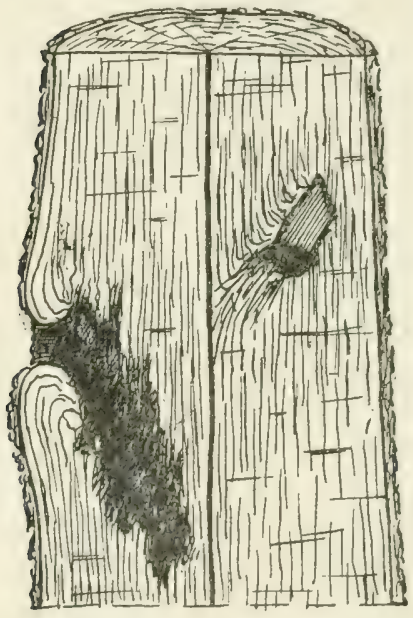

FIG. 43.- Branch holes and their treatment. To the right a plugged branch hole satisfactorily healed; to the left, a similiar hole untreater, giving entrance to rot. celium for some distance, but also exclude air and new infection. Then cover with a heavy coat of paint or tar. If the cavity is large, plug up with wood and paint, or fill up with rubble and cement, or with cement alone. In this way the trunk of a stately oak, perhaps a thousand years old, which had been hollowed out by decay, was restored to stability, the cavity being built up with brick and cement, and the color and fissures of the bark were successfully imitated.

Mutilations of the trunk or bole are treated in a manner similar to that prescribed for neglected branch wounds. In these cases, if no healthy and regular callus formation has begun, the wound should be trimmed back on its mar- 
gins to the live cambium layer, treated antiseptically as directed abore, and finally painted. At the same time the tree should be invigorated, as indicated before, by soil improvement and pruning.

If a fresh wound, made by any accident, such as the gnawing of a horse, be at once completely covered with melted tree wax ${ }^{1}$ so as to keep the parts below soft and moist, and protected by cloth bandages against further disturbances, a new rind or bark will develop directly from the living tissues, without the callus formation of the marginal cambium. The application of an antiseptic, like Bordeaux mixture, before the wax cover is put on, may also be useful to destroy fungus spores. Rapid growing deciduous species, if girdled or peeled in the earlier part of the season when the cambium is fully active, will respond with special readiness to such treatment, and will

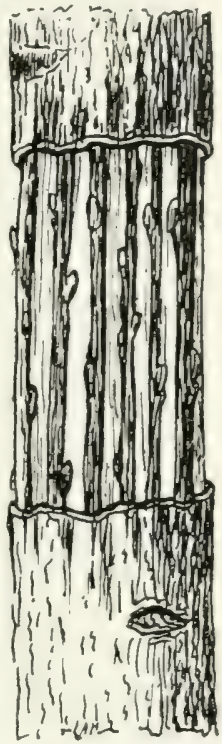

Fic. 14. - Method of bridging a wound with freshly cut young twigs. close a peel wound in the first year.

If the tree has been completely girdled, or if it coul 1 not be protected at once as described above, it can still be saved by an expert or skilful grafter through the process of "bridging," described as follows.

The margin of the wound is trimmed smooth, and a number of scions, freshly cut young twigs from two or three

I. servicuable tree wax is made by melting together by weight, one part tallow, two parts beeswax, four parts rosin, then pouring into cold water and working it with hands (which should be greased) until it becomes the color of taffy candy and develops a grain. 


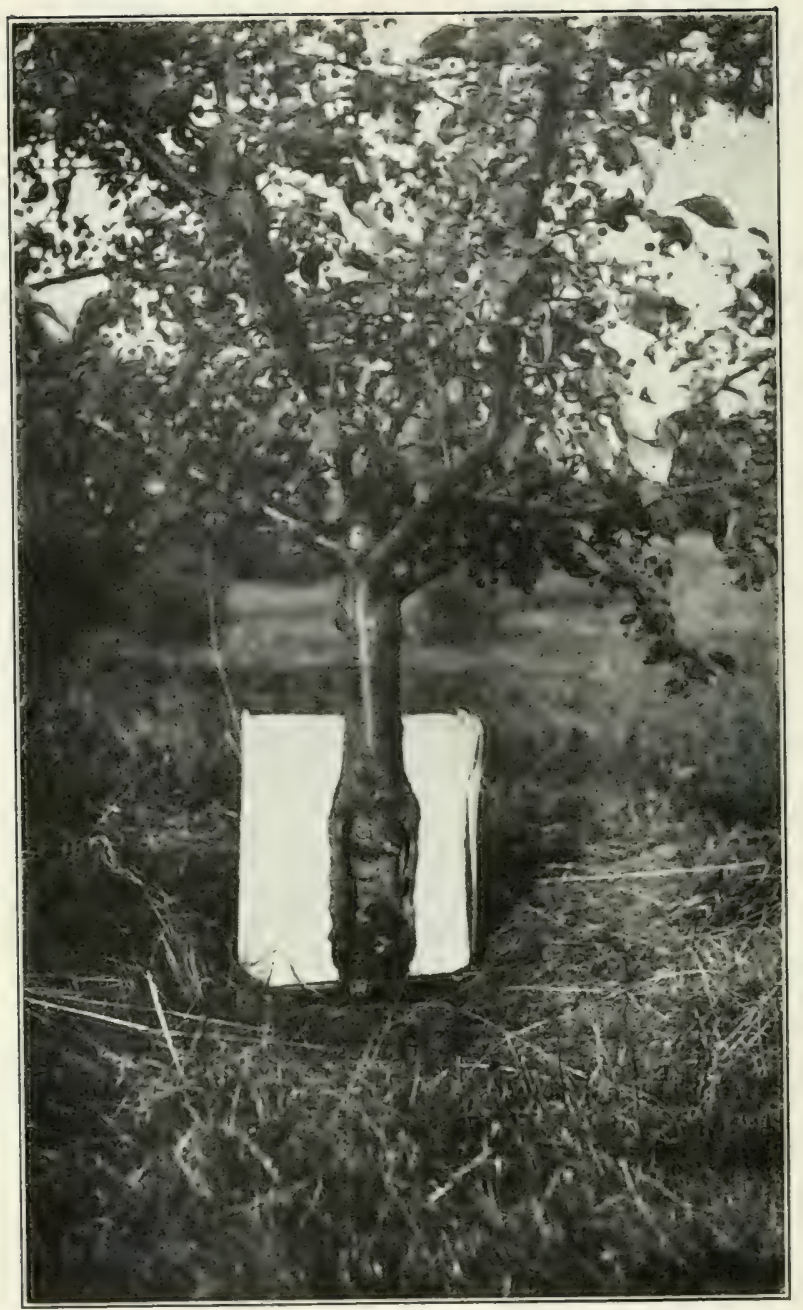

FIG. 45. - Succesful bridging of a (rab apple by the use of only two scions. The tree harl feen completely girlled by mice, hut bore a full crop of fruit a year after the repair. 
years old, are trimmed to appropriate length and with wedge-shaped ends grafted between bark and wood of upper and lower margin, side by side, bridging the wound. To keep the ends of the scions and the bark in place, a cloth bandage is applied at the two margins, and the whole scions and all - is covered by melted tree wax. If properly done, the connection of upper and lower portions will be re-established and the damage outgrown.

Smaller wounds may be treated in the same way, or as prescribed in the case of pruning wounds. In every such case of bridging, care should be taken to clean and cut out all decayed wood, dressing the edges back to live bark and applying the antiseptic tar or paint, or wax, if the wound is small and in young wood.

As it will have appeared from our discussions, cutting into the wood of a tree does not injure it in any way, except possibly weakening it mechanically, and no hesitation may be felt in remoring diseased portions, and, where it appears necessary, in substituting other serviceable material for the loss of substance.

If a branch is partially broken out of its crotch or socket, but still connected with the main trunk, it can often be healed on again, by putting it into position, after applying an antiseptic to the wound, bolting it securely to the trunk, coating the scar hearily with wax or paint, and heading back, so as to reduce the need of water in proportion to the injury.

With trees which are liable to breaking out at the crotch, such as the Silver Maple and EIm among others, it is wise to prevent such breaking by bracing them in time. This should always be done by the use of bolts rather than bands, for with the growth of the tree the bands constrict the natural expansion, obstructing the flow of water and food 


\section{General Care of Trees}

materials, and in time perhaps causing death. Bolts should be used with large washers and nuts, and possibly with a movable chain or link attachment between the braced branches to allow for wind motion.

A living brace may also be made by grafting an existing branch, if one can be found young enough and in proper position, into the brancin to be braced, or vice versa. This "ingrafting" is often seen in nature and answers well the purpose of support.

Treatment of Street Trees. Regarding the care of street trees in particular, we may add a few remarks on general policy.

The selection of suitable kinds - and that implies the removal, more or less rapidly, of unsuitable ones - is the first care.

The proper spacing of the trees is the next care, and that implies the removal of such as are interfering with or crowding those which are selected to remain. The distance for best development should be about equal to the height of the tree, hence the width should vary with age, or else should be chosen with reference to the ultimate height of the tree. As a rule, thirty to forty feet will make a finally accepted distance.

Trees which have become hopelessly decrepit and unsymmetrical should be removed to make room for better ones. This may be done gradually, by setting new ones before remoring the old ones, but the effect of the older, taller neighbors upon the smaller new comers should be kept in mind, and a species should be chosen which can bear the shade.

In city streets, where the natural enemies of insects, the birds, are largely absent, and where the health of trees is often precarious, and conditions are farorable to insect 


\section{Treatment of Street Trees}

damage, systematic warfare should be waged against these pests, the means of which are discussed in the next chapter.

In street trees the opportunity for mutilation is so great and the neglect so usual, that the tree surgeon will often be called upon to cxercise his knowledge and ingenuity in the direction of mending old damage.

Walking along the streets of any city one will find from at least twenty-five to lifty per cent. of the trees in a damaged condition. The principal cause of such damage is probably the gnawing of horses and the careless treatment of passers-by. The climbing irons of wire stringers and of careless tree-pruners also frequently lead to abrasions of the bark. Guy ropes attached to trees in building operations are a frequent cause of damage, unless properly protected by boards in such a manner as to properly distribute the pressure and prevent laceration and bruising of the bark. The piling of stones against the base of trees without protection is also apt to result in bruises.

The proper thing, of course, is to abstain entirely from such use of trees. But since the casual damage done can hardly be avoided by regulations, young trees, at least, should be protected by suitable guards, until their bark has become robust and less likely to become damaged.

The accompanying illustrations, showing a variety of guards as used in various cities of Europe and the United States, have been borrowed from a Bulletin of Cornell University Agricultural Experiment Station, ${ }^{1}$ and are selfexplanatory.

The following remarks on these protecting devices are taken from the same Bulletin.

"The most primitive guard in use is a handful of branches

1 "Shade Trees" by W. A. Murrill, Bulletin 205, Cornell University Agricultural Experiment Station, Ithaca, N. Y., I902. 
from a thorn bush arranged somewhat loosely about the tree trunk ... as on the streets of Fontainebleau. The next in order of simplicity, perhaps, is the jacket of pine poles seen often in Berlin. These poles are fastened together by means of wire and may be easily remored when desired. They are cheap and efficient, and not so conspicuous as the wooden box so well known in America. In Frankfurt, jacket guards for young trees on retired streets are made of willow branches woren into tall tapering basket-like forms, quite unique in appearance. In Bonn, the fine old Horsechestnut trees of Poppelsdorf Allee are protected in situations exposed to passing rehicles with shafts of stone planted about the tree at a little distance from its base. These shafts are columns of basalt, brought from the north bank of the Rhine.

"In Washington and many other cities, the most common tree guard is an elongated box made of narrow boards, which encloses the stem of the tree up to a distance of five feet or more from the ground. The box guard is easily made and very efficient. In London, the young trees are protected with wire netting, which is remored as the trees grow older, except in the case of those having tender bark; and on London streets, where iron guards are used, the trunk often had the additional protection of a wire covering.

"The best guards are made of iron, and, although somewhat expensive, are widely used, especially in Europe. In Paris and London, they are generally employed; in Frankfurt and Berlin, they are used on the busier streets; while in Antwerp, Bonn, and Cologne, they are being introduced with the trees recently planted. Unless city trees are under municipal control, the styles of iron guards are likely to be very raried and often cheap and inefficient. In Paris, they are contracted for by weight as well as measurement and 

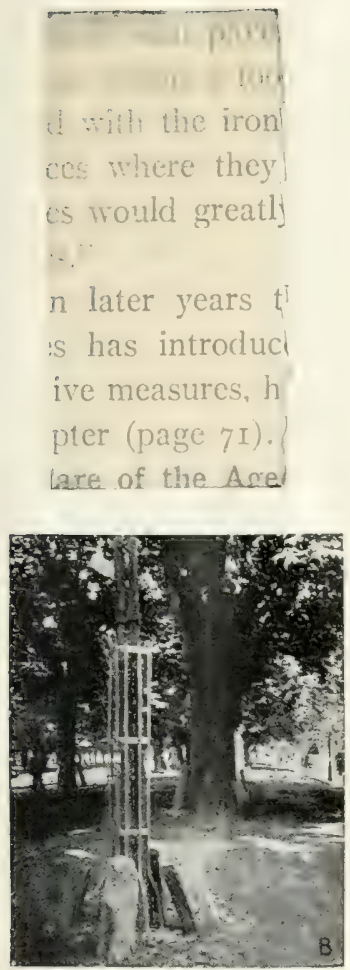
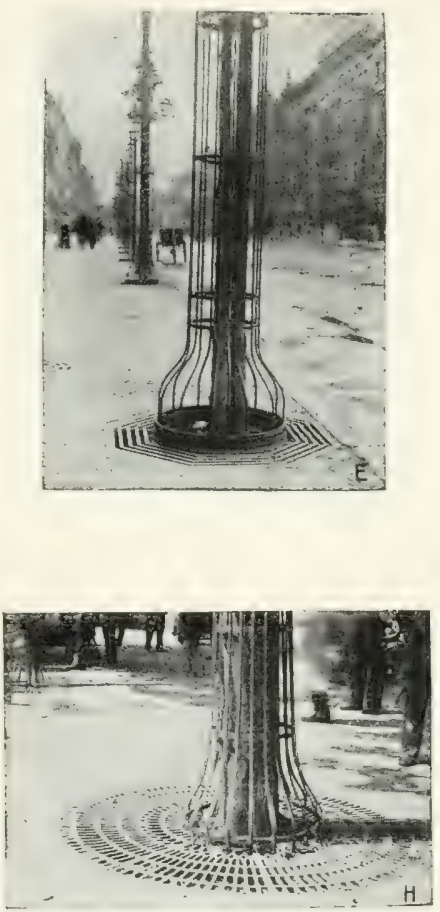

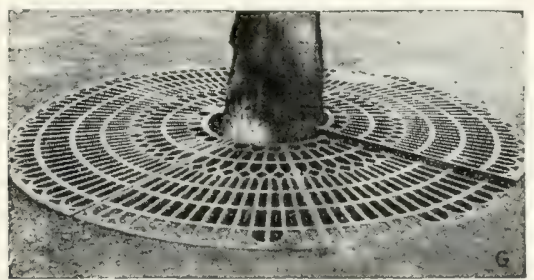

FIG. 46. - Various types of tree guards and grills. (After Murrill, from Cornell University Bulletin, No. 205.)

are very strong and durable. The Paris guard is about seven feet high, cylindrical in form, and constructed in 
two parts, the iron slats being riveted to smaty about $i$ in. It is fastened to the tree support at the thincblean. Till at its base, or, in the absence of the grillhe jiclset of pitel in the earth. This style of guard has bee are fastened thy parts of Europe.

ily removed wh

"In America, combinations of iron ro'not so conspicuo ire netting are frequently seen, while it is erica. In Fran to use rather low iron guards and cover the rects are mit he

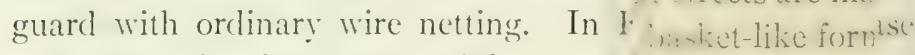
of the tree is often protected by a peri inated Hor of sheet-iron set on short legs, and above th _...smont in mist, closely woven wire.

"All guards of whatever kind should be fastened securely" to the tree in such a way that no injury will result from rubbing; and, as the trees grow larger, care should be taken to loosen and enlarge the guards as the trees require. Neglect in this matter has occasioned the death of quite a number of shade trees.

"Grills are designed to prevent the trampling of the soil about the base of the tree and are especially desirable on street corners and other places where many people pass. On pared sidewalks, where the traffic is large and the amount of exposed earth at a minimum, some such means of keejing the soil light and porous may be considered a necessity. Grills also afford an excellent means cf watering trees durings periods of drought. The construction of the grill may be readily determined by examining the accompanying illustrations. It is made of sections of iron grating which fit together about the tree in a circular, rectangular, or hexagonal form and are supported on wooden pegs driven into the ground. A special form of grill is sometimes used on very busy streets which extends outward beneath the sidewalk, leaving considerable space about the tree, while, being 
covered with parement, it permits free use of the sidewalk up to within a foot of the tree trunk. Grills are regularly used with the iron guards in Paris, Berlin, and London in places where they are needed. Their use in many other cities would greatly improve the general condition of street trees."

In later years the rapid multiplication of electric wire lines has introduced new dangers. These, and the protective measures, have already been discussed in a preceding chapter (page $7 \mathrm{I}$ ).

Care of the Aged. As we have seen, there is no inherent reason in tree nature why a tree need erer die of old age, for all its living parts are annually renewed, and, indeed, there are specimens of various species extant which count their age by thousands of years. Some Dragon Trees on the island of Teneriffe are estimated at over 5,000 years of age, and some of our Big Trees in California are, more certainly, over half that age; many historical trees have been known for 500 to $\mathrm{I}, 000$ years.

Yet, as we have also seen, old trees experience difficulties in carrying on their functions and in resisting the insidious attacks of parasites. When their vigor is impaired by unfavorable changes in their environment, especially as regards water-supply, the capacity of renewing lost parts and repairing damage is more or less lost, with some species sooner than others, so that we can speak of short-lived and long-lived species. Some also respond more readily than others to the pruning knife, especially when cutting in old wood; those known as good sprouters (see page 26 and Chapter VIII) belong to the first, the poor sprouters to the latter class. This knowledge indicates that greater care in the use of the pruning knife must be exercised in old age with trees of this class. While an old oak may be cut back 


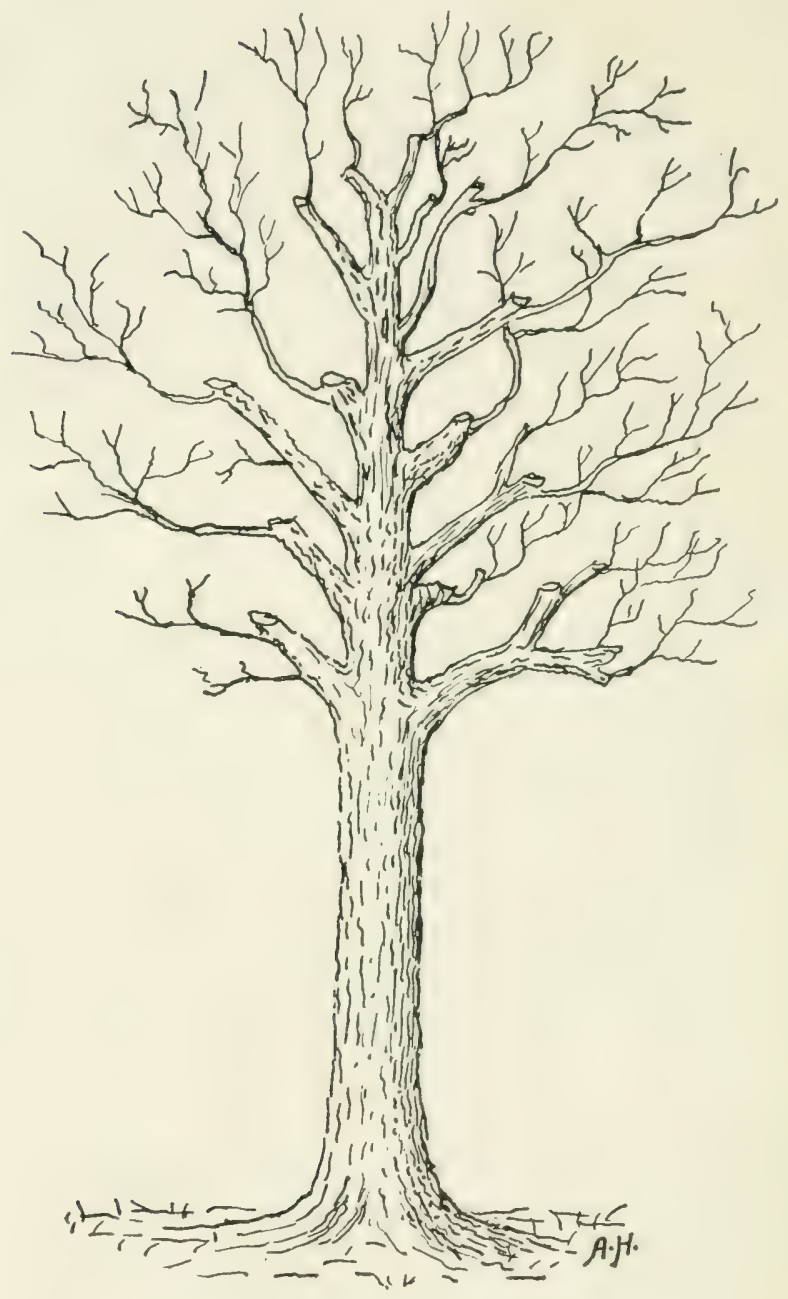

FiG. 47. - A restored aged tree.

into old wood with a fair chance of replacing the branch system, a Beech or Horse-chestnut or Ash may refuse to 


\section{Quack Medicines}

react to such treatment. Especially when the foliage of an old tree has become generally slim, caution is indicated in pruning.

On the other hand, improvement of soil conditions as regards water-supply will invariably show good results, and when by this means the old trunk has been brought to more vigor, the time for the knife has come.

Eren quite dilapidated ruins, hollow to the core, have been resuscitated and given a new lease of life, by building up with brick and cement the stability of the tree, and by applying the measures of invigoration described in detail.

Often it would not be worth while to preserve the disfigured ruin, if its beauty is already gone, but where special value is placed on securing an old landmark, a historical monument, or a stately veteran, much can be done by the simple process of soil improvement and pruning.

Quack Medicines. All kinds of prescriptions which are not based on an intelligent knowledge and appreciation of the life processes of the plant we may call quack medicines. Such are the indiscriminate scraping of the bark, painting it with lime without definite reasons, applications of fluids to the soil without knowledge of their value or diagnosis of their needfulness, boring holes into the tree and placing various powders or concoctions into them. This last procedure practised by the quacks may be harmless or harmful, according to what may be placed in the hole, but is mostly harmless. While it may not be impossible to drug a tree by such means, securing transfusion through the body, this field of medicine is so far undereloped, and the prescriptions of the quacks have not proved themselves effective. 


\section{CONTROL OF PARASITES}

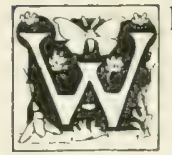

E have seen in previous chapters the character and effect of parasitic attacks on trees, how they are recognized, and also that their damage can be checked and reduced to a large extent by the mere care of keeping the trees in rigor. We are now to consider specific methods of controlling these fungus and insect injuries.

Fungus Parasites. The fundamental principle in combating fungus attacks is to prevent the infection of the host plant by the spores, or else to destroy these through the application of antiseptics or poisons, - so-called fungicides. But, if infection has already taken place, the spread of the disease is prevented by the destruction of the fruit-body of the fungus when formed, thereby reducing the crop of seeds, and also by burning the litter on the ground in which the fungus may live during one phase of its derelopment. Careful pruning and painting of all wounds will prevent the location and sprouting of the spores of fungi. If this has been neglected or delayed, and an examination (under the magnifying glass or microscope) shows that the mycelia of fungi are already developed, the parasite may still be suffocated, if the mycelium has not progressed too far, by applying an antiseptic, like carbolineum, which, especially if hot, will penetrate for some distance, and then covering the wound with a heary coat of paint, so as to exclude air 


\section{Fungus Parasites}

and water. Cutting out the affected parts and treating the wound as prescribed on page 89 , so that a healthy callus may form, is the especial remedy for black-knot and other canker diseases on branches.

Fungi which attack the leares are best combated by the application of poisons. Like the painting of wounds these applications are mainly to prevent the infection by killing the spores before they have a chance of sending their mycelia into the tissues of the host plant. It is therefore essential to make the application in due time, namely, before the appearance of the fungus in spring.

Leaf fungi are, as a rule, not very injurious, the unsightliness which they cause being usually the most objectionable result. Nevertheless, since practicable methods are now developed of preventing them by fungicides, which can be applied at the same time as the insecticicles, it is worth while to use them, for they benefit the trees in every way.

The best fungicide is the Bordeaux mixture, the formula for which is: - five pounds of copper sulphate (blue ritriol, or blue stone, ten cents per pound), dissolved by being suspended in a piece of cheesecloth or a coarse bag in hot water; five pounds of fresh (not air-slacked) "quick" lime, freshly and slowly slacked, after passing through a fine wire (30-inch) strainer, and diluted by adding little by little a gallon of water, to a creamy liquid of putty-like consistency, free from grit. These two liquid mixtures, each in a barrel by itself, are now diluted with twenty-four gallons of water each. They are then slowly mixed by being poured simultaneously into a fifty-gallon cask. This is the "five, five, fifty" formula. No iron or tin ressels should be used in preparing this mixture and, of course, care should be taken not to burn the clothes or fingers in the handling of both the blue stone and the lime. The lime is added to 
neutralize the acid of the copper salt, which would injure the foliage, the reaction leaving a copper hydrate, which, dissolved in the carbonic acid of the air, is the active principle in the fungicide. This solution should be used the day it is prepared, and before using should be strained to avoid trouble in the spraying nozzle. Since the Bordeaux mixture is a disinfectant so useful that every gardener or owner of trees should have it on hand and use it freely, it will save time to make a stock solution of blue stone in the proportion of one pound to two gallons of water, when two and a half gallons of this solution will be required to make a barrel of mixture. The lime may also be slacked beforehand, in the proportion of two pounds to one gallon, providing it is kept under water until used. In this condition it is not easily measured, although "half and half" will make about the proper mixture; but it is well to apply a simple test to show when sufficient lime has been added to the blue stone.

For this test an ounce of yellow prussiate of potash, obtained from the drug store, is dissolved in half a pint of water; if a few drops of this, added to the Bordeaux mixture, produces a brown color, it shows that not enough lime has been added. A simpler test is to hold a bright knife blade in the solution for a minute or more: if it comes out copper colored, more lime is to be added. A small excess of lime does no harm. Keep the solutions covered to prevent evaporation. When the two solutions are mixed they should be used within twenty-four hours; separate, they may be kept through the season.

There are now prepared limes in the market, powdered or partly slacked, which, if fresh, are more effective and more easily handled.

Since the mixture is not really a solution but an emulsion, which consists of minute insoluble particles of the sub- 


\section{Fungus Parasites}

stances in suspension, it is cssential for success to have the mixture carefully made as prescribed and thoroughly stirred up before using.

For plants with very delicate foliage, the formula may be varied to "two, two, fifty." A number of other combinations are used by experts for specific plants and purposes, but the one given will suffice for general practice.

The mixture is applied in a mist-like spray (hence the importance of avoiding. lumps of lime in the mixture by straining) by the same spraying apparatus and in the same manner as described later on for use with the insecticides, and, indeed, the addition to the Bordeaux mixture of five ounces of Paris Green (mixed to a paste in water) will answer to keep away both kinds of parasites.

The first application should be made shortly before, or just as the buds open, and again two or three weeks later. If rainy weather prevails - washing off the remedy and encouraging fungus growth - a third application may be $f$ necessary.

Indeed, this excellent disinfectant may be used as freely for trees as listerine or ammonia in the household, bringing about the general disinfection of branches, trunks and wounds as well as of leaves, and even the roots may be benefited. But spraying should never be applied to plants in flower, as the spray is almost sure to injure the blossom, and it should preferably not be done in rainy weather, as this has also been found to injure foliage and fruit.

As many of these fungi pass the winter either in or on old leaves, the burning of these in the fall or early spring is a means of keeping them in check; the removal of the litter, therefore, although, as we have seen, detrimental to soil conditions, has an advantage in preventing fungus and insect development. 
In a previous chapter we have seen how to deal with rot fungi of the wood. Prevention is the only remedy. If once established the fungi which produce root rot are as difficult to combat, sometimes indeed impossible, as the rot fungi in the wood. All that may be done, if a tree or a group is infected, is to isolate it by digging a ditch around it, in order to prevent the spread of the disease, making sure that the ditch is deep enough and so located as to inclose the infected area. The tree should then be remored and the roots burned. Possibly an application of Bordeaux mixture, more highly concentrated than for use on foliage, may be adrantageously applied. The rest of the ground should then be put in healthful conditions as described in the previous chapter.

Insect Parasites. To prevent and check the injuries of insects, as of fungi, much can be done by indirect means.

It is easier to ward off an attack of insects or to make conditions unfavorable for their multiplication than to destroy them after they are once established. Insects thrive on neglect; the rubbish around the base of the tree, the prunings and fallen leaves furnish welcome winter quarters to many, and the uncultivated soil is more farorable to their development than that which is frequently stirred and disturbed. Attention to soil conditions and surface conditions is, therefore, of value even in this direction. The scraping of bark to reduce hiding places for the wintering of pupx and eggs is also an indirect measure, but unfortu\& nately, as we have seen, may breed mischief in other directions, besides making the boles unsightly.

By keeping the trees in vigorous condition, the results of insect depredations can be minimized. perhaps in the case of bark-beetles, entirely avoided; and by encouraging birds 
-- the natural enemies of preying insects - the excessive development of the pests may be checked.

When we speak of insect pests we mean an excessive development of destructive kinds, for it will probably never be possible to exterminate them entirely, and all our measures can have in riew only a partial extirpation, or keeping them in check. Under natural conditions the equilibrium between the forces of nature is disturbed only occasionally and for a short time; an excess of insects preying on trees may develop, without a corresponding increase in their enemies, but, if not interfered with, the "boom" is quickly" followed by a "panic": the enemies increase and overdevelopment is checked. When man interferes, his methods sometimes unwittingly prevent the natural decrease or reduction of the pest.

For instance, there are certain fungus diseases attacking caterpillars, and parasitic insects laying their eggs into them. By destroying the caterpillars or the cocoons, these natural cnemies are destroyed at the same time, so that the very method of combating it favors the pest. Properly, therefore, an investigation as to the need or desirability of applying remedies, of spending energy and money, should precede the attempt. It is often not necessary to make the effort, although in our "unnatural" conditions of street and lawn trees, the reliance on such assistance by nature may be misplaced.

In addition to the enemies in the animal and plant world, there are inimical weather conditions, which may hold a developing insect pest in check. For example, carly frosts in the fall may kill large numbers, very severe winter frosts decimate them, while rainy seasons and wet, open winters are also inimical, particularly in developing fungus discases in the larvæ. 
These conditions, to be sure, are not under control, and the practical value of this knowledge applies mainly to the forester, with whom economy is a first consideration and who cannot afford preventive measures if their need is not surely established.

That the encouragement of the enemies in the bird world can be successfully used for ridding a locality of insect pests was proved with a rengeance by the city of Brooklyn, when the unusual pest of "inch worms" in the early seventies was subdued by the importation of the common English sparrow. It is a pity that the common sparrow was selected for this duty, as, in the presence of the lavish waste of grain and other palatable food which characterizes the American community he soon prefers this easier mode of living. But there are, outside of this common sparrow, few insectivorous birds that care to live in city streets, even if the small boy would let them. In the parks and country places, on the other hand, the cuckoos, thrushes, nuthatches, chickadees, wrens, creepers, vireos, and warblers should be encouraged by providing nesting places and insuring them peace. In fact, as almost all birds are, at least occasionally, insect eaters, especially when there is a large supply, they are all helpful in combating insect pests.

Unfortunately, birds may also take the useful insects which prey on the depredators, although this happens rarely, and the most prominent of these useful insects, the wasplike ichneumons, perhaps always escape. These wasp-like parasites, as well as the Tachina flies, lay their eggs on or in the caterpillars or grubs, their larve developing within the host, which they sooner or later kill, either before or after its pupation. Since from six hundred to twelve hundred parasites may derelop from a single pupa or larva of the hosts, the destruction of these would certainly be the oppo- 


\section{Civic Coöperation}

site of beneficial. It is only due to the protective color scheme of the caterpillars that some escape from the fate of becoming food for the parasite brood.

Besides these parasitic insects, there are others which eat the depredators directly. The interesting Hantis, Rearhorse or Walking-stick, is one of these; ants and spiders are others, which, however, even more than the birds, do not make much distinction between friend and foe. The larve of the tiger-bectles (Cicindelide) and "ground-beetles" (Carabidie), on the other hand, with some other beetle larvæ, are more useful caterpillar hunters, because feeding on specific injurious insects. Among the most important are the "lady-bugs" (Coccinella), whose small-headed, longlegged larvæ, often prettily colored, prey especially on plantlice and scale-insects. Quite a number of other friends could be mentioned.

While it is well to know these friends, it is in most cases impossible to rely on them for much practical help', especially in street trees, where wholesale methods of warfare become necessary, and no fine distinctions can be drawn, i.e., where poison is used, which generally kills both friend and foe.

Civic Coöperation. In the city, unbalanced conditions have been created by man and have been maintained so long that insect pests have the best chance for growing continuously worse, unless special effort is made to keep them in check. Theoretically, it would be possible by a supreme effort to get rid of all these pests, and then by moderate attention to keep them subdued. Practically, the conditions for securing this result are rarely attainable; especially when private owners do not fall in line with the efforts at extermination. While much may be done by private associated effort, there are always some persons antagonistic or 
indifferent to such efforts, and as long ats a few breeding places are maintained by private indifference or lack of public spirit, all efforts can be only partially successful. Unless laws and ordinances compelling eierybody to keep) his premises free from these nuisances are passed and enforced by fines and otherwise, we shall always have these pests with us.

In Germany, such laws of general application and ordinances for given localities, especially for combating insect pests in forests, have been in rogue for a long time. It is only by constant vigilance and by the absolute enforcement of such laws that the Colorado potato-beetle, again and again imported, has been kept out of Prussia.

Although in street and ornamental plantings the methods of combating insects are naturally different from those which are employed by the forester, the tree-warden can, nevertheless, be greatly benefited $l y$ knowing those of his brother arboriculturist in the forest.

The forester, being chielly concerned in economic problems, considers first the question of economy and of relative cost; he must balance the advantage in expenditure for combating an enemy with the saving in ultimate revenue resulting therefrom: he will, therefore, often let matters take care of themselves and suffer the damage, if he can see that it is not too scrious. The tree-warden. who has no economic object to attain, has no basis for calculating what he can afford to pay for the luxury of shade and beauty. Yet as he will want to aroid any unnecessary expense, he should follow the same line of reasoning as the forester in judging of the necessity and method of combating a peit. although he may come to a different decision. Especially in parks and large country estates the question of practicability may become serious. 
The necessity of measures against insects can in many cases be ascertained by timely observation and trial collections, as mentioned on the previous page, when the relative number of butterflies in the summer, or of cocoons, egg masses or wintering caterpillars in the fall, indicate the probability of next year's expectations. Next, an investigation of the health conditions of caterpillars and cocoons is indicated, for if at least fifty per cent. are found diseased, no measures need be taken. Signs of disease are sluggishness in feeding or other unusual behavior of caterpillars, although this will be possible for only an expert to judge. To make sure, fifty to a hundred caterpillars, larve, pupx or eggs should be collected, cut open, and the eggs or larvie of parasites found, or else they may be hatched under proper conditions. These investigations require some skill and entomological knowledge and are, therefore, best made by an expert. Next, the observation of weather conditions permits a judgment as to the likelihood of ordinary or extraordinary development. If the winter has been very severe, or else open and wet, or if early or late frosts are likely to have damaged the wintering caterpillars, there may be no necessity for making warfare.

To be sure, these prognostications require knowledge and judgment, but with an official entomologist in almost every state, it should not be difficult to readily secure an expert's opinion.

General Methods of Procedure. When it becomes necessary to fight a pest, there are four general methods to choose from: namely, searching for and killing the insect directly in any of its phases of development, egg, cocoon, larva, or imago; preventing it from reaching its feeding or breeding place by placing impediments in the way, when it can be collected and destroyed; trapping or baiting it; or lastly, poisoning its food. 
Among these methods, the last requires the least knowledge, and, if properly applied, promises the surest success. At the same time, it is practical only in the case of more or less isolated trees and becomes expensive in that of large specimens. Nevertheless, with the derelopment of practical apparatus and of serviceable poisons, this method is now so well tested, and demonstrated as practical in combating all leaf-destroyers on street and lawn trees as well as in orchards, that any community which has pride in its appearance and is without the apparatus for applying these insecticides, must be considered behind the times.

The orchardist, especially, who is not provided with this means of keeping his trees healthy is no better than the farmer without a cultivator, and may even be considered a public nuisance.

The majority of the injurious larve which feed on leaves are biting insects and eat their food, hence can be directly killed by poisoning this; the sucking insects, which, like plant-lice, plant-bugs, scale-insects and mites, suck the juices, and whose digestive organs cannot be reached by the poison, can, nerertheless, be combated by its use, if they are directly hit by the poison, so that their soft skins are penetrated, or if their breathing apparatus is clogged by it, or if they are otherwise disabled by the spray.

There are quite a large number of poisons or insecticides in use, each having some adrantages, and some being preferable for specific use; but, on the whole, for general practice, three remedies stand out as preëminently effective and acceptable, namely, the arsenical poisons, the kerosene emulsion, and hydrocyanic acid gas, which latter, however, is probably rarely practical outside the orchard.

Since the first-mentioned poisons are injurious to plants as well as animals, caution in their use is necessary; they 


\section{Biting Insects}

must be diluted in certain proportions with other substances, to make them harmless to plants and yet poisonous enough to kill the insects which eat the foliage corered by it. 'This is not difficult, since the insects continue eating and therefore accumulating the poison, which is distributed in small quantities. It may be added that, if ordinary precautions are taken, there is no danger to man from arsenical poisons.

Biting Insects. There are two poisons which answer most purposes in the case of biting insects, - Arsenate of Copper (Paris Green) and Arsenate of Lead. The latter, although acting more slowly, is probably the better for general use, because it adheres readily to the leaves, and remains therefore longer effective, reducing the need of repeated sprayings. It can be applied in considerable quantity without burning the foliage, the one objection, besides the somewhat higher price, being the difficulty of preparing the mixture for use. This is now overcome by a prepared paste, sold under the name of Disparene and costing fifteen to twenty-five cents per pound, which needs only to be stirred into water. ${ }^{1}$

These insecticides are best applied, like the Bordeaux mixture, by spraying, and are preferably applied together with it; for, if the Bordeaux mixture is substituted for ordinary water in mixing the insecticide, the possibly injurious , effects on the foliage of the Paris Green are avoided.

The application should be made before the trees show signs of serious injury, and that means as soon as the leaves are out, and they should be kept covered with the poison

1 To be obtained from the Borvker Fertilizer Co., Boston, Mass, who also prepare other insecticides and fungicides. Swift's Arsenate of Lead is also commendable; and the Vreeland Chemical Co. of Little Falls, N. J., prepares a paste, for which superior quality is claimed, at eleven to thirteen cents per pound. 


\section{6 \\ Control of Parasites}

during the early part of the season. This may, in a dry season, be effected by spraving a second time after two weeks, but if the season is rainy as many as three or four applications may be needed before the first of July.

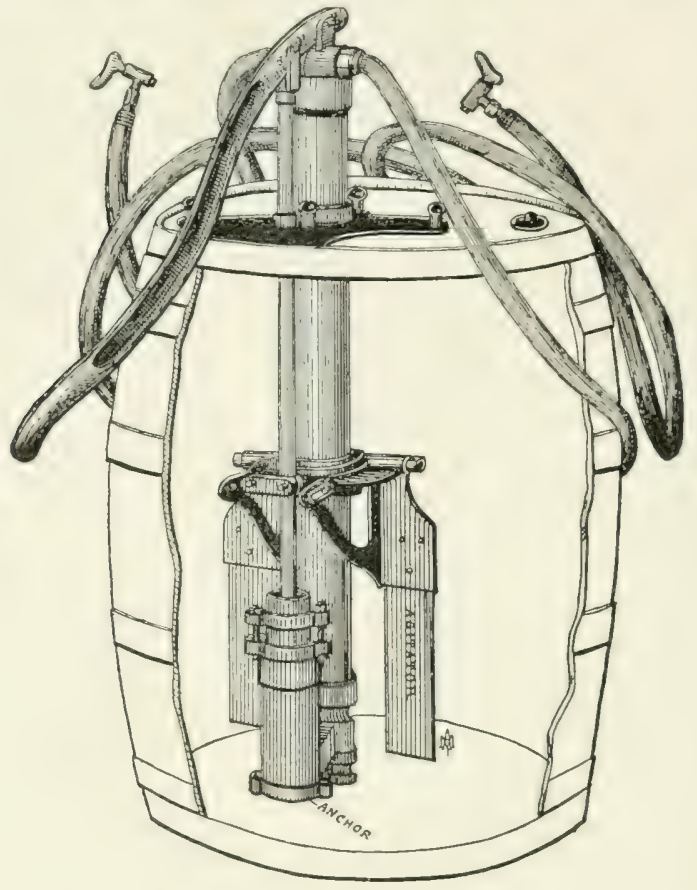

FIG. 48. - Barrel pump for spraying.

Arsenate of Lead mixture: Dissolve eleven to twelve ounces of acetate of lead (sugar of lead), costing twelve to fifteen cents per pound, in four quarts of hot water in a wooden pail, and four ounces of arsenate of soda $(96$ per cent. pure), twelve to fifteen cents per pound, in two quarts of water. For use, dilute at the rate of four to six pounds in a hundred gallons of water, the larger quantity for elm- 


\section{Biting Insects}

leaf beetle and gipsy-moth, the smaller for brown-tailed moth, tussock-moth, and fall web-worm.

Paris Green mixture: One pound of Paris Green, eighteen to twenty cents, made into a paste with warm water and stirred into one hundred to three hundred gallons of water or Bordeaux mixture, is a safe mixture, the stronger solution being for the elm-beetle. If water is

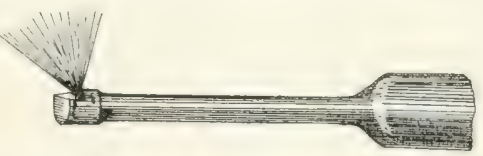

FIg. 49. - The "Stott" spray nozzle. used, the addition of one pound of milk of lime is recommended to prevent injury to foliage. Fill a barrel nearly fuli of air-slacked lime, fill entirely with water and let it stand until settled; the clear water above the lime is the milk of lime; or, two pounds of fresh lime to one pound of Paris Green, slacked in the usual manner, then strained through cheese cloth and diluted to fill a pail, may be substituted.

Paris Green (or better, if attainable, Scheele's Green, because cheaper and more effective) acts more quickly, but

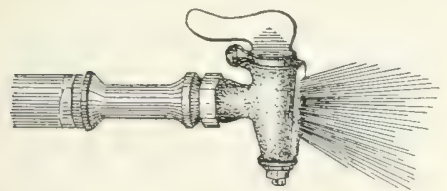

Fig. 50. - "Bordeaux" spray nozzle. is also more dangerous to the foliage than is the Arsenate of Lead, although the addition of milk of lime reduces the injurious effects. Yet it requires more nicety in preparation and use, and is also more easily washed off. But, if the Arsenate of Lead is not readily attainable, Paris Green (if unadulterated) is a sufficiently satisfactory all-round insecticide.

Since it has been shown that insects will avoid poisoned food until driven to it by hunger, it is essential to extend the spraying to all parts and to all food plants. 


\section{8}

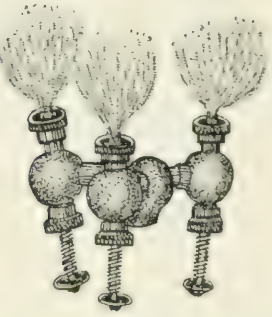

FIG. 5x. - Triple spray

"Vermoral" nozzle.

\section{Control of Parasites}

To have the spraying properly and thoroughly done is not always easy, especially with large trees and incomplete apparatus.

For private grounds of limited extent a fifty-gallon cask or tank with a strong, double-acting force pump ${ }^{1}$ (the working parts of brass and the valves also of metal), having an air cylinder of one and a half inches or more, and a stroke of five inches or more, attached to the top or side of the barrel, mounted on a cart, with fifty to one hundred feet of half-inch white cotton or rubber hose, ladders and lifting poles of bamboo or quarterinch gas pipe, will answer well enough for apparatus. The entire outfit, exclusive of the cart, costs between $\$_{30}$ and $\$_{40}$, the pump alone costing from \$IO to \$I 5. A barrel pump, satisfactory for general work on small places, can be had for $\$_{15}$, and a bucket pump, which can be used with an ordinary pail or bucket, good to spray bushes and small trees, may be had for from $\$_{3}$ to $\$_{7}$,

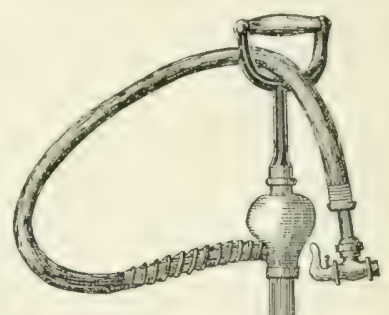
including rubber hose and nozzle.

The most important feature in the a!pjaratus is the nozzle,

I Knapsack pumps, of which there are scrernl makes in the market, are, as a rule, not practical for tree work. 


\section{Biting Insects}

which must throw a mist-like spray for a sufficient distance. Of the many nozzles in the market specially designed for the purpose, the Vermorel and the McGowen or Bordeaux nozzles seem to have found most favor; the latter is perhaps the best for general use in trec-spraying, because, although somewhat coarser, it throw the stream further. For satisfactory working it is necessary to keep the solution stirred and free from coarse particles which clog the nozzle.

A common wooden pail with a $I_{2}^{1}$-inch iron gas-pipe put through the bottom, which should be reënforced, and with 20mesh iron wire cloth attached half way, makes an efficient strainer.

For use in public parks and on street trees, a steam-pump apparatus, which can be had at from $\$ 400$ upwards, is perhaps preferable, although even

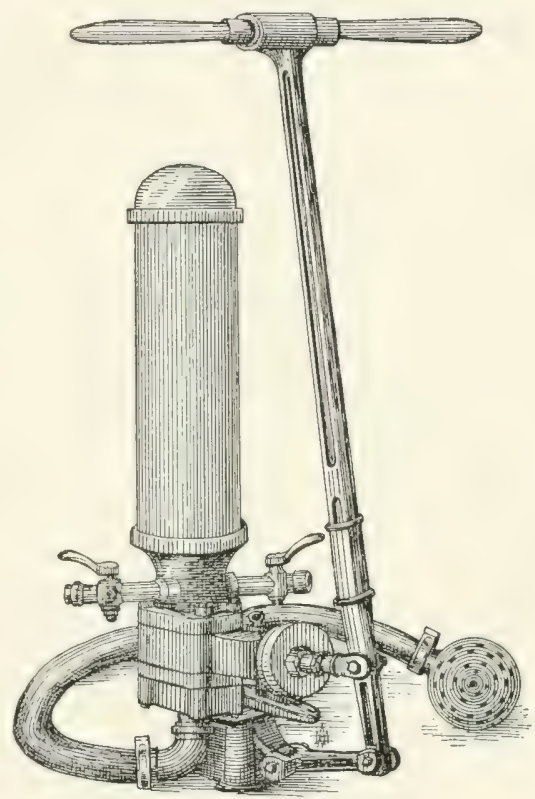

FIG. 53. - Tank sprayer. here the hand-pump apparatus with a stronger pump, larger cask and more hose, keeping the cost within $\$ 60,{ }^{1}$ may be still sufficient in smaller communities, where not too many trees are to be treated.

It would lead us too far to give a description of the vari-

1 The very complete hand apparatus used in Worcester and Springfield, Mass., can be had for \$125. 
ous forms which such apparatus might take. I full discussion may be found in the Yearbook of the United States Department of Agriculture for $I S()^{6}$, and in other publications, notably of the State Entomologists, various combinations are proposed. ${ }^{1}$

Since the spray mixtures are very corrosive, the apparatus should be thoroughly cleaned immediately after use by forcing pure water through it and

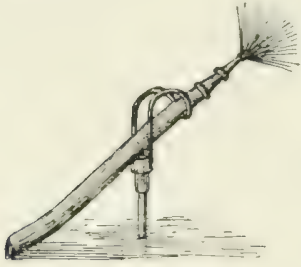

FIG. 54. - "Cen " nozzle holder. wiping off the exposed parts.

Failures in results from spraying come either from unsatisfactory apparatus, such as lack of an agitator on the pump, poor nozzles throwing a shower, instead of a mist, insufficient and variable pressure, or else unsatisfactory application, lack of thoroughness, failure to choose the right time or weather (wind and rain), and use of wrong materials, or improperly mixed ones.

As to the cost of spraying, the Entomologist of the Department of Igriculture estimates that, after a proper apparatus is installed. for a city like Brooklyn, X. I., an expenditure of $\$,, 000$ to $\$, 5,000$ would result in green shade trees all through the summer, and this expenditure would probably not need to be continued annually. The cost must necessarily vary according to the number and size of trees to be treated and to other circumstances, reported experiences

${ }^{1}$ Reliable dealers in spraying machinery are: Could Manufacturing Co., Seneca Falls, N. Y.; Field Force Pump Co., Elmira, N. Y.; Sydnor P'ump and Vell Co., Richmond, Va.; Morrell \& Morley, Benton Harbor, Mich.; Deming Co., Salem, Ohio; E. C. Brown Co., Rochester, X. Y.; Spraymotor Co., Buffalo, N. Y., and London, Canada; Rochester Spray Pump Co., Rochester, X. Y.; Friend Mfg. Co., Gasport, X. I.; Hardie Spray I'ump Mfg. Co., Detroit, Mich.; Wm. Stahl, Quincy, Ill. 


\section{Sucking Insects}

showing variations from ten cents to ten dollars per tree. ${ }^{1}$ Of the trees of Springfield, Mass., I6,000 were sprayed at an average cost of twentynine cents. This cost was reduced in Saratoga, for 5,667 trees of twenty to eighty feet in height, to seventeen and a quarter cents, and in Brooklyn, with FIG. 55. - "Vermoral" spray nozzle. steam apparatus for $8.7 \mathrm{I} 2$ trees, to twelve cents per tree, and this may be still further reduced by perfecting the apparatus and the organization. With hand apparatus, the cost for spraying trees up to forty feet in height may be as many cents as there are feet in height, but after that it increases more rapidly with the height.

It is hardly practicable for each tree owner in a city, town, or village to provide himself with a spraying outfit, but every city, town, or even village can afford to supply an apparatus which would serve the entire community and, either at public expense or by coöperative effort, all trees could be sprayed cheaply, and in a few years the insect question would be easy to take care of, if there is also cooperation in exterminating those insects which cannot be readily reached by poison.

Sucking Insects. As stated before, these poisons are effective mainly with those biting insects which devour their food. They are not effective, or only partially so, with scale-insects, plant-lice, borers, as well as Curculios, chinch-bugs, etc., and all other kinds that suck the sap of the plants. These are best reached by a kerosene or soap emulsion, also applied by spraying, but in such a manner that the insect is struck, for they act by contact.

I Reported by A. H. Kirkland in The Shade-tree Insect Problem. 
For the application of any of these mixtures a bright, sumny day should be chosen, and the trees should be dry. The spraying should just wet the plant without allowing the liquid to run down the trunk.

The ferosenc cmulsion is the standard mixture for this class of insects. Half a pound of whale-oil soap, or other soap, is grated and dissolved in one gallon of boiling water, and is immediately added, boiling hot, to two gallons of kerosene, pouring in slowly, and the mixture thoroughly agritated for ten to fifteen minutes, until the consistency of cream (with an increase of one-third to one-half in bulk) is attained. This is a stock solution, which will keep indelinitely, and in using must be diluted, adding from fifteen to twenty parts of water for soft-bodied insects, and seven to nine parts of water for hard-bodied larve, beetles, and insects.

There is some danger in the kerosene emulsion, if not properly made and if carclessly used, for the kerosene flowing down the trunk and collecting about the roots may interfere with their aëration and may eren produce death. ${ }^{1}$

The whale-oil soap by itself, or any good soap, is effective on soft-bodied insects and scales. The soap shoulk be marle of caustic potash rather than soda, as this is more effective and sprays more casily. A pound of soap finely divided $\Rightarrow$ and dissolved in three to six gallons of hot water is about the right strength.

I decoction of tobacco (one pound of tobacco stems to 1 one gallon of water, steeped for two or three hours and strained) is also elfective, and can be used without danger, like the soaps.

${ }^{1}$ A number of trees were killed in Ithaca in 1903 by foolishly applying pure kerosene to the bark with the croneous notion of lenetiting them. 


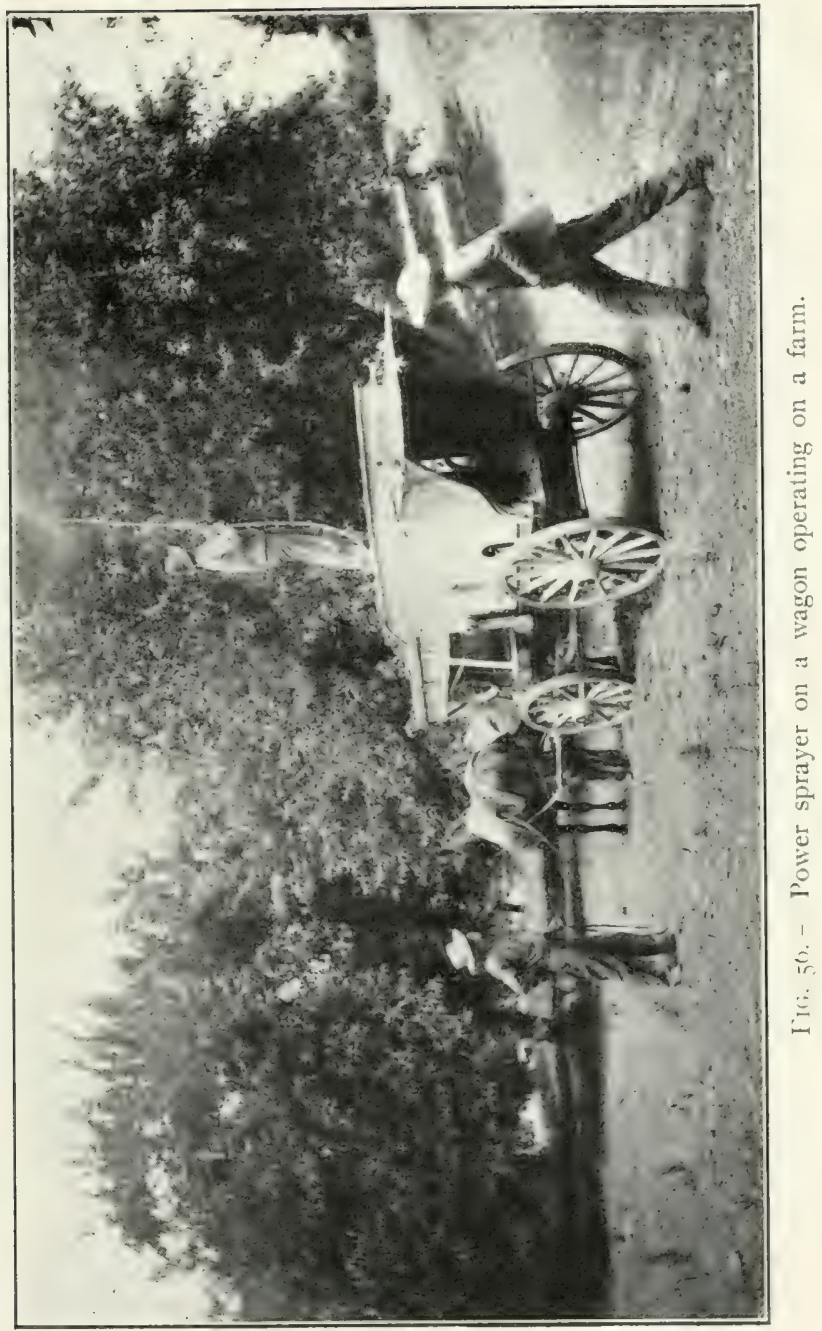


Mechanical Destruction of Insects. I large number of insects, among which are some of the most injurious, cannot be reacher by insecticides, and even with those which can be so combated, it is often impracticable to attempt this methor. Where it is impossible to apply the poisons, or also in connection with their application, mechanical means of destruction may be employed. This is usually best done when the insect is in a quiesecent stagse of development, namely, in the egg or pupa state, although in some cases the imago or larra state is more accessible.

These latter can also occasionally be trapped and baited. Moths, for instance, can be trapjed by strong lights, and special traps for that purpose are manufactured, but, aside from the fact that beneficial insects are also caught without distinction, these traps are practicable only under conditions which rarely prevail where shade or ormamental trees are to be protected. ${ }^{1}$

Baiting by confining a freshly issued female under a sieve, when many males will be attracted and can be captured, will also be rarely a practicable methor. But the trapping of caterpillars by the use of bands around the bole of the tree is quite practicable with all those insects which are ascending or descending the trunks. Such bands are merely a mechanical barrier to the progress of the caterpillars, which can then be brushed oll with wire brushes and burnt.

The simplest band is one of cotton batting, eight to twelve inches wide, long enough to go round the trunk and overlap two inches. This is tied tightly around the trunk, so that

${ }^{1}$ Lately a gasoline torch has been placed in the market, which it is proposed to make effective by both light and heat. Its merits are still under investigation, but it is probably not practical for use on large trees, even if the heat could be so regulated as to kill the insects and not the cambium of the tree. 
the batting can be turned orer and down like an inverterl tunnel, which forms the bar to the ascending caterpillars. The caterpillars collect below the band and should, from time to time, be gathered and killed. A banil of tarred paper may be substituted for the cotton, or else light burlap) (eight ounce, eight to ten inches wide). These devices are not very sightly; a neat metal protector, consisting of a brass band with teeth like a comb, tacked to the tree, is an improvement upon them, as regards appearance. Where the bark is rough, it may become necessary to smooth it, so that the band makes a tight joint. Where a large number of trees are to be protected, as in streets and parks, it will be found cheaper to use a band made of a sticky substance. For this purpose there are several preparations made from crude petroleum; a German one sold under the name "Raupenleim" "was the original one, an American one called "Dendrolene," ${ }^{2}$ and another, "Tree-Tanglefoot," all more or less greasy, smooth, and of butter-like consistency. The last mentioned remains effective a longer time, because it does not dry, but it is apt to injure the bark of young trees, hence in such cases it should be applied with a protective paper band underneath.

These applications are made, after having smoothed the bark, three to six inches wide and a quarter of an inch thick. There are devices for handling these substances expeditiously, but ordinarily a trowel may be used. The bands should be placed at sufficient height to avoid disagreeable accidents from contact with passers-by. Should the band become dry, it will have to be renewed.

These coatings can also be used to advantage to keep

1 To be obtained from Bowker Fertilizer Co., Boston; Wm. Mengel Son, New York.

2 To be obtained from Prof. F. L. Nason, New Brunswick, N. J. 
out borers, to prevent egg masses from hatching, and to kill scale-insects.

The insects which can be controlled by such bands are all those whose caterpillars are hatched out below the region of the band, but it is also useful with those which wander, seeking for new supplies after having defoliated one tree.

It is, of course, necessary to apply the band in season, before the caterpillars begin to wander.

The application of a lime wash (whitewash) to the trunks, has been very frequently practised, and it is without question a good protection against several insect pests, especially scales. It acts merely as a repellant, not as an insecticide. But the unsightliness should rule this remedy out for ornamental trees, wherever other methods are available. If used at all, the addition of flowers of sulphur ${ }^{1}$ (making bisulphide of lime), or else the addition of crurle carbolic acid (one pint to a hundred pounds of lime) will increase its efficiency.

Like all such coatings, the lime wash must be renewed to remain effective, since it is washed away by rains.

Borers and Bark-beetles. While there are many ways of combating the insects which attack the leaves and which live within reach, the various borers and bark-beetles are much more difficult to deal with since they are hidden from direct access during much of their life and especially during their dangerous stage. If their holes can be found, which is not always easy, the injection of carbon bisulphide into the tunnel and plugging the outlet tight with putty or hard soap will kill them, the bisulphide developing a gas injurious to the boring larva. Or else, they may be reached by a wire

1 Five pounds of sulphur and five pounds of lime boiled together in a (1) small quantity of water until dissolved, making a brownish liquid, to be diluted in a hundred gallons of water. 


\section{Borers and Bark-beetles}

run into the hole, or the worm may be cut out and the scar treated like any other wound.

In any case, tedious individual treatment is necessary, there being no wholesale method. Hence, where borers are to be feared, preventing their entrance by protective covers is the preferable methorl. Against the larger borers a wire mospuito netting, placed around the trunk loosely, so as not to touch the bark, set into the ground at the base and tied at the top, prevents the beetles from laying their eggs either under the bark scales or in a gnawed hole. This derice also prevents beetles in the trunk from emerging, leaving them to die without chance of reproduction. On branches, tarred paper or even newspaper will answer the same purpose, or else whitewash, to which Paris Green has been added, can be thoroughly applied with a knapsack jump through a Termorel nozzle. But this must be renewed every week or two until the middle of July, when the danger from tlat-headed borers is past. Still better is an application of dendrolene or "insect lime", which keeps effective for the season if applied properly at the right time. But all these measures are practically undesirable, and eventually removal of the infected tree is the only resort.

The most insidious and least amenable to remedies are the bark-beetles, the larre of which, minute white grubs, burrow in the soft wood and cambium laver under the bark, destroying the cambium; and since several broods are made during the same season, their numerous galleries eventually girdle and kill the trees. Little round shot-holes show the inlet and outlet of the small black or brown beetle, but when the broods of larvæ have been at work for some time, the bark is lonsened and can be peeled off without resistance.

Since these beetles hardly erer attack healthy trees, preferring those which have been otherwise weakened or under- 
fed, the main remedy is not to allow trees to get into such vulnerable condition. If a slight infection is noticed in time, in addition to promoting the general vigor of the tree, an application of whitewash with I'aris Green added, or of strong whale-oil soap suds with a little crude carbolic acid added, repeated as needful, may be employed. It may also be possible to cut out small infested areas of wood, and treat them antiseptically like other wounds. This has been successfully done on old elms at Brussels.

In the forestry practice of Europe, baiting of bark-beetles, which are specially destructive to spruce forests, is the only practical remedy besides clean lumbering. The beetles thrive most readily under the bark of the freshly felled timber, and, therefore, barking the trees immediately after felling, and the removal or burning of rubbish is practised. In addition, in the spring, a few "trap trees" are felled or billets laid out in the endangered places, on which the beetles assemble in large numbers to lay their eggs; the trap trees can then be removed and burned.

If the pest is once established, nothing can be done, except to cut out the infested trees in order to aroid further spread.

Root Destroyers. The root pests-such as the cut-worms, larvæ of certain moths; the wire-worms, larve of the wellknown clicking-beetles; root-lice, like the celebrated Phylloxera, which made such havoc among the rineyards of France, and other plant-lice, which feed on roots either wholly or at some time in their development - these are more to be feared for the lawn grass and other tender plants and for young tree seedlings, than for older trees, although they occasionally injure these too. Those which spend one phase in the open (and then they are also sometimes feeding on foliage, as the clicking-beetles and lice) may be decimated by poison or by collecting during that phase. 


\section{Specific Pests}

Otherwise, applications of hot water, which does not injure the roots, is recommended, or else the use of tobacco dust, the nicotine of which leaches into the soil with the rains and kills at least the plant-lice, while acting at the same time as a fertilizer. This ground tobacco is best placed in a trench around the tree, filling it liberally and re-corering the trench.

The application of potash fertilizers, such as kainit, or muriate of potash, preferably before or during a rain, sown broadcast or worked into the soil (ten pounds of kainit to a five or six year old tree) is said to destroy the grubs and any insect that lives in the soil. At least the tree will be benefited by the application and so invigorated as to resist the attacks, not only of this, but of any other insect pest.

Specific Pests. Since the methods of combating the various insects are based on their life habits, and since these difier considerably, it is necessary to specify more fully with reference to particular pests. In the following pages, therefore, the more obnoxious insects are more systematically treated and the more common enemies to shade trees are briefly described as far as needful; and the methods of controlling them are briefly given. It would not be practicable within the limits of this book to give more than the briefest statements. Those interested in further detail must find it in the very comprehensive literature, a partial reference list to which is found on page 375 , and especially to the excellent work of J. B. Smith, "Economic Entomology for the Farmer and Fruit-grower."

The insects obnoxious to tree growth may be roughly classed in the three large groups of bugs, beetles, and butterflies (including moths), each of which can be again subdivided into several smaller groups according to the character of the insect or its feeding habit. 
I. Bugs, comprising a number of insect families separated in strict classification into II miptere (half-wings: partly leathery), Orlhoplere (straight wings, membranaceous), etc.

Here belong the various plant-lice, bark-lice, root-lice, mealy bugs and scale-insects, also tree-hoppers, grasshoppers, and cicadas; a large number of species, on the whole but slightly injurious to tree life; besides some of those most destructive to crops, like the chinch-bug, cabbage-bug, squash-bug, etc.

Their mischief consists in sucking the say) and sometimes causing gall-like malformations of relatirely littie moment, although they can, if excessively developerl, cause the death of limbs and even of trees.

Plantlice have green to greenish-black, tlask-shaped bodies, covered with a soft, powdery bloom or wool, winged or unwinged; wintering in the exgr hatching as regetation begins and producing four to nine generations during the summer. They suck the juices of the foliage and twigs, and some produce gall-like swellings on the new-grown twigs of conifers, poplars, etc.; noteworthy only if unusually developed.

Spray at any time during the season with dilute kerosene emulsion (one part in lifteen parts of water), or with tobacco decoction, or with common soap) solution (one pound in eight gallons).

Bark-lice and Scales, mostly dull yellow-brown to black, hemispherical, globular, or convex bodies, the "scales" formed by excretions, the males winged, the wingless females attached to the smooth-barked twigs or leaves, from which they suck the sap, and where they winter, resuming their feeding and the laying of eggs in spring.

Besides various fruit trecs, dogwoods, mountain-as.s, 


\section{Specific Pests}

hawthorns, poplars, ornamental cherries, plums, currants and spireas are infested by the San José scale.

They are very productive, breeding in July and December, and spreading readily, as in the case of the well-known cottony cushion scale on orange trees in California; the white pine scale and the cottony maple scale, which occur also on other species, are perhaps the most common and are recognized by their white, waxy, fluffy excretions.

Judicious pruning or trimming in winter or mechanical dislodgment is the most practical remedy: Spraying with kerosene emulsion enforced by soap) suds (three quarts of kerosene emulsion and one pround of whale-oil soap dissolved in eight gallons of water) during the winter or in early spring before the protective scales of the new generation are formed is next best; the insect must be hit by the application, the spraying should be thorough, and should be repeated at least once. A lime-sulphur wash, or clse "scalecide," a petroleum preparation, which is more easily handled, may also be applied satisfactorily.

Root-lice, in so far as they are not merely phases of the before-mentioned, are also scaly, covered with a whitish excretion; remedies discussed on page I 48.

Grasshoppers. Some of the "katydids" or long-horned grasshoppers become in some seasons obnoxious by feeding on foliage, and laying their eggs in young twigs and leaves, causing them to die.

Spraying, collecting, and burning the litter (fallen twigs) may be practised, if chickens and turkeys do not keep them in check.

Wralking-sticks and the peculiar "Praying-mantis" or Rearhorse feed on the foliage of the trees, but are rarely important. If necessary, spray, or burn the rubbish in which the eggs hatch. 
Cicada or Sizentern-year Locust, when it emerges from its long underground life, becomes troublesome by laying eggs in twigs and branches, causing their death, and may become seriously injurious to young trees, in old trees causing only unsightliness.

'The sparrow is the best protection, otherwise only mechanical destruction is available.

2. BeEtles or Coleoplere have horny wings which form a cover over the posterior, folded membranaceous wings. Of the sixty-one families of beetles, seren contain species doing considerable damage, namely the snout-beetles or weevils, the bark-beetles, the long-horned, round-headed wood-borers, the flat-headed wood-borers, the clickingbeetles, the cockchafers, and the leaf-beetles. Besides these there are some minor pests found in other families. In most cases, it is the larre or "grubs" which do the damage, although occasionally the beetles themselves are the culprits.

Weevils or Snout-bectles or Curculios are mostly black, brown, or gray beetles, easily recognized by their beak-like mouth-parts. A rery large number of species do damage of the most varied kind. In some cases the beetles as well as the larwe feed on the leaves; the white or yellowish larva found in the chestnuts and hickory nuts, as well as in apples and other fruit and in peas, belong to this family, while the plum curculio feeds as a beetle on buds and leaves, and as a larva on the fruit; some bore into the young shoots to lay their eggs, causing them to die and fall, others into the pith of older branchlets; some lay their eggs in the midrib of leaves, causing their fall; and some roll the leaves into peculiar shapes either singly or in bunches, causing their death; the larve of others, again, injure the roots; and others behave like bark-beetles, destroying portions of the cambium, 


\section{Specific Pests}

or even like wood-borers, penetrating into the interior. They are especially obnoxious in conifers and more in younger than in older trees. The most important one damaging trees is perhaps the -

White Pine Weevil; it attacks the leading shoot in young trees, sometimes year after year, causing its death and leading to deformity by multiplying the leaders, one or more side branches taking up the leadership.

A protective cover of soap wash (one pound to a hundred and fifty gallons of water), to which Paris Green is added, may keep the weevil off. Infested branches should be cut off and burned and the formation of a single proper leader regulated by proper pruning. In plantations, baiting and collecting the beetles is probably the only practical remedy against the pests.

Bark Beciles are small weevils, generally not exceeding one-eighth of an inch, with very short snouts, of cylindrical form, and black, brown or gray color. Boring little hole's through the bark into the soft layers of cambium and sapwood in early spring, they enter and make a burrow close under the bark, in which the eggss are laid; these soon hatch and the larve continue the burrow in the cambium or wood, in galleries characteristic in outline for each species. At the ends of these channels they pupate and (in some of the species) within a month of the egg-laying the young beetles seek the old opening or a new one to mate and repeat the cycle, several broods being developed in the summer.

Remedies, as described on page $\mathrm{I}+7$, consist in removal of infected parts or trees, baiting, and keeping trees in rigorous condition.

Round-headed Wood-borers are large beetles with elongated body, greatly varied in color, recognized easily by their long feelers or antennx, which are longer than their 
bodies. Their white grubs live in the wood of trees. They are, as a rule, much less harmful than the bark-beetles, since they are less prolific. Nevertheless, in young trees of poplars, willows, chestnut, oak, ash, walnut, cherry, and apple, the grubs, especially those which burrow in the roots, do enough havoc to kill occasionally even large trees.

The most obnoxious seems to be the Locust-borer, which riddles young Black Locust trees until they die, or else undermines their stability; it also attacks walnut and hickory. The brown to black beetles, striped and banded with golden yellow and with a $\mathrm{W}$ on their wing-covers, gather in August and early September on the flowers of goldenrod, where they may be collected; they may also be collected as they lay their eggs soon afterward in the crevices of the bark. The larra issues the same fall and bores a quarter-inch hole under the bark and upwards, the ejected wood dust disclosing its presence.

Whiterashing, soaping, or covering with dendrolene, to prevent the beetle from laying its eggs in August, besides collecting the beetles, are the remedies for this and other similar borers.

The Oak-pruner and other twig-girdlers belong here. They lay their eggs in a twig and then girdle the twig at some distance below, so that it may die and be broken off by the winds, the larva developing in the fallen twig on the ground.

Flat-headed ITood-borers are large, broad, squarish beetles of metallic colors, with short legs, the footless grubs recognizable by the much broadened and flattened head and front part. The grubs live in the wood of trees, making burrows in the cambium, wood, or bark. The elliptic form of the holes through which the larve enter and the young beetles escape is characteristic. These beetles are chiefly injurious to deciduous trees - oak, beech, basswood, 
poplar, and willow --damaging and even killing the younger trees and young branches.

Pruning the infested branches seems the only remedy.

Clicking Bectles, similar in shape, but smaller than the former and of dull colors, are most readily recognized by their capacity of snapping and jumping when laicl on their backs, thereby regaining their legs. Their grubs are the long, slender wire-iurms, living for three years underground; they are especially injurious to grass crops and lawns, cutting off the grass just below the crown, the grass browning and dying in constantly enlarging patches. They also injure trees by feeding on their roots, while the beetles gnaw the young roots of deciduous trees and conifers.

Ditching around the affected patches of lawn and collecting the worms as they come out into the ditch, or poisoning them with Paris Green is applicable to the grass pests; hot water applications at the root, collecting the beetles or baiting them with poisoned wads of clover, potato, or cornmeal at night are methods applicable to the tree pests.

Cockchafers are large beetles, of which the well-known June bug is a type; they cause injury to leaves in the beetle stage and to roots in the grub stage; the latter, living for several years underground, are capable of ruining young plantations.

They are easily collected as beetles, by jarring the branches late in the evening, or better, in the cool of early morning, when they do not fly readily. When underground, the application of kerosene emulsion ten times diluted, or of a tobacco decoction, or else digging them out may be resorted to.

Leaf Bectles are small or medium-sized, often of bright and metallic color, of semi-spherical or cylindrical form and compact body. Both beetles and larva, which latter are 
also colored and have well-developed legs, usually live on the leares; the pupa generally and sometimes also the beetle wintering either underground or in the litter. The different species are more or less dependent on certain species of trees; willows, poplars, elms, also oaks and pines having their special pests. Here belong also the potato-beetle, the asparagus-beetle, and the cucumber-beetle. The most common and most destructive to ornamental trees is the imported -

Elm-leaf Bectle, the beetle being yellowish brown to greenish yellow with two or more black stripes on the wings, and the half-inch larva yellowish black with black spots and tufts of hair and wide yellow lines along the back and siries. The foliage is characteristically eaten, the soft tissue between the ribs being attacked in patches; the beetles eating irregular holes, the grubs systematically skeletonizing. The grubs work on the under side of leaves from May until August, together with the one to three or four broods of beetles, which lay their yellow bottle-shaped egg clusters on the under side of leares. The pupa winters under the fallen leaves near the base of the tree, and the beetle in all sorts of sheltered places; they attack the leares in spring (April or early May) as soon as these are fully developed, beginning at the top of the tree.

The many broods, the prolific reproduction, and the fact that both beetle and larva feed on the foliage, make this pest most injurious, since in one season it may destroy two or three sets of new foliage and exhaust the tree.

Besides destroying the wintering beetles or pupx, either mechanically or by hot water or kerosene, etc., spray with arsenites as soon as beetles begin feeding, a second spraying being applied when eggs begin to hatch or ten days later. Since the beetles are disinclined to $\mathrm{fly}$, a single tree 
may be kept nearly or entirely free, the spreading from other infested trees being slow.

3. Butterfles and Moths (Lepidoptera-Scaly wings). In these two orders it is only the larva or caterpillar which feeds on leaves, fruits, and softer tissues. The borlily distinction of butterflies and moths lies in the feelers or antenne, the butterllies having, with few exceptions, feelers terminating in a distinct club at the tip, which is absent in the moths. When sitting, the latter hold their wings usually spread out flat, the former more or less folded together; moths are night-fliers, butterflies are, as a general rule, on the wing only during the day. The caterpillars distinguish themselves from the grubs by their greater motility, having better developed legs, three pairs in front and generally two to five pairs at the other end; those living in the open are generally colored, and either hairy or beset with bristles or warts, those living inside their host plant or in the ground remaining colorless and naked. The moth caterpillars are mostly without hairs and have sixteen feet, and what is important as far as damage is concerned, do not, as a rule, live gregariously.

The more than three thousand species are grouped in different ways from different points of view. For our more practical purposes we may group them into the large and the small butterflies and moths, the former feeding exposed on or among the leaves, the latter concealed in the buds or in folded or rolled leaves. Of the large butterflies and moths there are three groups, which contain important injurious species, namely, the sphinxes, the spinners and the inch-worms, while among the small caterpillars two groups are notable depredators, namely, the leaf-rollers and the leaf-miners.

Sphinves or Hawk-moths are large butterflies with narrow, 


\section{58}

\section{Control of Parasites}

gointol wings. the front pair much longer than the hind wings: the laree caternillars are hairless and feculiarly marked by a hard. glossy eye spot or a curved horn on the last serment. The ash-tree sphinx and the pine sphinx are champles of this family. Their sige and a-ually rare. single vecurrence makes their damage molimarily not worth con-

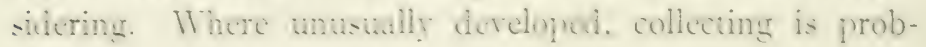
ably the readiest remedy.

Allicel to this group ure the fesins, whith clear wing iike bumets. whose caterpillars attack many cultivated plants

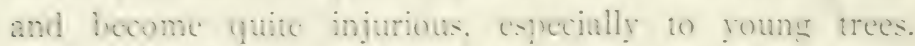
Willows pry lars. birches and alders are atucked hy them. They are borers. oftun confounled with the beetle-borers, the caterpillar living. like the grub of the beetle-borers, in the woud: some hollowing out brandhlets along the pith, whers. like the peach-burer, living butween bark and wood a linde below the groumd: whers bore in plum. pear. maple, graperines.

The same remelies used in the case of other borers are to he applied, namely. cutting out the culprit or preventing its ingres by applications of lime wash, dendrolene. etc.

Spimms are typical moths. of mulium size. brighty. colored. generally white, yellow. brown, gray, or black: trving at night: the caterpillars. which in some cases live for several vears and. as a rule, at least winter as such, are. with the excetion of those who live within the plant or ground, hairy, bristly, or warty. and rividly colored; they have a pronounced canacity for spinning and pupate in silk cocoons: the silkworms belong here.

Being chiefy gregarious, they are much more destructive than the former group, and. inciced. some of the met injurious pess are to be found among them. A few are wered. borers, the very lares whitish and black-sutted larrat living 


\section{Specific Pests}

from two to four years in the trunks or roots of trees, but the majority are leaf-eaters. Of this group it will be necessary to describe several in detail as being of great importance.

Tussock Moth. The caterpillar is easily recognized by its coral-red head, with a pair of long black plumes above it and a single one at the other extremity; the small male moth has delicately-marked gray or grayish-white wings, while the gray-bodied female is wingless; the cocorn is spun in crevices of the bark; the eggs are depresited on the empty cocoon in a consjicuous white frothy mass, which soon hardens, and in which the wintering takes place. The caterpillars emerge in May, hanging by silken threarls when young, spinning their cocoons in early July, the moths flying in July and August. Two or three generations form in a year.

They feed on maple, basswood, horse-chestnut, buckeye, elm, and a number of other species, and become in some localities a veritable scourge, wandering long distances for food supply.

Gathering the egg masses not later than the middle of May, or destroying them with creosote oil, which is easily done, is also most effective. A loose cotton band will prevent the ascent of wandering females and caterpillars. Spraying early in the season and as far as practicable on the under side of the leaves, where the young caterpillar. feed, or else later with stronger doses, and shaking the caterpillars from the limbs of younger trees may also be resorted to.

Forest Tent-caterpillar or .1Yaple-worm, a black to steelblue caterpillar, about two inches in length when full grown, with whitish diamond-shaped spots along the back. emerges very early in spring (April), clustering around the limbs in numbers when not feeding, and, if shaken off, hanging down 
by threads. The white or rellowish cocoons are spun in the leaves on the tree or on the ground, in crevices of bark or other shelter. No tents like those of the apple tentcaterpillar are made, but thin carpets are spun along the bark, and occasionally several terminal leaves are included in the web. The moths are recognized by their rusty brown or buff color; they fly in July, and lay their eggs on the lower twigs, encircling them in belts, corered with a brownish protective covering.

They feed not only on maple, but on a variety of species, and can become very destructive.

Collecting the eggr clusters, or cutting off the twigs with the egg clusters and burning them can be adrantageously practised with young trees in July or August. Crushing the clusters of young caterpillars, or else brushing, shaking, and jarring them down and preventing their re-ascent by a band of cotton batting, dendrolene, etc., or swabbing their nests in early morning with kerosene is effective in April to May, or else thorough spraying with kerosene emulsion or whale-oil soap or arsenite, ${ }^{1}$ as the leaves unfold. The collection of cocoons may also be resorted to, but care should be taken not to destroy them until the parasites have been hatched from them.

Fall It b-üom. I familiar sight during July, August, and September are the conspicuous silken webs, nests of young, pale yellow, black-headed, black-dotted and striped, hairy caterpillars, which, feeding gregariously, spin one or several leaves together, enlarging the web as they grow until the foliage of the whole limb is included. In southern latitudes, two broods appear in a season, the first one issuing in June. The dark brown pupa is spun in a silken cocoon

1 Boil one pound white arsenic with two pounds freshy slacked lime in one gallon of water for forty minutes and dilute in fifty gallons of water. 


\section{Specific Pests}

attached to crevices in the bark or other similar shelter, and in the ground if soft enough, wintering in this condition. The small, pure white or brown and black-dotted moths issue in June or July (the first southern brood in May), and lay their bright golden egess in large clusters on leaves, usually on the under side and near the end of the branches, from which the caterpillars issue within a week or ten days.

Besides the damage to the foliage, the disagreeable habit of the worms of droppling from the trees is obnoxious in city streets. Poplars, willows, box-elder, ash, cherry, elm, and basswood suffer most from this pest, but nearly all other trees are attacked if the food supply is scarce in a year of excessive development.

The easiest method of combating the pest is to cut off and burn the webs, or burn them on the tree with a torch, with proper caution to avoid injuring the tree. Spraying with arsenical poisons when the young caterpillars appear is also effective.

Bag IVorm. The bags, one to two inches in length, in which the caterpillars enclose themselves while feeding and in which they finally pupate, are the readiest sign of their presence. These bags are made of pine needles, bits of foliage and bark, and are gradually built up by each individual around itself. The caterpillars appear in s.Tay and early June, and at once begin the construction of their bags, first carrying them upright on their posterior body, then, as they grow heavier, hanging down. In spite of this impediment, they spin down and wander freely; finally, in September, attaching themselves hanging down from twigs, they pupate within the bag. The inconspicuous males, with black hairy body and glassy wings, fly in September and October; the females are wingless, hairless, and 
footless, and never leave their bags, depositing the eggst within them, and then dropping out to die, the egges wintering in the bag.

This is a dangerous enemy of conifers as well as of decirluous trees, mainly in southern latitudes.

The collection of the bags is the reacliest means of controlling them, besides spraying with arsenate of lead flifteen ounces to forty gallons of water) in May and June.

Gypsy Moth. This importer insect, in appearance somewhat like the Tussock-moth, so far almost harmless in its native country, Europe, has here become injurious, and that extremely so, although only in a very limiter locality in Massachusets. It is peculiarly interesting because of the fruitless cliforts to exterminate it, in which the State of Massachusetts has spent so far more than one million dollars.

The coloration in all stages is of a darker or lighter brownish or yellowish brown tint, the caterpillar, two to two and a half inches long when full grown, dotted with long hair tufts on colored blue and red tubercles; the egrg masses laid anywhere on limbs, fence rails or other objects, are covered with buff-colored scales, giving them a sponge-like appearance. It is in this stage that the insect winters, the caterpillars issuing from the end of April until the middle of June, and fecrling on the leaves of clm, maple, oak, indeed on almost all deciduous trees and shrubs, some continuing until the midclle of July, doing their work in clusters by night, and hirling in crevices by day. The moths emerge from the pupre in June and July, and deposit their eggss, which winter. Sometimes two broods occur.

The most effective remedy is the collecting and burning of the conspicuous eggr masses, or clse crushing and daubing them with creosote oil, hot if possible, during the fall, winter, and spring. Trees may be banded with burlap or insect 


\section{Specific Pests}

lime (about the middle of Miay), to prevent the ascent of the caterpillar during the feeding season, and finally a strong arsenate of lead spray (five pounds to fifty gallons) may be applied when the leaves are full grown and the caterpillars still young.

Carpenter Moth. Tarious species of moths known by this name infest in their larval stage various species of trees, boring large holes and galleries into the wood.

The oak-carpenter, although rare, is especially injurious, its rose-colored larva honeycombing the living woorl as well as the cut wood of Oak and Black Locust; the worms remain two or three years in the wood before developing into the moth, which is of gray color, flying in June or July.

The remerlies usually applied for borers may be used in this case, namely, covering the trunk with soft soap to prevent the oriposition in carly June, or applying bisulphide in the holes, or else digging out the worms.

Spiny Elm Caterpillar, Mourning-cloak or Antiopa. A common, beautiful, large butterfly, purpled brown or black, with a broad cream-colored border and a row of pale blue spots. The black, spiny caterpillars, white-speckled, and with a row of eight dark brick-red spots, feed gregariously, making light webs in their path. They are sometimes, in limited colonies, very destructive to the foliage, especially of the $\mathrm{cm}$, birch, basswood, and the various poplars. It is interesting, in that the butterfly hibernates and appears sometimes as early as March, making two broods in the season; the first brood appears in May, June, or July, the second in August. The eggs are laid in clusters encircling the twigs; the gray-brown, spiny chrysalis, hanging from fence rails, stumps, or other support is characteristic.

Spraying is the best remedy, or else shaking down the 
large caterpillars or bringing them down by a stream of water, or cutting off the infested branches while the caterpillars are still young and closely gregarious.

Army-worms or Cut-iorms comprise a number of species, some of which spin cocoons, others do not. They are typical, medium-sized, night-moths; the usually hairless caterpillars are also frequently night-prowlers. While mostly non-gregarious, some of them develop in such large masses, wandering over the ground, that the first name is applied to them, while the habit of cutting off buds and leaf parts leads to the second name. Some of the caterpillars are borers; others live underground, feeding on roots; the majority, however, live on the foliage of the host plant. The true Army-iworm, a brownish, white-striped caterpillar, from one and a half to two inches in length, with a brownish moth, making two or three generations in the year, more frequently damages grass crops than trees. The velvety black, yellow-lined, hairy caterpillar of the Erratic Armyworm, the mottled gray worms of another cut-worm, as well as many others, climb the oak, elm, cherry, etc., by night, revealing their presence by the cut-off buds and leaf particles which fall to the ground. Both deciduous and coniferous trees find enemies in this group. Most of the moths of this group fly in summer and fall, usually wintering underground as caterpillars or pupæ.

The climbing cut-worms, which winter as such underground, can be prevented from climbing the trees by various bands. They can also be baited with poisoned bran (one ounce of Paris Green to three ounces of bran), placed at the base of the tree. If whole areas are infested, in addition to banding the trees, ditching and collecting in the ditches is recommended.

INCH-WORMS Or CANKER-WORMS (Geometrids), also called 


\section{Specific Pests}

spanworms, measuring-worms, and geometers, from the manner in which the caterpillars more, drawing their hind parts after them by curving the back, a motion due to their having only two pairs of abdominal legs, are the larva of various species of moths, which are recognized by the fact that the four wings are of the same color, --snow-white, ash-gray, or yellow, - the caterpillars being mostly greenish to brown, and striped or dotted.

These worms are leaf-eaters, preying on maples, poplars, willows, pines, etc., being especially destructive to elms. The most injurious is the

Spring Canker-worm. The eggss of this spanworm are laid in patches on the trunk and limbs in carly spring, the caterpillars appearing at the end of April, and feeding through May and June. During the last two weeks in June they descend to the ground by sillien threads, to pupate beneath the soil surface. I few moths may come out in the fall and lay their eggs, but the majority appear in spring, The female is wingless and grub-like, and ascends the tree to deposit her eggs.

The other canker-worms vary mainly in the time of their stages of development, but in general all behave alike.

Banding the trees in March prevents the ascent of the females, thus forcing them to lay the egg masses below the barrier, where the hatching larve starve to death. Egg masses can be mechanically destroyed by means of dendrolene, or otherwise. If these preventives have been neglected, spray with arsenate, first when the leaves are half-formed, and, if necessary, at intervals of two weeks.

LEAF-MIINERS (Tine a) and LeAF-ROLlers (Tortrix), represented by orer two thousand species, are so named because their very small larvie mine in leares, buds, young shoots, also in bark, root, and fruit. The leaf-rollers also 
have the habit of rolling together needles or leaves, within which they pupate. The familiar "moths" of the household are characteristic of this group of depredators in general appearance and habit. They are much less injurious than the large moths and butterflies, as a rule causing at most only the death of twig ends; yet some are occasionally very destructive, especially to conifers. Imong these may be mentioned the Larch-moth, which causes the leaves of the larch to die and drop, and by repeated defoliation brings about the death of the tree; large areas of tamarack in the northern woods have been destroyed by this tiny insect; also the Pine-twister, which kills the end-buds, especially of young trees, and thereby causes a crooked or twisterl growth of the stem; and the Spruce-bud Tortrix; which has been responsible for the death of large areas of spruce and fir in New England, in conjunction with the secondary bark-beetles.

The Pine-bud It orm develops from cggs laid by the moth at the base of the bud of the leader in May; the larva soon develops, enters the bud, hollows it out and burrows back into the twig, in which retreat it winters, renewing its work in spring, and continuing until the moth is hatched, finally causing the death of the wig. Other bud worms vary only in the time of development, some being double-brooded, but all work in somewhat the same manner. The oozing out of resin at the point of entrance, forming a smaller or larger, crusted, resin-gall, is a sign of the presence of the burrowing pests. Some, like the spruce-bud worm, live on the outside and defoliate leaves, as do the large leafeaters.

The leaf-rollers infesting deciduous trees usually feed only on the outside leaves and buds; the eggs having been laid at the base of the end-buds, the larva hatch just as the buds unfold, and the youngest leaves are at once eaten. Later 


\section{Specific Pests}

on the older ones are attacked, one or several being loosely or densely rolled and spun together for a retreat. The death of twigs, and even of branches, by drouth is the result.

The only remedy for these bud pests is at once to prune the infested twigs as soon as the presence of the pest is discorered in Nay or June. Their detection requires close observation. With single valuable conifer species, it is possible to cut out the worm and clean out the burrow, dressing the wound with an antiseptic and with tree wax; if this be done in time, the leader may be sared. In the case of the open feeders, carly application of insecticides is advised.

The leaf-miners, which live inside the soft tissues of the leaves, skeletonizing them, are mostly much less injurious, and almost innocuous, except that they mar the appearance of the leaves. When dereloped excessively, the best remedy is to collect and burn the fallen leaves in the fall or spring, since in or among these the worms winter in specially constructed cases.

Any number of minor pests could be cited in aldition to the above. Moreover, from time to time, new pests, hitherto known only to the entomologist, or sometimes totally unknown, become prominent through unusual development. These will have to be combated by applying the principles described in this chapter. 


\section{CHAPTER VII}

\section{CARE IN PLANTING TREES}

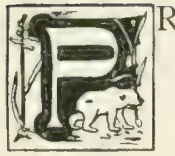

RACTICAL application of the physiological knowledge contained in the preceding chapters is needful at the very start, namely, when first establishing a tree. The first cause of trouble in transplanted trees and of death is not unfrequently to be found in the ignorance and lack of care exhibited before and during transplanting. Many trees set out are dead or are doomed to death before they reach the plant hole.

Transplanting a tree from one site to another is a surgical operation during which the patient needs special attention.

It is rarely, if at all, possible to take up all the fine rootlets with their root-hairs intact; these adhere closely to the soil particles, hence in the attempt to remove them a portion of the feeding apparatus is always mechanically destroyed. Next, the delicate root-hairs and fibrils are apt to dry out when exposed to the air, especially in windy, sunny, dry weather, and thus another portion of the feeding apparatus is lost; lastly, with larger specimens, the far-lying roots can practically not be reached and a third portion of the root system is cut off. Furthermore, if the plant material is shipped any distance, the vital activities are interrupted, temperature and mo:sture conditions may be unfarorable during transshipment and a partial drying out of roots, buds, or foliage is the consequence. 


\section{Care in Planting Trees}

As a result of these losses the balance between crown and root, between consumption and supply of water, is disturbed, and, unless this balance is at once reëstablished by pruning at the top and by favorable conditions for replacement of lost parts at the root, a part of the crown must die.

This trouble may be nearly or entirely avoided by transplanting with a ball of earth, when the root system is not at all disturbed. This is usually practicable only with small plants; as a rule, transplanting is done with the naked roots. Care should then be had to take up as much as practicable of the root system, keeping it intact, using a fork rather than a spade, and keeping in mind that the root tips are the important part; then the roots should be immediately protected against drying out by covering with moist soil, wet bagging, moss, etc., and be kept moist until the tree is reset.

If it has not been possible to secure the entire root system practically intact, then a proportionate amount of the crown system should also be removed by cutting back branches, using at the same time the opportunity for correcting the form (see page 98). This pruning is best done just before setting the tree, or, more conveniently, at once after setting while the knowledge of the conditions of the root system is still fresh in mind. If it is neglected, parts of the crown will die and these may not be the parts we are willing to spare. It does not matter much if the pruning at the top were more severe than necessary; the opposite matters much more.

When receiving nursery stock it should be opened at once in a shady cool place and the root packing should be examined. If it is dry and hot, the chance of securing a living plant is small. Nevertheless, by proper treatment plants may sometimes be recuperated; some species especially will stand a good deal of maltreatment and are able to recover. 
"Heeling" them in deeply in a trench under shade and in fresh soil, and drenching them thoroughly with water, keeping them drenched for a day or two, or even keeping them entirely submerged under water may restore what appeared quite hopeless material. Even if the leares of conifers have suffered, so long as the buds are still fresh looking, the case is not quite hopeless if proper care is applied in keeping roots and tips moist, and especially if rainy weather sets in.

Even if the buds of conifers are started, they can be safely transplanted, except the larch, which is sensitive in this respect. Broad-leaved stock, arriving after the foliage is out or with the buds started, is best stripped of its foliage or deprived of the most forward buds to prevent wilting, and to give time for the roots to take hold before too much demand is made on the water-supply.

In forest planting, where thousands of small trees are set, they are transported to the plant holes in a pail partly filled with water (better than a loam puddle), and the larger specimens should be similarly kept moist by various means on their way to the plant hole.

The advantage of nursery grown trees over naturally grown stock from pasture or forest lies not only in the more symmetrical crown which the nurseryman can produce by proper attention, but in the more compact root system, with feeding roots close to the stem, which he can induce, and which enables him to take it up and preserve it more readily in its entirety. The value of so-called "transplanted" or "sereral times transplanted stock" lies in the compact stocky root system, and in the properly trained crown, produced by proper pruning at each transplanting. In purchasing nursery stock, therefore, we expect not only live roots and buds, but a good form of root system and crown. 


\section{Care in Planting Trees}

Long, "leggy" roots and spindling branch systems are undesirable.

Knowing the ability of the tree to replace lost parts, and the conditions under which lost roots are most easily replaced, we can also prepare trees grown in field or forest for planting, cither while they are still in place, or by the nurseryman's method, transplanting them several times.

Th henever, in taking up trees, roots are injured or broken, they should be pruned with a sharp, smooth, draw-cut, which is best made in such a manner that its face will be on the lower side. This is done to accelerate healing and avoid rot, which is more apt to start on lacerated wounds, and to induce formation of new root fibers around the cut surface.

There is a great difference in different species as regards the abuse in handling which they can endure and the ease with which they repair damage. Generally speaking, those species which are good "sprouters", like willows, poplars, basswood, maples, catalpa - "sap-twood trees" - are apt to transplant "easily", that is they require less care. Indeed, they can be planted as mere poles and, if conditions at the base are favorable for root formation, such poles will grow into trees; nor is there any reason to anticipate that such trees will not grow into full-sized and normal form, the frequently asserted fears to the contrary notwithstanding. The tap-root trees, like the hickories, walnuts, oaks, and some pines, offer difficulties on account of their deep-going roots unless prepared beforehand by repeated transplanting and pruning, or by root-pruning in place while young. Some few other species, either on account of insufficient ability to make new feeding roots or on account of excessive transpiration from the foliage, are transplantrd with difficulty and for success must be prepared by root-pruning or severe 
cutting back. Such species are, besides the various hickories and other nut trees just mentioned, the magnolias, beeches, persimmon, and nearly all conifers, which are noted for the paucity and delicacy of their root-hairs and the ease with which these dry out, while their recuperative power is small; hence they require the greatest care in handling from the nursery to the plant hole. There is, then, considerable variation among the species, calling for more or less care in handling them, although with properly prepared nursery stock only the following simple rules need to be observed in order to be successful.

In setting a tree into a new position care should be had to make it easy for its roots to resume their function and to recuperate and form new rootlets as soon as possible. Three conditions are favorable to this object: sufficiently loose soil, sufficient supply of water, and close contact of soil and root.

Plant holes are usually dug too small. Roots are often crowded into narrow space, offering a limited feeding area, and find themselves placed against the hard sides of a lazy man's hole. Make the hole twice as large in circumference as seems necessary and fully as deep, so as to secure a comfortable amount of loose soil for roots to grow into. If practicable, the hole should be dug in the fall when the dug soil will be comminuted by the winter frost, and be in best condition for planting in the spring.

If the soil is not of satisfactory consistency or composition, supply a better soil, garden mold, or sandy loam, at least enough to imbed the outlying rootlets. This is especially often necessary in street-tree planting. If there are good and poor layers of soil coming out of a plant hole, keep them separate and fill back in such a manner that the best soil comes to the use of the rootlets, the poor layers on top and near the trunk. Soil from an old pasture or from along the 


\section{Care in Planting Trees}

roadside, paring off the sod, and, if need be, with sand adderl, or well decomposed humus from a swamp, furnish good material for filling in. Rotted sod may also be placed at the bottom of the hole to enrich the soil.

Manure of any kind is much better kept away from roots; it is apt to do more harm than good, both mechanically and chemically. But if extra care is desired, a mulching or top dressing to the depth of two or three inches with well-rotted manure, spent bark, leares, or other litter is commendable, as it prevents evaporation from the soil more persistently than even cultivation. Stones may also be used for this purpose. If manure is to be placed in the hole to cririch the soil, and especially to increase its water capacity, make sure that it is well mixed with the soil and kept away from direct contact with the roots.

Especially in planting street trees, the depth of the hole, and improvement of the soil is essential. A hole three feet deep, and an area of four square yards of prepared soil and an open space of at least one and a half yards unpared and cultivated, are the proper conditions for city trees.

Different species, we must repeat, make different demands on character and depth of soil (see Chapter IX), and hence more or less care in the preparation of the soil is required for different species.

In actually setting the tree, the first care is not to set it too deep. Many trees are lost from this cause, suffocation resulting by removing the respiratory organs of the roots from access to air. That shallow-rooted species especially do not like to have their roots deeply buried is natural, but is often not realized by the planter. Deep-rooted species also have some shallow roots specially designed for respiration and these must be kept near the surface. The proper 
depth is that at which the tree had stood in its original site, which usually can be readily recognized by a color line at the base of the stem. If planting in rery light soil, which is easily penetrated by air, the tree may without harm be set somewhat deeper to allow for settling. In such soil, to set the tree too high is eren more detrimental than to set it too low.

To secure the proper depth, fill in some of the soil, mounding it up and firming it at the center of the hole to nearly the height at which the tree is to stand; then. placing the tree over this mound, arrange its root system in natural position, and have an assistant (two can plant with more satisfaction than one) place some soil lightly over the outlying roots, while slightly pumping the tree up and down to get it just in the proper place; but one must be careful not to have too much soil on the roots or to pump too vigorously, thereby tearing off rootlets. Then, first fill in near the stem sufficient to make the tree firm, and then proceed to fill in over the feeding roots. It is in this part of the operation that the final success lies: to bring rootlets and soil in closest contact must be the aim; it is attained by using fingers and hands, or else by judicious use of water, small quantities at a time, which will wash the soil particles between the rootlets.

The use of water requires judgment and is in part influenced by the character and condition of the soil. In loose, sandy, well-drained soil an excess of moisture can hardly be obtained. Here, generous application of water during and after planting can only be beneficial. But in a compact, stiff, caking, clay soil, a free use of water is apt to lump the soil and prevent close contact with rootlets, leaving air spaces between roots and soil; finally, a superabundance of water without chance of drainage at the bottom may induce rot. In such situations, for best results, make the holes 


\section{Care in Planting Trees}

deeper than usual, and fill up with looser soil, perhaps mixing in sand with the clay. Or, at least, exercise care in the use of water, not giving more than the soil can readily absorb. In general, avoid applying water while planting if the soil is fresh and moist, except towards the end of the operation, when, before filling in the last two inches or so, a deliberate dose may be applied and, after it is soaked in, the planting may be finished by firming the soil well with the foot and completing the filling of the hole with loose soil. Then a few stones, or light mulch, or other cover (see page I73) may be placed over the planting ground to keep it cool and moist. If dry weather follows, water and cultivate. If rainy weather follows, it may become desirable to remove the mulching in order to avoid choking.

While most trees and shrubs will stand watering all over with a sprinkler, and will be grateful for it, the broad-leared evergreens, like rhododendron, resent it, and their foliage is apt to "burn," turning brown.

If need be (according to size), the trees may be staked to keep them undisturbed from swaying winds, and to give the root system a chance to establish itself, taking care that the tree is attached to the support in such a manner as not to be injured by rubbing off the bark in the swaying of the wind. Many trees are lost by neglect in staking them, when by swaying, contact between soil and root is disturbed, and the latter dries out, or else is broken off.

When planting in fall, especially with smooth-barked trees liable to sun-scald, it may become desirable in exposed positions to protect the bark by a $\mathrm{V}^{\prime}$-shaped guard or a lath screen or a rope of straw, which prevents the drying out.

Such care in planting, as described, is not by any means always taken or always necessary to attain success. Under farorable conditions of soil or weather, with rigorous species 
or specimens, and especially with smaller-sized plant material, less care will still produce satisfactory results. The experienced tree planter will know how far under given conditions he may neglect the precautions. The forester who plants by the thousand or million cannot afford to observe all the rules, but then he does not expect to have all his trees live. Planting perhaps twenty-five to thirty per cent. more than he expects to start, and ten times as many as will survive until harvest time, and choosing young small plant material, he reduces the need of attention to the details. The planter of street and lawn trees, however, who desires each tree to live will be the more successful the closer he follows the details and the spirit of the ideal method described.

The question as to proper time for transplanting has been discussed ever since the age of the Greeks and Romans. Theoretically speaking, trees may be transplanted any day in the year, if the proper precautions are taken, but practically, it will be well to choose a time when the least care is needed, i.c., during the period when vegetation is at rest, fall, winter, or early spring.

Considerations of weather may influence the choice in different localities: in regions with well-marked spring and summer rains, spring is the best time; in regions with dry spring and rainy autumn, fall planting is indicated; misty or rainy days are, of course, most farorable, except possibly in compact clay soils.

Physiological reasons make it desirable to choose a time when, shortly after planting, root growth is most active. This consideration would indicate the fall as the most favorable season for deciduous trees, since with them root growth continues into the winter, and besides, the absence of transpiring foliage avoirls a drain of moisture such as is 


\section{Care in Planting Trees}

experienced in conifers. A cool, moist September calls for earlier, a dry and warm month for later planting, and if drouthy conditions continue, the planting is best deferred to the spring season.

The best time for conifers, which terminate root growth early in the fall, and retain their foliage during winter (with few exceptions like Larch, Bald Cypress, etc.), is shortly before vegetation starts anew in spring, the roots beginning their activity before the buds.

If planting in summer becomes necessary, this is best done after the period of rest in the root activity, which occurs in the driest month, varying with the seasons, but in general occurring in July to August. Some have advocated transplanting conifers preferably in August, but there is no special reason for this preference except the lull in the vegetative activity, and the weather conditions may often be the opposite of favorable at that season. It is successful when rainy weather follows.

Winter planting should be practised only when it is to be done with a ball of earth which can then be frozen, permitting transfer without disturbance of root system.

The frost-heaving which is apt to occur in high elevations and northern latitudes when trees are transplanted late in the fall can be prevented by placing sod or other mulching around the tree.

The size of the plant material influences the success of the planting more than is realized by many planters. The desire to secure a tree of good form and size is often better subserved by planting a small one and biding the time needed for its growth than planting at once a larger size. There are two reasons for surer success of smaller trees, namely, the fact that they can be more readily taken up without loss of root, and because the necessary care in their 
transportation and setting out is more casily applied, the small damage, if any, being more readily repaired. Yet, but for unforeseen accidents, if all the care is used which we have recommended, there is no reason why an experienced tree-planter should not make a success of every transplant as far as keeping it alive is concerned, esprecially if the trees are properly preparel for transplanting (see below). It must, however, not be overlooked that size means expense and only he who does not shirk the latter can make sure of success. Still, there are objections to transplanting very large trees, in that a considerable amount of cutting back must be done and it takes many years before the satisfactory form is reëstablished. Especially conifers, which, as a rule, do not admit much pruning, are best planted in small sizes unless they can be moved with a ball of earth. Yet the writer knows of a case of successful moving of a whole avenue of Norway spruce, thirty to forty feet in height, without such precaution.

As a rule, while for forest planting two- to five-year-old plants are preferred, the street planter will wish to set trees which have carried their crown above man-height or nearly so, and the lawn planter may also best remain within these limits. The transplanting of larger trees than eight to ten feet at most in height is a specialty which is better left to experienced hands. It requires time (two or three days), labor (eight to twelve men), and expense, which should not be lightly undertaken, especially as it is doubtful in result. It is best done with trees prepared for the operation.

Large trees- the writer has transplanted centenarian oaks succesfully - may be and should be preprared for the operation by digging a ditch, two or three feet wide, around the tree at a distance proportionate to its size, cutting through all the side roots, leaving the tap-root, if any, 


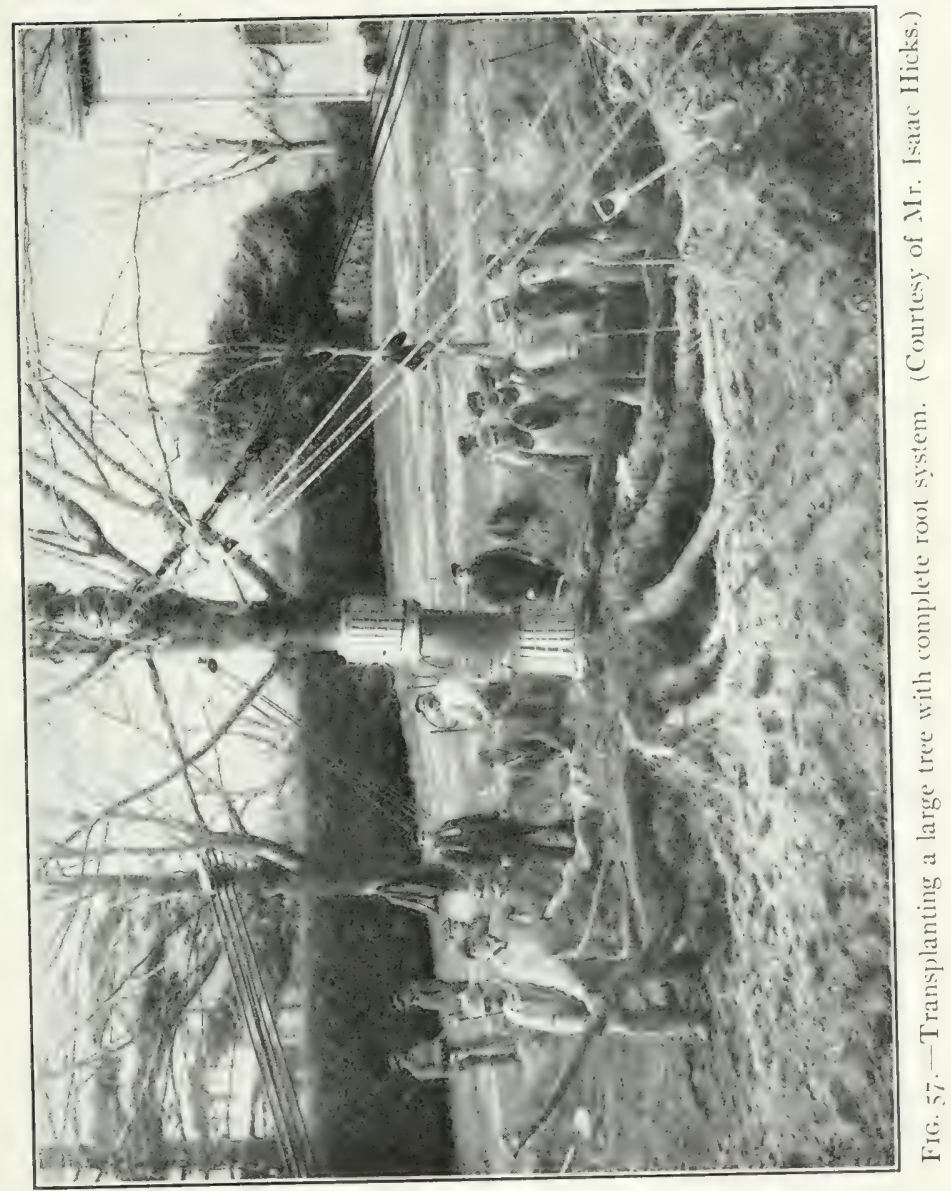


intact, filling the ditch with rich garden mold or loam, and keeping it well watered. At the same time the tree must be suitably braced, and proportionately cut back. New feeding roots will be established in the rich mold. Within a season or two the tree is ready for transplanting with a compact root system. It is then best taken up with a ball of earth, leaving the new roots undisturbed and, where practicable, freezing the ball of earth around them. In setting such trees, secure bracing is one of the main points, so as to avoid swaying by the winds.

It is sometimes possible to find large trees fit for transplanting under such conditions as to make the preparation just described unnecessary, and to permit taking up practically the entire natural root system, just as from a nursery bed, and to transplant with naked roots. But this requires still greater care, and since in moving very large trees a considerable amount of mechanical apparatus for safe transportation is required in order to prerent injuries, special wagons being patented for the purpose, this is altogether a piece of work to be entrusted to a specialist, although by keeping in mind tree physiology as explained, there is no difficulty in it. Increased care not to expose the roots to the air is required for conifers, and in these, success can only be expected with small size's, or with medium sizes when the roots can be kept in continuous soil envelope.

Alogether, the use of large trees is advisable only in rare cases; it is expensive and uncertain in results at best, although some experts seem to be more than usually successful. ${ }^{1}$

Perhaps a few words regarding spacing of trees, in addition to what has been said in regard to spacing of street

${ }^{1}$ See Isaac Hicks \& Son, Westbury Station, N. Y., and Peterson Nurs ery Co., Chicago, who make a specialty of transplanting large trees. 


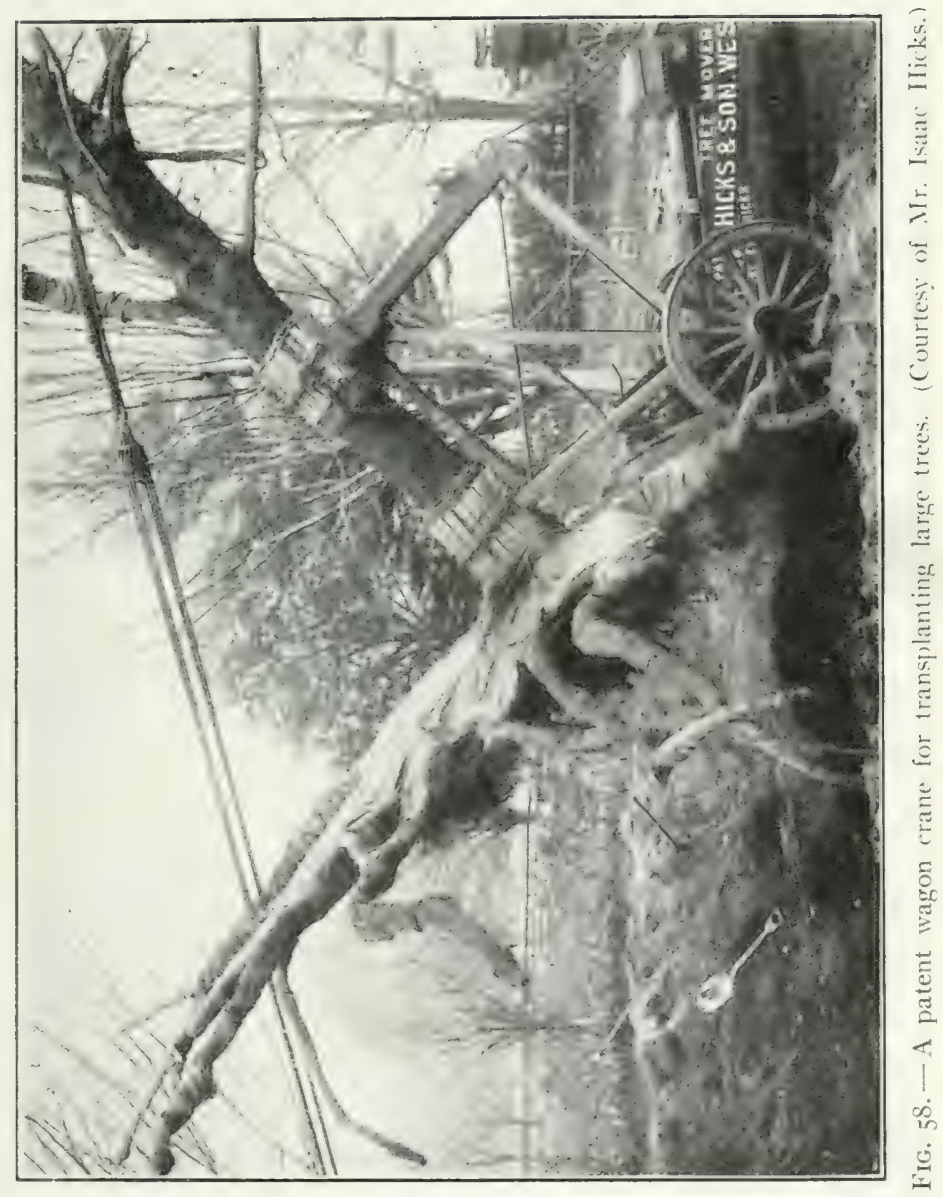




\section{I82 Care in Planting Trees}

trees, will not be amiss, for it is a difficult question, and rarely discussed with good reasons.

The object to be attained and the character of the plant material must form the basis for consideration. In forest growing, with small plant material, where the immediate object is as soon as possible to secure a close soil cover, and the ultimate object to secure branchless boles, the spacing is kept between three and six feet, rarely wider, whereby both objects are best secured, when of the 1,500 to 5,000 plants set out on an acre, not more than 250 to 350 are expected or allowed to live till harvest time.

In ornamental planting we have to consider also the immediate and the future effects, which, through the growth of the trees, change continually. The landscape gardener must foresee the ultimate relations into which the plant material will grow, the final sky line which it will produce, but if he planted solely with reference to that future, he would miss producing inmediate, or at least early, pleasing effects. Like the forester, therefore, he must plant more than is finally to remain. He deliberately designs to remove at the projer time sume of the trees which he has set out in order to produce effects before they have attained their full stature. The failure of the future manager of a park in applying the axe at the proper time has spoiled the artistic design of a Downing in the Smithsonian grounds in Washington, and is spoiling many other parks in this country, wherever a monkey love of trees on the part of the public has tied the hands of the manager and he dare not disturb the original planting.

There are two methods of "sing trees in ornamental planting, namely, either in groups, or in single specimens. Closer spacing is indicated in the former, wider spacing in the latter case. Where specimen trees are planted they should 


\section{Care in Planting Trees}

have ample space, so as to aroid all interference and give ample distance from disturbing effects. To gauge its proper space, the planter must be sumewhat familiar with the spreading habit of the species, which may vary from ten feet for many of the smaller conifers, to a hundred feet and more for the spreading oaks. The space between may then be filled out with temporary specimens, which must be remsel as son as they begin interfering with the favorite, or else with low shrubbery.

For streets and arenues, where not the single specimen, but a rull loosely connected is desired, a distance of at least thirty to forty feet will suffice for the majority of species that are usually planted, and leave enough space to permit free circulation of air and light. With low trees this may be reduced to lifteen to wenty feet. Contrary to orthodox belief, the writer would not hesitate for the salie of quicker shading efiect, to put temporary trees half way between the fermanent ones, even of a different species, to be removed when the latter require it. But, to be sure, the same lack of julicinus use of the axe at the proper time, as is usual in the parks, is apt to frustrate the results of such a plan.

When planting groups, where not the form of the single specimen, but the combination of foliage of different kind is sought, when a judicious combination of shade-enduring slow growers, and light-needing rajid growers is made, a distance varying between five and fifteen feet, and with low shrubbery even closer, will usually be found satisfactory.

The tendency is always to plant closer than desirable, nor is it objectionable, provided the planting is thinned out at the proper time by the use of the axe or by removing and transplanting undesirable or interfering parts. 


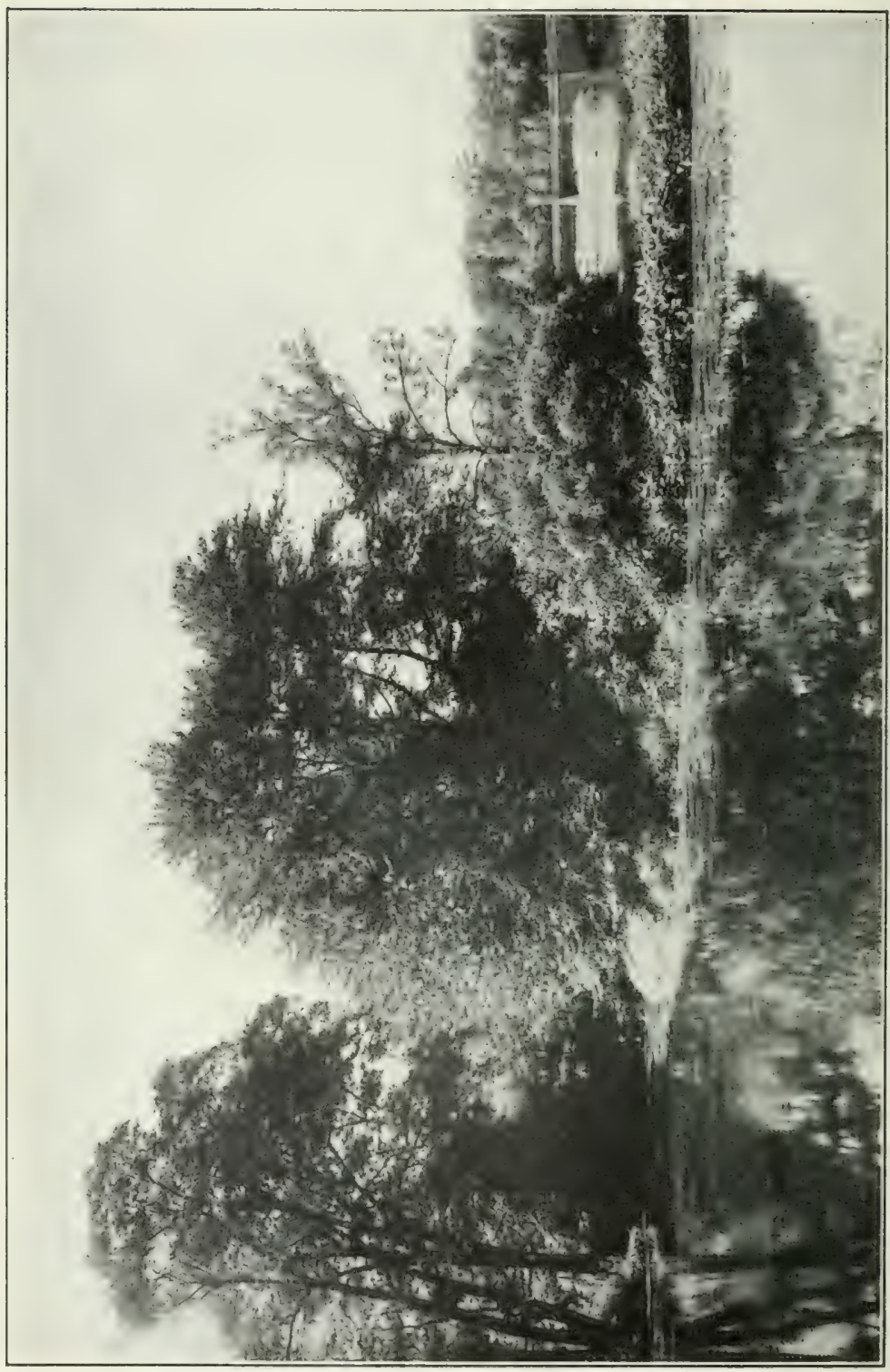

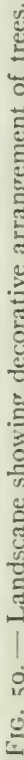




\section{CHAPTER VIII}

\section{ESTHETIC FORESTRY OR WOODLAND PARK MANAGEMENT ${ }^{1}$}

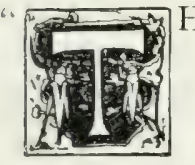

HE beautiful must be taken care of; the useful will take care of itself."

It is questionable whether this remark of Goethe's is as true to-day as it was in his time. It seems that we have entered upon a perior when the esthetic aspects of our surroundings occupy us almost to the extent to which the old Greeks were accustomed to develop them. At least, a momentum has been set up by the preachers of the beautiful which bids fair to carry us on in this direction with little effort.

Forestry as a useful occupation has struggled hard, if not as yet in vain, for recognition in this country; it is jurac tically still an unknown art, and now we are already discussing esthetic forestry. Forestry is, in the first place, not one of the esthetic arts, but an industrial art, the object of which is similar to that of agriculture; namely, the management of the soil for the production of wood crops. Yet the natural beauty, the sylvan charm and woodsy flavor of a forest, suggest readily the esthetic element which stimulates our artistic sense. Indeed, sylvan beauty is an "inevitable byproduct of the forest."

Even the forester, whose business it is to grow logs rather

1 Parts of this chapter were published before in Second Report of the American Park and Outdoor Art Association, 1898. 
than trees, whose idea of a forest is a mass of trees like a massed army, straight, tall, stripjed of all unnecessary branches, cannot close his eyes entirely to the beauties of the object of his industrial activity. Hence the foresters of Europe who manage forest properties mainly or merely for the money revenue that may be derived from the sale of timber have in many instances had an eye toward the utilization of the artistic elements at their disposal, at least in some corner of their districts.

In England, the artistic aspects of forestry have probably become more prominent than on the Continent, the rich landed proprictors holding their woodlands mainly for game preserves and pleasure grounds; their forest management becoming more and more park management. But it has been reserved for our people, even before industrial forestry has become an establisherl art, to set aside for park purposes immense woodland areas, where the practice of esthetic forestry is called for.

The various national parks belong to this class; into which has also fallen the forest preserve of the State of New York, aithough originally designed for quite a different purpose. The Metropolitan Park sistem of Boston also comprises large areas of native woodlands which it is intended to leave as such for pleasure purposes, so that we may speak of them as forests in which esthetic forestry is to be practised. Here perhaps for the first time we find a conscious attempt at making the esthetic sirle in forest areas paramount on a large scale.

In other large parks, like Central and Bronx Parks in New York, Forest Park in St. Louis, and Soldiers' Home in Washington, small areas of forest growth are left to natural development, or at least they are natural woodlands, intended so to remain as far as the park managers may permit. 
In the larger woodland parks, finally, such as the Adirondack Forest Preserve, the rational manner of carrying an esthetic forestry is, after all, that which the German forester practises in those places where a large community has ready access to his industrial forest, and uses it incidentally as a pleasure ground. He has regard to both the material and esthetic interests of the forest, managing it for wood-crops and revenue without overlooking the pleasure it may afford; making it accessible by wagon and foot, providing springs and shady nooks with rustic resting places, and combining, as architecture usually does, the beautiful with the useful.

The forester's road system may be none the less perfect from the purely utilitarian view because it meets the demands of art; the by-paths into the depths of sylvan recesses are not less useful because they may be made with due regard to pleasant windings and easy travel; the thrifty, young plantation will present aspects of beauty as well as of interest to the visitor not less delightful because of the frankly acknowledged purpose which it is finally to serve. Even the well-conducted logging operation will have its attraction to him who is not saddled with a monkey love of trees. Some of the picturesque effects of the crooked and gnarled specimens of oak and beech, the true forester will, to be sure, reduce to a minimum, but in the inspiring sublimity of lofty boles he will substitute other effects not less artistic because the utilitarian object is apparent. Finally, the beauty of a well-conducted forest management with its system and order in the forest, as well as in the books, will appeal to the thoughtful visitor and, if he finds that all this pleasure can be had for nothing, nay, with a financial benefit, by which his taxes are reduced, he will bless those esthetic idealists, who starting from an entircly opposite 
point of view have taught him to combine industrial and esthetic art, pleasure, and profit.

In the smaller woodland parks and woodland portions of city parks, such management is probably rarely practicable, hence not a forester but a park manager and landscape gardener is here in place.

A pleasure forest or park woodland is quite different from the usual pleasure park. Both the objects and the methods of treatment are different. The park is to give pleasure mainly by its artistic elements, the forest or woodland mainly by its natural elements; the park exhibits art with a superimposition of naturalness upon artificially created or preserved groups of trees; the pleasure forest relies upon its natural naturalness, with merely a helping hand toward artistic appearance.

Hence a let-alone policy is much more desirable in the forest than is possible to permit in the park. But, while the proper principle in the woodland park is to let Nature take its course, that does not mean that man should not interfere with Nature, for Nature is not always esthetic, she creates many things that are not beautiful, and leares undone many that man conceives as enhancing natural beauty, for Nature works without object, not even the object to please. Hence the axe and saw are constantly in demand, here to remove a stag-headed tree that has lost its beauty and interferes with a better progeny, or an old trunk that is not only ugly in its unsoundness, but breeds the enemies of the healthy; there a sprawling limb needs lopping, or even a healthy tree or group of trees must be invaded to free a rarer component of the forest which is being choked out by its sturdier competitors. There is no part of the park that really requires more judgment in its treatment than this natural woodland. 


\section{Esthetic Forestry}

While the well-meaning but poorly-informed tree-loring public improperly resents the interference with Nature, adrocating the extreme let-alone policy, the park manager may fall into the other extreme of trying to assist Nature too much. The mistake which otherwise good park managers are apt to make is that they transfer their conceptions which fit the tree on the lawn to the tree in the forest. The tree on the lawn, single or in groups, we admire for its symmetrical individual form, which is secured by preventing interference on the part of neighbors. In the forest it is not the indiridual, but the ensemble, that pleases. Thus the astmmetry of the whole is to be considered rather than the symmetrical development of the individual. Here the trees should be rather crowded so as to assume the type of the real forest-grown tree. Pruning to form would here be out of place and the orderliness of the formal park a hopeless mistake.

Nevertheless, improvement and assistance to Nature is by no means excluded, but here we must let Nature lead and only follow her up to correct her esthetic errors; while in the formal park the landscape gardener must be positive, here his art must be subordinate, confined almost entirely to negative measures.

Each forest in its virgin condition exhibits a different type according to its composition, and so each woodland l rark may differ and yet fulfil its function; in other words, no hard and fast rules as to its appearance can be laid down. If a bit of hemlock forest has luckily become part of the park, or a growth of pine or spruce, it would be poor taste to disturb their "purity" by introducing admixtures or undergrowth. In the very monotony of the dense conifer forest, with its tall clean symmetrical shafts of even development and its somber shade excluding all undergrowth lies 
its distinctive charm and grandeur. On the other hand, the hardwood forest with its variety of mixture demands variety of development in its component members and shrubbery in varied form. Between these two extremes all kinds of gradations are, of course, conceivable: the composition and age of the particular growth will justify more or less close approach to the one or the other type which the park manager should maintain.

There are at least three directions in which his judgment must be exercised; first, as to the location of the woodland park portions; if there be any choice, secondly, as to the outlines of these portions; and thirdly, as to the composition and interior form.

Usually, perhaps, when natural woodlands are included within park areas there is but little choice as to their location; it is preordained, and only when new plantings are to be made is such choice possible, except that the existing woodland can be altered in its aspects and extent.

Where the entire park is a natural woodland, it should be the aim to bring into it as much variety as the character of the forest type permits. Variety pleases, not uniformity. Dense thickets here suggest the depth and distance of the wild woods, and even in a small area make the size appear greater and extend its limits in imagination. A dense stand of clean boles without underbrush suggests the mystery of sylvan solitude; while a more open stand with a grassy floor invites one to a ramble among the trees leading to small openings of grassy glades, or, if possible, to a formal park with lawns and shapely single trees in groups. The treatment, of course, is somewhat dependent on the size of the whole, each separate type requiring certain proportions in order to be effective. Too much variety on a small area may become undesirable because unnatural. 
In a formal park, the dense parts are best disposed on the outskirts, which aids in increasing the feeling of distance and in excluding the outer world; but in larger parks an occasional belt of natural woodland within its borders adds to the "woodsiness" of the whole.

Where natural woodland is skirted by lawns or grassy glades, particular attention is to be paid to the character of the outlines. While there is not necessarily an objection to a straight division line between the two types, an uneven line is, as a rule, more pleasing. A change from the open glade into an open stand on a more or less straight line is indicated with a coniferous forest, which, if young, will have its boles beset with branches to the base, or, if older, with its straight, uniform trunks standing separate, will bring out the contrast between its dark recesses and the sunny outside. With the deciduous and mixed woods, undulating lines will usually be found more pleasing and, if possible, the undulations should generally be deep, jutting out with sharper angles into the open, with gentler roundings on the sinuate portions, the juttings out being of varying lengths.

These outlines should be kept as dense as possible with undergrowth in the projections; only in the sinuous parts should they be more or less open, inviting to their cool shade. The form of the outline should to some extent follow the contour of the land (unless it be flat), rounding hillocks, following up ravines, and encircling depressions. There is need of constant attention and use of the axe, to keep the outlines dense and in good form.

If any planting is to be done on the woodland border to effect the gradual change from the formal park or garden to the natural wood, great care should be used in the choice of material, especially avoiding violent contrasts and select- 
ing as far as possible species of native growth, or at least closely related to those which occur in the woodland itself, and such as are surely adapted to climate and soil. In studying the native flora, suggestions will readily come.

If the object is to fill out an open growth at the base, it is essential to plant only shade-enduring trees and shrubs, such as the Rhododendrons (e.g. R. accrifolium and alnifolium), Azaleas, Philadelphus, Daphne and Privet, and some of the Viburnums among the shrubs; and of trees the Yerr, Holly, Spindle-tree, Blue Beech, Ironwood, Dogwood, with such small trees as Service-tree, White and Black Thorn, and Mountain-ash. In front and in the more open places may be planted some of the more light-demanding shrubs.

Although the interior is to be left to Nature as far as possible, yet it requires the correcting hand of man in improving the composition. It goes without saying that decrepit and crippled specimens and all dead wood must be remored, for these are unsightly features; but occasionally malformations, such as a gnarly oak, or a low-topjed, spreading beech, may recommend themselves for retention on account of their picturesqueness.

We have to realize that constant change is the law of nature, and that therefore a natural woodland never remains as it is, any more than does a formal park; nor can we in any way aroid the change, although we can gire it direction by the timely use of the axe and possibly of the planting tool.

In a previous chapter it was pointed out that the different species of trees can be classified as to the amount of light they need or of shade which they can endure. In addition, we can also classify them according to the persistency of height growth and, to some extent, to the persistency of life. With such classification of the species which we find in our woodland, we can predict the likelihood of the 
permanency of our composition. We can make sure, for example, that the tolerant and persistent growers, such as the beech, the sugar maple, the holly, the hemlock, the firs and spruces, will be able to hold their own in the struggle for light and air-space; while such extremely light-needing and not persistent growers as the aspen, white birch, black locust, soft maple, will soon be crowded out; finally the lightneeding and yet persistent growers, like the Tulip tree, the oaks, the Yellow Birch, and the pines, if their heads are once above their neighbors, will be able to maintain themselves.

With such knowledge we can formulate the general policy, namely, to reduce more or less rapidly the short-lived, lightneeding species, which cannot maintain themselves in a mixture; and to keep the last-named species with their heads free and preferably in small groups, when the central ones at least will maintain themselves, those on the outside of the group succumbing gradually and being removed as dead wood. In this way these species have maintained themselves in the natural forest, otherwise the shade-endurers would occupy all the ground, where not prevented by unsuitable soil conditions. These latter alone will insure permanency and should in most cases form the bulk of the woods, for in addition to permanency they also furnish the best protection to the soil by their shade and abundant leaf fall.

There is one other feature influencing permanency which is often overlooked. Much of the woodland of hardwoods or deciduous trees which comes into park use is composed of coppice, i.e., sprouts from the stump, the trees having been cut again and again and being replaced by stool shoots, not seedlings. Such stool shoots are of the nature of branches from the original bole, and do not grow in the same manner as do trees which grow from seedlings. Although develop- 
ing very rapidly at the start, they cease in height growth much sooner than secdling trees. In addition, not only have the stumps usually been injured by careless axemen, but such woodlands have generally been burned over repeatedly, thus injuring the stumps by fire; as a result decay has set in, and it is difficult to find really healthy stumps. The sprouts may nevertheless grow up into quite respectable trees, but they are on an unstable basis and are shortlived. The woodland parks of the Boston Metropolitan park system are probably largely made up of such sproutlands.

The proper policy here is to gradually replace sprouts by seedlings, either favoring volunteer growth of the latter or deliberately securing them from natural seeding of the sprouts or by planting. In this planting, the light requirements of the species used must be carefully considered. Moreover, it must not be forgotten that the seedlings grow more slowly than the sprouts, which, therefore, are vigorous competitors and must be kept constantly in check until the

- planted specimens are well established and can take care of themselves.

In the selection of plant material, the possibility of new introductions is offered, but, while variety in composition leases, yet the choice must be made with circumspection, not only as regards the capacity of permanent maintenance, but of adequacy. "Beauty must be true, good, and adequate": the new introductions must be adapted to the locality, preferably indigenous or, at least, not entirely inharmonious with the main body of the woods, they must have elements of form or other qualities which make their introduction appear natural and desirable, and they must be adequate to the effect desired. If, for instance, coniferous growth is absent, some shade-enduring spruces, firs, or hem- 


\section{Esthetic Forestry}

locks may come in, singly and in groups, especially in glades and depressions, or, where an opening exists on an elevation, the light-needing pines and larches may find a place.

Whatever may be true in the formal pleasure park, in the pleasure forest it is not beautiful to plant all kinds of trees in all sorts of places, mercly for the sake of variety. The great charm of the pleasure forest lies in its naturalness.

We must insist again that naturalness is the object of the woodland park. Hence in thinning out we would not, as is recommended by some, cut with reference to the individual merit or beauty of the single tree, removing interfering trees to allow it to develop freely. On the contrary, except to prevent suppression of specially desirable species or individuals, natural adjustment should be allowed to take its course, the axe correcting rather than directing development.

Nevertheless, we want to have it well understood that "whether in woodland or plantation, the work of the axe is never completed; it is randalism to lay it away." The cutting must, however, be done under a well-conceived plan, with a knowledge of what its effect should be and will be.

It is usually best to select and mark in summer the trees to be cut, for then conditions of the leaf canopy --- the deciding feature - can be easily seen, but the actual work of removal is better left to the winter months, when it interferes least with the pleasure of visitors.

While orderly appearance makes necessary the removal of the fallen leaves from lawns, it is worse than waste of time to do this in the woodland park, unless necessitated by the warfare on some insect pest.

As regards the insect pests, it is evident that spraying is practically excluded, and hence collecting, mechanical destruction, or baiting are the only practical measures. 
So great a variety of conditions are possible in such woodland parks, that it is well-nigh impossible to give specific rules as to their management and only the general principles can be laid down, upon which with judgment the park manager must base his operations. 


\section{CHAPTER IX}

\section{CARE IN THE CHOICE OF PLANT MATERIAL}

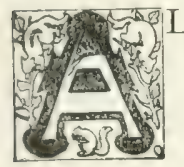

LTHOUGH this book is not designed to be a guide in the laying out and planting of grounds, it seemed nevertheless germane and desirable to add a chapter on the selection of plant material, inasmuch as the after-care is to some extent influenced by the original choice of trees. Nuch trouble can be avoided in caring for trees, if the right kinds of trees have been planted, since, as we have seen, the different species are more or less liable to damage by insect pests, fungi, and other injury, are more or less resistant, are more or less hardy, more or less adajtable to unfarorable situations, more or less easily kept in satisfactory form and condition.

To be sure, if we were to plant only those which are cntirely free from troubles, the list would be a small one, and the gratification of our tastes would be scanty. Yet one should at least know what to expect by going beyond this select list of the few species.

Looking through the following enumeration we shall find that, after all, a large number of species are practically free from trouble, if properly placed and tended. We must, however, realize what has been intimated in another chapter, namely, that insect pests and infections, i.e., fungus diseases, have an opportunity for spreading when the same host plant is multiplied. A city of elms, for example, is naturally apt to become a city of elm-beetles, the elm other- 
wise being no more subject to insect pests than many other species which are supposed to be immune, because the, opportunity for extraordinary multiplication of its enemies has not been given.

General Considerations. In addition to economic treeplanting for orchard and forestry purposes, which lie outside the scope of this book, there are three objects for which trees are planted, namely, shade, ornament, and botanical interest. The selection of plant material will in the first place be influenced by the prominence which one or the other of these objects may assume, and it will in addition be circumscribed by the situation and space at command. Different points of view will guide the selection for street and avenue planting, for planting in yards and small places, for planting on lawns in small or large parks, and for planting with special purposes in view, like the binding of shore or dunes.

In all cases, however, except where the botanical interest - i.e., the collection of specimen trees - is uppermost, the two paramount considerations are adaptation to climate and adaptation to soil.

While in street planting and in public parks, only trees of proven adajtability should be used, in other cases experiment is not excluded, although there should be at least a reasonable expectation of success to warrant the choice, which should be made with a knowledge of the points discussed in Chapter III, concerning the selection from localities of the most unfarorable climate in which the species is at home, or at least from a locality which compares most nearly to that to which the specimen is to be transferred.

As regards adaptation to soil, we must emphasize again that in most cases physical conditions, especially of watersupply, are of more moment than chemical composition; 


\section{General Considerations}

and that all species thrive best on one kind of soil (see page 24), but some can be grown under less favorable conditions; enduring, however, not preferring, as some would have it, drier or wetter situations and shallow soils.

IThile, for the start of the tree, the soil in the plant hole can be improved, it must not be forgotten that, in most cases, the tree must eventually grow into the native soil, in which it must be adapted to help itself. Especially is this true in regard to the depth. There exist, however, wrong notions as to the depth of soil needed: a soil of four to six feet is deep for most species, and if fissured rock underlies the surface soil at from two to three feet, the conditions are favorable enough for adaptive species, even with deep-going roots, the roots penetrating into the fissures which form good drainage channels. Only when impenetrable layers of rock or ground-water lie within two or three feet from the surface will species with tap-root or heart-root fail to thrive, eventually showing the effect in rapidly tapering and spindling form.

In streets, the natural deficiencies of the soil are further accentuated by such disturbances of water-supply as the impediment of parements, and the underground drain pipes, etc., under which conditions hardiness and adaptiveness as regards root development are naturally most essential.

We should here again lay stress upon the fact that there is a more or less close interrelation between soil and climate, and that the one can in part compensate for the other; that is to say, a poor soil (as regards water-supply) will accentuate the deficiencies of climate, while a deep, wellwatered, well-drained soil will make it possible for species to endure climatic ills to which they would succumb under less satisfactory soil conditions. Hence hardiness is, at least in part, dependent on soil.

Similarly, there may be provided some natural or artificial 
protection which may enable a specimen of a half-hardy species to endure adverse climatic conditions. And, finally, there is such a thing as individual hardiness, a given specimen enduring what the species in general may not be expected to survive.

Again, local variation of climatic conditions, due to aspect and protection against winds, is quite remarkable. Thus the north or the south slope, the top of a hill or a depression, often produces sufficient difference to enable a species to thrive in the one and not in the other limited locality; although the two may be only a few hundred yards apart.

IVe may not, therefore, draw valid conclusions from single observations, and the word "hardy" may only be understood in general terms.

For determination of the likelihood of hardiness, we have referrerl to a publication of the Canadian Experiment Farms, by Dr. Wm. Saunders, in which are given the results of long-continued tests of a very extensive list of trees and shrubs in the untoward climate of Ottawa, Manitoba, and the Northwestern Territories. ${ }^{1}$

Besides the two paramount considerations of climatic and soil-adaptation, the following points will enter into the selection of plant material.

I. Ornamental value; which depends upon outline, habit of growth, and final form of crown, as well as upon character, shape, arrangement, and color of foliage and bark, the autumnal tints to which it changes, and, although in a minor degree in trees, on flowers, fruit, and bark.

2. Shading value; which depends not only on the size, form, and density of the foliage, but also on leaf period, i.e., the earlier or later leafing-out and the earlier or later fall of foliage. 


\section{General Considerations}

3. Rate, persistence (longevity), and mode of growth, the branching being either spreading or upright; points which are of importance, especially in the grouping of trees and in the selection for certain special situations, such as small places, narrow streets, etc.

4. Relative water and light requirements are essential considerations in grouping trees; the latter quality especially in connection with the rate of height growth, fitting or unfitting them for grouping and underplanting.

5. Cleanliness of habit; a consideration which deserves attention especially in street-tree planting, where continuous shedding of foliage, flowers, fruit, or other parts littering the ground is undesirable.

6. Liability to insect pests; which is closely related to the requirements of cleanliness, and increases the need of care.

7. Liability to fungus and other diseases.

8. Endurance and recuperative powers; which enable the trees to repair damage readily and to respond to pruning and other restorative treatment.

9. Special requirements or habits which give additional point or else exclude the use of some trees in given situations. Such requirements or objects to be attained may consist in proper grouping, in fitting special locations of valley, slope, or hill as to foliage, color, or outline, in furnishing shelter, in withstanding special hardships, such as winds, untoward soil conditions, deleterious gases, etc.

In the choice of street trees in particular, endurance and recuperative power are most essential; cleanliness of habit coming next. Being planted for shade, the degree of such shade is a matter of consideration, and thus the length of leaf period forms an important part in this consideration.

Rapidity of growth usually means short life, hence where the planting is to be of permanent character, as in streets, 
fersistence rather than rapidity of growth should be looked for, keeping in mind that ultimate size must also be considered with reference to the width of the street.

With these points in mind we shall briefly examine the more common of our native species which lend themselves to ornamental planting, and such of the exotic, arborescent flora as have become thoroughly and generally established in our country; and finally give a few lists of species adapted to special situations and purposes.

There are in existence several thousand species, varieties, and forms of trees, and perhaps not less than two thousand are found cultivated in park.s and gardens, and of North American species alone nearly two hundred and fifty. But, if we confine ourselves to the consideration of the enumerated (nearly four hundred) species, we shall have at least included the best for general use.

As we have said, adaptation to climate is a conditio sine qua non. Hence, we limit the enumeration of species adapted to climatic conditions in the Eastern States, north and south. Nor can we enter into an extensive discussion of the ornamental value of our many species. In this respect we may only give a few general hints, referring the reader to such discussions of this phase of the subject as are found in books on Landscape Gardening.

A few general remarks regarding ornamental values and some other guiding points, which may accentuate essentials in this respect, and a few facts, known to the professional landscape gardener, but not often discussed in books, may well precede our enumeration.

Ornamental value is in the first place a matter of individual taste; but there are standards of taste which it is well to consult before setting up one's own standard.

Since the impression of beauty is largely produced by the 
appearance of appropriateness, the ornamental value of a tree must always be judged with reference to the place in which it stands or is to be put. Hence, a conifer whose beauty lies in the pyramidal, or rather conical crown with branches down to the base is not beautiful as a street tree, because its inappropriateness of form in such position is at once apparent; the copper beech, a beautiful object in itself, loses its ornamental value by being planted promiscuously and in large clumps; like all unusual things it is beautiful only in singleness when properly set off. Similarly the use of drooping trees, dwarfs, fastigiate forms, or of any peculiar colors or shapes in masses and set out promiscuously; or of antagonistic shapes in combination, destroys the ornamental value which any one, singly, might possess.

Hence, it is possible only to point out those characteristics in the development of species which furnish the basis for judging ornamental value; the individual situation or location being an essential point in such judgment.

Since in northern latitudes the deciduous-leaved trees are without foliage at least for half the year, the shape of the crown and the kind of bark should receive more consideration than is usually the case. Indeed, the skcleton of the branch system (made up of branches and twigs of varying number, length, thickness, position, and angle of insertion) imparts to the crown its typical aspect both in winter and summer, for the position and density of the foliage is dependent on the position and density of the branchlets.

We recognize in the first place the monopodial type, i.c., the one in which one main axis or hole persistently dominates the whole system into late life, the branches remaining relaatively inferior, as is usually the case with firs, spruces, pines, and other conifers, at least during their young periori, and with the Tulip-tree among the broad-leaf kinds; the dichopodial 
type, in which, as with the elm, a constant forking into equally strong branches takes place; and the polypodial or multifarious branching type, to which the majority of trees conform. But even this latter, apparently lawless type, has points of symmetry; it can be classified and the law of its development recognized. The number and distribution of long and short shoots, of stout and slender twigs and branches, arranged opposite or spirally, the straightness or crookedness of the single limbs, the angle of insertion, the erect, spreading or more or less pendent habit, are variously possessed by the different gencra and species, and account for the variety of tree crowns; while the relative development in length of the bole and branches give rise to the varying outlines: conical, globular, elliptical, umbrella-shape, vase-shape, and the unsymmetrical straggling outline.

But while we can recognize types to which the species on the whole conform, there is individual variety which removes single trees more or less from the types, and this fact of the variability in form and other characteristics must not be forgotten in selecting plant material.

Not only is there great inherited individual variety in trees of the same species, but the height growth, outline, and general form, size of foliage, and even color, are much more influenced by the soil in which the tree grows than is usually realized.

The great variation which we may observe in this respect in trees of the same species is sometimes so astonishing that we might be inclined to class them as different species. Seeing, therefore, a particularly pleasing form or color in one situation, we must not expect that the same effect may be duplicated in another quite different situation.

The same difference, although less striking, is observed in the leaf period. Not only general and local climatic con- 


\section{General Considerations}

ditions, but also local soil conditions will cause one tree to bud out earlier and retain its foliage longer than another tree of the same species. That the length of leaf period is a habit capable of inheritance is proved by the fact that sevcral of the exotics which are frequently planted have invariably a longer leaf period than native species of the same genus; the European elms, linden, and maples are examples.

Another very important point, also often overlooked, is that the form of crown changes from the young to the old tree: there is a beauty of youth and a beauty of maturity, while adolescence is often marked, as in man, by awkward and unsatisfactory looks. This is especially the case with conifers; for the change from the shapely conical young form to the broad stately umbrella-shape or the compactly globular or ascending rhomboidal form of old age, interposes a less pleasing, longer or shorter, intermediary stage. The description of the outline or form of a tree can therefore refer only to one period of its life, usually the mature stage.

In selecting rare species which nurserymen are apt to propagate by grafting on other stocks, it should not be overlooked that these stocks may produce undesirable results: a different rate of growth may cause bulging at the juncture, the lower trunk being either more rapid or less rapid than the graft in gaining diameter, or the foliage may revert to that of the mother stock, etc. Hence, in purchasing such grafted trees we must assure ourselves that experience has proved the stock upon which the graft is made as trustworthy.

The same disappointment which we may experience in the form development, by virtue of unsuitable soil conditions may, of course, extend to the shading value and to the rate of growth. The tree which in a rich soil developed a magnificent canopy of foliage will be scantily furnished in a 
dry soil, and its rate of growth will be in proportion to its feeding. Even the tolerance of sharle is relative to the supply of water. And as rigorous constitution fights off disease, so, insect pests and fungus diseases attack the least vigorous, and hence in the last analysis are to some extent in relation to soil conditions.

From what has been said, it stands to reason that all descriptions of form and statement of characteristics, unless more extended than can be given in this book, refer only to some stage of development and to typical trees and conditions, from which nature may deviate a hundred times.

\section{LIST OF TREES DESIRABLE FOR SHADE AND ORNAMENT}

While in office at Washington, the writer spent much of his leisure in becoming acquainted with the wealth of ornamental material planted in the small parks of the city (some four hundred species). He caused to be compiled plats of all the parks and small places, locating each tree by number, so that at a glance, by reference to a numbered list, it could be named. There was also compiled, under his direction and personal supervision, a description of the species with such notes of interest as the tree-lover and tree-planter would appreciate. The manuscript, nearly completed ten years ago, when the writer left oflice, has unfortunately remained locked up in the drawers of the Department with which he had been conn:ctect, and failed so far of publication. The writer mentions this incident merely to justify his presuming to give advice on the choice of ornamental trees.

The following list of nearly four hundred species and varieties does not in any sense pretend to be a complete enumeration of the trees which deserve attention, but it contains all 


\section{Trees for Shade and Ornament}

the best known and tested, and a few less known but commendable ones.

To become acquainted with such a large amount of material some kind of classification is desirable. Since, from the ornamental point of view, the character of the foliage is a more important consideration than the fruit (although the latter is used in botanical classification), it has seemed desirable to make it the basis for sequence in our enumeration.

The trees with needle-shaped leaves coincide with the botanical family of conifers, and we have grouped them under common generic or family names in alphabetical sequence.

The broad-leaf trees could be grouped, from the ornamental point of view, under trees with simple leaves, and those with compound leaves, and each of these two groups might be again, with less precision, grouped into large-leaved and small-leaved trees. Size, to be sure, can only be a relative measure, in a general way accentuating the relative leaf-value of the different groups, and the impression of coarser or finer effects of foliage. Since, however, many genera contain species with large and small leaves, which would require that they be separated and much of the information duplicated, we have preferred to restrict the classification into those with compound and those with simple leares and give under each a list in alphabetical order of the genera by Latin names with cross references from the common names; discussing under the genus points of similarity in ornamental value, the characteristics and requirements which are in common; and giving under the species only the distinctive features.

The buyer of plant material from nurseries will find great variation in the names given to various trees in different catalogues; indeed, even the botanists have not yet come to 


\section{Choice of Plant Material}

a stable nomenclature. We have tried to give the latest accepted Latin name, and, if there are sereral the one which has been most generally employed hitherto is placerl in parenthesis.

The common names are also often confused, and one has to be careful in ordering stock to make sure what plant is meant, and that nume and plant are identical. This is rery important, since nurserymen's use of names varies greatly. The only sure means of settling the irlentity of the plant and name is to quote the Latin name with its authority, as is done in the list except for synonyms and varictices. For our native species we have relied chiefly on the nomenclature of Sargent's Manual, and Bulletin $\mathrm{r} 7$ of the Division of Forestry.

Beyond mere mention, we have not gone into the nurserymen's rarieties, which consist usually of a change in stature (dwarfs), of form (pendulous, fastigiate), of leaf form (cutleaved, crinkled), or leaf color (golden, red, sjotted), or color of flower. These can be selected from the catalogues, when such special forms are needed, the behavior of these forms being otherwise mostly like their parents, except that they are apt to be more tender, and that they will more or less readily revert to their type, if conditions are not favorable to preservation of the form.

In the notes, we have followed as nearly as possible the same sequence of points, and have tried to supply, in the briefest style, information such as the planter would ask. Descriptions of ornamental features are at best poor, and, to select material, one should have seen a sjecimen tree at the nursery or elsewhere (making sure of proper identification) in order to jurlge of its value for the purpose in hand.

Since nurserymen and others still confound trees and shrubs, classing among the latter small trees below an arbi- 


\section{Trees for Shade and Ornament}

trary size, we may repeat that the definition of a tree which the writer made many years ago, and which Professor Sargent adopted for his Silva has been followed. This recognizes as trees ail woody plants which grow in nature as a rule with a single stem, bearing a definite crown. Where, however, a genus furnishes shrub forms as well as trees, these have also been briefly referred to in the tree list.

The height of trees varies greatly according to conditions of growth, hence only an apjroximation to the usual maximum dimensions can be given. We designate as tall trees, those over 75 feet in height; medium size, from 25 to 75 feet; low, from to to 25 ; dwarfs, below ro feet.

For ready reference we give an alphabetical list of the genera and species enumerated, the numbers in parenthesis preceding the species-name coinciding with those of the species discussed in the following pages. Varieties are placed in parenthesis.

\section{A. CONIFERS. TREES IVITH NEEDLE-SHAPED LEAVES}

AbIes (23) amabilis, (24) grandis,

(25) magrifica, (26) nobilis, (27) balsamea, (28) Fraseri, (29) pectinata, (30) concolor, (3I) Nordmanniana, (32) Cephalonica, (32a Appollinis), (33) Pinsapo, (34) Cilicica, (35) Veitchii, (36) homolepis.

Cedrus (I) Atlantica, ( ( $a$, glauca), (Ib, fastigiata), (2) Libani, (3) Deodara.

Cephalotaxus (83) Fortunei. Chamaecyparis

(Retinispora)

(6) sphceroidea (thuyoides), (7) Lawsoniana, (8) Nootkcinsis, (9) obtusa, (10) pisifera, (гоа, plumosa), (זоb, squarrosa), (זоc, nana), (rod, pygmaa), (roe, aurea).

Cryptomeria (I7) Japonica.

Cunninghamia (22) Sinensis.

Cupressus (4) sempervirens, (4a fastigiata), (5) macrocarpa.

GingKo (37) biloba.

JUNIPERIS ( (6) Virginiana.

LARIX (43) decidua, (44) laricina (Americana), (45) occidentalis, (46) Lyallii, (47) leptolepis.

LIBOCEDRUS (I8) decurrens.

PiceA (7I) excelsa, (72) rubens

(73) alba, (74) pungens, (75) orientalis, (75a Kosteriana), (75b Parryana), (76) polita. 
Pinus (49) Strobus, (50) Lambertiana, (51) monticola, (52) Koraiensis, (53) Peuce, (54) excelsa, (55) Ayacahuite, (56) Cembra, (57) silvestris (57a, rigensis), (58) laricio (Austriaca), (59) brutia, (60) resinosa, (61) divaricata, (62) rigida, (63) pungens, (64) palustris, (65) echinata, (66) glabra, (67) ponderosa, (68) Pinaster, (69) mughus, (70) pumilio.

Podocarpus (84) alpina.

Pseudolarix (48) Krempferi.

Pseudotsuga (42) taxifolia (Douglasii), (42 bis) macrocarpa.

\section{B. BROAD-LEAF TREES WITH COMPOUND LEAVES}

Acacia (9x) decurrens, (92) pubescens, (93) Julibrissin.

Esculus (94) Hippocastanum, (95) Pavia (rubra), (96)glabra, (97) octandra (flava), (98) parviflora (macrostacliya).

Arlanthus (99) glandulosa.

Aralia (IOO) spinosa, (IOI) $J a$ ponica (Sieboldii).

Caragana ( $\mathrm{IO} 2$ arborescens, (Iо3) spinosa, ( $\mathrm{IO}_{3}$ bis) frutescens.

Cladrastis (IO4) inctoria (Virgilia lutea).

Cytisus see Laburnum.

Fraxinus (I05) Americana, (ro6) nigra (sambucifolia), (I07) lanceolata (viridis), (108) quad-
Retinispora see ChamaecyPARIS.

Salisburea see Gingko.

SEquora (20) sempervirens, (2I) gigantea.

Taxodium (I9) distichum.

TAxus (77) baccata, (78) cuspidata, (79) Canadensis.

Thuja (II) occidentalis, (I2) gigantea, (I3) Japonica, (I4) orientalis.

ThuYopsis (I5) dolobrata.

Torreya (80) Californica, (8I) taxifolia, (82) nucifera.

Tsuga (38) Canadensis, (39) Caroliniana, (40) Mertensiana, (4I) Hookeriana (Pattoniana). rangulata, (IO9) excelsior, (I IO) ormus.

- Gleditschia (89) triacanthos, (90) inermis.

Gymnocladus (III) Canadensis.

Hicoria (II2) minima (amara), (I 13) Pecan (olivaformis), (I I4) ovata alba, (I I5) laciniosa (sulcata), (гі6) alba (tomentosa), (I07) myristicaformis.

JUGlans (II8) nigra, (IIg) cinerea, (I20) ruprestris, (I2I) regia, (I2 I bis) Sieboldiana.

KOElREUTERIA (I22) paniculata.

LABURNuir (I23) vulgare (Cytisus).

Melia (124) Azedarach. 


\section{Trees for Shade and Ornament}

RHUS (125) hirta (typhina), (126) copallina, (127) Cotinus, (128) glabra, (128a, laciniata), (I29) semialata Osbekii.

Robrnia (85) pseudacacia, (86) inermis, (87) viscosa, (88) hispida.

\section{BROAD-LEAF TREES WITH SIMPLE LEAVES}

ACER (I37) saccharum (sacharinum), ( ( 38 ) nigrum, ( I39) Floridanum, (I 40) rubrum, (I4I), sacharimum (dasycarpum), (г4ia, Weiri), (г42) Pennsylvanicum, (I43) spicatum, (I44) Negundo, (145) macrophyllum, (I46) platanoides, (147) psendoplatanus, (I48) campestre, (I49) monsspessulanum,(I50) Ginnala (Tartaricum), (150a, laciniata), (I5I) Schwedleri, (152) Reitenbachi, (I53) Worlei, (I54) crispum, (155) Japonicum, (156) polymorphum (palmatum), (I56a, atropurpureum dissectum), ( $56 b$, sanguineum), ( $5_{5}^{6 c}$, roseopictum).

Alnus (157) glutinosa, (I57a, imperialis), (I58) cordifolia (cordata), (I59) rugosa (serrulata), (г60) incana, (г6г) viridis, (I62) maritima.

Amelanchuer ( $6_{3}$ ) Canadensis, (I64) alnifolia, (165) Asiatica (Japonica).

ANDROMEDA see OXYDENDRON.

Betula (i66) alba, (i66a, atropurpurea), (I67) populifolia,
SopHORA (г 30 ) Japonica, (г zоa, pendula), (I3I) platycarpa, (I32) secundiflora.

Sorbus (I33) Americana, (I34) aucuparia, (135) Aria, (136) torminalis.

Virgilia, see Cladrastis.

(I68) papyrifera, (I69) lutea, (i 7o) lenta.

Buxus (I 7I) sempervirens, ( I $7 \mathrm{I} a$, suffruticosa), (I II b, aurea), I $7 \mathrm{I} C$, argentea), (I $\mathrm{I} d$, angustifolia), ( I 72$)$ Balearica.

Carpinus (I75) Caroliniana, ( I76) Belulus, (I77) Japonica.

Castanea ( ( 78 ) Americana (dentata), (I79) sativa, (I80) pumila.

Castanopsis (I8I) chrysophylla.

Catalpa (I82) cordifolia (speciosa), (I82) bignonioides, ( 183 ) ovata (Kampferi), (184) Bungei.

Celtis (I85) occidentalis, (186) Bungeana (Sinensis).

Cercidiphyllua (i87) Japon. icum.

Cercis (I88) Canadensis, (I89) siliquastrum, (I9o) Sinensis (Japonica).

Chionanthus (igi) Virginica.

Connus (I92) florida, (i92a, rubra), (I93) alternifolia, (194) amomum (sericea), (195) sanguinea, (I96) stolonifera, (197) circinata, (198) Mas, (199) alba (tatarica, sibirica), (I99a, Si- 
berica variegata), (199b, Spathi), (200) Honda.

Crategus (201) Crus-galli, (202) coccinea, (202a, macracantha), (203) mollis, (204) pyracantha, (Pyracantha coccinea), (205) Oxyacantha, (206) sanguinea, (207) monogyna, (207a, Pauli). Drospyrus (208) Virginiana, (209) Kaki.

FAGUS (210) ferruginea (Americana), (2II) silvatica, (2IIa, purpurea), (2І1 b, heterophylla), (2IIc, quercoides).

ILEX (2I2) opaca, (2I3) aquifolium, (2I4) latifolia, (215) crenata, (2I6) vomitoria, (2I7) verticillata, (218) monticola, (219) lavigata, (220) glabra, (22I) decidua, (222) Cassine.

Liquidairbar (223) styraciflua.

LiRIODENDRON (224) tulipifera.

Magnolia (225) fietida (grandiflora), (226) macrophylla, (227) tripetala, (228) glauca, (229) acuminata, (230) Yulan (conspicua), (23I) obovata (purpurea), (23І $a$, gracilis), (232) parviflora, (232a, Watsoni), (233) stellata (Halleana), (234) Kobus, (235) hypoleuca, (236) Soulangeana, (236) speciosa, (237) Alexandrina.

MoRus (238) rubra, (239) nigra, (240) alba.

Nyssa (24I) sylvatica, (242) uniflora.

Olea see Osalanthus.

Osmanthus (243) Americanus,
(244) aquifolium, (244a, ilicifolium), (245) fragrans, (Olea fragrans).

OSTRYA (245 bis) virginica, (246) vulgaris.

OXYDENDRON (247) arborea (Andromeda).

Paulownia (248) imperialis.

Pirus (249) Malus, (250) coronaria, (25I) spectabilis, (252) Ioensis Bechtel, (253) baccata, (254) prunifolia, (225) floribunda, (255a, Parkmanii), (256) Toringo, (257) Sinensis (Japonica), (257a, Moorlosi), (257b, macrocarpa), (257c, roseo flore pleno), (257d, grandiflora), (257e, nivalis), (257f, simplex), (257g, foliis rubris), (257h, Niedzivetzkyana), (258) Maulei.

Platanus (259) occidentalis, (260) orientalis, (26I) Wrightii, (262) cuneata, (263) acerifolia.

Populus (264) deltoidea (monolifera, Canadensis), (265) balsamifera, (266) dilatata, (267) alba, (268) tremuloides, (269) grandidentata, (270) laurifolia, (270a, certinensis), (27ob, Bereolensis), (270c, Petrovski), (270 bis) Rasumofskiana.

Prunus (Cerasus) (27I) PseudoCerasus hortensis, (272) Japonica (Sinensis), (273) Pissardii cericifera atropurpurea, (274) Amygdalus, (275) Persica, (276) Armeniaca, (277) Mume, (278) spinosa, (279) angustifolia (Chicasa), (280) maritima, (28r) 


\section{Conifers}

serotina, (282) Padus, (283) Pennsyvlanica, (284). Mahaleb. Quercus (285) alba, (286) macrocarpa, $(287)$ lyrata, (288) stellata (obtusiloba, minor), (289) Primus (montana), (290) Michauxi, (291) Muhlenbergi, (292) velutina (tinctoria), (293) mibra, (294) coccinea, (295) palustris, (296) cuneata (digitata, falcata), (297) Phellos, (298) imbricaria, (299) nigra, (300) Virginiana (virens), (301) chrysolepis, (302) ilicifolia Banisteri, nana), (303) prinoides (humilis), (304) Robur (pedunculata, sessiliflora), (304a, filicifolia), (304b, purpurascens, atropurpurea), (304C, pendula), (304d, fastigiata), (3०5) Cerris, (306) conferta (Pannonica).

Rhasinus (307) Purshiana, (308) Caroliniana, (309) alnifolia, (3I0) cathartica, (3Ix) Frangula, (3І1 $a$, asplenifolia).

Salix (3I2) Babylonica, (3І3) alba, (3 3 3a, regalis), (3I4) vitellina aurea, (3I5) fragilis, (316) candida, (3I 7) purpurea, (318) decipiens, (319) nigra, (320) hirta, (32I) Voronesh, (322) caprea pendula, (322 bis) Niobe, (323) discolor, (324) lucida, (325) incana, (326) rosmarinifolia, (327) argyrocarpa, (328) pentandra (laurifolia).

SASSAFRAS (329) officinale (Sassafras).

TAMARIX (330) parviflora (Africana), (33I) Germanica, (332) Gallica, (333) Indica.

Tilia (334) Americana (335) Europaa, (336) pubescens, (337) heterophylla, (338) argentea. (338 bis) dasystyla (euchlora).

Toxylon (339) pomiferum (Maclura aurantiaca).

Ulirus (340) Americana, (34I) campestris, (341a, suberosa), (342) fulva, (343) alata, (344) racemosa, (345) scabra, (345a, pendula), (346) parvifolia.

\section{A. CONIFERS}

The ornamental value of the conifers consists in their evergreen habit - for all except the Larch, Golden Larch, Bald Cypress, and Gingko retain their leares throughout the winter. They are highly ornamental in their interesting, usually somber foliage of gray to dark green shades; in their symmetrical, conical form during the early period of their life, with a branch system persisting at the base for a long time; in the dignity of the straight, cylindrical trunk 


\section{I 4

and high towering, variously-shaped crown in later life; and in the picturespue and rugged beauty of the old and timeworn trees. Although they lack the interesting seasonal changes of the deciduous trees, the persistence of their foliage makes them especially effective for enlivening winter scenery, and for shelter. Special care is, howerer, necessary in the proper use and location of this family.

On account of their shape, mole of growth, and relative inability to repair damage, they are not fit for street trees; but broad avenues with wide parking may be made attractive by widely spaced spruces or firs (not in rows!). Their best use is in single specimens, or in small groups, to accentuate an elevation, or a boundary; or in masses for distant backgrounds, where they enliven the sky-line; or, in mixture with deciduous trees, in the woodland portion of the parks, when small groups fading out into a few scattered ones should be used; also in single specimens on a lawn, but not too frequently; finally, for the botanical interest in a "pinetum." As a rule, they fit better into country places than into city parks, especially small ones, where they should be used sparingly and with great circumspection, since they are apt to suffer and become unsightly, especially during the transition period from youth to old age. Nost of them being somber, they should not be placed near houses, but rather at a distance against a livelier background, using those with the most vivid shades of green srouped with the deciduous dark shades behind, or the dark shades massed, with bright-berried and bright-foliaged trees and shrubs in front.

Generally speaking, conifers prefer light sandy welldrained soils and, with a few exceptions, they are unsuitable for limestone soil. Their form especially depends on depth of soil. Pines belong preferably in well-drained sandy 
soils, and are very light-needing; spruces, being shallowrooted, and able to endure only medium shade, require moist, not too light soils, and cool situations; firs, being most tolerant of shade, must have deep and well-watered soil, and can endure a compact one. The last two mentioned groups, being mostly of alpine or mountainous range, must as a rule have specially satisfactory soil conditions (depth and moisture), in order to stand our drouthy atmosphere. But few are adapted to sca-coast condition, or can endure city smoke.

Many species are remarkably immune from diseases if placed in proper soils; poorly drained soils, however, being apt to give rise to physiological and fungus diseases. Only in forests, where large numbers of the same species invite multiplication of insects, is there much trouble to be anticipated from these pests. In their youth some of the species are liable to be damaged by, or to succumb to, frosts and drouth and since they rely on two to ten years' foliage, which must be replaced, if lost, the recuperation of injured parts is often difficult and slow.

\section{CEDARS AND CYPRESSES}

Under these names, which have been promiscuously applied to members of this group, we can combine several genera of trees which are botanically allied and have also much in common as regards aspect, form, and behavior. They are characterized by an upright habit of branches, a shingle-like arrangement of small, scale-like leaves (excepting Cedrus, Taxodium, and Sequoia), and often by a close stringy bark. Having mostly a full supply of foliage, at least when young, they are effective in large plantings as accent trees, also in formal plantings as individual specimens.

They are represented in nine genera, namely, Cedrus, Cupressus, Chamacyparis (including Retinispora), Libocedrus, Juniperus, Thuja (including Biota), Thuyopsis, Sequoia, Taxodium. Most of them, especially Chamacyparis, Juniperus and Thuja, have characteristic 


\section{I6 Trees for Shade and Ornament}

juvenile forms of foliage, which give rise to many different varieties of form.

They are especially free from insect pests, and are usually arlaptive as regards soil, light-needing or only moderately tolerant of shade, and easily handled.

Cedrus. The true Cedars are large trees, from Africa, Asia Minor, and India, and hence fit mainly for southern climates; very distinct and

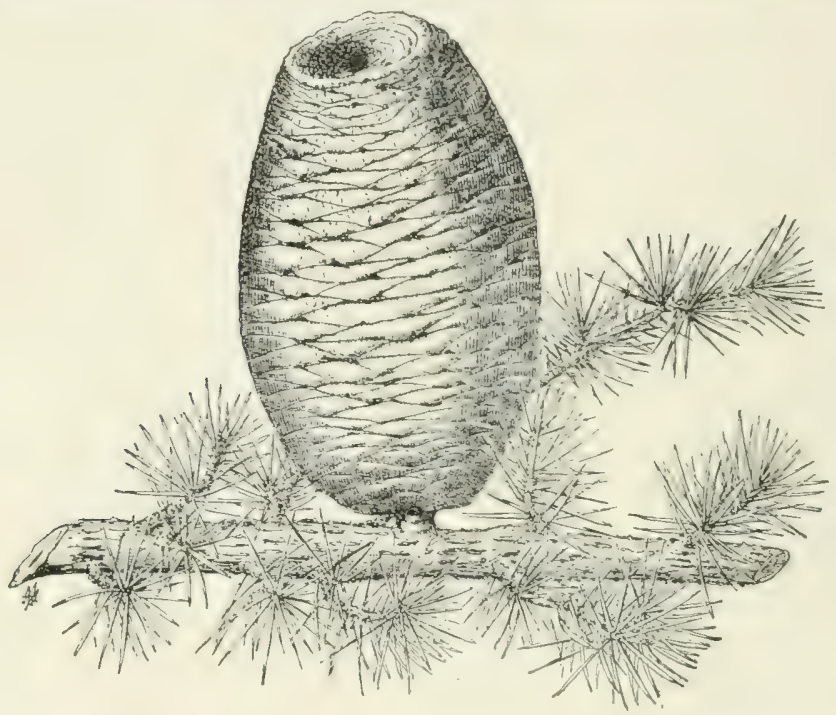

Fig. 60. - Cedar of Lebanon. Cedrus Libani Barr.

picturesque in form, with a stately, wide-spreading habit, and rigid foliage in fascicles, with ponderous, erect cones. They need welldrained soil, and are subject to no special troubles. To be used mainly for specimen trees. Mainly for southern planting.

C. Atlantica Manetti. (1), Silier Cetar, the hardiest, may, if sheltered, be grown as far north as New lork. It is of pyramidal form. There is a variety, _ glauca ( $\mathrm{I} a$ ) (blue), the most desirable form, with a fine silvery-hued foliage; and a columnar variety - - fastigiata ( $\mathrm{I} b$ ).

C. Libani Barr. (2), the true Codar of Lebmon, is of broad spreading habit (flattening its crown with age) and bright, bluish-green foliage. 


\section{Cedars and Cypresses}

C. Deodara Loud. (3), Deodar Cedar, an admirable tree from India, of pyramidal form, with somewhat pendulous branch tips, with dark bluish-green, very long ( 2 inches) rigid needles, of rapid growth, is a light, airy, graceful, lawn tree.

Cupressus. The true Cypress. This genus of medium to small trees, usually less symmetrical than the firs and spruces, and, with their slender branchlets, more graceful, contains some ten species of semi-

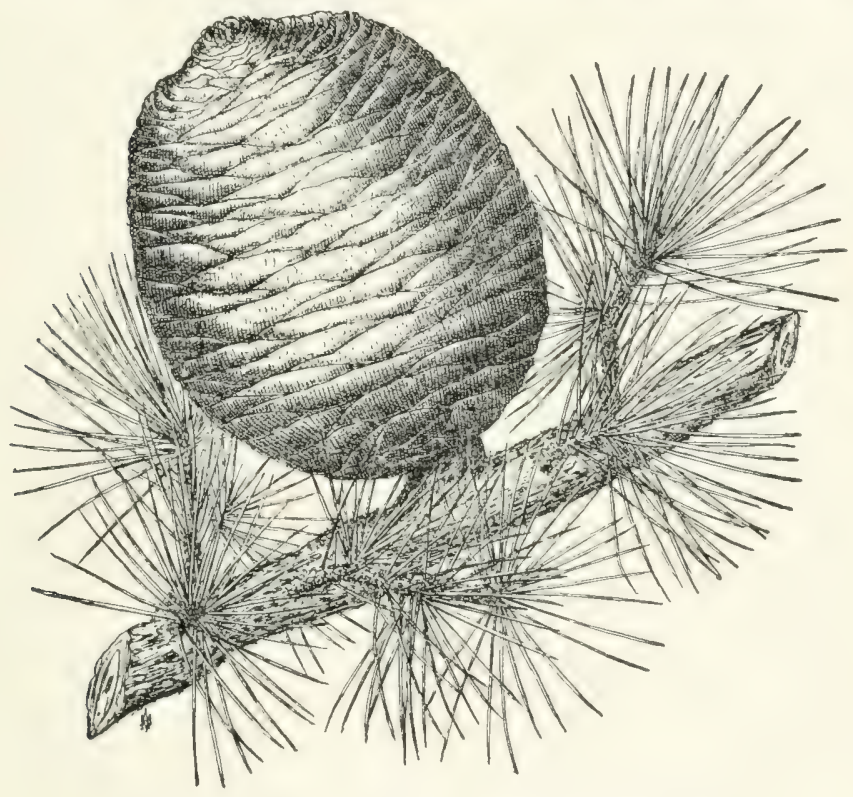

Fig. 6r. - Deodar Cedar. Cedrus Deodara Loud.

tropical distribution, hence they are only fit for southern climates, and deep, sandy loam.

C. sempervirens Linn. (4), the best known, European; and especially the columnar variety, fastigiata $(4 a)$, is used much in cemeteries, being somber with its dark green foliage and erect form.

C. macrocarpa Hartw. (5), (large-fruited), the well-known IIonterey Cypress, much planted in California, resembles the common Juniper, but has more feathery foliage. It is specially fit for seacoast planting. 
Chamæcyparis. (By some classed with Cupressus, and some forms called Retinispora.) Cedar. A genus of medium size to tall, highly ornamental trees, with five species (but nearly one hundred nursery men's forms) which are characterized by the broad, flattened spray's of foliage, and pyramidal habit, with erect branches. The foliage is very variable, and changes with age; the young form, which largely gives rise to the many nursery forms (Retinispora, formerly called Retinospora) is lincar and sometimes sharp-pointed. These latter are especially fince in masses. With the exception of (6), which is native as far north as Maine, the other two species from the Pacific Coast and the Japanese forms, are only semi-hardy north of New York. Moist, sandy soil is generally preferable; they are somewhat shade-enduring.

C. spheroidea Spach. (thuyoides) (6), White Cedar, is especially well developed in New Jersey and southward along the coast; a mediumsized, graceful tree, of spreading habit, with light green foliage, resembling the Arborvitæ.

C. Lazesoniana Parl. (7), Lazeson's Cypress, from the northern $\mathrm{Pa}$ cific Coast, is the best known ornamental species, excelling in its graceful foliage and pendulous branch tips - an Arborvitæ foliage with IIemlock habit. It is extremely variable, giving rise to over sixty forms, with varieties in color and habit. It is best used as single specimen on the lawn and especially near water.

C. Nootkansis Spach. (8), the Alaska Yellow Cedar, is hardly yet introduced for ornamental planting, but claims attention.

C. obtusa $S$. \& $Z$. (9), and pisifera $S$. \& $Z$. (10), the two Japanese species, the former quite harfly, the latter less so, are better known in their varieties under the name of Retinispora - and dwarf forms, among which especially the feathery - plumosa (Ioa) and the silvery blue — squarrosa ( $\mathrm{IO} b$ ), excel in elegance; —— nana (dwarf) (Ioc), and pygmaa (pygmy) (rod) in low stature, with several brilliant - aurea ( $\mathrm{I} O \mathrm{C}$ ) (golden) varieties. They are fit for small places.

C. oblusa generally furnishes the potted Japanese dwarf trees.

Thuja or Thuya (including Biote), Irborzite, also called thite Cedar, are tall to medium size, rapid growing trees of regular, formal, conical habit with short, much ramified branches. Their formality is such that they may not be planted in masse's except as screens or windbreaks, or for hedges, for which they are well adapted, as they bear pruning well. They are especially effective near the border of water, 
or in single specimens on prominent points. They are arlapterl to a variety of soils and easily transplanted.

T. occidentalis Linn. (II) is our native northern Arbonite or White Cedar, a medium-sized tree, narrowly conical, with compact head, which furnishes a large number of useful nurserymen's varicties with variegated foliage, dwarf habit, etc. The foliage is pale green, becoming brownish in winter. It is fine for avenue planting and also makes a perfect hedge.

$T$. gigantea Nutt. (12), the Pacific Coast Giant Arborvita, reaches a height of over two hundred feet, grows very rapidly, and is most beautiful; the short, closely set, horizontal branches are pendulous at the tip. Coming from a moist, mild climate, it can be used only for southern planting, unless the seed is brought from Montana.

The Japanese T. Japonica Maxim. (I 3 ), semi-hardy in the north, and the Persian $T$. orientalis Linn. (14), fit only for southern ranges, offer hardly any superior points.

Thuyopsis. $T$. dolobrita nana S. \& Z. (I 5), Tom Thumb,

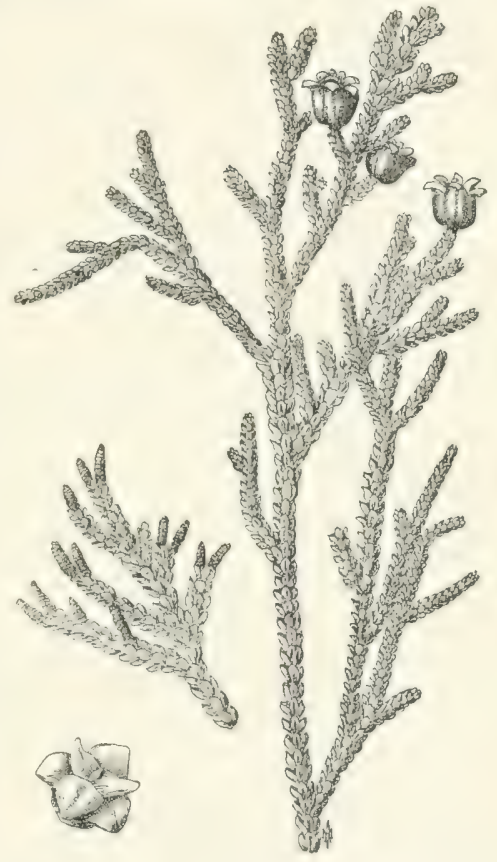

FIG. 62. - Tom Thumb or Japanese Arborvitae. Thuyopsis dolobrata nana S. \& Z.

a Japanese Arborvitze of small stature, is one of the most beautiful of this group, semi-hardy as far north as Massachusetts.

Juniperus. Juniper or Red Cedar. This genus contains some thirtyfive species, mostly small trees, of pyramidal and even columnar form, and rather stiff habit, and slirubs, hence useful in small places, the low forms for rocky slopes, covering of sand banks, planting of lanes, windbreaks, screens, etc. They are less symmetrical than other conifers. They are, as a rule, adaptive to soil conditions, from sand to lime, from swami 
to dry, rocky, or gravelly hillsides, and among the best conifers for seaside planting, being easily transplanted. Although light-needing, they are well adapted for hedge work. 'They are free from insects, but suffer occasionally from a fungus on the branchlets (Juniper apple).

J. I'irginiana Linn. ( 16$)$, the native Pencil (edar, ranging from Canada to Florida, is of conical, but very variable outline, and some-

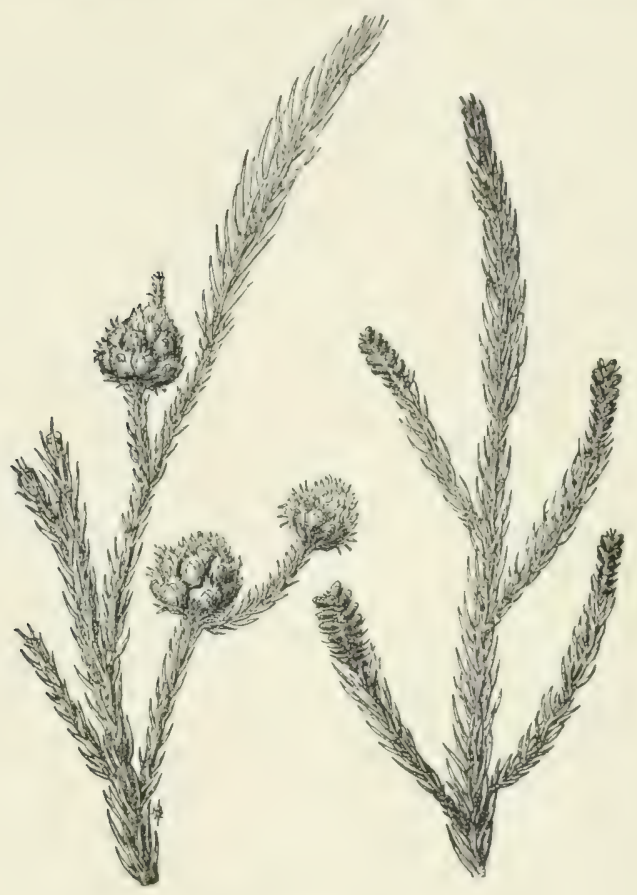

FIG. 63. - Cryptomeria Japonica Don.

what stiff branch habit, but often with slender pendulous branches; sometimes columnar, capable of being trained to any shape. The foliage, when young, is sharp pointed, later in appressed sprays similar to Arborvitæ, in winter sometimes turning dingy brown. It is adapted to dry, rocky soils as well as swamps, but thrives lest in well-drained, loose, not too rich, cool loam.

Cryptomeria. C. Japonica Don. (1 7), from China and Japan, is only 


\section{Cedars and Cypresses}

semi-hardy north of Philadelphia, unless compensater by soil conditions, but perfectly successful in Withington. It is the most important timber tree of Japan but has hardly any superior ornamental features.

Libocedrus. L. decurrens Torr. (IS), the Pacific Coast Arborite or Incense Cedur, is a large, rapid growing tree, for planting from New

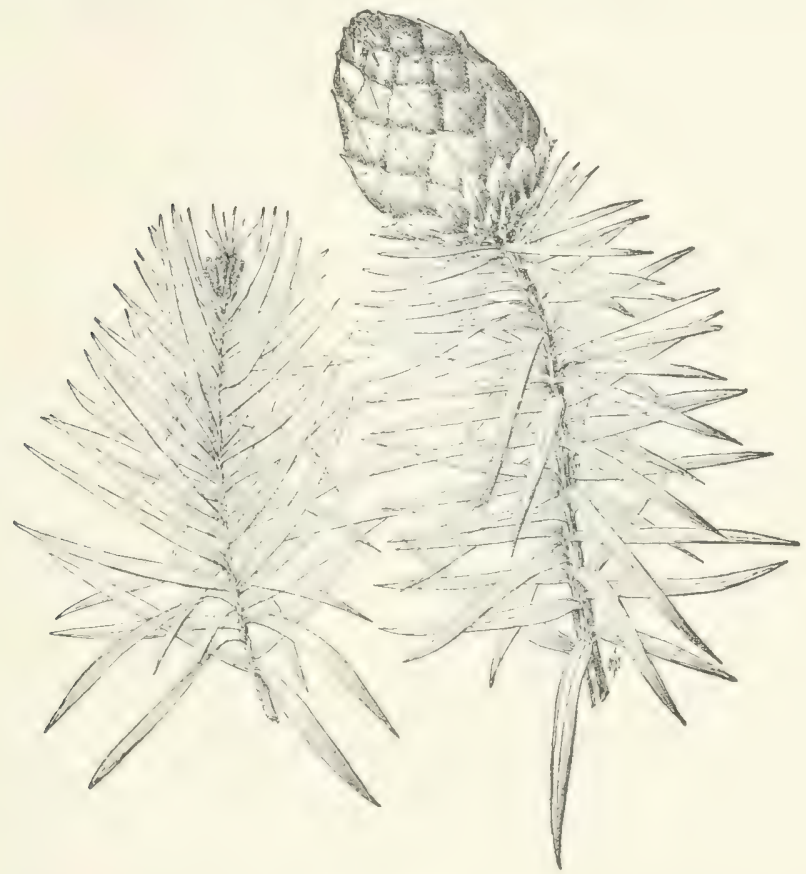

FIG. 64. - Cunninghamia Sinensis R. Br.

York south. It is one of the most ornamental conifers in its symmetrical narrow-conical form and its graceful, strikingly bright green, feathery foliage in frond-like sprays, placed radially. It requires welldrained soil, is intolerant of shacte, hence loses lower branches early. It is especially fit for formal planting, as in cemeteries.

Taxodium. T.distichum Rich. (Io), Bald Cypress, a deciduous conifer, tall, and of rapid growth under favorible conditions, is one of the most interesting and most attractive specimen trees, with its light green, 
most graceful, fathery foliage and spiry top. Nthough of southern origin, it is hardy as far as New England, and although a tree of the swamp, it is adaptive to many soil conditions, but thrives best in moist, sandy soil, although it will do well on drier situations, varying in form according to soil.

Sequoia. The two giant tree sfecies of this senus, differing widely from each other, but both exceedingly beatutiful and omamental, have in the Cnited States hardly yet been apprewated for their ornamental value: they are less planted here than in Europe, and less than they

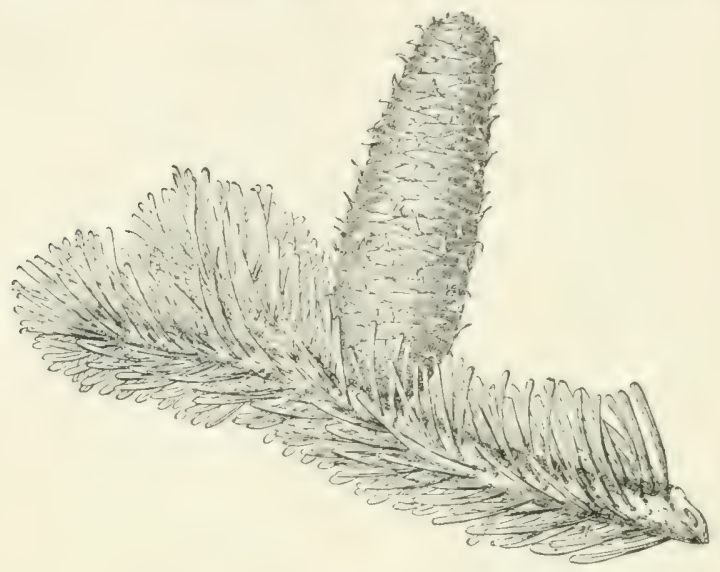

FIG. 65. - Abies Nordmanniana Spach.

deserve. Their climatic limits, to be sure, make success doubtful in the East, except in certain po-itions where in the soil compensation can be made for the drouthy climate, and also provided that the plant material is collected from the driest sites.

S. semperiirens Endl. (20), Retriood, the most beautiful of the two, is less hardy than the Big Trec, and requires a cool, humid atmosphere, for which even a deep, well-watered soil does not readily compensate.

S. gigantea Decne. (2I), the Big Tree, is hardier than the Redwood and has sustained itselt in Rochester, N. Y., for forty years, although now showing signs of sulfering. With a follage between the Cypress and the Arborvite, and a gracefully curved branch habit, it forms a beautiful lawn tree. It is not selective as to soil, except that the deep 


\section{Cedars and Cypresses}

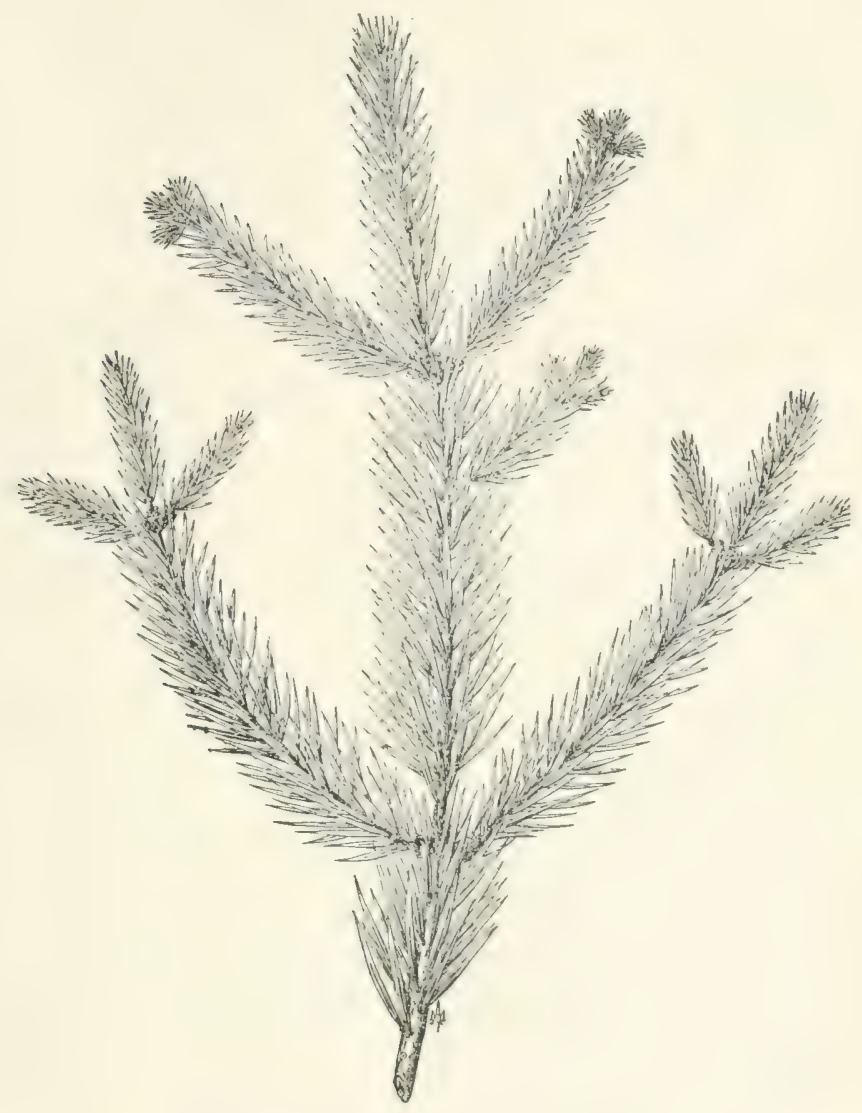

Fig. 66. - Abies Cephalonica Loud.

root system makes a deep soil preferable and early transplanting necessary.

Cunninghamia. C. Sinensis R. Br. (22), from China, fit only for the South, or in more northern latitudes with careful protection, is a medium-sized tree, rapid-growing, in form resembling the Araucaria or the firs, but the branches are more pendulous at the tips; the foliage is light green, shining above, whitish beneath, and sharp-pointed; shade enduring. 


\section{FIRS}

Abies (see also Picen, Spruce). This ganus contains some twentythree species from northem and monntainous habitats, requiring cool

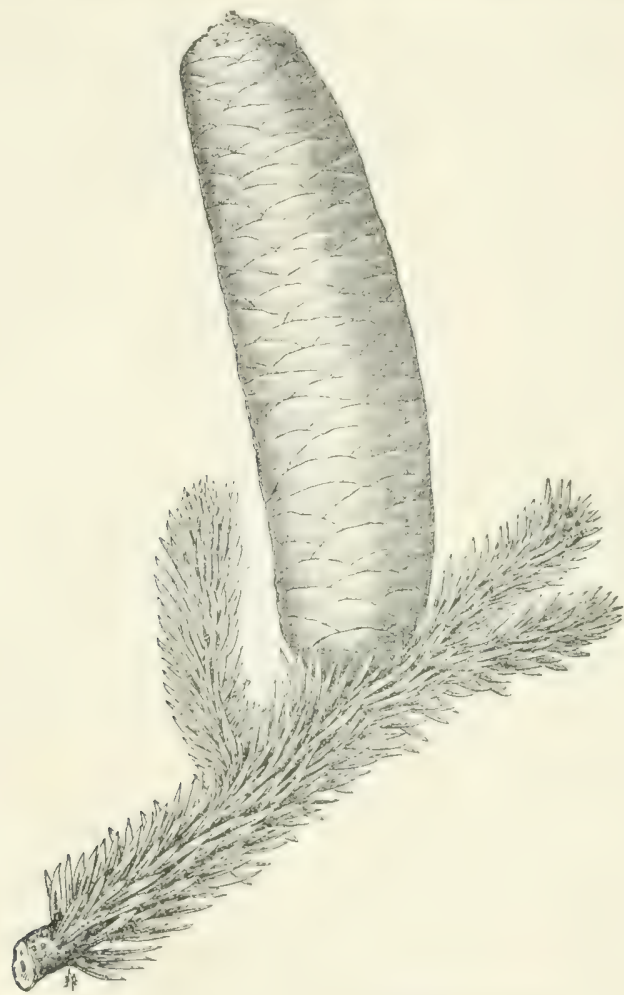

Fig. 67. - Abies Pinsapo Boiss.

positions for best stecest. They are mosty tall, shapely conical trees of symmetrical, stiii, and formal branch habit, but less so than the spruces; mostly with blunt-peinterl, llat leares, arranged comb-like; densely foliaged, the leaves persisting for seren to fwelre gears, cones standing erect, the scales lalling wif when mature. 'They are usually of slow but persistent growth, and highly haule-enduring. Moist, 


\section{Firs}

deep soil is required, since the firs are deep-rooted and come generally from humid rlimates (mountains) or swamps. They are little infested by insects, but are apt to suffer from drought and frost, also from fungi.

The fine Pacific Coast specics, A. amabilis (23), grandis (24), mag. nifica (25), nobilis (26), are unfortunately not hardy in the East. The eastern $A$. balsamea (27) and A. Fraseri (28), and the European $A$. pectinata (29), lack desirable ornamental value in comparison with other firs.

A. concolor Lind. \& Gord. (3o), if selected from Colorado and not from the Pacific Coast range, is perfectly hardy in the East, even in the spray of the sea. It is most ornamental, with its long, soft, gray-green needles and splendid form, is of rapid growth and without any troubles - the best fir for planting.

A. Nordmaniana Spach. (3I), from the Caucasus, is as hardy as the former, and, with its rich, lustrous, heavy foliage, dark green above, silvery underneath, the opposite in color of the former, and also one of the finest,

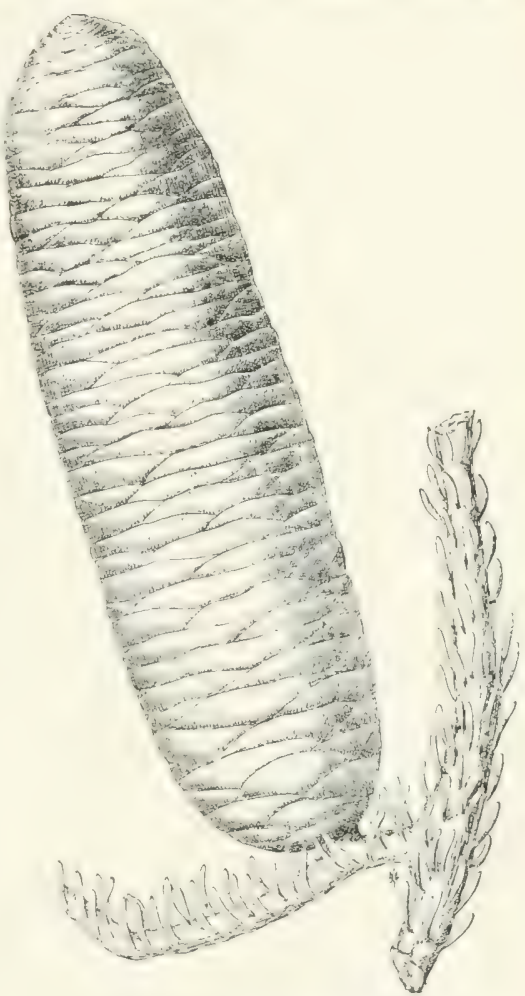

FIg. 68. - Abies Cilicica Carr. most dignified ornamentals, retaining its fine form long. It is free from troubles, and especially frost-hardy.

A. Cephalonica Loud. (32), and var. Apollinis (32a), from Greece, are more spreading in habit than the former two, and somewhat sprucelike in appearance. They are hardy south of New York and more adapted for southern planting than most firs. 
A. Pinsapo Boiss. (3.3), from Sinain, is a small tree for southem planting, merely as a specimen tree for the interest of its jeculiar, rigid, sharp-pointed, thick foliaere, set around its branches and shoots, griving it a stiff uniegue appearance, entirely different from all other firs.

1. Cilicica Carr. (34), from Asia Minor, is hardy on the whole, but liable to damage by frost; a small tree with foliage dark green above, silvery white below.

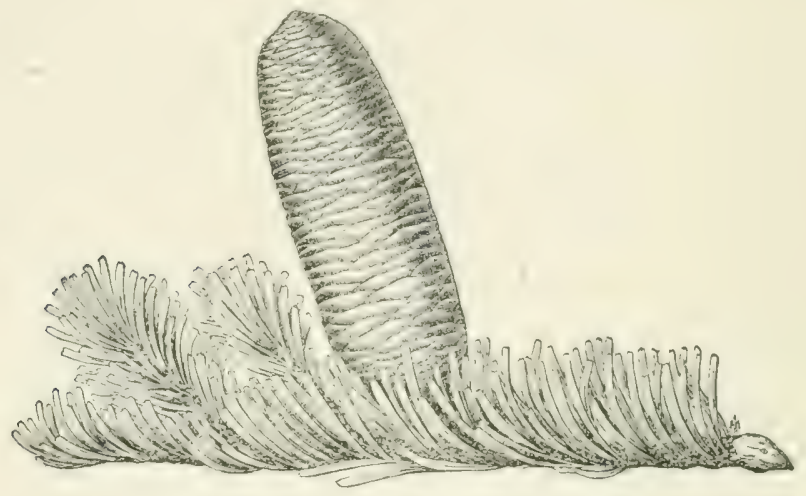

Fig. 69. - Abies Veitchii S. \& Z.

A. T'eitchii S. \& Z. (35), and homolepis S. \&. Z. ( 16), both from Japan, are both very hardy and of the most beautiful form when young.

Gingko. G. biloba Linn. (37) (Salisburia adiunlifolia), Maiden Hair Tree, a medium-sized tree from northem China, is the most interesting and unique conifer, a botanical curiosity, with broad, fan-shaped, deciduous leaves instead of needles, and fleshy, lerry-like (ill-smellings) fruit instead of cones. It is quite harly in New York, and semi-harly as far north as Ottawa. It is picturesque rather than ormamental, with a straggling branch habit, of irregular, open, conical form (with occasional exceptions). Although used for street planting in Washington, it is hardly to be recommended for this purpose, on account of its form and undesirable fruit. It is best planted in single specimens on lawns and near houses, and perhaps masied with deciduous trees and shrubs of leathery, dark green foliage. It is a very rapid grower and, in this country, absolutely free from insects. 


\section{Hemlocks and Bastard Hemlocks}
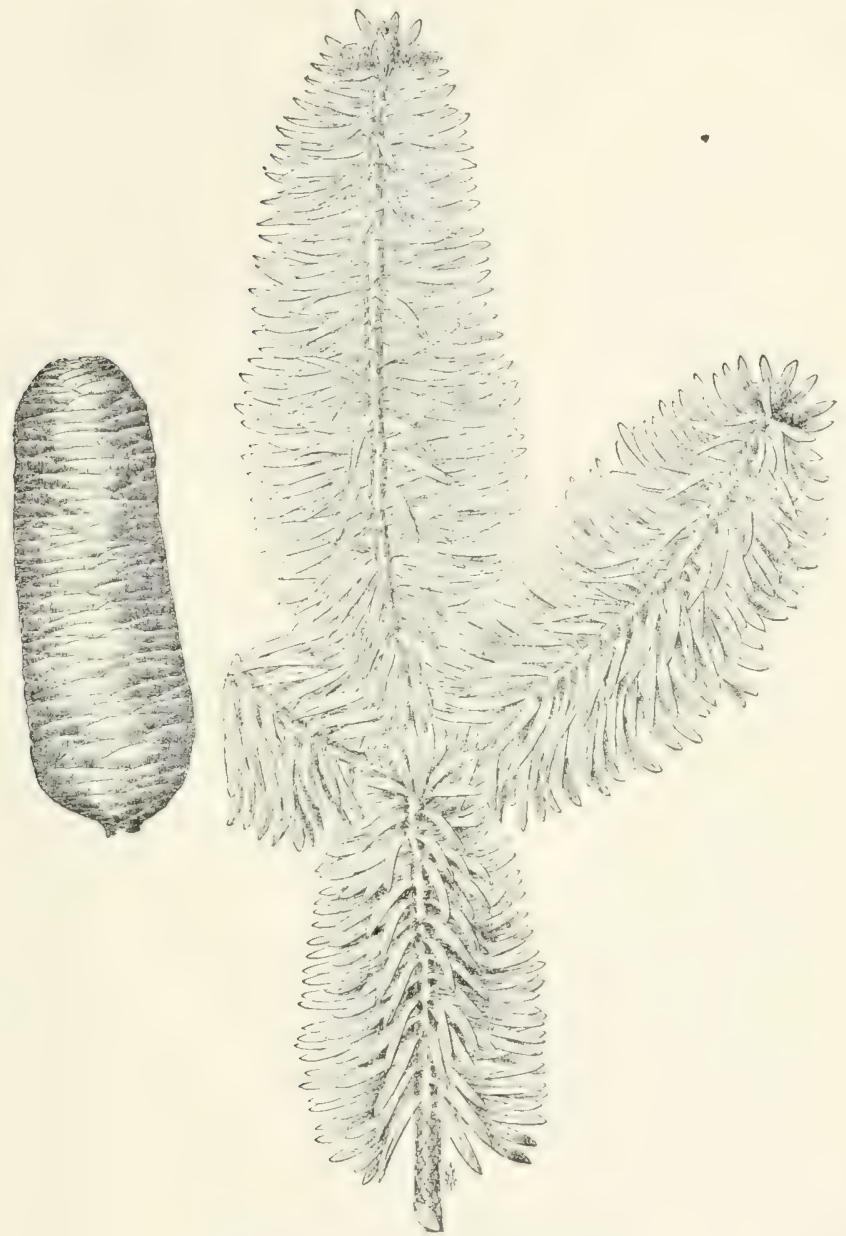

FIG. 70. - Abies homolepis S. \& Z.

\section{HEMLOCKS AND BASTARD HEMLOCKS}

Under this name we may group two genera of tall trees, closely allied botanically, which have also similar habit of fuliage, cones, and branching, namely, the true hemlock $T$ suga (seven species) (formerly botan- 


\section{Trees for Shade and Ornament}

ically ranged under Abies and pepularly under Spruce), and Pscudotsuga, also formerly considered under Alies and variously called Douglas or Red or Yellow Spruce or Fir, or Oregon Pine.

If symmetry, formality, stiffness and stateliness are the characteristics of firs and struces, graceful elegance of form, unsymmetrical yet regular, pendulousness of branch tips, and softness of foliage characterize the hemlocks, the most beautiful of our conifers. Being of alpine or northern origin, the hemlocks prefer a cool, humid atmosphere and cool, well-watered, light loamy soils; while they still grow, to be sure, in dry soils, they do not thrive in wet ones. 'They transplant easily (not from the woods), but resent changes in their surroundings when once adapted. They are free from insects and other troubles, except that the Douglas Fir must be selected from those localities of its wide range which prevent its succumbing to drought or frost. They are very shade-enduring trees, fit for planting singly and in groups as a background to flower and especially rock gardens, as undergrowth for taller evergreens, or among broad-leaved evergreens like rhododendron, and for hedges which are not to be too formal.

Tsuga. T. Cinudensis Carr. (38), the common Hemlock of the northeastern United States, rangring south to Georgia, on the northern slopes of mountains. Its very dense, dark green foliage with faint white lines on underside is the most pleasing of all conifer foliage, both in detail as well as in mass. It is a moderately rapid, but persistent grower, and free from troubles. It is best planted singly on lawns, where at least fifty feet of growing space is available, and in groups, also for hedges. Drouthy situations should be avoided.

T. Carolinima Engrom. (39), the hemlock of the Carolina Mountains, is more compact in form and foliage and of lighter hue. It seems hardy north to Ontario.

Of our two westem hemlocks, T. Wertensiana Carr. (40), the common hemlock of the lower mountain ranges, shows little difference from our Eastern species, but

T. Hookeriana Carr. (4 $\mathrm{r})$, formerly Pattoniana and Mertensiana, the Alpine Hemlock of the Pacific Coast near the timber line, as yet little planted, is very distinctive, with a wealth of dense, dark, crowded, bluish-green foliage, and quite a picturesque, unique, terracedarrangement of branches in tiers. The trunk of old trees too is unique, with a brown-colored bark in fissures resembling that of the oak.

Pseudotsuga. P. tavifolia Britt. (42) (formerly Douglasi), Douglas 


\section{Larches}

Fir, is one of the most important, large timber trees of the West, with a wide range, from the arid slopes of the Rocky Mountains in Mexico and Arizena to the humid shores of the Pacific in British Columbia. For eastern planting it is most important to secure plant material from the proper region (high northern slopes of eastern Rocky Mountains) in order to secure hardiness. For lack of proper selection of seed, many failures in ail points for which the species is famous have occurretl. Otherwise it is one of the finest conifers, rivaling the hemlocks which it resembles in the pendulous habit of its branchlets and in its flexilste foliage, while in the greater length of the latter it resembles the firs (but its purple bud is the sure mark of distinction). Its pendent cones with trident bracts extending from under the scales add to its interest and beauty. It varies greatly in pendulousness and in length and color of the foliage, which sometimes is as silvery blue as the blue spruce. The mountain form is best, hence selection is necessary. It is adaptive to all soils, but prefers lighter ones. In suitable localities it is one of the most rapid-growing conifers, and easily transplanted, being shallowrooted like the spruce and, also like the latter, tolerant of shade. To emphasize its beauty it is best planted in single trees.

$P$. macrocarpa Lemmon. ( 12 bis), a sipecies lately differentiated from the former, comes from southern California, and hence is not fit for eastern planting, at least not in the North.

\section{LARCHES}

Larix and Pseudolarix. Ten speries of tall and medium-sized trees, of northern and alpine range. What the white birch represents among the broad-leaved trees, the larch represents among the conifers, namely, the elements of delicate feminine grace, ejuecially when the soft feathery light green foliage of earliest spring appears on the small protuberances or spurs of the slender branches. It is the first tree to leaf out (these being deciduous-leaved conifers), turning into golden yellow autumn tints, and adding beauty by the cones, which are purple red when young. The branch system is slender, sometimes pendulous; its conical outline is often straggling and not very beautiful, but if placed against a bold background is striking and picturesque with its spiry top. 'They are very rapid growers and most light-needing, and hence fit only for open, sunny positions. Unfortunately they are subject to insects (leaf miners) and fungus diseases. They should be used with greatest discretion 
and where picturesqueness is desired in bold, wild lansdeape, rather than on cultivated lawns, also perhaps for formal avenues and accent trees in large parkis, although in later life they lose their formality.

The one mostly planted is -

L. decidu Mill. (4.3) (Europou), from Europe; a medium-sized mountain tree, apt to suffer in the lowlands unles compensated in the soil for our drouthy atmosphere, although otherwise not selective as to soil; it will grow in the most barren, rocky sites, for which it is indeed best fitted. It is easily transplanted, but should be planted early in spring, as it buds out very early.
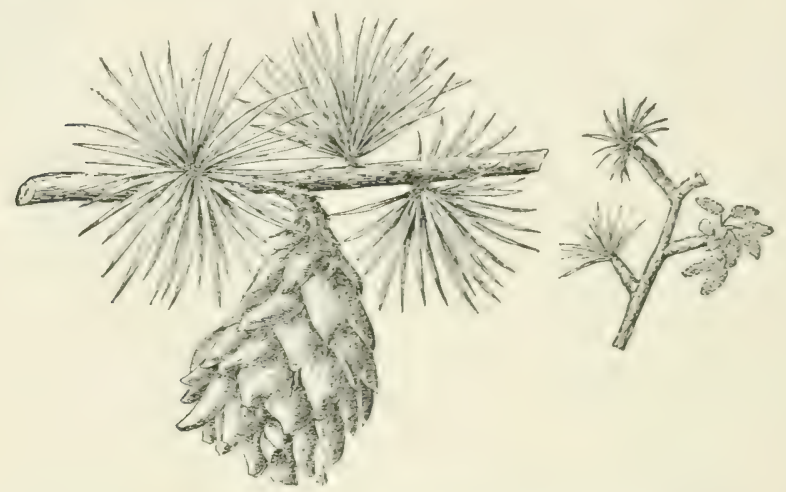

FIG. 71. - Golden Larch. Pseudolarix Kaempferi Gord.

L. laricina Koch. (Americand) ( 4 ), the native, northeastern American Larch or Tumarack, a medium-sized tree, is very different from the European, being a tree of the swamp; less dense and compact in growth, less graceful and symmetrical in form, with shorter foliage. It is adaptive to wet places, and is best used in open groups. Lnfortunately this species is subject to a destructive sawtly, which also attitcks other larches.

The other American larches, L. Lyallii Parl. (45), a small tree from timber-line of the northern Rocky Mountains, and L. occidentulis Nutt (46), Western Larch, a tall tree (up to 250 feet) of the arid eastern mountain slopes from Oregon north, are hardly tested as to their ornamental value. The Japanese L. leptolepis Murr. (47) does not add much new beauty, except in its deeper golden autumn tints.

Pseudolarix. P. Kampferi Gord. (48), Colden Lurch, is a large tree 
from China resembling the true larches very closely, except that the clusters or rosettes of leaves are larger, the leaves longer, turning to a clear yellow autumn tint different from other larches. It is hardy north of Massachusetts. Its freedom from insect pests and fungus diseases seems to be its special advantage.

\section{PINES}

Pinus. The largest genus of the conifers, with about seventy-five species, of which over half are found in North America, and altogether over six hundred varieties in form, from mere shrubs through all the gradations of size to the tallest trees (over two hundred feet) and in every variety of form. There are among them some of the hardiest conifers, adaptive to the driest soils and drouthiest climate, as well as to swamps and humid climates, with representatives ranging almost to the Arctics and to near the equator, in valleys, and in mountains to near timber-line.

Highly important as timber trees, their ornamental value is, with few exceptions, less than that of most other conifers. Yet by the introduction of large masses and proper variety, as background, a strong characteristic sky-line can be secured, as with no other group. Somewhat like the spruces in habit, although less formal, the white pines should lend themselves to avenue planting, while yellow pines, being more rugged in habit, are more fit for picturesqueness, particularly as accent trees and for sky-line effects.

Owing to less symmetrical form and more rapid changes in habit, the awkward period intervening between the conical young form and the picturesque old crown (broad, flattened, or rounded) is more pronounced and more extended than with other conifers. The foliage is less dense, though longer and more flexible, persisting only two or three years, in fascicles of two to five, which, in the older trees, is crowded in tufts to the end of the branches. They are all light-needing, mostly rapid growers, with variable root system, but usually deep-rooted, and easily handled.

There are generally three groups to be distinguished, which differ in character of development, soil requirements, ornamental value, as well as in other respects, namely the white pines, the yellow pines, and the nut pines.

WHITE PINES. This is the most uscful and at the same time the 
most ornamental group, with tall to medium-sized trees, tufts of long, soft, dark green needles with a whitish cast, five in a sheath, long, pen-

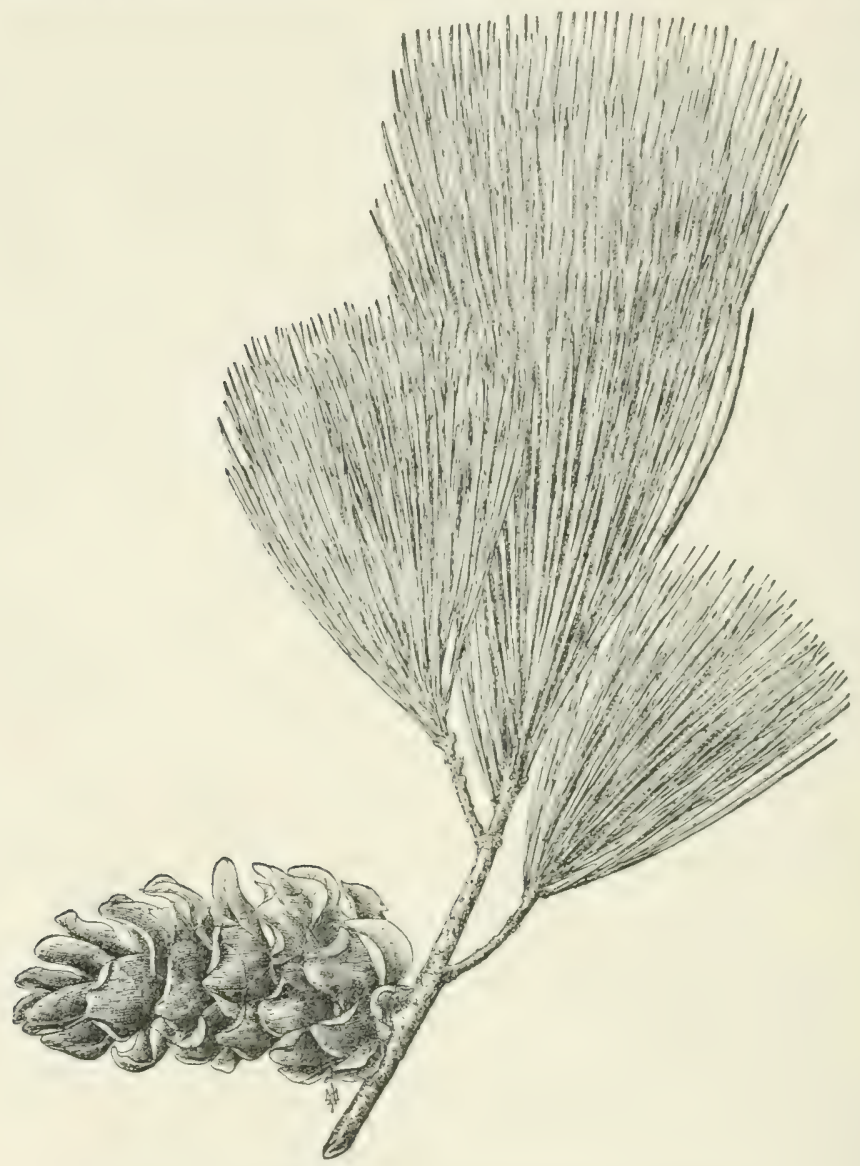

FIG. 72. - Corean Pine. Pinus Koraiensis S. \& Z.

dent cones, and a habit of growth more nearly like the siruce, preserving their conical form into old age; indeed, there is hardy an awkward stage discernible. They are rapid growers and somewhat shade-endur- 


\section{Pines}

ing. For best development and health, these require somewhat better soils than the next group, but will grow in almost any soil.

Pinus Strobus Linn. (49), our common White Pine, a large timber tree, with a fine feathery foliage, is one of the very best conifers for

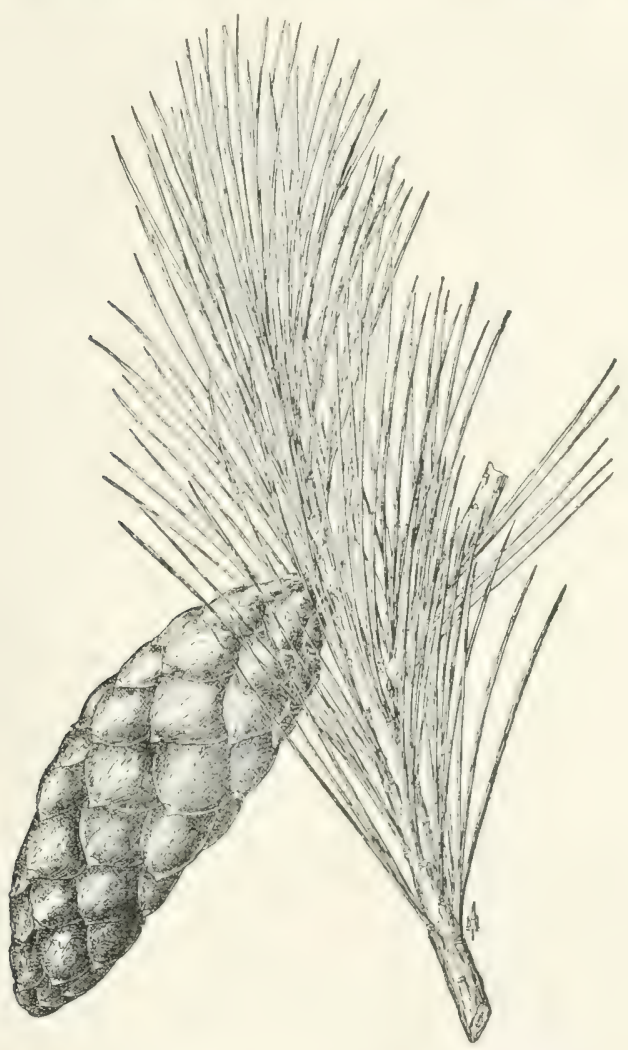

FIG. 73.- Greek Pine. Pinus Peuce Griseb.

northern planting in specimens, groups, groves, hedges, etc. Its range extends on the mountains from Canada to Georgia, but in the valley it is hardly satisfactory below Mason and Dixon's line. It is best suited to medium soils; in dry and poor soils it remains slender and assumes a graceful tapering shape, in compact soils its form becomes 


\section{Trees for Shade and (Onament}

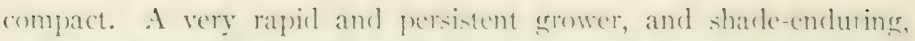
it is well suited for mixture with decidusus trees, especially the lightfoliaged ones. Enfortunately, twe pests are troubling it: the Cottony. Scale, which is, howerer, not very detrimental and can be combated (page 151), and the Tortrix (pater 165), which destroys leaders, griving rise to unsightly double leaders or candelatora, and is less easily prevented.

P. Lambertimu Douer. (50), the Sugatr Pine, of northern Califomia, a magnificent representative of this erroup, with darker foliage and enormous cones (one to two feet long), is, in the East, hardy as far north as Massachusetts in enood, deep soils, but rather a slow grower. Hardly superior to the white pine ornamentally, and probably subject to the same damage.

P. monticult Don. (5I), the Silier Pine of the West. If collected from its Rocky Mountain habitats, it would be hardy, but has hardly any points superior to $P$. Strobus, except a lighter whitish foliage, from which it derives its name.

Four foreigners in this group deserve attention:

P. Koraicnsis S. \& Z. (52), from Corea and Japan, is a very hardy tree, for smal! places, with daker, bluish, very dense foliage and compact habit, superior ornamentally to our white pine. An edible, fineflavored seed (nut) adds to its interest.

P. Peuce Griseb. (53), from Greece, of similar habit in color as the preceding, is a small tree, growing slowly and forming a narrow conical crown.

P. cxcelsa Wall. (54), the Bhutan Pinc, from the Caucasus, and P. Ayacahrite Ehrenl). (55), the Mexican White Pine, both with longer bunches of slender needles, somewhat pendulous branches, and loose or open form, are adapted only for southern planting, although the Bhutan pine is semi-hardy in the North.

P. Cembra Linn. $(56)$, the Sieiss Stone Pinc, a large tree, also a white pine, lacks grace of foliage, the needles being stiff, and only in the form of the old trees is it superior. It is very hardy, but is of remarkably slow growth, and therefore to be recommended only where a slow grower is wanted.

YELI,OW PINES. This is the largest erroup of pines, much more varied in ornamental value than the former group, but generally of less value than the white pines, lecatuse of the rigidity of foliage, and the stiffer, more straggling habit, and long, awkward stage of development. 


\section{Pines}

The old trees, as a rule, develop a broad, umbrella-shape or spreading crown, except some of the western pines, which, at least in their native

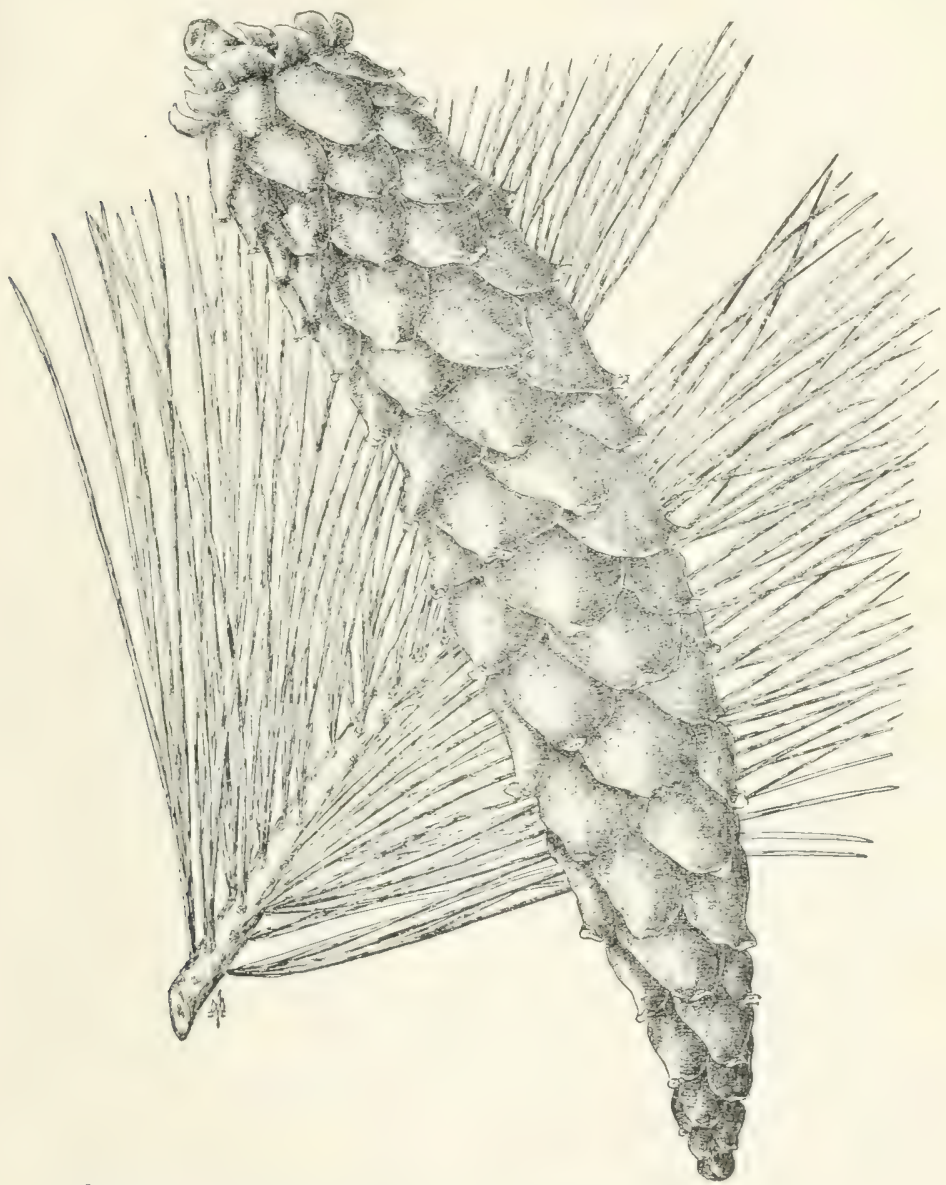

Fig. 74. - Mexican White Pine. Pinus Ayacaluite Ehrenb.

mountain climate, preserve a conical outline throughout. The yellow pines generally are not as rapid growers as the white pines, and more light-needing but adaptive to poorer soils. For single specimens on 


\section{Trees for Shade and Ornament}

broad lawns, or to crown a headland point, the broad majestic stateliness of the larger ones is useful.

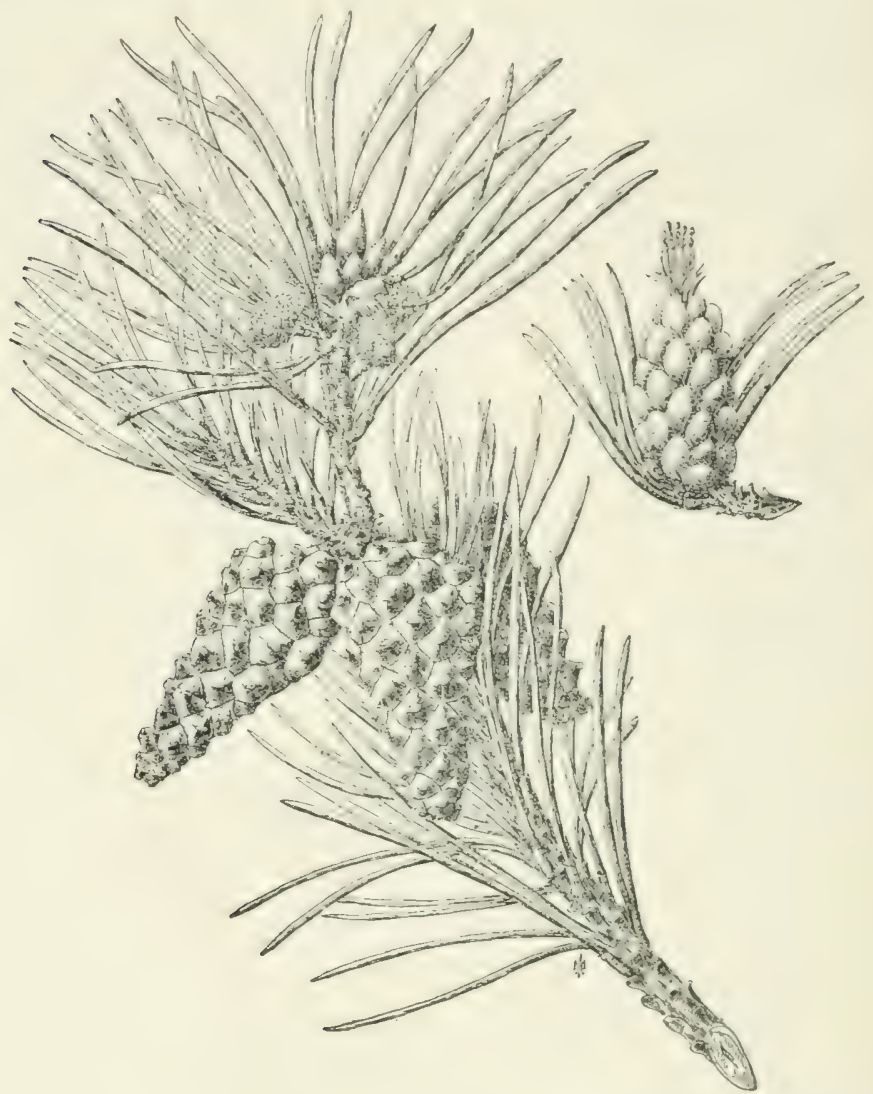

Fig. 75. - Scotch Pine. Pinus silvestris Linn.

The two best known and most planted, because hitherto the cheapest, are:

P. siliestris Linn. (57), the Sootch Pinc, a tall tree, native of northern Europe, which is noted for its frugality and great rapidity of growth, but has only small ornamental value, wih it: stili, stout branches and 


\section{Pines}

gray-grcen foliage. The variety rigensis $\left(55^{\prime}\right)$, Riga Pine, from Russia, is reputed to be much superior on account of its straighter, more sym-

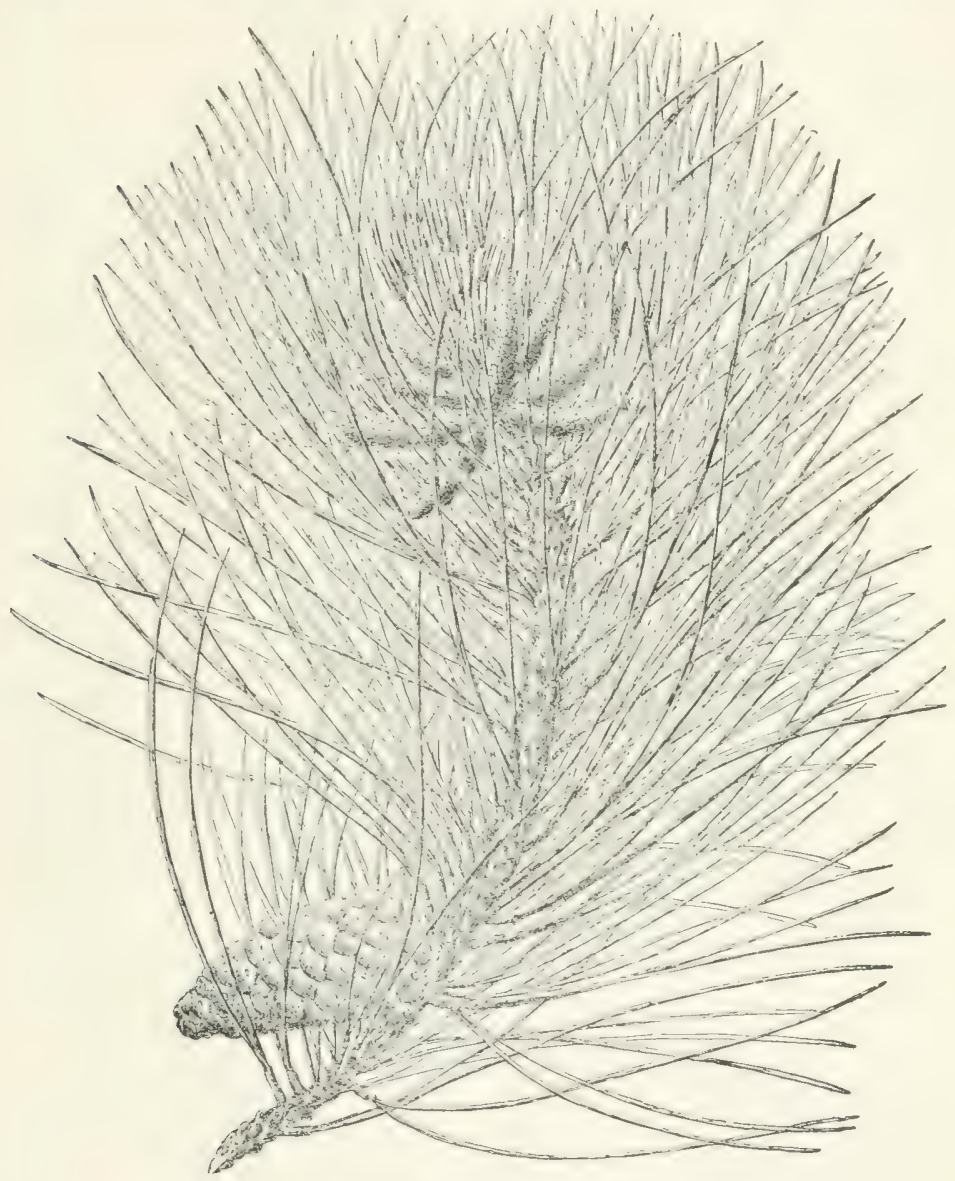

FIG. 76. - Black Pine. Pinus Laricio Poir.

metrical growth, while the common Scotch pine is apt to grow early into straggling habits. But the slow habit of the tree of northern origin must be taken into consideration. In groups or masses at a distance Scotch pines make a picturesque appearance. 
P. Laricio Poir. (58), or its variety Austriaca, Corsican, and Austrian or Black Pine, almost as frugill, harly, and as rapid a grower as

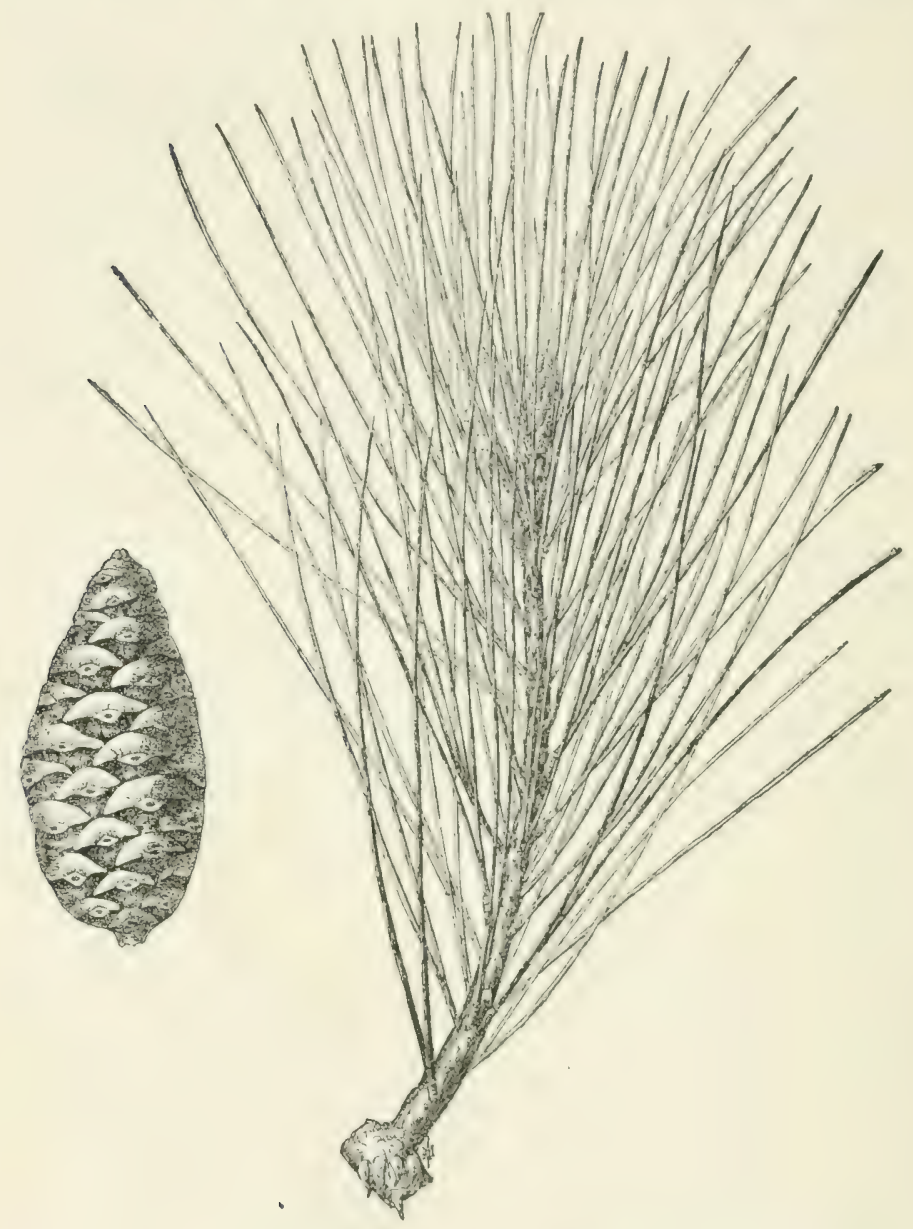

Frg. 77. - Calabrian Pine. Pinus brutia Tenor.

the Scotch pine, differs from it in the dark, dec], blue-green, almost black, dense foliage - the densest of the pines - and the still stouter 
branches forming a compact growth of coarse character, with a round head. Its adaptability to limestone soils, to poorly drained ones and to searoasts, especially of the species itself, is useful. It is specially suitable for backgrounds in masses and quite desirable for lawns. It thrives well in cities and sets off well against city architecture.

A near relative of the Austrian pine from Calabria, P. brutia Tenor (50), in color between the two former, with longer, wary tufts of leaves, offers additional ornamental value.

Our own species have been much more rarely planted, although several of them are superior to the exotics; the best of the northern ones is -

P. resinosa Ait. (60), Red or Voredy Pine (does not grow in Norway!), with its long, rich foliage, a growth as rapid as the White or Scotch Pine, and a more symmetrical habit and more sturdy form, although becoming open in later age; is adaptive to sandy and gravelly soils, as well as to swampy conditions. Remarkably free from troubles. Grood in massing with other species.

P. dizaricata Dum. (Banksiana) (6r), Jack or Gray Pine, is a small tree with slender, flexible, spreading branches (apple-tree-like), and light gray to bright green, short foliage. It is the most northern pine, and adaptive to any soil. Of botanical interest rather than of high omamental value, yet graceful withal, and with a drooping habit, it is well adapted to planting in small places. Its cones remain mostly closed until fire opens them; it is the "fire pine" of the North.

P. rigida Mill. (62), Northern Pitch Pine, has value for special purposes only, namely, on sterile, dry, and rocky sites, where it often assumes picturesque form; and for seaside planting, on sand dunes, etc. Its ability to sprout from the stump when cut or burnt has been made much of, but the sprouts do not grow into trees.

P. pungens Michx. (óz), Talle. Wounlain Pine, is a small tree ranging from the mountains of P'ennsylvania to Georgia and 'Tennessee, with broad, spreading crown, and long, dark sreen foliage; picturesque rather than ornamental. The peculiarity of retaining its large closed cones on the branches for many years adch to its interest. It is adapted to the same places as $P$. risida, but for more southern range; the southern "fire pine."

Of southern species there are several of ornamental merit.

P. palustris Mill. (64), Longleaf Pine, a tall tree of slow growth, fit only for planting south of Washington. With its long (one foot in 


\section{Trees for Shade and Ormament}

length), brush-like, lively blue-green foliage, andwang its large silverywhite bud, with its canclelabra-like, upturmel ends of branches, it is a striking specimen tree. Its unusually decp growing rosts require deep, well drainerl sand soils, and it is diriticult to transplant, excopt in small specimens.

P. chimata Mill. (mitis Mx.) (165), Shorlleaf Pine, extending is. botanical limits into Nuthern States, compares farorably with any of the yellow pines of similar character, and should be more widely planted than it is.

P. glabre Wialt. (66), Spruce Pine, one of the far southern species, with a very fine, flexible, stenter folliage and globular form, is one of the most promising ornamental pines for southern planting, although as yet hardly known.

P. ponderosa Dougl. $(67)$, Bull Pine, is a stately and very hardy tree from the western mountains; of long, stout, light-colored folliagn; retains its conical shape in deep soils, but flattening its crown in poor soils. Its omamental value is hardly established, but it promises well, being at least equal, if not superior, wh the Austrian pine which it resembles.

The European species, P. Pinaster Sol. 108) (maritima), Cluster Pine, resembling $P$. Laricio, but not arlapted to limestone soils, nor hardy with us, offers no special points of ornamental value.

P. II ughus Scop. (69) and P. Pumilio Haenke (70), (montumu Mill), the two popular dwarf pines from the Pyrences and Aps, are shrubs rather than trees, growing up with several stems from the ground, or at least branching low, and often growing in bush form. Where a low mass of foliage is desired, as to hide unsightly places, etc., they fumish an excellent material. They are much used in rock gardens and formal plantings with other evergreens, and are perfectly hardy. Numerous varieties are in existence.

\section{SPRUCES}

Picea. (Formerly confused with .lbies, or the names transposed, just as the common names of spruce and fir, and eren hemlock, are often promiscuously used or interchangerl, although the distinction between the different grencra is easily make.) There are in existence some eighteen species of morthern or alpine range, which are not fit for southern planting, although the Norway spruce appears perfectly at home in Washington. 'Tall to medium size, and some small trees; with sharp- 


\section{Spruces}

pointed, four-sided needles set spirally around the branchlets (persistent five to seven years); the pendulous cones remaining entire when falling; they are densely foliaged and shade-enduring to a large degree. They are medium to fast growers, very symmetrical in youth, the crown

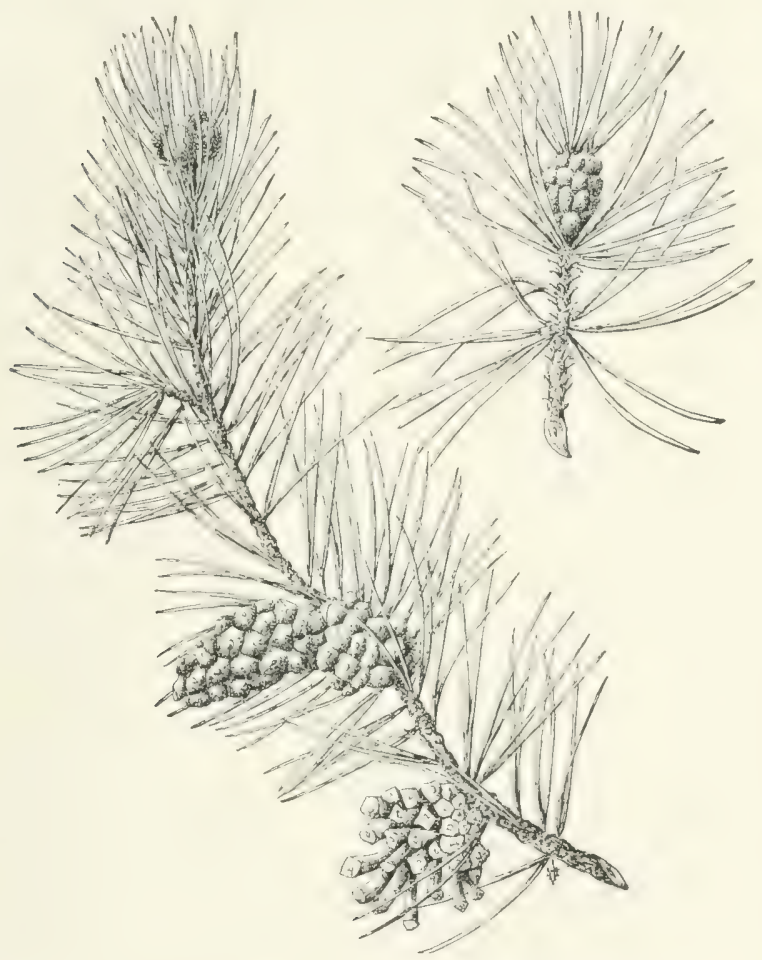

FIg. 78. - Dwarf Pine. Pinus Mughus Scop.

generally rounding off in old age. They are shallow-rooted, and therefore easily transplanted. Most of them are adaptive to any soil on northern slopes, except the extremes of dry or wet, but the best form is attained in fresh, deep soils. They are adapted to planting as specimens and in groups, for windbreaks, shelter, hedges (stand pruning well), also for avenues, and as a foreground tree in large deciduous plantations. 


\section{Trees for Shade and Ornament}

The bet knuwn, mest popular, and most planted, hecause cheap, easily handled, growing most raphilly, and heing very beatutul when on satisfactory soils and used with judgment as to situation, is -

P. excelsa link. (7 ), Voratey Sprues, a large tree from Europe of greatest economic ats well ats omamental value, with its grand symmetry of graceful, llowing outline, formed by the Gothic arches of branches and often gracefully pendent branchlets, beset with dark green foliage. A very rapid grower, makines sometimes three or four feet in a season. In about thirty years it reaches the awkward statge, when lower branches die. This happens earlier in poorer sites, where it is also thinner in foliage, and becomes rageged and open. It is very variable and there are in existence a creat many forms, dwarf and otherwise, which should be used with discretion. The specimens for planting should be selected from these which have developed the long, pendent shoots, for in these consists its beauty when planted in single specimens. For grouping, the stiffer forms may be used. To achieve its best appearance in singleness, not less than thirty feet growing space should be allowed. It is well adapted for windbreaks, screens, and hedges, standing the shearing as well as any species.

The nearest approach in appearance to the Norway spruce of our northeastern species is -

P. rubra Link. (rubens) (72), Red Spruce, the common lumber tree. Although picturesque, it is less ornamental and a very sluw grower; a medium-sized tree, less adaptive than the Norway spruce, and so far not often planted.

Ornamentally, the best species of our Eastern States, with a range to the northwest, is -

P. alba Link. (73), White Spruce, a medium sized tree and one of our most hardy conifers, retaining its symmetrical form and full branching longer than any other. It is altractive by its cheerful, light bluishgreen, rather long, slender foliage. It is adaptive to drouthy conditions if collected from proper localities, e.g., Black Hills; to seathores and to a varicty of soils from dry to swampe. Its compact habit lit it for small places, at points, and in front of groups with darker foliage.

The only other native spruce suitable for planting is -

P. pungens Engelm. (7+), Blue Spruce, from Colorado and other parts of the Rocky Mountains, noted for its remarkable blue to silvery foliage. It is hardy and adaptive to drouthy conditions. The blue color for which it is prized is not only variously distributed among 


\section{Spruces}

individuals, but its persistence depends on satisfactory (well watererl) soil conditions. It varies greatly in individuals. Two nurserymen, Koster and laarry, have brought into the market superior specimens of

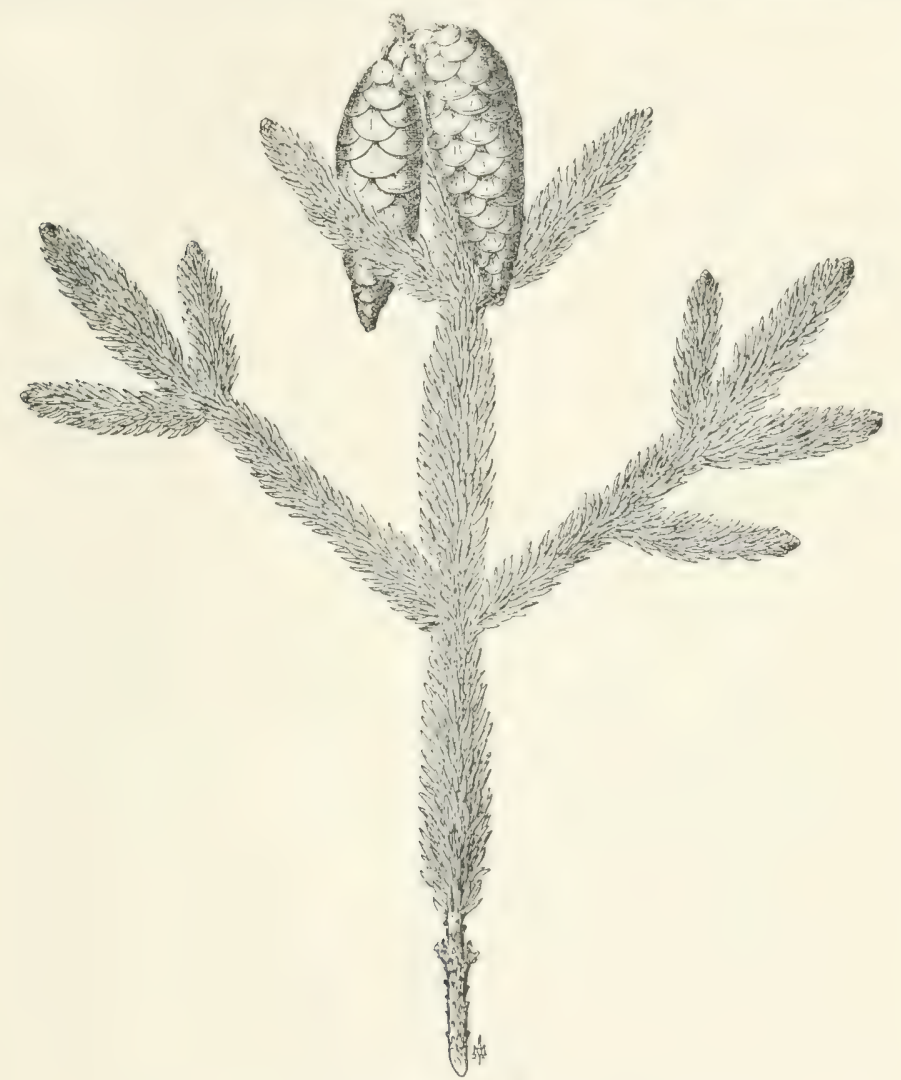

FIG. 79. - Caucasian Spruce. Picea orientalis Carr.

intense blue color, as Kosteriana (75a) and Parvana glauca $\left(75^{b}\right)$, which are secured by grafting on $P$.excelsa stock. These prove not only more generally but more persistently blue, and superior from this point of view to the original type. In dry situations, the tree becomes with age positively ugly, with a stragerling, uneven branch development, 


\section{Trees for Shade and Ornament}

with very dark, almost black foliage, only the last year's shest showing the blue color. It should be used sparingly, we light up dark comers, and singly on small lawns.

Of other exotics adapted to our climate, there are worthy of note -

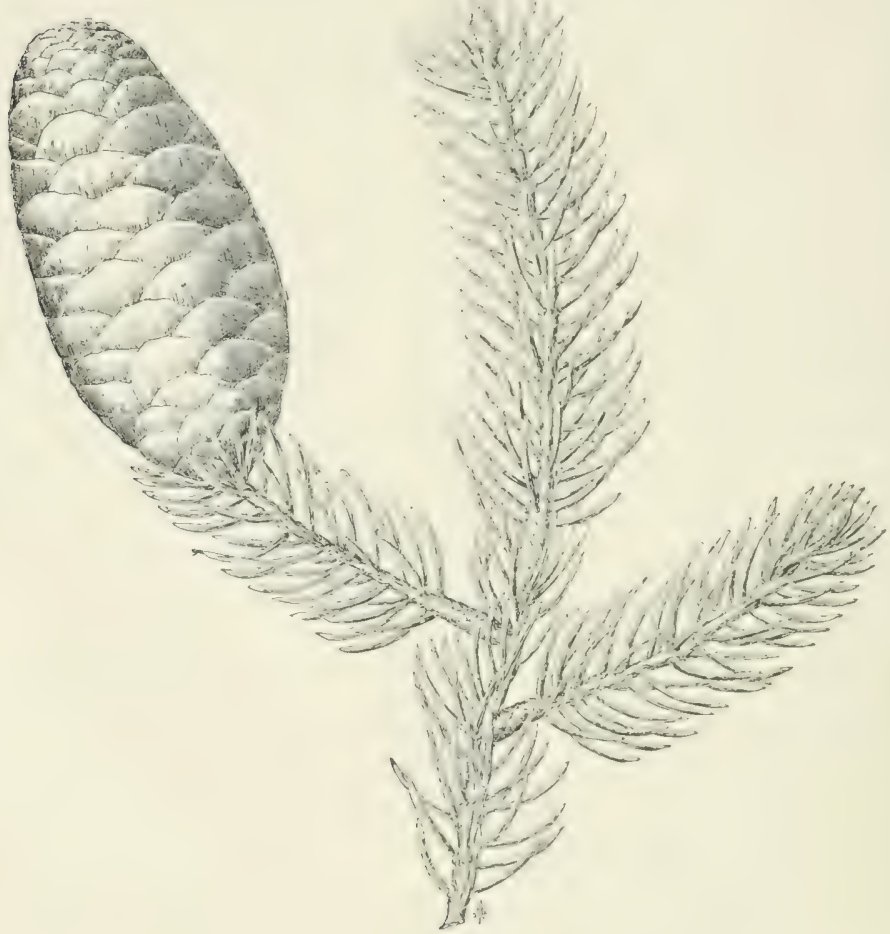

FIG. 8o. - Japanese Spruce. Picea polita Carr.

$P$. orientalis Carr. (75), from the Caucasus, the most graceful and distinguished of all spruces, with its short, crowederl, (dwsty appressed, very dark, glossy foliage, sinular to the Vorway, with somewhat pendulous branchlets; the branches persistiner to the ground for a lone time. Being of slow growth and a medium-sized tree, it is well adapterl for small places. Very hardy.

$P$. polita Carr. (76), from Jaynan, is almost the opposite of $P$. oricn- 


\section{Yews}

talis in the stoutness of its branches and the rigid bristling, spreading foliage, picturesque rather than ornamental. It is also very hardy.

\section{YEWS}

Taxus. This genus of small trees and shrubs, six species and many forms, furnishes some of the hardiest and most frugal conifers, well

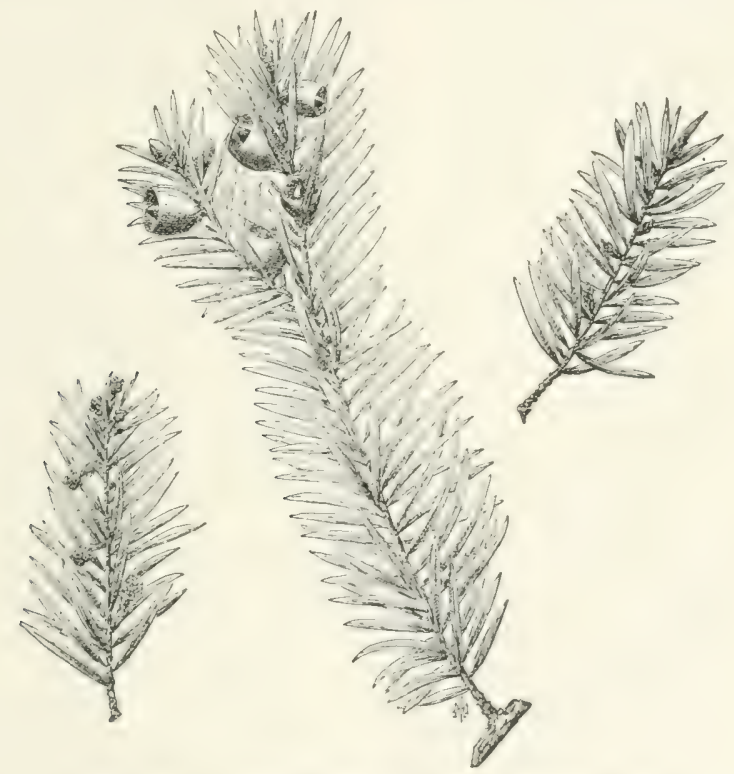

Fig. Si. - English Yew. Taxus baccata Linn.

adapted for underplanting, as they bear shade well, indeed prefer shady positions, and grow very slowly; also wherever low forms are desired, and for hedges. Their rich, dark, glossy foliage, with a yellowish cast (n) the under side, give them somewhat of a funereal tone, which is increased by the remembrance of their frequent use in cemeteries, to which they lend themselves on account of their very slow growth and their small, compact form, especially in the fastigiate forms. They are very useful in formal gardening and against formal architectural work. The red berries add to their attractiveness. They are ustally planted as shrubs and in the many varieties of nurserymen's forms. 


\section{Trees for Shade and Ornament}

T. bacata Linn. (77), English Ieat, is with us merely a shrub and not hardy; especially when planted in the open it is apt to suffer from frost.

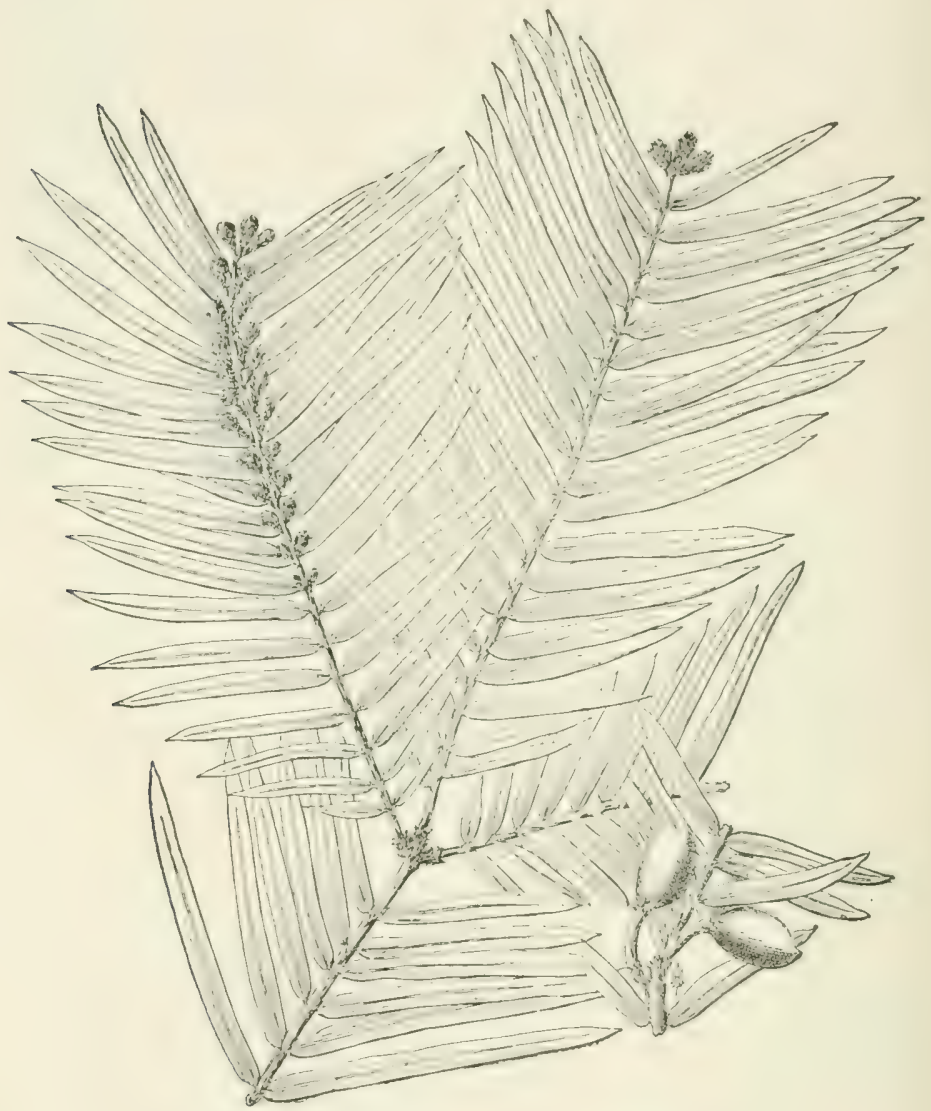

FIG. 82,-Cephalolaxus Fortunei Hook.

T. cuspidata S. \& 7. ( 78$)$, from Japan, is much hardier, without any special difference in aspect.

No more satisfactory low, shrubby cover of ground and beneath shady trees could be suggested than the hardicst of all- 


\section{Acacias and False Acacias}

T. Canadensis Marsh. (79), a prostrate shrub of our northern woods, which grows to a beautiful specimen when developed in nursery rows.

Torreya. T. Californica Torr. (80), the California Nutmeg Tree, and $T$. taxifolin Arnott (8I), from Florida, are two small trees of the yew type, neither of them hardy in northern climates; with interesting, sharp-pointerl foliage, and open, stately form. They are insect- and fungus-proof. The Japanese T. nucifera S. \& Z. (82) is probably hardier than the native ones.

Cephalotaxus, a genus with several species of small trees and shrubs from Japan and China, is mainly fit for southern planting, but possibly hardy as far north as Philadelphia. The best, C. Fortunci Hook (83), is of highly ornamental aspect and more graceful habit than the true yews, its sharp-pointed foliage being of livelier color.

Podocarpus, a genus with more than forty species of small trees, of tropical and sub-tropical mountainous range, is fit only for southern planting, although $P$. alpina (84), the hardiest, may be grown as far north as Philadelphia.

\section{B. BROAD-LEAF TREES}

The ornamental value of the broad-leaf trees is to be sought mainly in the variety of foliage, growth habit, and form. The changeableness of color in the foliage, the variety of tints in the fall, and again in early spring upon the reawakening of Nature, and the variety of branch systems in their naked winter condition furnish unending attraction, both in the single tree, allowed to grow in perfect form, and in the properly grouped clump. A number, especially of the low trees, are also attractive by their flowers, which in most of the tall ones form only a very passing interest.

\section{BROAD-LEAF TREES WITH COMPOUND LEAVES ACACIAS and FALSE ACACIAS (Locusts)}

We may consider together under these names four gencra of the Pulse family,-Acacia, Albizia, Robinia, Gleditschia with some 


\section{Trees for Shade and Ornament}

four to five hundred species, varieties, and hybrids, medium-sizerl to (mostly) small trees and shrubs, which besides their pod-like fruit. have also similar, small leaflets, forming a graceful foliage, generally beset with thorns or spines. Some have striking flowers, which form an adclitional ornament. They are adaptive to poor soils, and are very light-needing.

Robinia. Three native species have their valuable points: $R$. pseuducaciu Limn. $(\$ 5)$, Black Lacust (in New Fingland called Honcy Locust), the best known; a small to medium-sized tree, is hardy everywhere. It is most interesting and beatutiful when in fower, with large, pendent, fragrant, white dusters (May, Jume), set off by the yellowish-ereen to dark green foliatge. In winter the unattractive pisis persist, and the straggling branch system, with rough, ridgy bark on the old trees, and short prickles on the smooth bark of the banches, detracts from its looks. It excels in its rapidity of growth, the ease of transplanting, and adaptation to almost any soil, even the poorest and driest; but it is variable in outline according to the site, from the handsome, roundish or elliptical form and upright habit on cool, rich loam and not too poor sand (under such conditions making a fine lawn tree), to the ugly, straggling, and unsatisfactory form on compact clay soil, especially in old age, when branches here and there begrin to die. To be used mainly for grouping by themselves on knolls and to cover sandy or gravelly wastes; singly, near houses, and on small grounds for cheap, rough hedges. Lnfortunately, a borer working in the lower trunk disfigures, although rarely kills, the tree; a leaf fungus not infrequently attacks it, and it has the bad haloit of suchering from the shallow roots. Easily propagated by cuttings. It grows very rapidly, but not persistently, and makes a hard, durable wood, fit for fence posts, etc.

A variety, incrmis ( 86$)$, without thoms, has usually a darker hued foliage.

R. ziscosa Vent. (8;), Clammy Locust, so called from its sticky branchlets and leaf stems, smaller than the former (ten to fifteen feet down to a shrub), is similar to the preceding species, but with larger clusters of rose-pink flowers, appearing later and continuing longer.

R. hispida Linn. (88), Rose Aracio, appearing more often as a low shrub than a tree; from the southern Allecthanics; a very desirable ornament and the hardiest of all; large rose-colored flowers appear very early in life (June and July); more prickly than the other varieties; has 


\section{Acacias and False Acacias}

the same habit of stockering ats the others, hence to be used where this is not an objection. Good for seaside planting on sandy wastes.

A very large number of nurserymen's varieties, with small variations, especially of the black locust, have their uses.

Gleditschia. G. Iriacanthos Linn. (S9), Honey Locust (sec Robinia), or Therethorned Acaciu, the first name from the sweet yellow pulp of the poods; the second from the long-three-pronged spines which beset trunk and branches; is a medium-sizel tree, one of ten species of more southcrn distribution, yet very hardy. Very different from the foregoing in outline, spreading in branch habit and often irregular, with inconspicuous green flowers and very large broad brown pods, which, together with the stout spine- make it an olject of interest in its leafless condition, hut also add to it w unclanliness, since the fruit falls little by little for some time. Its folizge, light areen turning to clear yellow, with wather shorter leaf periorl, differs also very much from the former; it is clegant in detail, delicate and epen, giving it an even airier aspect than that of the black locust. It has none of the bad habits of the latter, is free from insects, and adaptive to all soils from dry to wet. Light-needing and a rapid grower.

The variety, inemis (90) without spines, has a somewhat more slender and loose habit.

Of the true acacias there are several hundred species, found chiefly in Australia, in tropical, sul)-tropical, and desert ranges, generally as small trees or siruls with very small, graceful, feathery foliage, and fincly colored, fragrant fluwers. The following species is especially useful for southern planting:

Acacia. A.decurrens, Will\}. (or ), Black Wattle, from Australia, with frofuse, fem-like leares, with loner racemes of bright yellow flowers.

A. pubescens R. Br. (92), the Ilairy IIattle, a small spreading tree or shrub, is a very fine ornament with its gracefully cut foliage and abundiance of fragrant light yellow flowers, on pendent branchlets, appearing very early in spring. It has been found hardy as far north as Boston.

Albizzia (Acacia). A. Julibrissin Durazz. (93), from Persia, is a specially beautiful, spineless, small tree, the most ornamental of its group and much planterl; with exquisite feathery, pinkish flowers in franicles (July) and most graceful foliage; spreading and round-headed in outline. Only half hardy at Philadelphia; needs rich and warm situations. 


\section{HORSE CHESTNUTS OR BUCKEYES}

Esculus. Large, medium-sized and small trees and shrubs from the United States and Asia, of well-appreciated ornamental value, with rich, palmate foliage and attractive tlowers. They are cxcellent shade trees, requiring, however, rich soil for their best development.

A. Hippocustumum Linn. (05), Horse (hestuul, from China, nearly hardy to (Mtawa, is the best linown, the largest of the genus, and one of the best shade trees. It is a tolerably rapid grower of rather roundish or oval outline, regular, somewhat coare, at first stiff, branch halit; branches becoming pendent with the tips of branches peculiarly curved upward, with heary, luxuriant, deep green, flaccid foliage, becoming golden bronzed in autumn, leafing carly, but also browning and shedding its foliage carly (August). I profusion of stiff pyramids of white, showy flowers (May) is a striking feature, but also adds to its uncleanliness, which is most felt when the large nuts and burs fall in early autumn. A "shot hole" fungus sometimes attacks the leaves, making them unsightly with brown specks; it is also liable to sun-scald, but is otherwise free from troubles. For wide arenues and public places it is one of the best species; also good for lawns singly, being too formal in habit to group well.

A. Paria Linn. (05) (rubra), Red Buckeye, a small tree native in the South, but hardy northward, is commendable for its fine brick-red to dark red flowers. There are several forms, varying in color of flowers, and a dwarf with pendulous branches.

A. glabra Willd. (96), Ohio Buckeye and .1. octandra (flava) Marsh. (97), Sueet Buckeye, natives of the Southern State's, deserve much more attention than they have so far received. They are small to mediumsized trees, lacking the showy flowers of the first two mentioned, having pale yellowish-green ones, but a more elegant foliage, and smaller fruit with less coarse burs, being therefore more cleanly. Hardy to Ottawa, and there hardier than the horse chestnut.

A. pariffora Walt. (gS) (mucrostuchyu), Dieurf Horse Chestnut. A native of the Soruthem States, a large shrub (fifteen to twenty feet), sometimes growing into tree form with a broad well-rounded head, is a most desirable plant in it: proper place, in the North hardy to semihardy in sheltererl positions. It is attractice in its dark, smooth, rich foliage and peculiar long erect spilies of white flowers, appenting during the scanty flower scason (July). It suckers readily, spreadin:; 


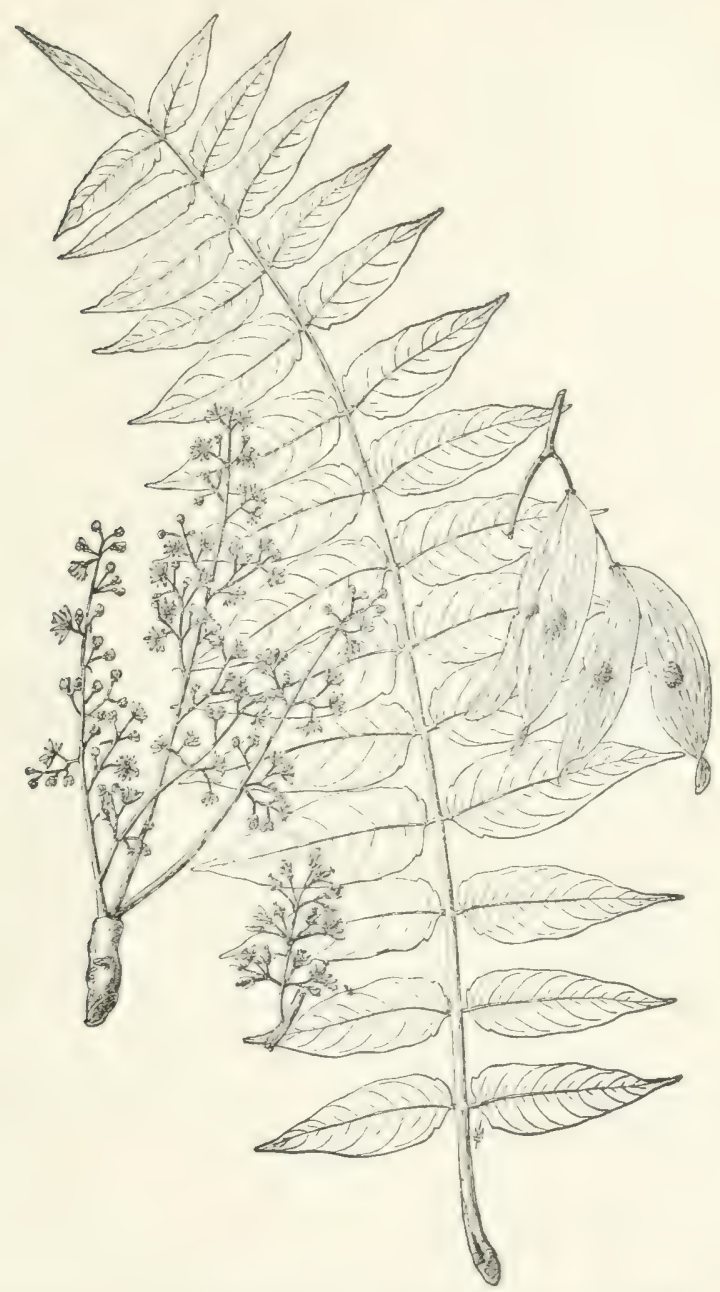

Fig. 83. - Tree of Heaven. Ailanthus glandulosus Desf.

rapidly, and hence to be planted only where this habit is not objectionable, or even desirable. It is adapted to stiff soils.

Ailanthus. A. glandulosus Desf. (99), Tree of Heas'en. A large tree from China, but so generally pianted as to appear like a native. It is 
highly interesting and ornamental, its large fronds of pinnate leaves giving it a strikingly graceful and tropical appearance, which is heightened by the very large, singular bunches of flowers and fruit. In winter, its stout, rusty brown young twigs and shoots give it an interest. Not hardy in Ottawa. In form it is somewhat open, but when full grown is of stately habit, and peculiarly fissured, somewhat smooth, gray bark. It is an extremely rapid grower, and most adaptive to soil and climate, but light-needing. It has the advantage of being absolutely free from insects or other troubles, but has two objectionable features, namely, the disagrecable smell of the flowers of the male tree, which may be avoided by planting female trees (recognizable?); and the habit of suckering and strong rooting at the surface (also more strongly developed in the male tree), which makes it undesirable near dwellings and parements. It is therefore to be used with discretion. For rapid, tall shrub effect or top filling it may be used advantageously by cutting back annually, as it is a most vigorous sprouter.

Aralia. A. spinosa Linn. (то)), Angelica Tree, Hercules Club, one of some twenty-five or thirty species, is a shrub or dwarf tree (twelve to sixteen feet), of southern native habitat, and not quite hardy in the North. With its stem beset with sharp prickles, shedding both leaves and branches in winter, and leaving a bare pole, it is a botanical curiosity, but also very ornamental with its tufts of very large, twice- and thricepinnate leaves at the tip of stem and branches, and with its wealth of large clusters of fleecy, white to greenish-tinted flowers in summer, being quite tropical in appearance. It is a rapid grower, hence, like the Ailanthus, giving quick effects as tall shrub and top filler. It is very shadeenduring and adaptive to various soils, best in moist, even wet ones. It suckers profusely and hence can be cut down for wintering, but this habit, if not to be utilized, can easily be kept in check. It is liable to attacks of scale.

Most of the other species are tender herbs or shrubs, but Aralia Chinensis Linn. (Fatsia Japonica, or Sieboldii or Dimorphanthus. Mandschuricus), from Japan and China, a very elegant shrub, with finelycut, deep glossy foliage, is perfectly hardy as far north as Ottawa; hence it should be used in preference to the native form.

Caragana. C. arborescens Lam. (102), Sibcriun Pea Tree. This small tree (fifteen to twenty feet) or large shrub, one of several interesting 
species, with compound leaves (eight to ten leaflets) and pea-shaped pale yellow flowers, is hardy everywhere, easily grown and adaptive, and makes one of the best sturdy hedges.

C. spinosa D C. ( $\mathrm{I}_{3}$ ), also from Siberia, similar in leaf and flower, is a low shrub) (four to six feet) with long, thorny branches, but does not appear to make grood hedges. It is specially adapted for sandy soils.

An entirely different type as regards foliage, having only two to four leaflets, is represented by---

C. frutcscens D) C. (103 bis), from Southern Russia and China, hardy to Ottawa. This is a small tree, half the size of arborescens, and more graceful and attractive, with its golden-yellow inch-long flowers.

Several other Asiatic dwarfs of this genus are found equally hardy but without points of superiority, except perhaps $C$. pygmad D C., a small shrub with fine foliage and handsome golden-yellow flowers.

Cladrastis. C. tinctoria Raf. ( $\left.10_{4}\right)$ (Virgilea lutea), Icllow-IIood. This small to medium-sized tree, often even shrub-like in habit, of limited range in Kentucky and Tennessee, but hardy to semi-hardy into Canarla, is a first-class ornament for small places, with short trunk and spreading branch habit in refined curves. The foliage is made up of rather large compound kave's, formed of small, short, pale green leaflets looping gracefully and turning bright yellow; it has equally graceful Ionse clusters of fragrant white, pea-shaped, wistaria-like flowers (June), hanging from the ends of the little branchlets. The long leaf-stalks, remaining into winter and enclosing the buds, are interesting, but somewhat detractive from its winter aspect, which otherwise its smooth, gray, beech-like bark renders attractive. It is a moderately rapid grower, and adaptive to various soils.

\section{ASH}

Fraxinus. A genus economically very valuable, with thirty to forty species of large to small trees, in all parts of the temperate zone; is ornamentally of less value than many others, because of the stiff, open, bare, and spreading branch habit. Yet they are interesting in their finelyridged, whitish-gray to dark bark, and their elegant foliage of light hue, which, however, is late in making its appearance, and early in falling. All are light-needing and of medium rate of growth. Their tracing root system permits easy transplanting. They are adaptive to wet 


\section{Trees for Shade and Ornament}

and compacted soils, but thrive lest in drier situations. Their freedom from insect pests would recommend them for street trees, but their

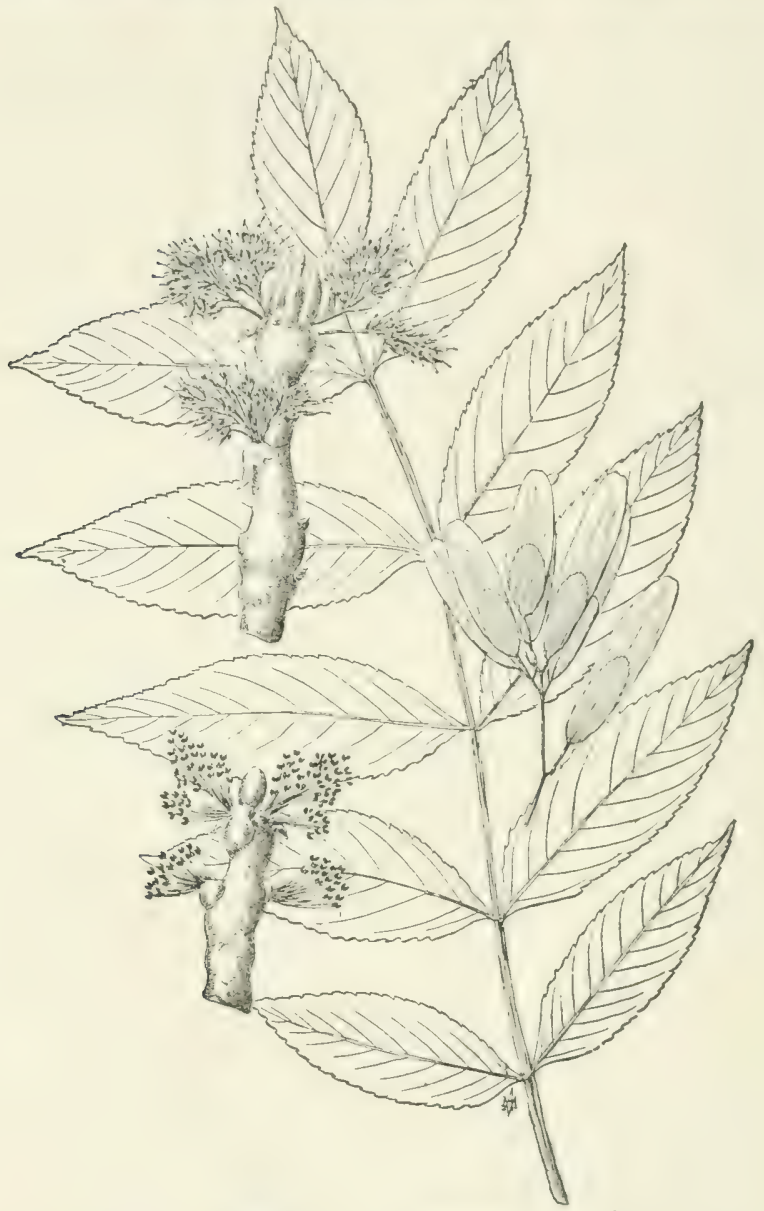

Fig. 84. - English Ash. Fraxinus excelsior Linn.

short leaf period and their requirement of soorl soil rule them out here. Their best use is for color effect against darker foliage, along country roadsides, and for marking a point in the lanciscape. 


\section{Ash}

Of the eight American species, several resemble each other so closely that a distinction is difficult, even to nurserymen, and practically, except as to size, unnecessary from the omamental point of view. The two most distinct species are:

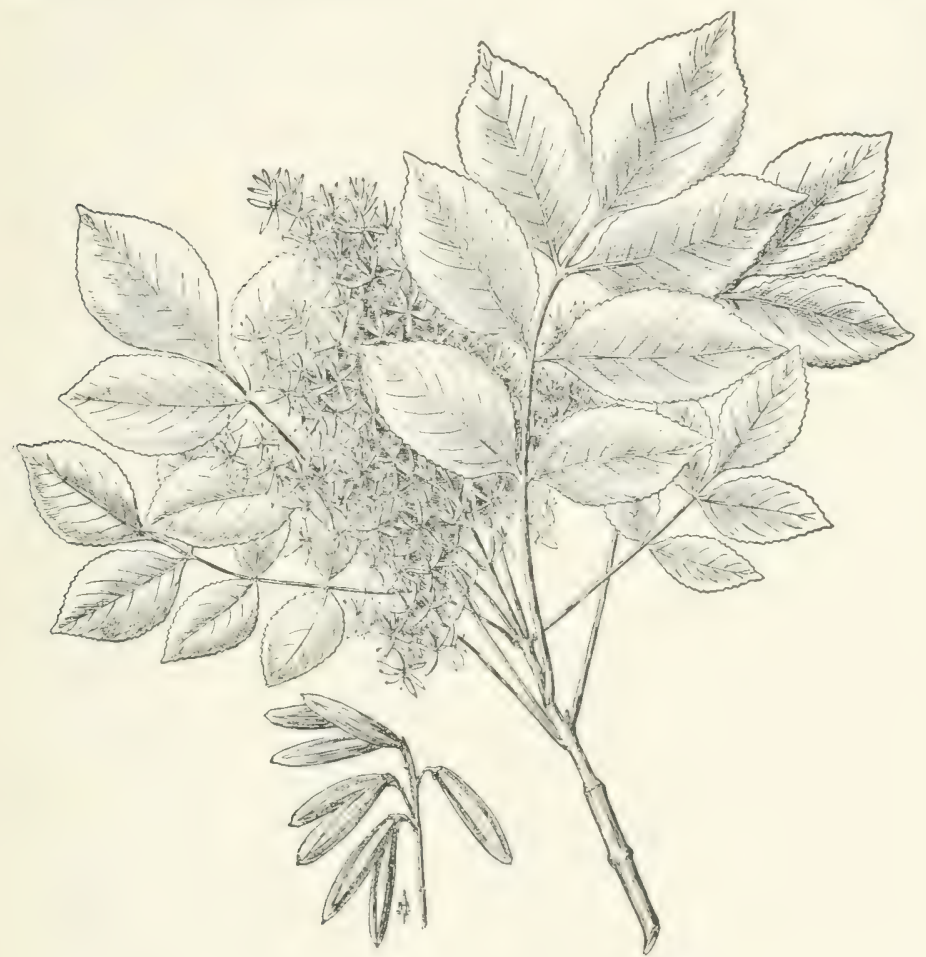

FIG. 85. - Flowering Ash. Fraximus Ornus Linn.

F. Americana Linn. ( 105 ), White .1sh, of eastern distribution from north to south, the largest, most typical of the crenus, and the best in form.

F. nigra Marsh. (106) (sambucifolia), Black Ash, a rather rare tree of the sramp, with a darker, denser foliage of slenderer leaves, and a dark gloomy aspect of stem and branches.

F. lanceolata Borck. ( $\mathrm{IO}_{7}$ ) (viridis), Green Ash, of more western distribution, a smaller tree, is often mistaken for white ash and mixed with it in nurseries. 
F. quadrangulatu Michx. (ros), Blue .1sh, is adaptive to dricr situations than the other species.

Of European specis there are two quite distinctive ones, both more ornamental in their greenery than the Anerican flut not quite hardy at Ottawa):

F. excelsior Linn. (IO9), the so-called English Ash, a native of Europe, with various varietice, is quite altractive, with its finer, small, serrate folliage and black buts. It is liatse to a black knot fungus disease.

F. Ornus Linn. ( 10$)$, Flowering Ash, a small tree from the Mediterranean countrie's, with round head, more compact than most athes, with its numerous, white, feathery flowers (Maly, Jume), makes an attractive tree for small places and in front of groups.

Gymnocladus. G. Cinndensis Lam. (11 I), hentucky Coffec Tree, is a large tree of southern distribution, but hardy as far as (Otawa. With large, very luxuriant, and striking, tropical-fooking foliage, similar to the Ailanthus, finely-fissured bark, but raseged, stout, somewhat crooked and straggling branch system, it is picturespue and interesting rather than beautiful, with heary secel buds and apparenty budless, bare branches. It is well adapted for suburban street tree-planting, but requires deep, rich soil. It is specially free from pests.

\section{HICKORIES}

Hicoria $($ Cary $(l)$. There are nine species of large and small trees, all confined to eastem Lnited States. Most of them are of great economical value and some (pecan and shellbark) more prized for their fruit than for ornamental and shate purposes; yet the lofty, symmetrical, closely-knit, rather elegant, aspiring form of the large species, the rather pale, medium to small siad compound leaver, turning golden yellow, the picturesque, somewhat siarled, pendulous branch system, render them worth while for planters on lases urounds, singly in pastures, or in groves with other tres. Ifaving a very deep root system they need deep and preferably rich soil. They are free from insects, but suffer, although rarely, from the leaf spot fungus. They are best used in single individuals, near house's, in fields, and to accenturte an elevation.

The best species for ornamental use is perhaps:- 


\section{Walnut}

H. minima Britt. (II2) (amara), Bittemut, native in Canada, which is of very upright habit and elegant foliage, with close, finelyfissured bark. It is adaptive to swampy conditions.

H. Pecan Britt. (113) (olivaformis), of more southern distribution, is similar to the former, but still loftier. It is hardy as far north as New York.

H. ovata Britt. (I I 4), Shellbark, hardy in the North and also suitable for southern planting. H. laciniosa Sarg. (II5) (sulcata), Shagbark, named from its flaky bark, often developing a narrow elliptical form with pendulous branches, is most valuable for its fruit.

H. alba Britt. (II6) (tomentosa), Hockermut, thrives in the poorest soils.

H. myristicaformis (I 7 ), Vutmeg Hickory, a small tree, with small, elegant, deep green foliage, golden-yellow underneath when grown in rich soil, deserves attention, especially for small places. It is, however, of southern range, hence its hardiness is doubtful.

\section{WALNUT}

Juglans. Of the ten species of large, medium, and small trees, three or four deserve attention, although none of them is of very high ornamental value, both foliage and branch system being rather coarse, and outlines irregular. Their leaf period is especially short. Having tap-roots, they are rather difficult to transplant, and need a deep, rich soil for good development. They have the advantage of being free from insects.

The largest and handsomest of this group is the native species--

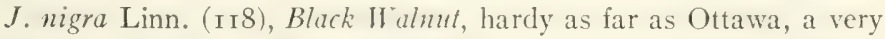
large tree, growing rapidly, of spreading habit, and varying outline, with blackish, strongly fissured bark and dark green, large, rather dignified foliage; with a short leaf period at both ends, and no interesting autumn colors. It is an unneighborly tree, being very greedy and shady, its coarse foliage decaying slowly, as well as being rather unclean. It is fit only for wide spaces, singly or in groups, when the shade and light effects in its foliage are pleasing, and its sturdy growth, bold ramifications and noble stateliness are effective.

$J$. cinerea Linn. (ing), Butternut or IIhite Walnut. A smaller tree (up to one hundred feet), of more northern range and less choice of 


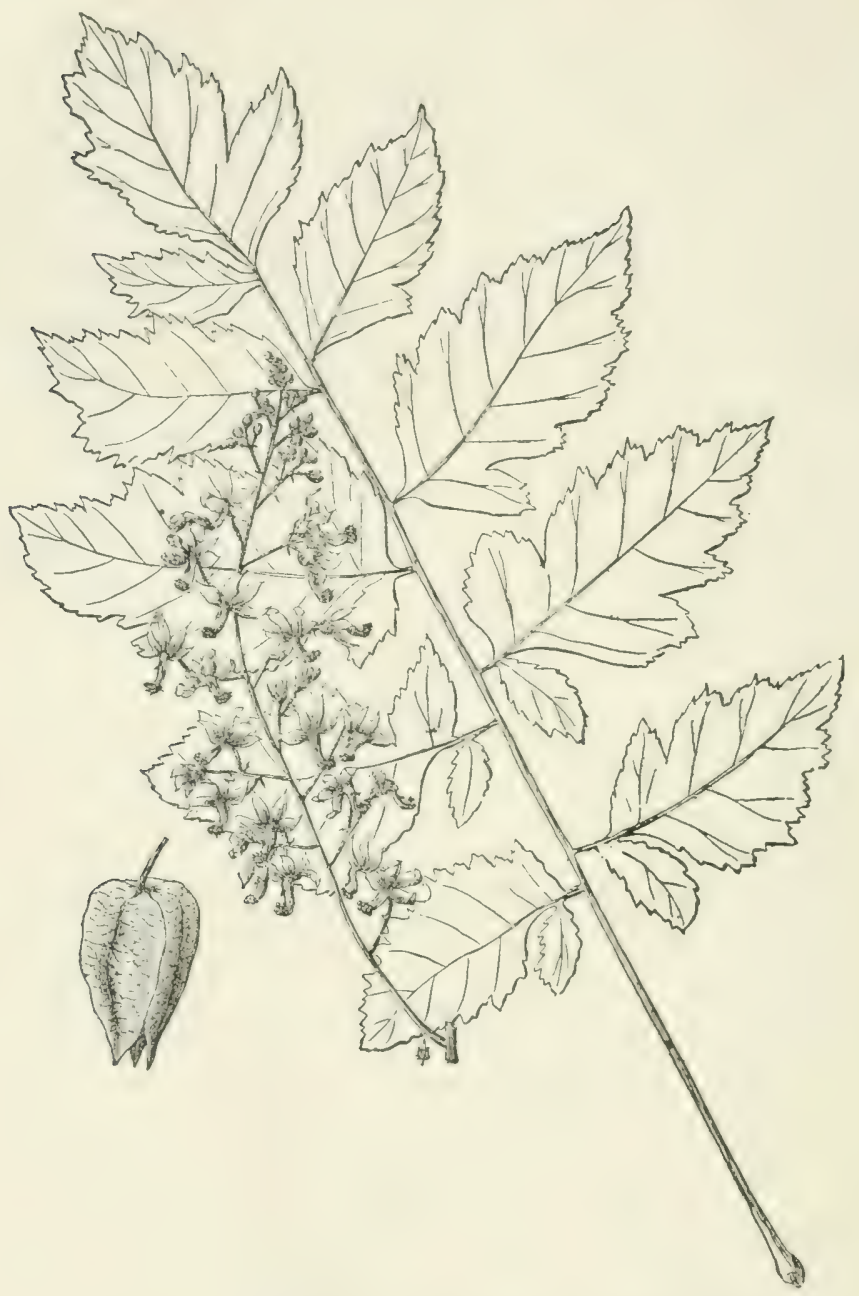

Fig. 86. - Varnish tree. Koelreuteria paniculata MIaxim.

soils, but inferior to the former in its more straggling habit and uncertain outline, sparser, coarser foliage, with still shorter leaf period. It is light-colored in bark and foliage. It is sald to group well with the 


\section{Walnut}

Austrian or Scotch pine, and makes a natural appearance on rocky ground, if the soil is rich enough.

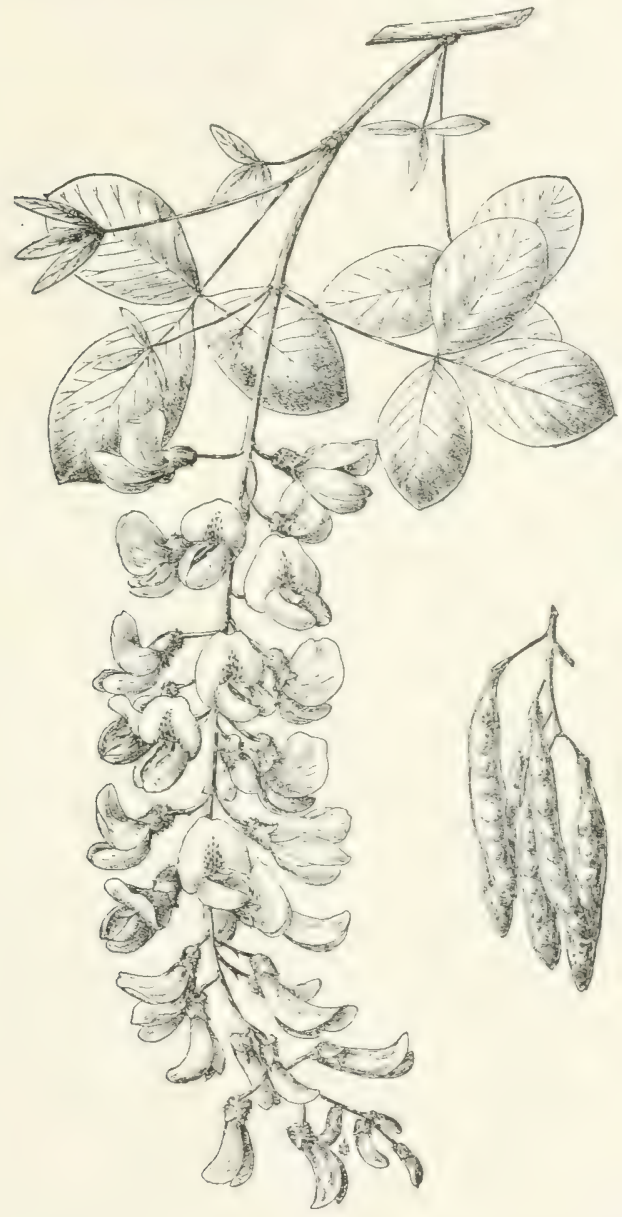

FIG. 87. - Golden Chain. Laburnum vulgare Griseb.

J. rupestris (120), the Califomia species, a slender, small tree of more upright habit, otherwise resembling the black walnut, would probably make a good ornamental tree in Southern States. 
J. regia Linn. (12 I), called English W'alnut, but a native of Persia, a small tree of roundish outline, flattening its crown with old age, has little attraction outside of its fruit, unless its glossy, light green foliage,

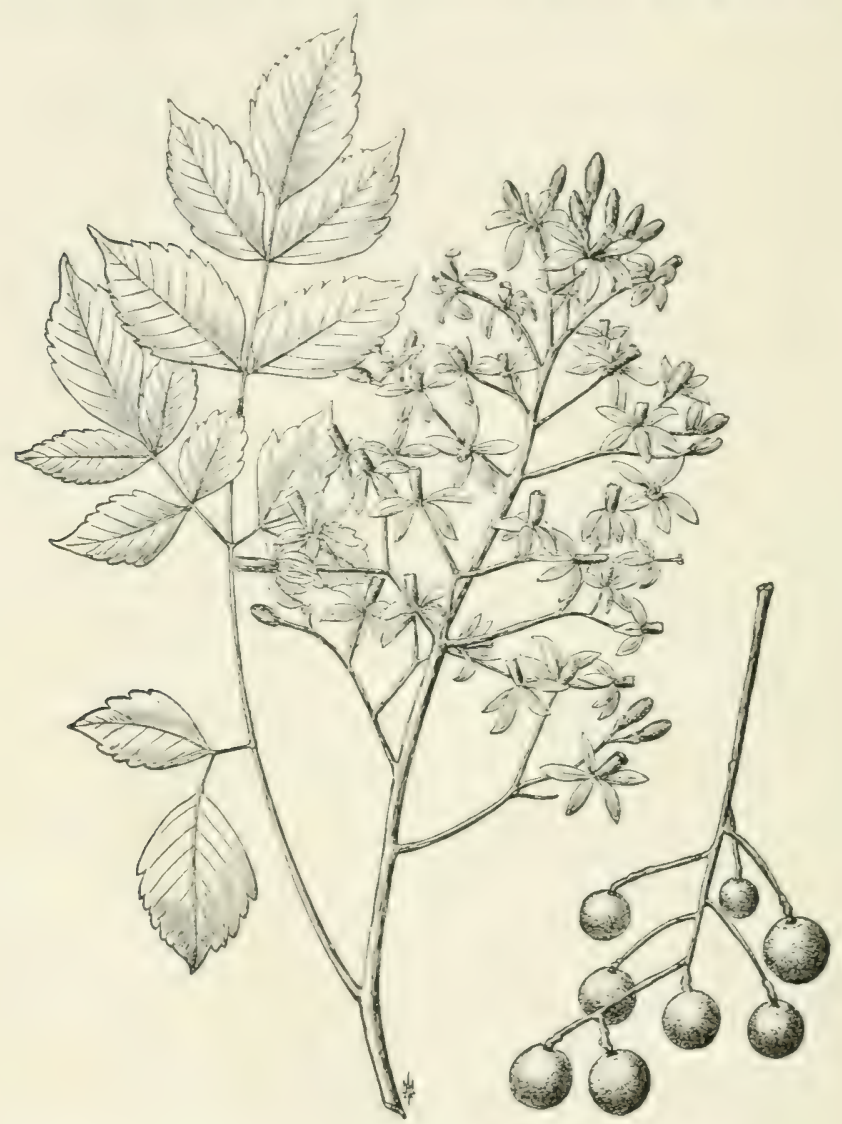

FIG. 88. - Chinaberry or Umbrella Tree. Melia Azedarach Linn.

smooth, gray stem, and purplish branches are needed for contrast. Probably not hardy north of New York.

An interesting cross tree of rupestris and regia has been produced by Luther Burbank, which excels in rapidity of growth. 


\section{Sumach}

J. Sieboldiana Maxim. (121 bis), from Japan, a small broad-crowned tree, is from the omamental point the best, and in addition excels in hardiness, being perfectly at home in Ottawa.

Kolreuteria. K. paniculata Maxim (I22), Vamish Tree, is a well-deserving small tree with broad rounded outline, from China and Japan, half hardy to Massachusetts and into Canada. The somewhat stuff, open, irregular, but picturesque branch habit is relieved by a rather heavy foliage of elegantly cut, compound leaves, dark green, changing to deep yellow, and by large panicles of showy, bright yellow, small flowers (July, August), borne on the ends of the shoots, giving it a rare and graceful appearance at it time when little else is in bloom. Peculiar green pods of fruit add to its interest. It is shade-enduring, gives a pleasant shade without obstructing the view, and has a long leaf period. It is best suited to cool, deep soils, but is also adaptive to dry soils, easily propagated, but slow growing, and free from insects. It is adapted to small parks and small places, and in the foreground of groups.

Laburnum. L. vulgare Griseb. (123) (Cytisus), Golden Chain, Laburnum. One of the most ornamental small trees, often shrul)-like, from Europe; with a slender upright habit forming an irregular, picturesque head, with slender-stemmed, smooth, shining leaves and long, pendent racemes of yellow to purplish "Golden Chain" flowers (April to June). Grows in any soil not wet. Does not respond to pruning. Adaptive to small lawns and foregrounds or borders of groups.

Melia. M. Asedarach Linn. (124), Chinaberry, Umbrella Tree, is a small tree from India and Persia, for southern planting only; here long established and running wild. It is one of the best shade trees, with a very dense, rounded crown, and a very long leaf period, ornamental in its bright green, doubly pinnate foliage, and numerous lilac-colored flowers (April), followed by yellowish berries. It is adapted only for use as single, small ornamental or shade trees.

\section{SUMACH}

Rhus. Of the one hundred or more species of trees, shrubs, and vines, among which are several poisonous ones, three native and two 


\section{Trees for Shade and Ornament}

foreign species, each entirely different from the other, lend themselves to ornamental use on atcoumt of thower and fruit as well as of foliage, which is expecially beautiful in atumn coloring. Most adaptive to sterile soils, and free from troubles, they are among the most satisfactory ornaments, as small trees, or shrubs in masses.

R. hirla (L.) Ludw. ( 125 ) (typhina), Stughorn Sumach, so called from its stiff, prong-like, rather open and coarse branch system, the youndr shoots being velvety, is a small tree, with a compound leaf resembling but more graceful than the dilanthus, tuming brilliant scarlet and crimston in the autumn; with an early, striking, erect fituit stand of scarlet berries holding on through the winter and becoming velecty purple. It suckers batly. It is rustic in its asject with its open unsymmetrical branch system. It is adapted to grouphes in small shrubbery and for neglected, rough, stony corners, for which it and its congeners are specially fitted. It is best userl in erroups with other shrubs to hide its poor form, and set off its elegant foliage.

R. copallina, Linn. (126), Diearf Sumach, native from New England south, is also a small tree, lut often shrub-like, with more compact form and with glossier dark green foliage than the precerling, pale to white beneath, turning rich maroon, although otherwise similar to the former. It is adaptive to most sterile soils. It often remains not over a foot high, spreads freely by root suckers, and hence is useful for quickly covering rocky and barren spots and sand banks.

R. Cotinus, Linn. (127), Smoke Tree (I'netiun Sumach), Mist Tree, Purple Fringe, so called from its jeculiar misty-looking inflorescence, a dwarf tree (up to eight feet), from the Caucasus, but hardy to Ottawa. It is a peculiarly pleasing object in a small lawn, with its formal round head, bluish-green, almost circular leaves, turning rosy crimson, with very long leaf period and unusual, flesh-colored, feathery or wigr-like flower heads. Hardy and adaptive to all soils. 'To be used both singly and in groups.

R. glabra Linn. ( 28 ), Smooth. Sumbch. A small tree or shrub (threc to ten feet high) with smooth branches, of similar halsit and adaptation an the preceding, and the hardiest of all, with showy foliage and crimson fruit, retaining the latter long after the foliage has fallen. I variety, laciniatu ( $28(l)$, smaller in stature, with fern-like, cut foliage, is still more elegant in its crimson autumn colors.

R. semialata Murr. (129), (()sbekii), Osbeck. Sumach, is a variety of an Asiatic species, semi-hardy, of larger size (twenty to thirty feet) 


\section{Mountain Ashes}

than the native species, and a more rapid grower. Dark green shining foliage above, rusty-colored beneath, and its pure white showy flower heads (July; August) are its beauty, the fruit and autumn colors (orange to crimson) being less conspicuous.

Sophora. S. Japonica Linn. ( 130), Pagoda Tree, one of the twenty-five species of trees, shrubs, and herbs, mostly of southern distribution, is a pretty, erect, round-headed, small to medium-sized tree from Japan; only half hardy north of New York and Massachusetts. It is attractive by reason of its smooth, dark green bark for winter effects, and in summer by its graceful, delicate, dark blue-green foliage, and large panicles of cream-white, pea-shaped, late flowers (August, September). Otherwise, it resembles the Black Locust, and, like it, is adaptive to dry soils.

A pendulous variety, pendula ( $13 \circ a$ ), is one of the best weeping trees in existence.

S. platycarpa Maxim. (I3I), also from Japan, with large yellow flowers, is hardier than S. Japonica and may therefore be used farther north.

S. secundifora Lag. (132), the native Texas species, a small tree or shrub, with finely scented, large, violet-blue flowers (June, July) and glossy leaves, is commendable only for southern planting.

\section{MOUNTAIN ASHES (SERVICE TREE)}

Sorbus (Pirus). This genus contains some thirty species and a number of varieties of small trees, mostly of northern range and from mountain sites, hence very hardy, belonging to the apple tribe (which see on page 294). They are among the most pleasing hardy ornamentals because of their finely cut, ash-like leaves, turning orange-red in autumn, their flat clusters of white or pink, compound flowers (May, June), and the yellow to scarlet-red clusters of berry-like fruit, which hang on from July throughout the winter. There is very little difference between the two best known species:

S. Americana Marsh. (133), American IIountain Ash, which produces a greater abundance of fruit, but less brilliant in color than the following, has more taper-pointed leaves and is perhaps of smaller growth; and

S. aucuparia Linn. (I34), Rowan Tree, the European species. Both 


\section{Trees for Shade and Ornament}

are small trees with roundish apple-tree-like outline and open crown, growing in any soil, and especially tit for rocky hillsides, hy themselves as garden trees, or in foreground of conifers to add picturespuesness. They are both free from leaf insects, but liable to attacks by the apple borer. They are casily transplanted, but not responsive to pruning.

S. Aria Crantz. (I35), White Beam, from Europe, is a small tree with conical outline, attractive by its pleasing and distinct deep green, deeply cut foliage with downy white underside, which gänups well with evergreens.

S. torminalis Crantz. ( $3^{6}$ ), Hild Serice Tres, a handsome, small, round-headed tree, with spreading habit, and foliage of lobed leares, the upper side dark or bright green, the lower white, turning bright red, and with orancre-red fruit, is noteworthy for its adaptation to clry and exposed sites and especially to limestone soils.

\section{BROAD-LEAF TREES WITI SIMPLE LEAVES}

\section{MAPLES}

Acer. A large genus, with sixty to seventy species of large, medium and small-sized trees, and some few shrubs, which comprises the most satisfactory group of ornamental trees for lawn and roadside planting, of wide range, adaptive to a variety of soils, and most easily transplanted. They all have a pleasing diversity of variously cut foliage, quite variable in outline and color, mostly turning into brilliant tints. The majority are of upright habit. They are shade-enduring and as a rule rapid growers, generally clean and liable to few insect or other troubles. Most of them are fine specimen trees.

At least five native species have value as ornamental and shade trees:

A. saccharum Marsh (137) (saccharinum), Sugar Maple, the one mainly used for sugar orchards, and its southern counterpart, 1. nigrum ( $13^{8}$ ), Black. Maple, usually not recognized as different, are both first-class shade and ormamental trees, with a most compact crown of globular outline, rather stiff, upright branch habit; the black maple leafing out earlier, with darker, less deeply lobed, generally larger, and more flaccid foliage; both turningr pale yellow in autumn. They are moderately rapid and persistent growers, especially in rich soils, and very shade-enduring, adaptive to a variety of soils, but best devel 


\section{Maples}

oped in good loam. They are preferably used as single specimens, but make fine avenues, if not planted too close together.

Closely allied, and similar in all respects, is the species of the Gulf States-

A. floridanum Chapm. (139), fit only for southem planting.

1. rubrum Linn. (I fo), Red Haple, of similar range as the sugar maple, is a most satisfactory tree from every point of vicw. Similar in form to the sugar maple, although perhaps less stiff and regular in branch habit, its beauty lies in the dark green foliage, pale to white underneath, turning every sharle of red, and in the bright scarlet flowers and fruit which appear in early spring before the leaves. It is arlaptive to swampy situations as well as to the dricst. If properly placed, it is a sturdy and a more rapid grower than the former.

A. saccharinum Linn. (I.tI) (dasycarpum), Silier. Maple, resembles in some forms of foliage the red maple, although otherwise it is quite different from the former two, being irregular in outline with a rather open crown and a straggling, spreading, yet graceful branch system, with long slender, often pendent, branchlets. The foliage is deeply cut into many acutely-pointed lobes, pale green above, silvery white beneath, and very variable in outline, but always most elegant. It is a medium-sized tree, but rapid grower, especially in rich loam, where it develops its best form and shadiest crown, but it thrives also in sandy and gravel soils, with a slimmer development. Unfortunately its long, weak branches are easily broken by storms, hence its beauty is of limited duration except in sheltered places. By systematic pruning this trouble can be checked to some extent.

A most pleasing, cut-leaved variety, A. If cirii ( 14 I $a$ ), vies with the cut-leaved birch in elegance, but, like all such freaks, is to be used with discretion.

A. Pennsylzanicum Linn. (I 42 ), Striped Maple, Moosewood, a small, slow-growing tree of upright, handsome, oval form, with large, dark green, flaccid foliage, long pendent racemes of flower and fruit and green-striped bark, is one of the most attractive small trees of northern range, the most shade-enduring of this very shade-enduring genus. By grafting on other maples, it can be made to grow to much larger size. It needs rich soil for best development. It is fine for large border plantations.

A. spicatum Lam. (143), .Mountain. If aple, occurs generally as a shrub, with small, pleasing foliage, turning to a variety of colors in autumn. 
1. Negunde Limn. (1+4), Boxther, .1sh-lowed Maple, is a small to medium-sized tree, native from Manituba south, with compact, rounded

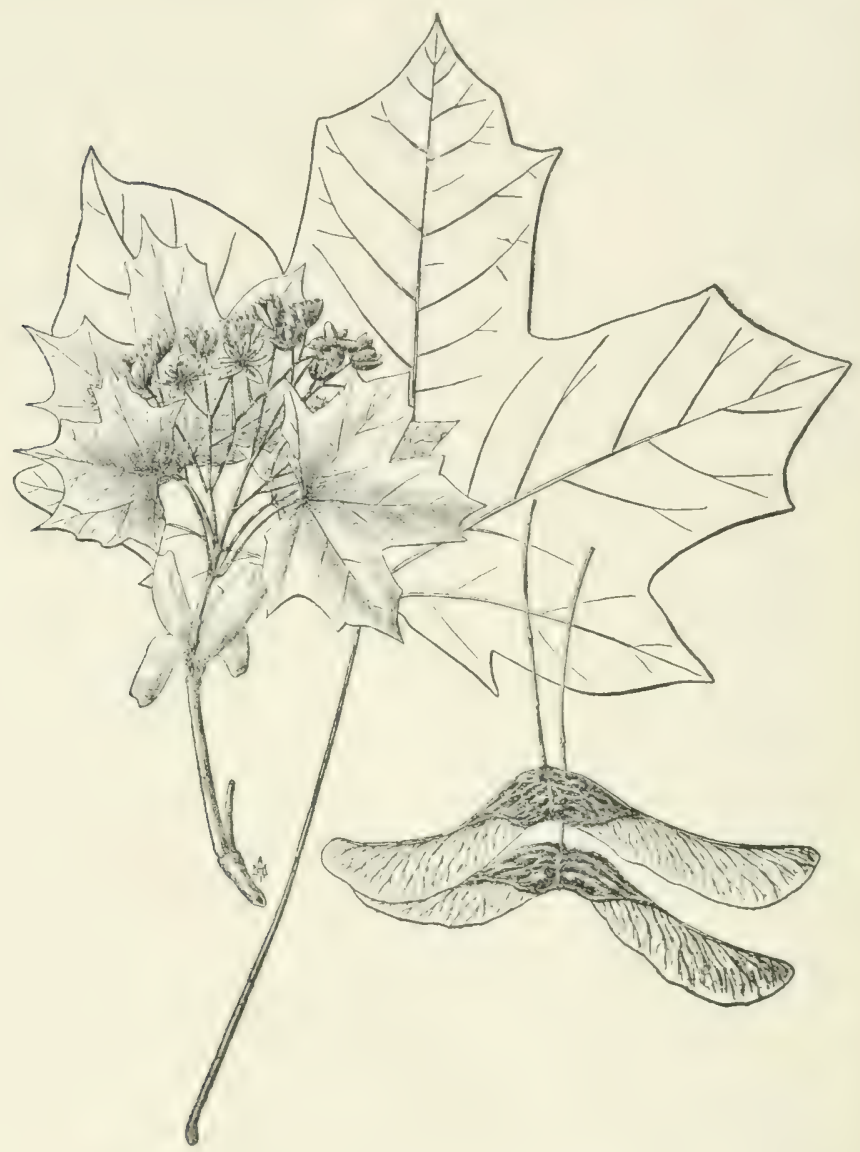

FIG. 89. - Norway Maple. Acer platanoides Linn.

crown, its green branchlets of interest in winter, and its ash-like foliage in summer. It is of very rapid growth on good soils, but short-lived on poor ones, although adaptive to almost any soils excepting wet ones. 


\section{Maples}

It is shade-enduring and very sharly, a gnod street tree for narrow streets, and well adapted for grouping with conifers.

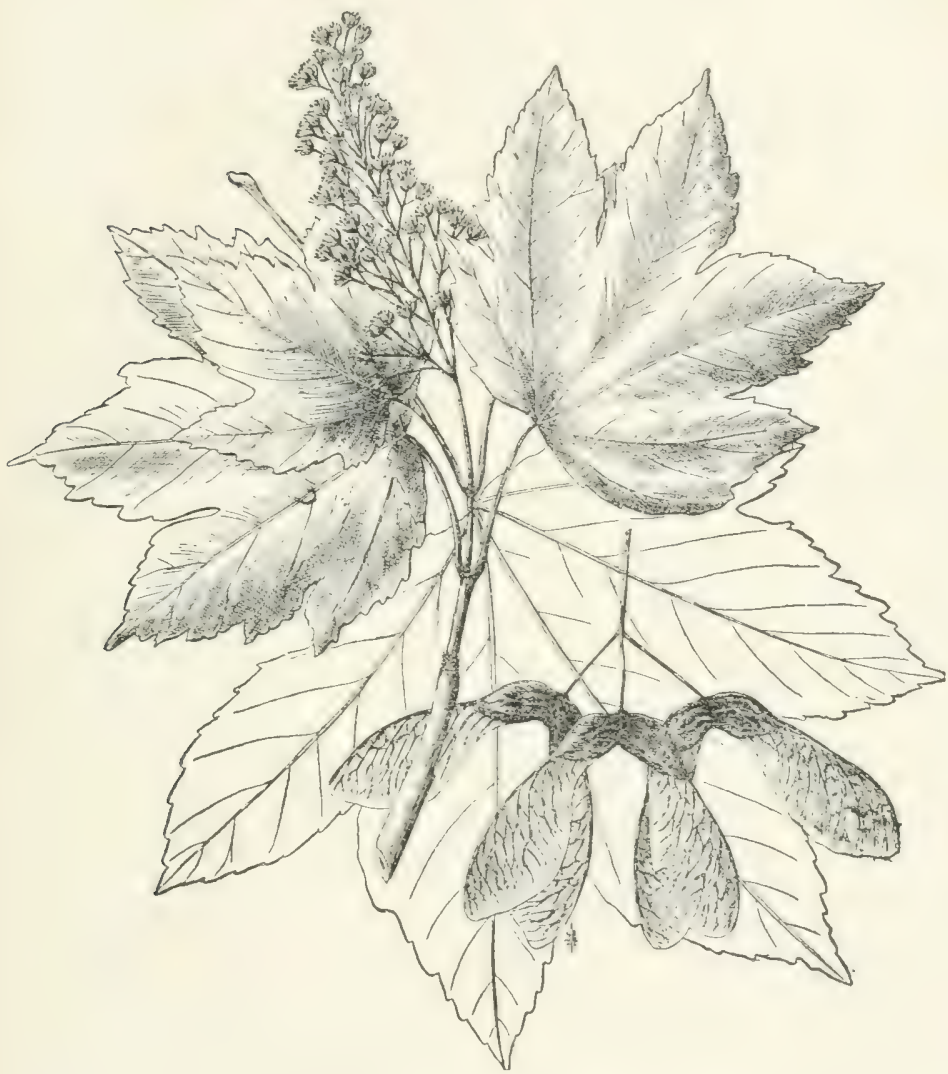

FIG. 90. - Sycamore Maple. Acer psendoplatanus Linn.

1. macroply yllum Pursh. (i 45 ), the Pacific Comst or Oregon . Iaple, is a large, rapid-growing tree, striking by its immense size of foliage; hardly hardy north of Washington.

Of the many exotic species at least four European ones are desirable, and especially the first two mentioned are not only perfectly acclimated, 


\section{Trees for Shade and Ornament}

but have points which make them equal, if not superior in value, to the native species:

A. platunoides Linn. (s 46$)$, Vorcery Maple, is nearest in outline, habit and form of foliage w the sugar maple, except that the foliage is usually larger, of somewhat darker shade, and its dense, finely fissured, brownish lark is superior to the gray, flaky bark of the sugar maple. It is the finest and earlicst blomer among the maples, with pendulous

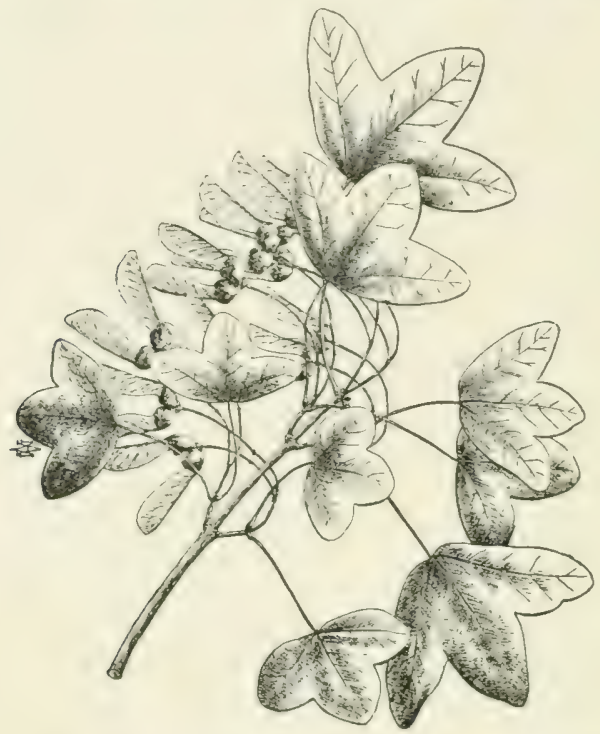

FIG. 9r. - Mediterranean Maple. Acer Monsspessulanum Linn.

clusters of greenish yellow flowers (March, April), and excels in its long leaf period. It is very hardy, a very rapid grower, and adaptive to any soil and situation; a perfect shade tree, free from all troubles, altogether the most serviceable maple.

A. pseudoplatimus Linn. ( $1+7$ ), Sycamore Maple, al:on from northern Europe, and hardy at Ottawa if grown from northern seed, is quite distinctive from all other maples by its large, rich, dark green, thick leaves on long reddish stems, and its long pendents of conspicuous, although green, flowers and fruit, a striking ornamental. In outline and branch habit it is less elegant and symmetrical than the former, being stiffer 


\section{Maples}

and statelier. Of rapid growth, and only slightly less adapted to soils than the former, it is an excellent shade tree, and is especially desiratile near houses.

There are three or four other small exotic maples deserving attention:

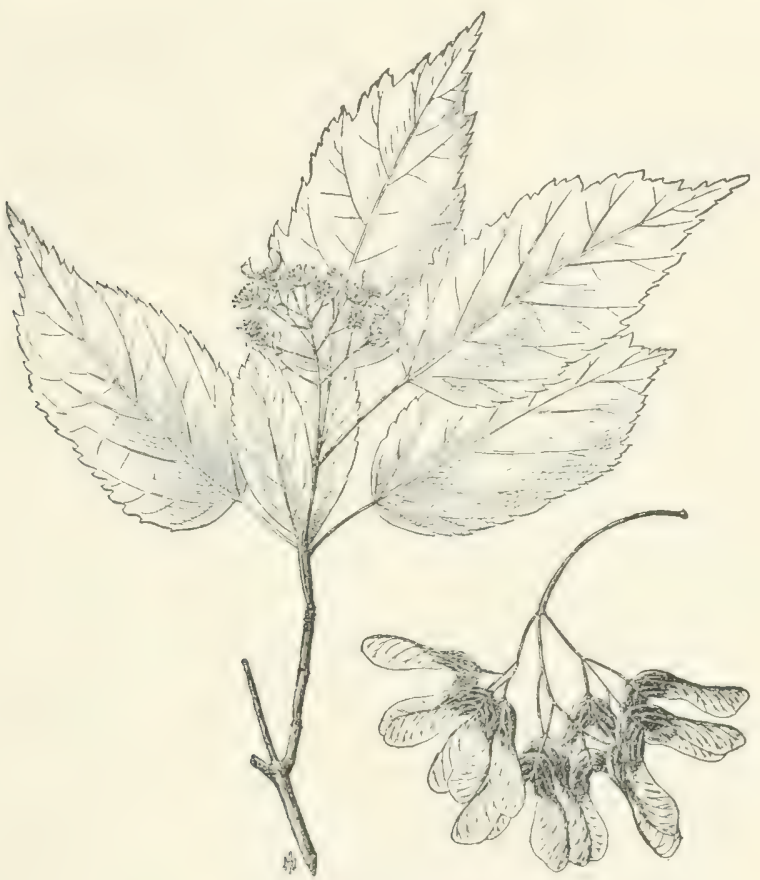

Fig. 92. - Tartarian Maple. Acer Ginnala Max.

A. campestre Linn. (I+8), known as English Maple, but distributed through all northern Europe, a tree rarely over thirty feet, with small roundish-lobed, attractive leaf, the foliage remaining green also in winter. Its iery formal hahit, making a very stocky, round head, fits it especially for planting on knolls, at comers, near a bend in the road, as the center of low shrublery, or in formal work. It is of slow growth, perfectly hardy and adaptive to soils.

A. Monsspessulamem Linn. ( 149 ), from the Mediterranean, very similar to the English maple, is fit only for southern planting. 


\section{Trees for Shade and Ornament}

A. (iimmala Max. ( 150$)$ (Tirturicum), Turturian .Ifaple, from Rusia, and hardy in .lanitoba, is a small shrul, or tree of shrub-like, irregular, roundish to elliptical form, with a dense, very pleasing, shiny foliage of roundish outline, not lobed, but only more or less deeply notched, which

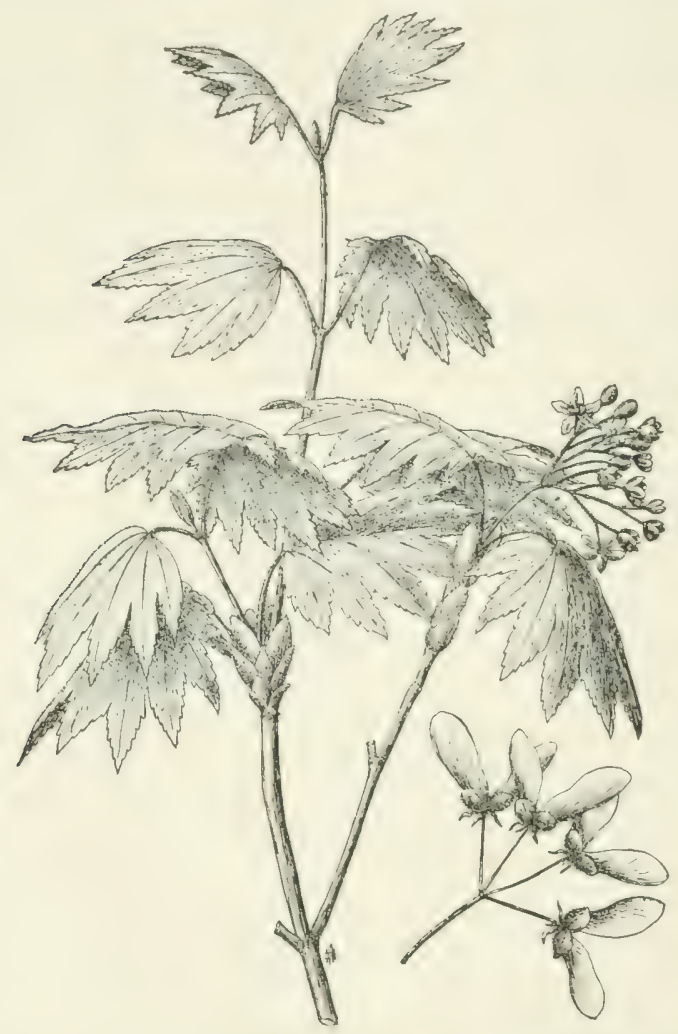

Fig. 93. - Japanese Maple. Acer Japonicum Thunb.

turns orange, crimson, to dark purple, answering the purpose for which the dainty Japanese maples are used, where these are not hardy. The fruit also colors pleasingly.

A number of nurserymen's varietic's increase the usefulness of this genus. Of these may be mentioned, besides .1. Wcirii, above referred to: 
1. platanoides laciniala ( $\mathrm{I} 50 \mathrm{a}$ ), a most distinguished cut-leaf variety; 1. Schaedleri ( $\mathrm{r}_{5 \mathrm{I}}$ ), a fine Dorway maple, with the foliage turning first crimson, then copper color, and 1. Reitenbachi (152), another Norway, first green, then with advance of the season turning biood-red to purple; A. Horlci ( 153 ), a sycamore maple, with golden-hued leaves in spring. A mere oddity is the Lagle-claw Maple, A. platunoides crispum ( 154$)$.

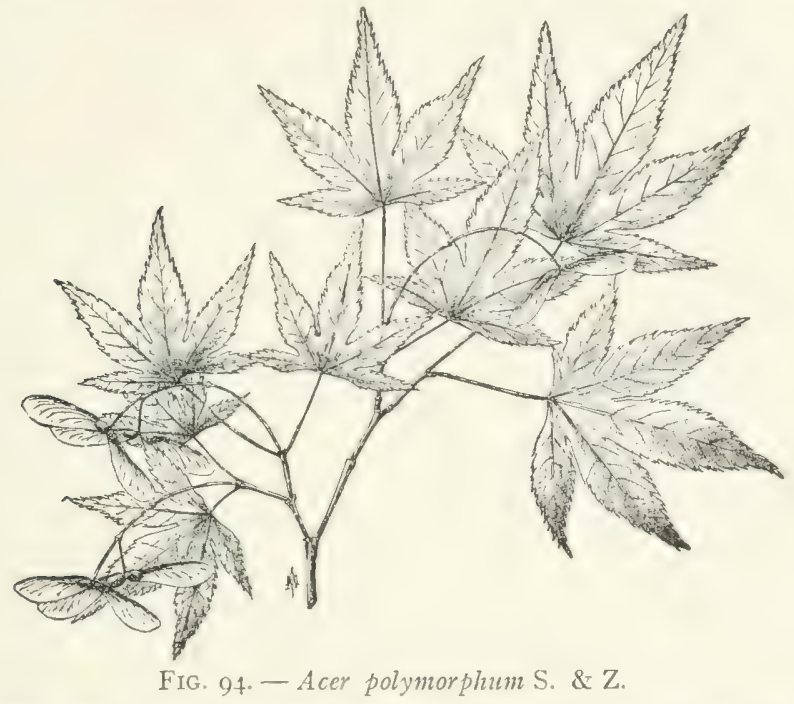

Besides the native mountain maple and the Tartarian maple, which often grow into shrub-like forms, there is a group of maples from Japan, of two species and a long list of varieties, mostly dwarfs, which, although trees in form, are shrub-like in effect on account of their low stature. They are peculiar, and at the same time most delicate in outline and in type and hue of foliage; for color effects unique and most interesting in carefully arranged, refined plantations, or single specimens near the house.

A. Japonicum Thunb. (155), the type ten to fifteen feet high, with bright green, merely scalloper or fluted leaves, and delicate pink flowers in early spring, is hardy to semi-hardy into Canada. It has given rise to a number of varieties, with larser, smaller, deeply cut and variously colored foliage. 
A. polymorphum S. \&. 7. (palmalum) (156), the basis of the finest series of low varieties, the type twetwe to eighteren feet, with deceply ant to palmate (ive-fingered) latses, formed of oblong to chliptic, small leaflets of various shates. The prettiest, dainticst is .1. atropurpureum dissectum (1 560 ), hive or six to twelve feet high, with a foliage of fern-like appearance and clark purple follage throughout the year, on grac. ful, spreading sprays of branchlets. Not hardy in Ottawa.

A. sanguinem (1566) (blool-leaved) vies with the former for first place, with a brighter-colored hue.

A. roscopichm ( $156 c$ ) is a rarer treelet, with variegated white, yellow, rose, and green tints.

\section{ALDERS}

Alnus. Some twenty species, mostly of northem range, hence hardy, of small trees or (mostly) tall shrubs, rapid growers, with dark, simple foliage, mainly adapted for wet soils alongr streams, but will thrive in drier sites. They are useful as cheap nurses, for grouping in thickets. and as fillers, and combine well with foliage of a leathery or semi-evergreen character, for fringe's alongr watercourses, ponds, and lakes, massed as they appear in nature, and as a bickinround to refined plintations; the few tree forms fit for small lawns. Their early flowers, appearing with the first breath of spring in graceful, yellowish tassels, are their most attractive feature.

Of the tree forms, the largest and best is the European-

A. glutinosa Gxrtn. (I57), Black Alder, an interesting as well as handsome small tree, with a symmetrical, conical, or elliptical outli:e and with luxuriant, shiny, dark green foliage, of very long leaf period; its slender, yellowish, tassel-like catkins in carly spring, and its conclike fruit and dark bark making fine winter effects. Although most natural near water, it will grow well in dry situations, and is very com. mendable for small places. It is somewhat subject to attacks by leaf miners. It is a rapid grower, adaptive to all solis, and hardy even to Manitoba.

A cut-leaved variety, A. imperialis (157a), is very handsome, with compact, very fincly shaped foliage, and pleasing, conical form.

A. cordifolia (cordata) Ten. ( $5^{8}$ ), from Italy and the Caucasus, a round-headed tree, is said to be still more ornamental than the former, with a distinct, glosicier foliage, changing to orange-yellow, lut is not quite hardy in the north. 


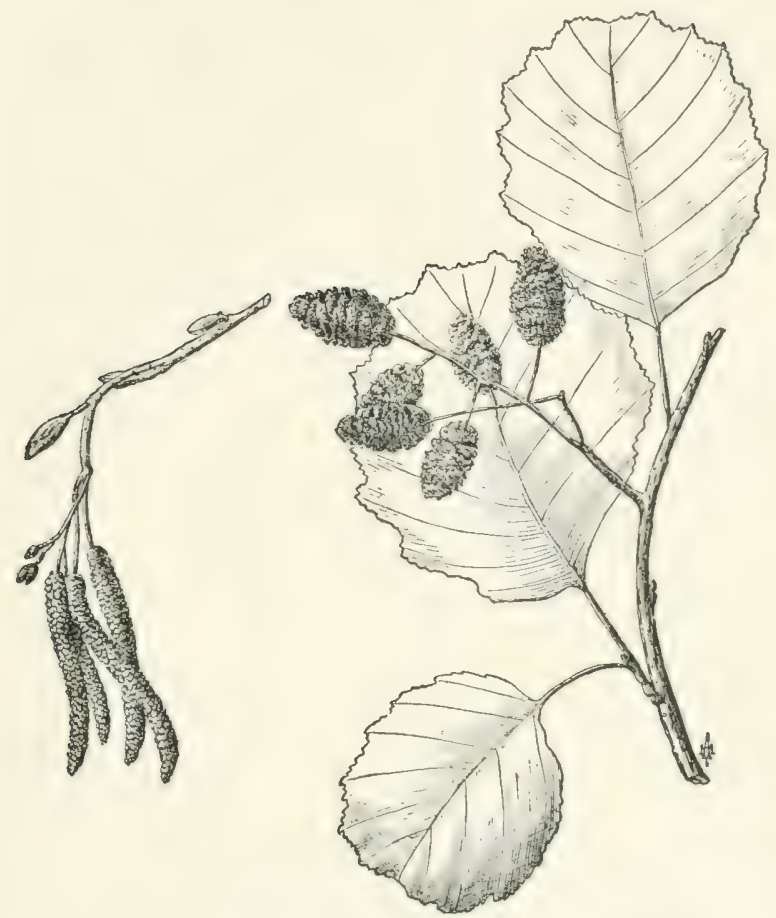

FIG. 95. - Black Alder. Alnus glutinosa Gaertn.

The native species, six in number, are mostly shrubs or shrub-like trees, useful for grouping on rocky sites and along watercourses, so far but little utilized; among them, A. mgosa K. Koch. (I59) (serrulata); A. incana Willd. (I60), with brown and white dotted branches; 1. viridis D. C. ( $16 \mathrm{r}$ ), our commonest native shrubs; A. maritima Muhl. (162), with shining foliage and attractive by the development of male catkins in the fall. All of these lend themselves effectively for massing, alone or with willows, their foliage starting earlier and remaining longer. They are most adaptive, and easily transplanted.

\section{SHADBUSH OR JUNEBERRY}

Amelanchier. A. Candensis Medic. ( $\mathrm{I}_{3}$ ), one of the representatives of a genus of the rose family, from North America and Japan, with a few 


\section{Trees for Shade and Ornament}

ipecies of small trees (fifteen to thirty feet), is one of the loveliest of early bloomers in the woods (early . April), with pure white, delicate flowers in short, open racemes, appearing with the delicate foliage in

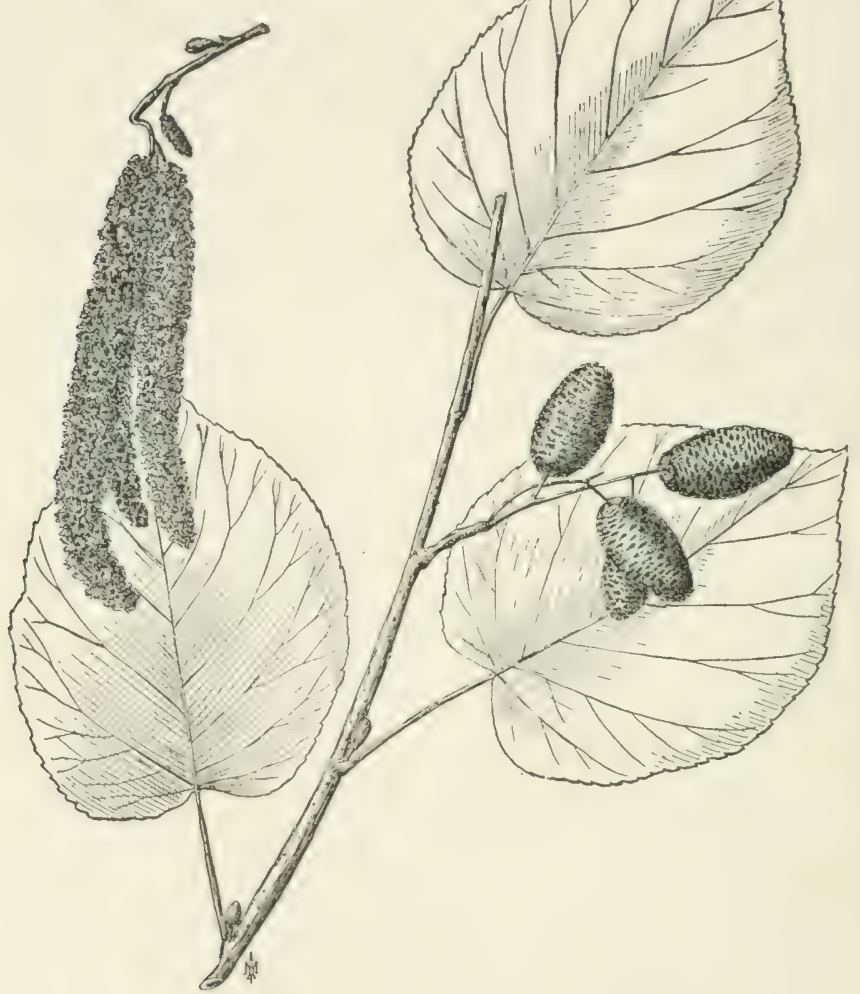

Fig. 96. - Italian Alder. Almus cordifolia Ten.

profusion, beginning the show when quite young. The thin, roselike, light green leaves turn golden-yellow; the dark blue, edible fruit is formed in June, and gives rise to its Canadian name, Sugar Plum. A round-headed small tree, it is hit for small places or to be grown in shrub form on hillsides, embankments, etc., being hardy everywhere. It is good as a filler in large masses and combined with evergreens. 


\section{Birches}

1. alnifolia Nutt. (r64), Sascatoon Berry, a western species, is smaller, beginning to tlower when two to three feet high, and is later in blooming, otherwise similar to the above.

A. Asiatica Endl. (165) (Japonica), a Japanese species, differs loy the bright scarlet fruit, which hangs on until leaf fall, and is a stronger grower.

\section{BIRCHES}

Betula. Some thirty-five species, all of northern distribution, large, medium, and small trees and some shrubs $(B$. nuna). There are two groups distinguishable, which differ very much ornamentally, the white or paper birches, and the gray or black birches. The former are smatl trees and comparatively short-lived, characterized by their conspicuous white bark, peeling more readily in sheets, and usually with finer foliage than the gray birches, which have a darker, more compact, less flaky bark, and a simpler, coarser leaf form. It is the white birches, and especially the cut-leaved European variety, which, owing to their delicate, graceful foliage, tuming golden-yellow, their slender branches often with pendent branchlets, and their pure white bark, made Henry Wrard Beecher call them (after 'Tennyson) "the ladies among trees." Birches, especially the white one's, are among the most light-needing species, and are very rapid, but, with the exception of the yellow birch, not persistent growers. They are arlaptive, especially the white ones, to poor, sandy soils, and to any soils not wet (except the cherry birch). Having a tracing root system, they are easily transplanted, but as their fibrils are very delicate, this is preferably dome in early spring. As single specimens for small places or near the house, or in groups along watercourses, or on rocky ledges, or grouped with larch and hemlock, the conifers of similar grace, they are highly commendable. The white bark being rery conspicuous, such grouping with more sumber surroundings brings best effect. Lnfortunately, the white birch, especially the cut-leaved variety, suffers from a wood borer, which often becomes destructive.

B. alba Linn. (166), the European Birch (botanically, sereral species of small difference are distinguished), is the handsomest, the most graceful of the white birches, to which the above description applies most typically, and this, in its natural type, and still more in its cut-leaved form, with its pendulous branchlets and gossamer-like tracery of foliage, is most in use. It slonld not be confounded with the much l:ss 


\section{Trees for Shade and Ornament}

attractive, short-liverl, native White Birch (B. populifolia Ait. (167)), so common in New England, which is of use only when treated as a shrub.

A purple-leaved variety (atropurpurea) is very fine for color effect.

B. papyrifera Marsh. (168), Puper Birch, the most northern native tree species, is quite different from the above, with a sturdier, stouter, more open branch system, and large, oval foliage, handsome in a different way, and worthy to be planted in northern grounds more than it is, especially in combination with evergreens and variously colored deciduous trees for winter effect. A distinct and most pleasing form with narrow, glossy leaves and pendulous habit was found by the writer near Quebec.

Of the gray birches, two specie's, both native to our northern woods, have their ornamental value, differing mainly in the color of their bark.

B. lutea Michx. (I69), Fellow or Gray Birch, a stately tree, growing to large dimensions, of roundish outline. The small spurs or twigs from which the foliage develops give it a lively winter aspect, to which is added in older trees the pleasing effect of the bark of yellowish, silvery hue (from which the name), peeling off in very fine layers and curling back, giving it a somewhat shaggy, interesting appearance. The branch habit is upright and stouter than in the white birches, and the outline oval. The simple foliage is peculiarly arranged in pairs. It is adaptive to heary clay soils, but also to lighter ones, less light-needing than the white birches, but as rapidly growing. It is best used in single specimens in places where its large size can be accommodated.

B. lenta Linn. (170), Cherry or Sieet or Black Birch, is a mediumsized tree, of somewhat more southern distribution, hardly distinguished in its foliage from the former, but with a somber, dark, close bark, resembling that of a black cherry when young, and not, or hardly, peeling; of regular, graceful, roundish outline, and sometimes with pendulous branches. It is adaptive to wet soils.

\section{BOX}

Buxus, the well-known evergreen, is represented by a number of species of small trees and shrubs, two of which, with several varieties, are in cultivation. They are mostly trained into shrubs, especially useful for borders and hedges, capable of being sheared into any form, which has led to the well-known aberrations in formal gardening. Their shade-endurance makes them desirable for under-planting. 


\section{Box-Hornbeam - Chestnut}

They are especially adapted to combination with other evergreens, like laurel and rhododendron, and for winter effects. Tender to semihardy in the North.

B. semperierens Linn. (I7I), from England and southern Europe into Asia, is the common Box, a tree growing from three feet (north) to fifteen feet (south). The variety B. suffruticosa (I7I $a$ ) is the one mostly employed, being a dwarf, and hence easily kept as a low border. Varieties, B. aurea ( $17 \mathrm{I} b)$, with yellow-striped, and $B$. argentea (I $1 \mathrm{IC}$ ), with white-striped leaves, $B$. angustifolia ( $\mathrm{I}$ I $d$ ), with narrower leaves, and several others have their value.

B. Balearica Willd. (172), Minorca or Japanese Box, from western Europe and Asia, with large, yellowish-green leaves, makes a pretty tree, with compact, round head. Needs winter protection in the North.

\section{HORNBEAM, WATER BEECH, BLUE BEECH}

Carpinus. C. Caroliniana Walt. ( 75 ), is one of the most satisfactory, small (twenty feet), native, hardy trees of wide distribution; beech-like in appearance, with the same kind of gray, smooth bark, the stem peculiarly corrugated, with outline rather roundish or flat, horizontally spreading, somewhat straggling branch habit, with many small twigs, often pendulous; leaves beech-like, but thinner and more closely together, turning crimson, scarlet, or orange-yellow. It is a slow grower and shade-enduring, like the beech, but adaptive to more barren soils, although best near good water-supply. It is specially fitted for water scenery, also good for hedges which shear well, for undergrowth, and as a filler; free from insects.

C. Betulus Linn. ( 176$)$, the European species, hardly differs from the American, and is less hardy.

A number of Japanese and other exotics, small trees and shrubs, are used, among which $C$. Japonica ( 177 ) excels in graceful habit and elegance of foliage.

\section{CHESTNUT}

Castanea. A genus of five species, tall trees to shrubs, of considerable economic value, as well as ornamental by form, leaf, and flower.

C. Americana Raf. ( 178 ) (dentata), the native species, which is hardy into Canada, differs little in character from the less hardy European, C. satiz'd Mill. (I79), except in the size of the nut and longer leaf 


\section{Trees for Shade and Ornament}

period. Our species in its youth is of erect symmetrical habit, but in time becomes spreading and inclined to low branchine, formines a very broad, roundish crown with short, pendulous body; it is picturesque rather than pleasing in its outline, with a clean, grlosy, rather coarse foliage. The white, feathery, semi-pendent catkins, in Jums, lend additional attraction and even grace to the flowering tree. It is a very rapid grower, and adaptive to a variety of soils except wet and compact ones, but needs deep soil for its heart roots. Like all nut trees, it is not easily transplanted in older specimens. It is comparatively free from insects and other troubles, but unclean, the fall of the long flower catkins, of the fruit and its burs, and of the coarse foliage making continuous litter. In excellent sprouter, it repairs damase easily, and is moderately shade-enduring. It is best usid in specimens on large grounds, where it may rival the oak in picturesqueness, or else in groves. Lately, a most destructive fungus disease has developed in this species, which is making havoc in planted as well as in natural growths.

C. pumila Mill. (180), the associated Chinquapin, of more southern distribution (from New Jersey south), is a small tree, or more often a low shrub, and has a more attractive foliag. when in shrub form, namely, a narrower and silvery white leaf, a desirable ornament.

Castanopsis. C.chrysophylla I). C. ( ISI), the Pacific Coust Chinumapin, with a foliage glossy green above and golden-yellow on the under side, is hardy only in the South.

Catalpa. C.cordifolia Jaumel (speciosa). The well-knoirn Cala!pa or Bean Tree, is one of eight species, native, and from Asia, four of which are hardy. It is a small to medium-sized tree of southern and western distribution, but half hardy as far north as Ottawa, and perfictly so in New York. It is mainly of interest because of its large, tropical-looking and rather ungainly foliage, which is among the latest to appear and the earliest to fall, and for its large, upright panicles of striking, white, purple-tinged flowers, appearing late (June, July), and for itsold fruil puls (beans), which hang on through much of the winter. It has not much claim for beauty, with its ungainly, sprawling limbs and unsymmetrical outline. The successive fall of its flowers, leaves, and fruit makes it uncleanly, although it is free from insects and only occasionally attacked by a leaf spot fungus. It is easily transplanted and a very rapid grower on good soil, and is satisfied with most soils unless excessively dry. Its 


\section{Hackberries, Nettle Tree}

commercial value has been lately much overrated. Its main use is among flowering shrubs, for its flowers and large leaves.

C. bignonivides Walt. ( 182 ), its less desirable congener, is of more straggling habit, otherwise difficult to distinguish, and is very likely substituted in nurseries, unintentionally.

Of slightly superior value are the Japanese and Chinese species C. oiat, Don. ( $\left.8_{3}\right), K($ mpjeri), with smaller, more pleasing foliage, the small flowers with dull purple dots and the fruit in more delicate pods; and C. Bungei C. A. May ( I 84 ), a dwarf, with large glosy foliage, sometime's confounded with a nurseryman's round-headed, grafted form of bignonioides.

\section{HACKBERRIES, NETTLE TREE}

Celtis. Some fifty or sixty species in various parts of the world, trees or shrubs, have a secondary omamental value, inferior to that of the elms which they much resemble, although their more compact crown, their freedom from insect and funtrus diseases, their thriftiness in almost any soil, are advantages.

C. occidentalis Linn. (I85), Hackberry or Nettle Tree, a medium size to large tree, native and of wide distribution from north to south and west, is hardy in the Canadian Northwest. It is elm-like, but with smaller, darker foliage, more compact and spreading habit, and with a very dense foliage. It grows in most soils unless excessively dry. It deserves more attention for roadside planting and as a sharle tree than it has sn far received. Its freedom from diseases makes it especially desirable.

C. Bungeana Blume (186) (erroneously called Sincnsis, which is another species, not hardy), is a native of Clina, but, in protected positions, is quite hardy in the North. Its dark green foliage, glossy on both sides, is said to make an excellent shade tree.

Cercidiphyllum. C.Japonicum S. \& Z. ( $8_{7}$ ), from Japan, is one of the best of the recent introductions, being a small bushy tree (although in its native habitat growing to timber size), of pyramidal, almost fastigiate form, and handsome, roundish foliage of purplish tinge when unfolding, later becoming bright green, and turning yellow: and scarlet in the fall. Its foliage develops on small spurs or short shoots all along the stems and branches, making it specially leafy when young and the foli- 
age persists through winter in it: younger stages. It is harely as far as Ottawa and grows rapidly in rich, moist soil.

Cercis. C. Cancidensis Linn. (ISS), Rad Bud, Iudas Tree, is one of seven species, native and from southern Europe and Japan; a small

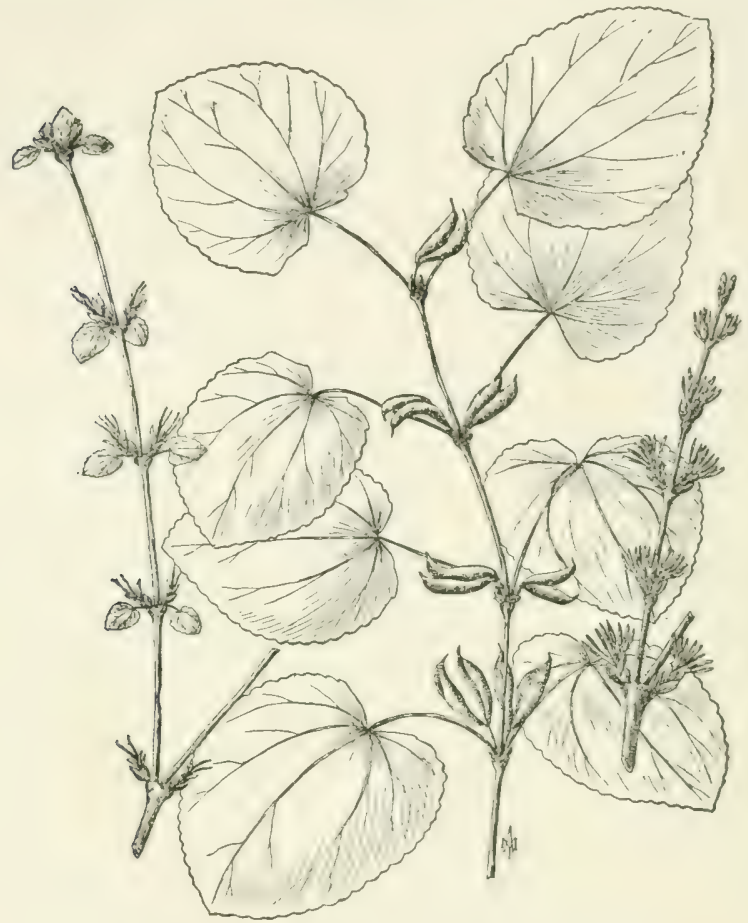

FIG. 97--Cercidiphyllum Japonicum S. \& Z.

(twenty-fore to thirty feet) native tree of wide distribution from New Jersey south, but hardy farther north, and apt to "winter-kill" in unprotected situations. It is of roundish outline, and most pleasing and showy, not only in its profusion of bright pink to red flowers which in April before leafing adorn in a singular fashion the almost black-barked branches and even the trunk, hut also in its round, somewhat heartor kidney-shaped, glosyy, dark, bluish-green foliage (May), light green 


\section{Dogwoods}

to silvery underneath. It thrives best on well-drained soils, is easily handled and free from insect troubles. It may be used very satisfactorily for its early flower effect in front of conifers and grouped with shrubs or other small trees on woodland edges. Its color effect being very strong, it is best combined with early bloomers of lighter color.

The European C. Siliquasirum Linn. (I89), and the Japanese C. Sinensis Bunge. (I90) (Japonica), the latter more shrub-like, are less hardy and have hardly any superior points except that they bear larger and more profuse flowers.

Chionanthus. C. Tirginica Linn. (rgr), Fringe Tree, is a small, slender tree, often shrub-like, native from I'ennsylvania south, but in sheltered positions hardy north to Ottawa. Its large, deep-green and glossy, magnolia-like leathery foliage (unfortunately late in leafing out) and an abundance of long drooping panicles of delicate white, peculiarly shaped, lace-like flowers (May, June), constitute its ornamental value. It is free from insects and fungus diseases, and adaptive to most soils, but prefers moist ones. For borders of groups and in single specimens, or among garden shrubs, it is satisfactory material.

\section{DOGWOODS}

Cornus. Some thirty species, small trees and shrubs and perennial herbs, of wide distribution, and mostly hardy and frugal. Many of them are attractive in flower, foliage, and fruit. They are very compact, bushy, and shade-enduring, indeed are preferably grown in the shade, and in northern localities in protected places. They are adaptive to soils and free from insects, except a scale. They are primarily used for large border plantings in coarse naturalistic arrangement, and for color effect in winter and carly spring. Many of them having variously colored branches, they especially lend themselves for winter effects.

C. florida Linn. (192), Flowering Dogutood, mainly of southern distribution, but hardy into Canada, a tree rarely over thirty feet, very spreading, apple-tree-like in habit, is the earliest and most luxuriant bloomer, its large greenish-white flowers appearing before any foliage is out. The foliage, crowded to the ends of the twigs, is made of rather broad shining leaves. With its brilliant crimson to dark red foliage and its scarlet-red berries, it makes fine autumn effects. It is specially 
adapted for skirting boundaries of ererereen groups, and for the interior of groves, but it needs rich soil and grows slowly.

Of sereral varieties the red-flewering one (rubra) may have its place in grouping with the white-flowering; a pendulous one makes a grool weeping form.

C. alternifolia Linn. (193), Alternate touf Dogatood, is a smaller

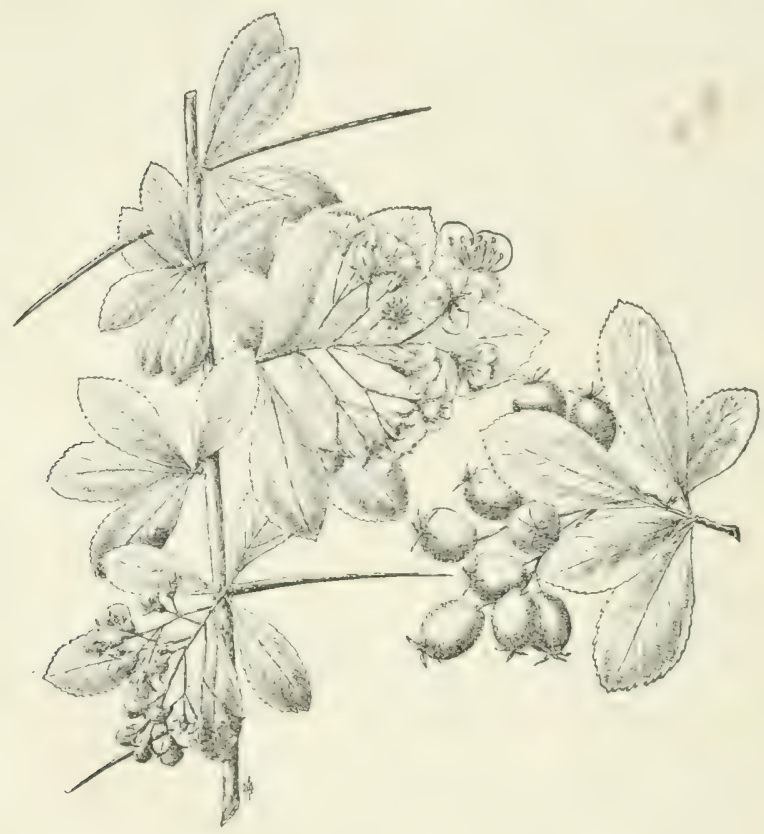

FIG. 98. - Cockspur Thorn. Crataegus Crus-galli Linn.

hardy native tree, or more often a shrub, with smaller yellowish-white flowers (June) in hat clusters, and llack to blue berry-like fruit, with foliage datk sreen above and frale leneath, with a horizontal spread of bright shiny-green branchlets.

For winter effects the furplish branches and silky down of the native C. amomm Mill. (I94) (sericea), Kinnikinnik, a spreading shrub (five to ten feet) (bearing white flewers in (lusters and blue berries), and the red branches of the red Lurepean C'. sanguinea Linn. (I05), or 


\section{Thorn Trees. Hawthorn}

of the American stolonifor (Igh), Red Osier, also both shrubs, are commendable and hardy.

C. circinata L'Hert. (197), native from Canada to Floridla, is a shrub) (five to ten feet) with numero stender branches and sprearling hearl, especially useful in that it thrives in sandy soils. The white thowers appear in flat cymes (May), and are followed by pale blue fruit.

For early color effect, the European -

C. Mas Linn. (198), Cornelian Cherry, half hardy into Canada, a small, round-haded tree or shrub, with glosiy foliage, and a profuse inflorescence of telicately scented, yellow flowers, followed by large, elliptical, red fruit, is commendable.

C. alba Linn. (199) (turtarica, Sibcrica), an Asiatic, very hardy tree species with white flowers and white berries and fine, red branches;

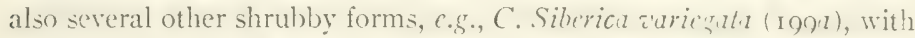
variegated, yellowish-white and green foliage, are us:ful for contrasts, but the finest of the rariegated is C. Spethi (19gh), the leaves dark, almost bronze in spring, assuming yellow and white margins, which persist.

C. Honda Burg. (200), a recent introduction from Japan, is a small tree, similar to $C$. florida, the flowers appearing after the leaves and being whiter and star-shaped, and the bracts (which are the showy part) elliptical. It is hardy in Massachusetts.

\section{THORN TREES, HAWTHORN}

Cratægus. A genus of over one hundred and fifty species and many varieties, mostly of northern range, furnishes small trees and shrubs, highly ornamental throughout all seasons in their form, foliage, flowers, fruit. Their form is rather irregular, sometimes straggling, but usually sturdy and of roundish outline, and they can be readily trained to any desired form. The foliage of each is distinctive, usually prettily cut, dense, of lively hue, and turning to various brilliant autumn colors. The flowers are white, pink, or scarlet, in some cases double and roselike, generally in flat-topped clusters, appearing in the different species at different times, and hence may be made effective by grouping them together. The apple-like fruit is yellow or red, in a few cases blue, and hangs usually long into the winter. They are mostly spiny.

They grow best in rich loamy soil, but adapt themselves to stiff clay as well as to light, sandy soil. They are very hardy, healthy, and 


\section{Trees for Shade and Ornament}

sturdy, although leaf-miners, weevils, apple-borers, and other insects are not entirely absent. A powdery mildew sometimes attacks the foliage. Having a long tap-root, they should be transplanted early. They are moderately shade-enduring, respond well to pruning, and are suitable for hedges. 'They are most satisfactory ornaments for small grounds, yards, ficlds, etc, in grouping with low shrubs. As they are easily transplanted from fields, they may be used for quick effects, as accent trees, etc.

Not less than one hundred and thirty-two species are described as native to the United States, but there is still doubt as to their identification, some holding as species what others recognize as varieties. At least four or five, however, deserve special attention.

C. Crus-galli Linn. (201), Cockspur Thorn, a tree, perfectly hardy, growing sometimes to a height of forty feet, of very wide distribution, with wide-spreading branches in characteristic, shelving tiers or whorls and sometimes pendent branch tips, with thick, dark green, glossy leaves, turning bright orange and scarlet, with pinkish-white flowers (May, June), and bright red (edible) fruit hanging on into winter. It is adaptive to any soil and situation (seaside), and more shade-enduring than most of the others.

C. coccinea Linn. (202), Scarlet Thorn, a smaller tree (ten to twentyfive feet), of the same wide range and beauty, with regular form, light green, thin but dense, wedge-shaped foliage, white flowers (April, June), and striking, scarlet fruit, hanging long. A species or variety, C. macracantha (202a), has longer, slender spines and fragrant flowers. Several other varieties are in existence.

C. mollis Scheele. (203), IThite Thorn, which has sometimes been considered a variety of coccinca, but is now recognized as a species, is a most showy tree, with large leaves, bright green above, hairy beneath, large white flowers and brilliant, scarlet fruit, which does not hang long; but the white branches with chestnut-brown spines are effective throughout the winter.

C. pyracantha Pers. (204) (Pyracantha coccinea), the evergreen native species, is a shrub, some ten feet in height, its glossy leaves turning brownish-purple and hanging on long, and its scarlet fruit making it a most desirable omament in groups and for hedges, although a slow grower. It is hardy as far as New York.

C. oxyacantha Linn. (205), the true Hawthorn, is the best known European species, a well-shaped tree, of not more than fifteen to twenty 


\section{Persimmon - Beech}

feet in height, with rigid, spreading branches and many stout spines, deeply lobed and tonthed, glossy, roundish foliage, white, fragrant flowers in flat clusters, and deep red fruit persisting into winter. This species is hali hardy in Ottawa. A Siberian form of this, and a Siberian species, C'. samguinea Linn. (206), have been found hardy in the Northwest. A number of varieties, with pink, scarlet, and double flowers, offer additional ornamental value. Very subject to attacks of plant lice. A good hedge plant.

C. monogymu Jacq. (207), from North Africa and Asia, fuinishes a large number of useful forms, mostly shrubs, with double flowers, and other variations; among them, C. P'auli (207a), Paul's Double Scarlet, is most brilliant in color in early spring.

\section{PERSIMMON (EBONY)}

Diospyrus. D. Tirginiana Linn. (208), one of one hundred and eighty species, all exotic but this one, is a medium-sized to small tree, mainly of southern range, but hardy north of New York in sheltered and warm spots. It is of minor ornamental value, but of botanical interest, with its peculiar, platy bark, and brown plum-like fruit. When at its best, of pleasing aspect, with a rounded or elliptical outline, open irregular branch system, and glossy foliage, turning to rich orange. It is adaptive to almost any soil, but thrives best in deep rich ones. Having a long tap-root, it does not transplant readily. It suffers occasionally from a leaf spot fungus. It is best used in groups of small trees or shrubs on small places.

D. Kaki Linn. (209), the Japanese species, prized for its large fruit, is fit only for southern planting.

\section{BEECH}

Fagus. A small genus with five species; of wide, mostly northern range; large trees. Two of the species with three or four varieties are among the finest, most magnificent ornamental and shade trees in existence. With stately, upright form of oroid outline, in later life spreading; becomes ample and an admirable show in winter, with its slender, graceful sprays of twigs in shelving tiers, and long pointed brown buds and silver-gray, smooth bark. Delicate, pale green, glossy foliage in 
spring, becoming deep green in summer and turning brown, finally bleaching out white, persisting partly through the winter. Best developed in a loamy, even stili, deep), moist soil, but will also grow in shallower and drier situations and limestone soils; although then rooting near the surface and being poor in form. It is a rather slow grower, but is one of the most sharle-enduring frorest trees, and so shady that no grass will grow under it. Free from insects, and clean, but in later life liable to fungus discase, and in its gouth to frost and to sun-scald. Somewhat difficult to transplant on account of its deep rooting. A superior tree for lawns with ample space, rivaling the oaks, which it excels in quiet elegance. It is excellent for grouping with evergreens on a large scale.

Two species are planted:

F. foruginen Ait. (210) (.1mericana), .1merican Beech, distributed throughout the eastern United States and Canada and -

F. silvatica Linn. (2II), European Beech. The latter is somewhat less hardy but rather superior by virtue of its earlier leafing out, with

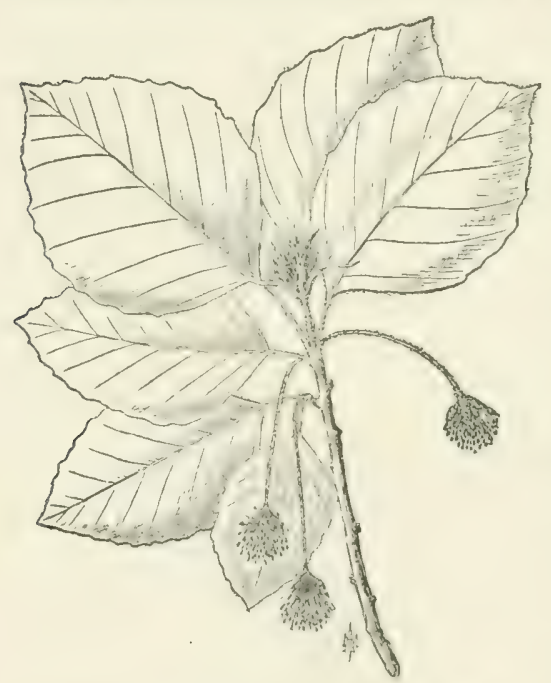

Fig. 99.-European Beech. Fagıs silvatica Linn. smaller, more delicate foliage, fringed by long hairs around the margin, and with a more compact form.

For color effect, a natural, well-known variety, purpurea (2п $a$ ), Purpleleaved or Copper Beech, furnishes the finest darkleaved form, fit for small surroundings and for contrast. It needs favorable sites to maintain its beauty.

Several cut-leaved and pendulous varieties are rather attractive; especially var. heterophylla $(2 \mathrm{I} b)$, and var. quercoides (2IIC), are beautiful, dense, low trees, with interestingly lobed foliage. 


\section{HOLLIES}

Ilex. This large genus of some one hundred and seventy-five species of world-wide distribution, and a large number of varieties, furnishes small trees and shrubs, of much ornamental value by virtue of their foliage, which in several species is evergreen, spiny, and unique, and by their deticate, white flowers, and their bright berry which hang. throughout the winter. Their great sharle-endurance and their slesw srowth fit them especially for under-planting; indeed, the evergreen species thrive best in the shade. They do not transplant easily when old, having a deep-going root. They are free from insects, but somewhat liable to frost, and "burn" badly. Since these are diøecious, i.e., male and female on different plants, and since the berries are their great attraction, care must be taken to select female trees. They are well adapted to grouping with other evergreen and leatherleaf foliage, and where dignity, yet not overmuch formality, is desired.

I. opaca Ait. (212), the native, evergreen Holly of the Middlle and Southern States, is hardy to half hardy worth into Canada, a small tree of oval outline, flowering in June, and much used for its red berries as a Christmas green. It thrives best in (leep rich soils and in the shade, although growing also in dry, barren situations, but not in wet and compact soils. It is not easily transplanted, and in exposed position its leaves become brown and shabby ("burn"). When transplanting, the leaves should be removed and the tree cut back.

I. aunifolium Linn. (2r.3), the En, rish (European) IIolly, is less hardy, thriving in New England, although only in well-protected places, but is superior to the former because of its larger, darker, thicker, more wavy and bristly, glosiser foliage, and greater abundance of red berries. To increase its hardiness, it is reafted on routs of the American holly. It prunes well and makes a first-class hedge.

The very striking, golden-leaved, silver-edged, mottled, and many other showy varieties are tender.

The two Japanese species, of the eleven native there, have hardly yet come into use, but are of great promise, namely:

I. latifolia Thunb. (2I.4), a larger tree, with much larger (up to seveninch) leaves, with red berries, said to be most beautiful;

I. crenata Thund. (2I5), with much smaller (one-inch), finer leaves and black berries, is a gem, and more easily transplanted; mostly in 
shrub form and much brancherl. Neither of them appears to $x$ quite hardy north of New York.

For more southem planting also, the native slarub or tree, I. a'omiloria Ait. (2I6), Cassene, may be mentioned.

The decidusus-leaved, native hollies, which hardly remind one in their foliage of the evergreens, are all shruls, of value ly virtue of the ir bright red fruit, for early winter effects ( $I$. verticillata Gray (2 I 7), monticold Gray (2Is), la'iz'ala (iray (219)), or for their shisy, leathery leaves (I. glabra (iray (220), decidua Walt. (221), (itssine Dahoon (222)), and are hardy.

Liquidambar. L. styraciflua Linn. (223), Red Gum, Siecet Gum, Bilsted, is a tall, bulky tree, native from Connecticut to Texas, and hardy. It is of conical, symmetrical, regular outline, rather open coarse branch habit, with large, star-shaped, glossy leaves resembling the maple, turning brilliant purple to scarlet with yellow tints, and with interesting ball-like sharp-pointed pendulous fruit hanging on through winter. 'The gray corly-winged bark of the sturdy brancles and the reddish-black deeply fissured bark of the trunk add to the winter effect. It is a most ormamental tree, free from insects, easily handled, moderately shade-enduring, and giving a pleasing shade; of molerately rapid growth. It is fit for use in formal landscape, and for shade.

\section{MAGNOLIA}

This family contains two genera with a large number of species, mainly of southern distribution, larere to small trees and shrubs. They are noted for their large and showy thowers and large leaves, generally clustered at the endes of the branches, and their coarse, epen, stragesling branch habit, although some have shapely outlines. 'They are medium to rapid growers, usually free from troutses, lighth-needing, with a decp root system, requiring special care in transplanting.

Of the large trees, the most satisfactory and most widely adapted, useful, interesting, and ornamental, is -

Liriodendron. L.tulipifera Lim. (22.4), Tulip Tree, Whitcaed, Y Cllow Poplar, the "Giant Tree" of the Last, with a range from north to south and into southwestern (Ontario. (irowing rapidly and of fine symmetrical form, ils perfectly straight stem and conical outline reminding one of the conifer habia. Besides its plasing form, its value lies in the medium-sized, peculiarly shaped, glossy foliage, in the fall turning 


\section{Magnolia}

golden-yellow; a unique, tulip-shaped flower, yellowish green, tipped with orange (June); a cone-shaped, erect fruit, hanging on through the winter; a soft, finely fissured, gray bark, and, in older trees, up-curved branch tips. It is, then, an object of interest through all the year; without insect troubles and with hardly any fungus disease; without bad habits. Having a deep root system it requires care in transplanting, thriving best in strong, deep, well-drained, clay soil, but adaptive. It is very light-needine, and does not stand pruning well. For shade near the house, single on large lawns, or for stately avenues, it is most commendable, but is less favorable in streets.

Of the true magnolias, most of the native ones are fit only for southern planting.

Magnolia. M. fietida (L.) Sarg. (225) (grandiftora), Bull Bay, of the Southern States, half hardy as far north as Philadelphia; with deep green, leathery leaves, persisting through the winter, large, white, showy flowers, and large, showy, red fruit; it is the most. handsome of the family.

The other species of southern range are mainly of botanical interest, odd and tropical-looking, especially the very large-leaved (two feet), and large-flowered -

1I. macrophylla Michx. (226), and the Umbrella-tree, M. tripetala Linn. (227), found as far north as P'ennsylvania and hardy even on Long Island.

Of magnolias of more northern range, the small tree, often shrublike-

M. glauca Linn. (228), Sieump. Magnolia, found native as far north as Massachusetts, is unexcelled for usi in clusters, in wet places, and elsewhere on rich ground. Its glossy, small, thick, rubber-like foliage, in favorable situations hanging on until midwinter, its exquisite, creamwhite, fragrant flowers, continuing to blossom from June to September, its deep red seeds in the green foliage, mahe it worthy of more attention than is so far bestowed on it.

11. acuminata Linn. (229), Cucumber-tree, the other northern magnolia, is half hardy to hardy as far north as Ottawa. A tall, stately tree, the most shapely of the magnolias, upright and regular, cone-like, artificial in its make-up, with large, luxuriant foliage cruwded to the ends of the twigs, it is excellently adapted for the center of groups and as a background, or as a single tree on lawns, where its peculiarities are to be the attraction. 
The exotic magnolias from China and Japan form quite a group by themselves, and are prizel for the profusion amd magnificence of their early thowers. They are hardier than must of our natives and can be grown as far north as . Vew Encrland, forming must desirable ornaments for every sarten and small place, especially when grouped with kalmia, rhodedendron, and wher everescen shrublery. For best flower (fïects they should be kept trimmed to shoub form. There are many species, varieties, an 1 hylurils, varying mainly in color and size of flower.

The most commonly planted, remarkable for the profusion of their large iragrant flowers which appear lefore the leaves in earliest spring, are -

1I. Iulun Desi. (23) (conspicu, 1, al small tree from China, semi-hardy into New York and New England, with pure white flowers;

II. obos'ata 'Thunb. (23I) (purpurea) is usually a large shrub with stout branches and purple flowers, and a variety of this, M. gracilis, is a small bushy shrub, with slender branches and dark purple flowers (May, June).

II. pariffurd S. \& Z. (232) and .II. Watsoni Hook. (232i) excel by their large, creamy-white flowers with crimson stamens.

II. stellatu Max. (233) (Halleina), one of the most beautiful of the smaller trees (eight feet), compact and with spreading branches, is quite hardy, bearing profuse, small, white, dainty, and fragrant fluwers when quite small, and very early (March, April).

11. Kobus Thunb. (234), from Japan, one of the hardiest (as far as Toronto, is a medium-sized tree, with yellowish-white flowers blouming rather later in life.

II. hypoleuca S. \& Z. (235), a tall tree from Japan, and also quite hardy, with very large leaves, bright green above, silvery-white to bluish beneath, and very large, fragrant, creamy-white petals with scarlet stamens, blooming after leafing, and showy fruit in fall.

11. Soulangeana Soul. (236), probably a hybrid of the two preceding, of lower stature and spreading habit, with immense white flowers appearing later than those of the former, is also one of the hardiest.

1/. speciose $(236 a)$, also a hybrid of the above, with red and white or rose-colored flowers, appearing still later.

II. Alexandrinu, another hybrid, is a small tree of bushy habit, with large, pink flowers (April, May). 


\section{Mulberries --Tupelo-Osmanthus}

\section{MULBERRIES}

Morts. A genus of a doubtful number of species, mostly small trees and shrubs, of minor ornamental value, but pleasing in their shining, dark green, roundish foliage, and valuable because of frugality and shade-endurance. Whan planted as a shade tree the edible fruit is rather a nuisance, as it litters the ground.

M. rubra Linn. (238), the native Red Mulberry, distributed north into southern Canada, is a medium-sized tree, most readily grown, and a good shader.

M. nigra Linn. (239), the Black Mulberry, from Persia, and $M$. alba Linn. (2+o), the IIhite Wulbery', the two silkworm feeders, are small trees or shrubs and have no special points superior to the foregoing, except that they are probably hardy farther north and have a finer foliage.

\section{TUPELO}

Nyssa. For brilliant autumn colors there are few native trees finer than the two native species of large trees:

N. sylvatica Marsh. (24I), Pepperidge, Sour Gum, of the north, and $N$. aquatica Linn. (uniflora) (242), Large Tupelo, of more southern range. Their small, dark, glossy, ovate leaves, turning fiery scarlet in autumm, and lasting for wetes, give rare brilliancy w eroups of duller hue. In form they are straererlizg, hut by the shelving tiens of their tortuous, spreading branches are often interesting. This form seems dependent on soil, wet or dry ones, to both of which it is adapted, while in better soils it is ayt to develop short branches and a columnar outline. No troubles except occasional leaf fungi may be anticipated. Unless properly prepared in the nursery, they do not transplant readily.

\section{OSMANTHUS}

A genus of the olive family furnishes three species, dwarf trees, one from the United States, the other two from Japan and China, only semi-hardy, which are desirable, especially as winter ormaments, for their evergreen foliage, similar to holly.

O. Americanus B. \& H. (243), five to six feet, with long (four-inch), thick, glosig leaves, and purple, nut-like fruit from the axillary, sessile flowers in threes (June). 


\section{Trees for Shade and Ornament}

O. aquifolium Sicb. (2t+), a somewhat taller tree, from Japan, with glossy, holly-like, spiny leaves, sweet-sented, white flowers, appearing

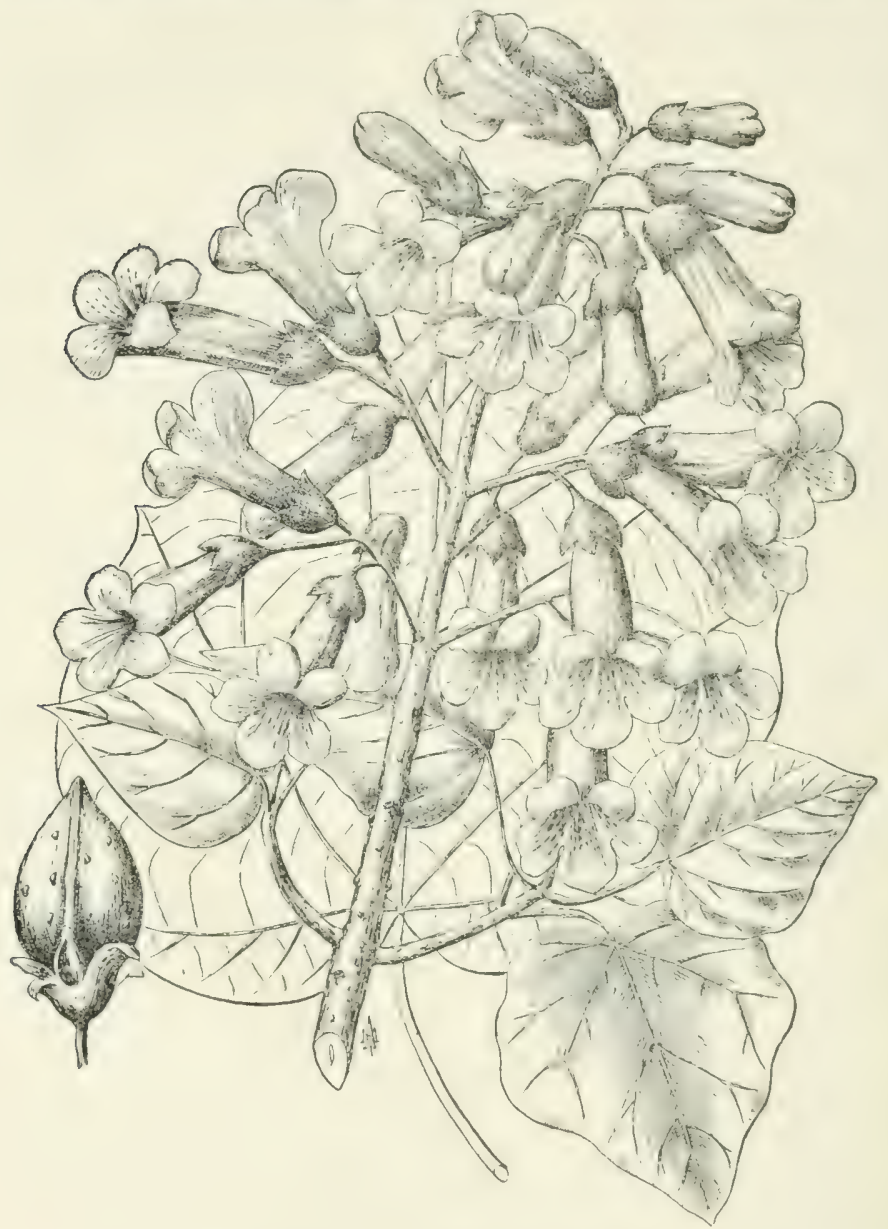

FIG. I00. - Paulownia. Paulownia imperialis S. \& Z. .

in the fall; is superior to the former. I variety, O. ilicifolium (2ffa), with smaller leaves and more compact head, is hardier than the species, 


\section{Hop Hornbeam. Ironwood}

and advantagecusly used on light soils for a ground cover in woods, standing shade well.

O. fragrans Lour. (2+5) (()lea fragrans), is a small tree, eight to ten feet, from China, distinguished by its pretty, very fragrant, yellowishwhite flowers (June), but with less showy foliage; its hardiness questionable. It may be grown in pots.

\section{HOP HORNBEAM. IRONWOOD}

Ostrya. O. T'irginica Willd. (2.45 bis), is a small, native tree, with thin, birch-like foliage, tuming a fine russet; similar to Carpinus, but of more regular outline and branch habit and with more delicate foliage, the young twigs reduish (birch-like), the old bark flaky. The pendulous green, odd-shaped fruit ardels to its ormamental value, which is similar to the Hornbeam. Its use is similar to the preceding, the gray bark adding to its winter effect.

O. r'ulgaris Willd. (carpinifolia) (2+6), the European species, has no special superior points.

\section{SORREL TREE}

Oxydendron (Andromeda). O. arboreum D C. $(2+7)$. A beautiful and characteristic small tree (fifteen to forty feet), of the Heath family (see Shrub), native of the southern Alleghanies, with spreading crown, shiny leaves, which turn early into glorious autumn colors; graceful siprays of large, white, bell-shaped flowers appear in early summer; this tree can be well grouped with Kalmia, Rhododendron, and other evergreen shrubs of the kinsl, showing to especial advantage as the center of the group.

\section{PAULOWNIA}

Paulownia. P. imperialis S. \& Z. (2.48). This is a small to mediumsized tree from Japan; of rather straggling, open form, very large and tropical-looking, Catalpa-like leaves, and abundant, large, purplish blue or violet, most fragrant flowers in stiff, terminal panicles of large size (June); followed by nut-like fruit. Striking rather than ornamental, it can be kept in form only by severe pruning, which it stands very well, and then its luxuriant foliage is valuable. Cut back to the ground every year, it can be readily kejt in bush form, making shoots 


\section{Trees for Shade and Ornament}

of six to eight feet in a year. Most easily propagated from seeds or cutting, and a most rapid grower in almost any soil. It is only semihardy north of New York.

\section{APPLES AND APPLE-LIKE FOR MS (QUINCES, MEDLARS, CRAB APPLES, ETC.)}

Pirus (including Cydonia). This is a family of a very large number of species and endless varieties of small trees and shrubs, of wide dis-

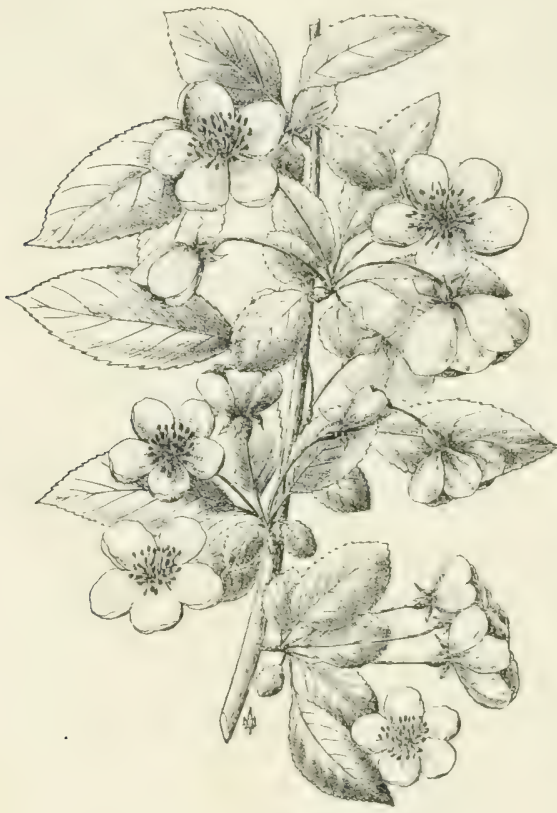

FIG. IOr. - Pirus spectabilis Ait. tribution, furnishing, besides our best fruit trees (apples, pears, quinces), a considerable number of ornamentals, both native and exotics; pleasing, some by form, some by foliage, some by flower and fruit. They are mostly hardy, and usually adaptive to soils, and easily transplanted, but they are, like all freely cultivated plants, liable to a considerable extent to insect troubles and fungus diseases.

Besides the common apple ( $P$. Malus Linn. (249)), which, with its rounded head, especially when in flower, is a most pleasing object in a rustic landscape, two small crab apples, both with roundish heads, the one native, the other from China, deserve special notice.

P. coronaria Linn. (250), from the Middle and Western States, with pale red, swect-scented flowers, appearing with the leaves, followed by a yellow-green fruit; also a variety with double flowers; and -

$P$. spectubilis Ait. (251), from China, the most ornamental in form, 


\section{Apples and Apple-Like Forms}

with oval, smooth leaves, and double rose-colored flowers in umbels (April, May), also a variety, $P$. flore roseo pleno, whose flowers are nearly two inches in diameter. Similar to this is -

P. Ionsis Bailey var. Bechtel (252), with very fragrant, rose-like,

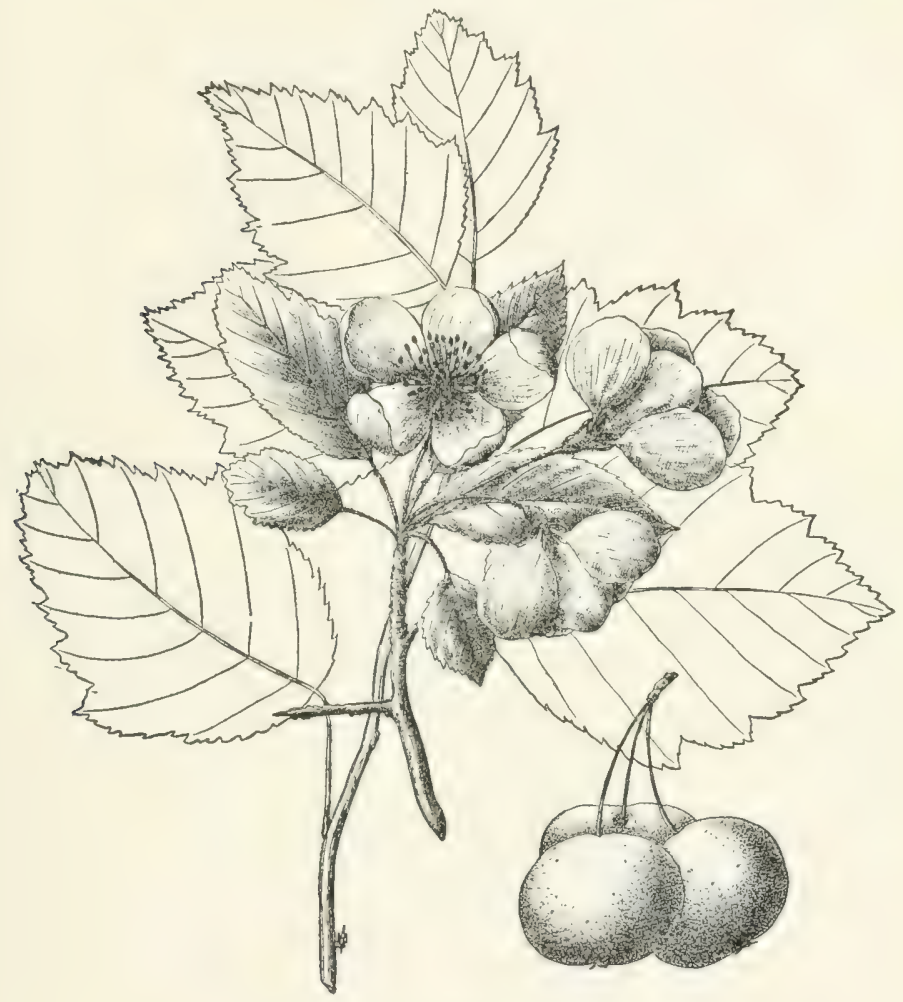

FIG. 102. - Pirus Ioensis Bailey.

double flowers, appearing after the leaves are fully developed, lengthening the period of apple blossums by several weeks.

$P$. bacalu Linn. (25.3) and P. prunifolia Willd. (254) (with larger fruit), Siberian Crab (Paradise 1pple) with a profusion of handsome white flowers, and small yellow and cherry-red fruit. This tree is hardy as far as the Canadian Northwest. 


\section{Trees for Shade and Ornament}

Two Japanese Crabs, both perfectly hardy and free from insects and diseases, are often planted:

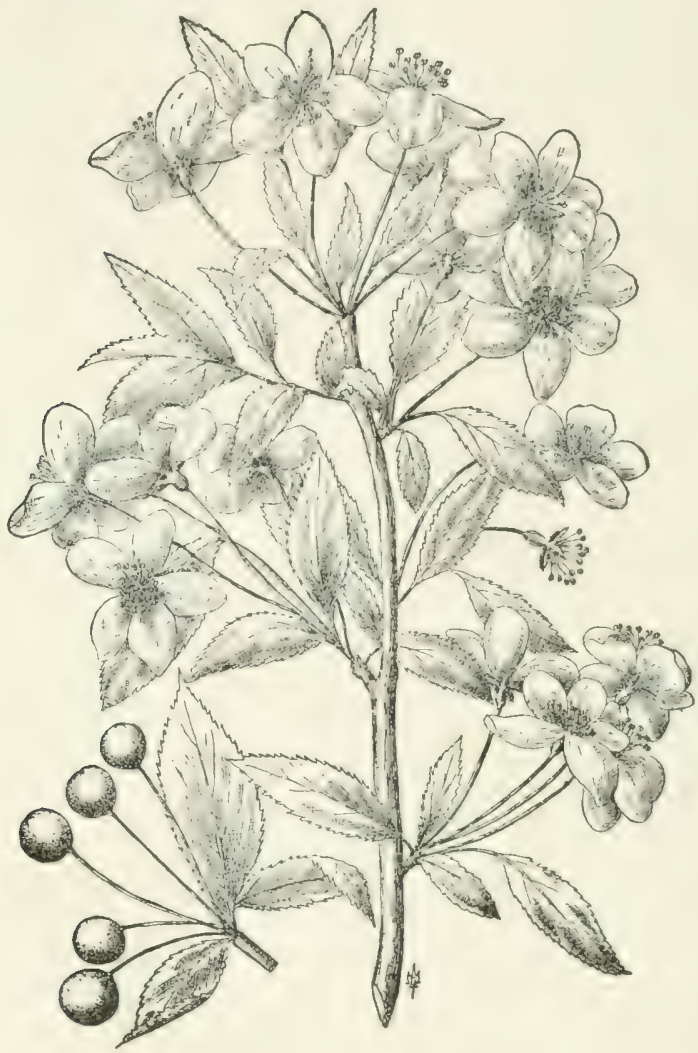

FIG. I03. - Pirus baccata Linn.

P. floribunda Nichols (255), one of the most ornamental of its kind, a dwarf, with a profusion of rich rose-red flowers in early spring, continuing into the summer; followed by a red fruit on long stalks. The variety Parkmanii (255a), with rich dark foliage and semi-double flowers, has proved less hardy.

P. Toringo Sieb. (256), also a dwarf, with white flowers in small clusters, the fruit the size of a large pea. 


\section{Apples and Apple-Like Forms}

Of quinces the most commonly planted is the well-known -

$P$. Sinensis Lindl. (257) (Cydonia Japonica), Japanese Cuince or Japonica, or Strawberry Bush, most attractive with its wealth of vari-

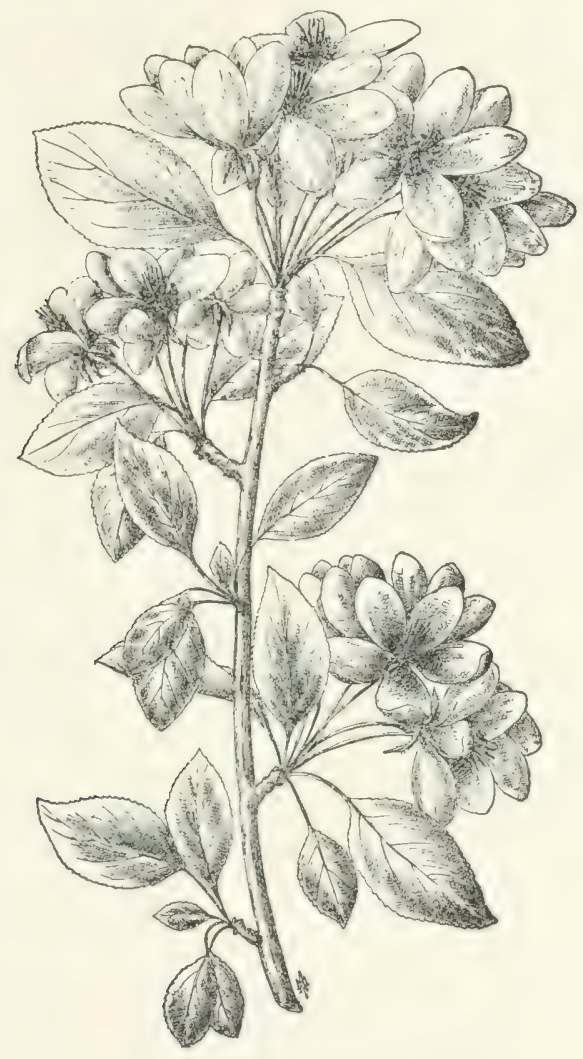

FIG. I04. - Pirus prunifolia Willd.

ously-shaded, mostly dark red or scarlet, very fragrant flowers, appearing before the leaves, and its dark, glossy, vari-hued foliage. It is well adapted for hedges, indeed being superior to many other hedge plants. It is especialiy striking when in flower and when trained as a standard with pendent branches. It is most easily grown from cuttings, and quite hardy, but for best results should have a rich soil. 
A number of varieties present variations in color foliage and stat. ure. Of these may be mentionerl: P. Moorlosi (257a), with pendu-

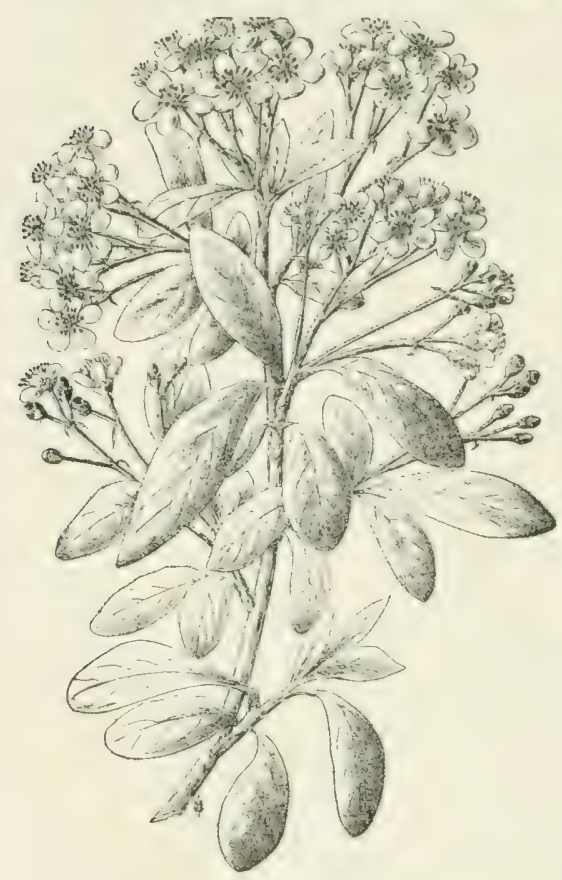

FIG. 105. - Pirus floribunda Nichols.

lous branches, low stature, small, narrow foliage, and pink to white flowers; $P$. macrocarpa $(257 b)$, with very spreading habit and light red flowers; $P$. roseo flore pleno $(257 \mathrm{C})$, with large, semi-double rose-like flowers; P. grandiflora $(257 d)$, with very large, pink and white flowers, and graceful habit; $P$. nivalis $(257 e)$, and simplex (257f), with white flowers; $P$. foliis nubris $(257 g)$, a low bush with dark red leaves and salmon-red colored fruit. A newly introduced attractive variety -

P. Niedzivetzkyana $(257 h)$ excels in red color, all parts of the plant partaking in it.

P. Maulei Mast. (258)

is useful because of its dwarf form (three feet) and compact habit, with a plenitude of thorns, dark green, lustrous foliage, and large, showy flowers, varying from orange to scarlet. The hardiest of the Japanese quinces.

\section{SYCAMORES. PLANE-TREE}

Platanus. Of the six or seven species, native and of oriental origin, two species are frequently planted, one native and one exotic. They are imposing trees, of rapid growth, broad, spreading habit, with massive limbs, but open-branch system and rather symmetrical outline, with large leaves, whose size makes up for their scanty number, with 


\section{Sycamores. Plane-Tree}

an interesting, pendent, ball-shape fruat (buttons). Still more interesting and effective in its color scheme is the yellowish-brown to gray bark which pecls off in irregular patches ("Clothes tree"), cxposing a

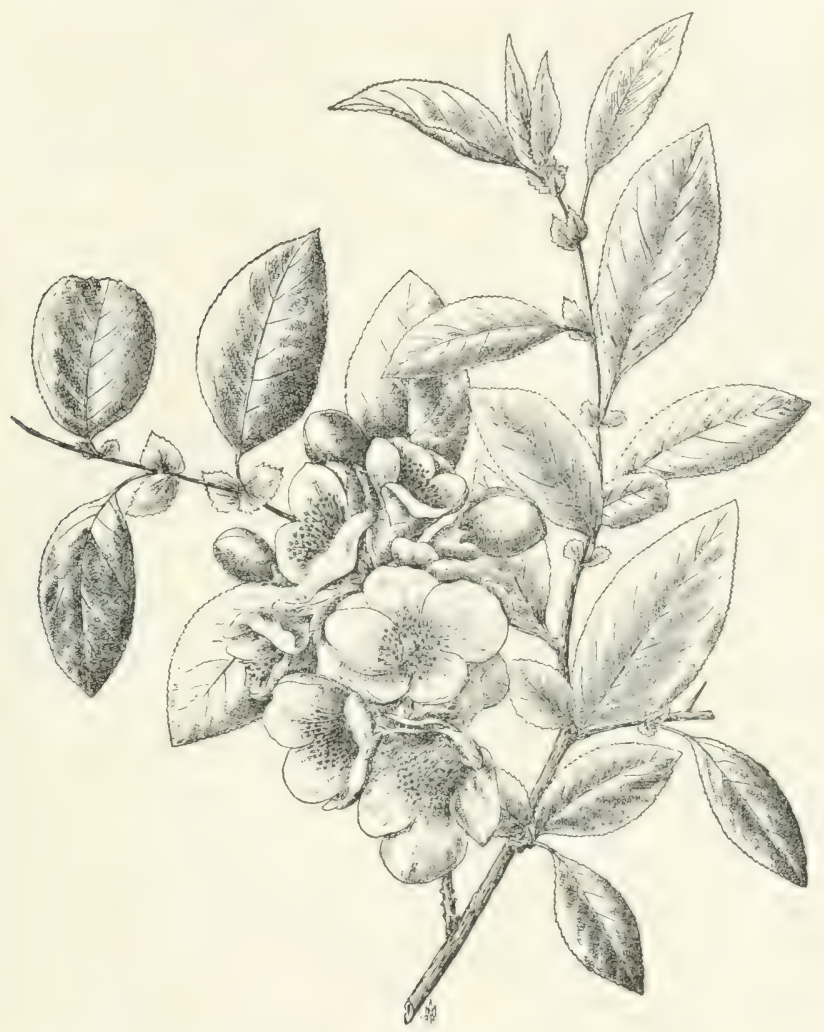

FIG. 106. - Strawberry Bush. Pinus Sinensis Lindl.

white to greenish skin, and giving the stem and branches a mottled appearance.

P. occidentalis Linn. (259), the Ancrican Sycamore or Buttonaend, is hardy into Canarla, but unfortunately liable to injury by a leaf fungus. It grows to ponderous size. Its soft, grayish, large foliage does not group well with other trees, hence it should be usted alone, and 
especially for stately arenues and wide streets. The scanty branch system can to some degree be improved upon by proper pruning. It has a long leaf period but no attractive coloring, and it is rather uncleanly because of shedding its bark. It is adapted to most soils, even wet ones (a swamp and overflow tree), and is very light-needing; it transplants easily.

P. orientalis Linn. (260), the European Plane-tree, is very much like the former, except that it is later in leafing, and with two fruit-balls from one stem; somewhat denser foliage; more compact habit and possibly whiter skin; is free from fungus troubles, but less hardy.

P. Wrightii Wats. (261), from Arizona, is superior in the shape of its deeply indented foliage and deserves trial in southern planting.

P. cuncuta Willd. (262) and acerijolia Willd. $\left(26_{3}\right)$ and some varieties of these have no particular points of superiority.

\section{POPLARS}

Populus. This widely distributed genus of some twenty-five species, of which eleven are indigenous to North America, is composed of tall to small trees, of very rapid growth. They are among the most lightneeding and most frugal species, adapted to all kinds of soils, the driest as well as the wettest, but thrive best on well-watered ones, - the tall trees are indeed greedy for water. Tolerably healthy and without troubles, except that some sucker undesirably. They are most easily transplanted, and most of them hardy.

The name indicates the popularity as a widely planted tree, on account of the ease of its propagation (planting of poles or cuttings), and the rapidity of its growth. They have also certain valuable ornamental features, the light shade they give, and the lively aspect of their motile foliage, quivering in the slightest breeze.

They are to be used with moderation, mainly in single specimens along watercourses and wet meadow's, near houses, on avenues, where their formal monotony is not objectionable, for highways and as accent trees.

P. deltoidea Marsh. (264) (monilifera or canadensis), Cottonwood, is the largest, a native of widest range and also one of the most ornamental, with its large, clean, glossy foliage, moving in every breeze; with the longest leaf period, its foliage coming early and staying late, turning pale yellow in the fall. It is a good street tree, as it does not sucker 


\section{Poplars}

much, stands smoke and abuse, and is unclean only when the catkins fall. It becomes rather a massive object, with open, broad crown, when the young, more conical period with slender branch habit is passed.

The other northeastern native, with a different lance-shaped, triangular form, and a different tone of foliage (yellowish beneath) -

I'. balsamifora Linn. (265), including its variety candicans, Balsam Poplar or Balm of Gilcad, so called from the fragrant large brown sticky buds, is of more symmetrical, slentler, and tapering form; it is adapted to planting on roadsides, near houses, and near water, but is somewhat more liable to sucker than the former.

Of exotics that have been much planted -

$P$. dilatuta lit. (266), Lombardy Poplar, of Europe, is used mainly for its pryamidal, aspiring form, where sentinels are needed as at the entrance of parks, to mark the position of houses, or to make some joint conspicuous; or in the background to create the impression of distance. Its late leaf period and golden-yellow autumn tints are also pleasing. Unfortunately it suckers readily.

P. alba Linn. (267), Silver-leaf Poplar or Abele, also of Europe, furnishes a unique material for color effect, with a striking, peculiarlyshaped, three- to five-lobed leaf, dark glossy above and silver-white downy beneath, the effect leing heightened by the greenish-white bark of branches and trunk. It, however, suckers worse than any of the poplars and hence has fallen into discredit; but is nevertheless useful to make conspicuous a high point, or to set off a group of dark firs, etc.

Two small trees have value in special situations -

P. tremuloides Michx. (268) and grandidentata Michx. (260), the native Common, and the Large-toethed ispen, which, if grown on good soil, make handsome round-headed trees with pleasing foliage; the latter especially gives an elegant and airy appearance with its silky young foliage, later assuming a glossy, dark green color and somewhat leathery texture. It is of roundish shape, with yellowish-green stem and branches. It is also less liable to suckering than is the Common Aspen.

Several Siberian species have been introduced, mainly for their special hardiness. Of these there may be mentioned one also for its ornamental value, namely:

$P$. lantifoliu Led:b. (270), which is the hasis for the forms known under the names Certinensis (27oa), Bereolensis (27ob), and Petrowski $(2700)$, differing more or less in the shape of the foliage. The growth of these is more sturdy than that of our natives ones, compact and yet 


\section{Trees for Shade and Ornament}

aspiring; the foliage very heary and dense, of darker color, oblong to roundish, and characteristically disposed in horizontal layers. These forms are scemingly less liable to rust fungi, very rapid growers, and thoroughly hardy.

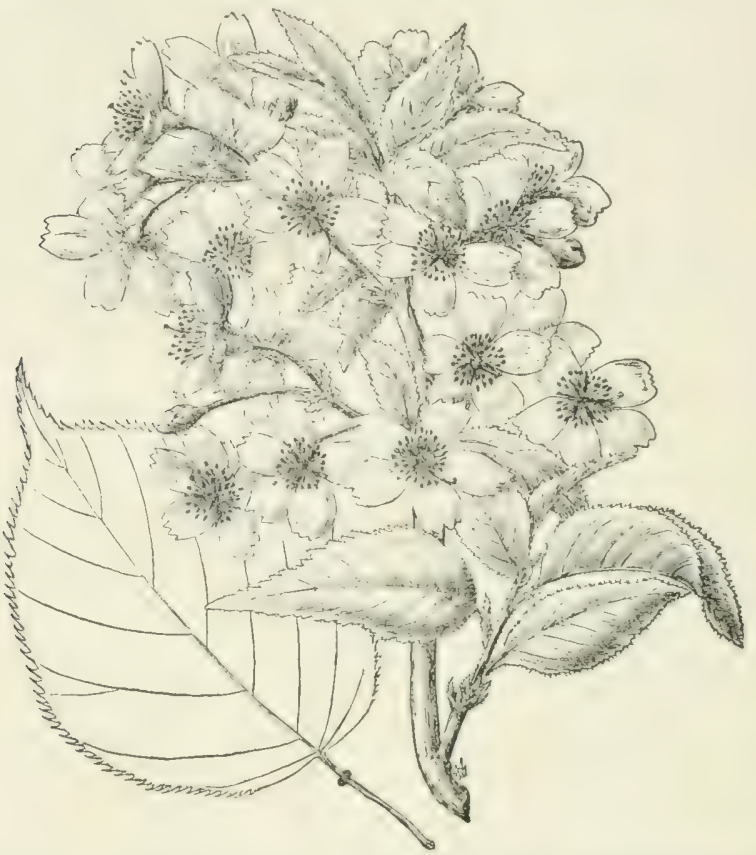

Fig. Io7. - Japanese Flowering Cherry. Prumus Psetudo-Cerasus Lindl.

P. Rasumofskiuna (2jo bis) is another Russian, with oblong foliage, which seems little known in this country, but in its native habitat is considered by far the finest, forming a large picturesque tree, and is the most rapicl grower of all the poplars. A specimen at Ottawa proves perfectly hardy, and promises to live up to its reputation.

\section{CHERRIES, PEACHES, PLUMS}

Prunus (Cerasus). This large genus of the rose family, with about seventy-five species, contains many small trees and shrubs worthy of 


\section{Cherries, Peaches, Plums}

attention. Their omamental value in form, foliage, and flower is enhanced by that of the fruit. Although the flower display is rather short, its early appearance, and the easy growth and hardiness of these trees, being mostly of northern distribution, are commendable

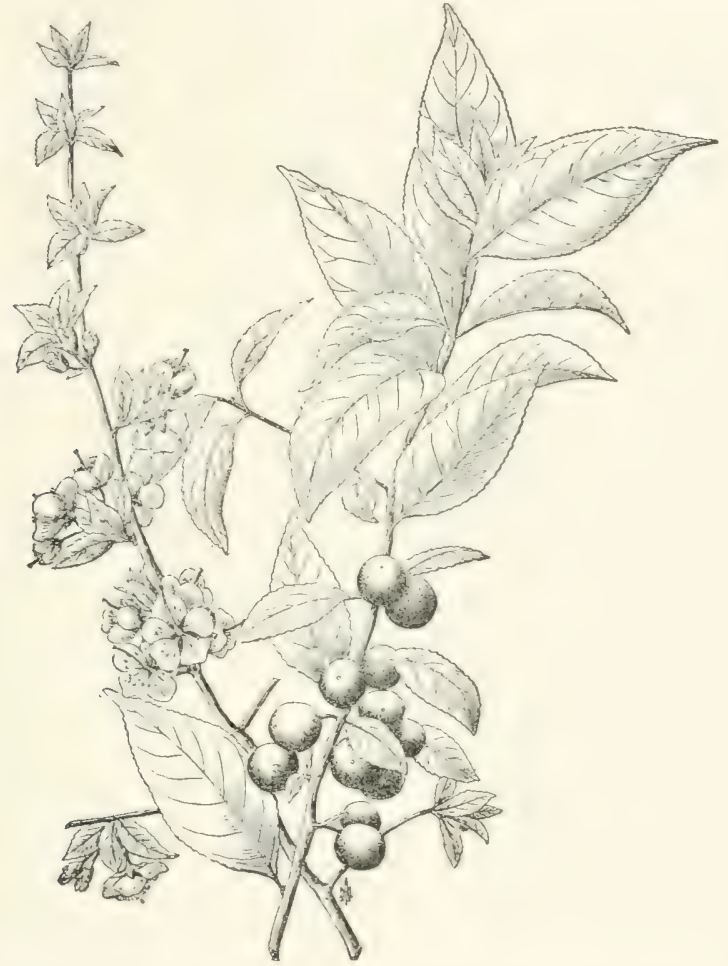

FIg. 108. - Japanese Almond. Prumus Japonica Thunb.

features. They are mostly light-needing, short-lived, and unfortunately liable to both insect and fungus disease's, and somewhat to frost. They prefer light soils. For flower effect in woodland plantings and in front of other shrubbery and trees, as accent trees, and for temporary use, they have special value.

The most ornamental species are those from China and Japan, generally seen in rarieties and nurserymen's forms, with double and rose- 


\section{Trees for Shade and Ornament}

color or pink flowers; these have also the advantage of being without insect enemies (as yet!).

P. Psendo-Cerasus, var. hortensis Max. (271), the celebrated Flowering Cherry from Japan, and a long list of other varietie's and forms, are very valuable in form and in flowering, some with large double white flowers (April, May). They are only half hardy in New England.

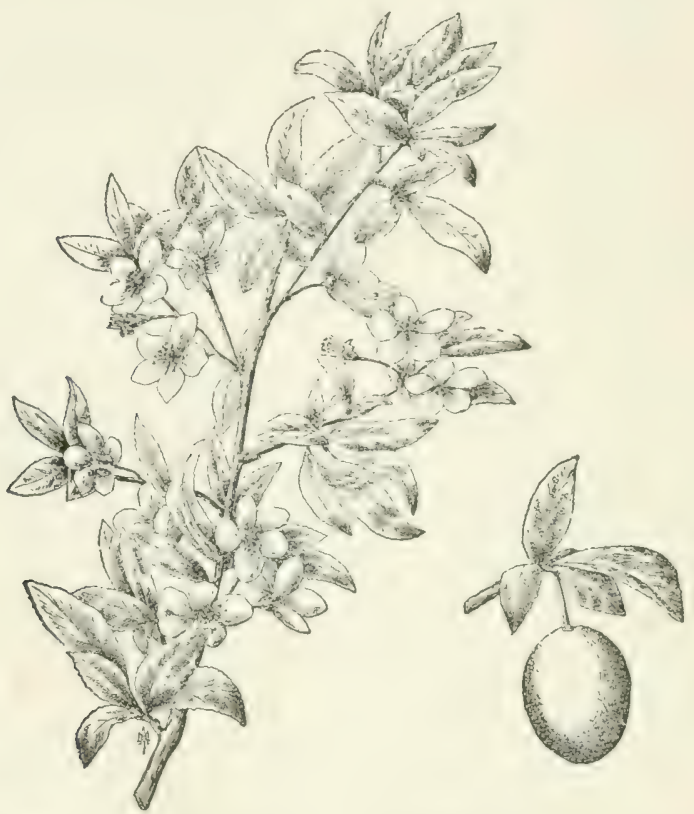

Fig. rog. - Japanese Plum. Prunus Pissardii Dipp.

P. Japonica Thunb. (272) (Sinensis), is a small tree of the almond tribe, with a profusion of large, white, rose-like tluwers arriving in advance of the foliage. Varieties of dwarf habit and of red or ruse-colored flowers are equally showy. There is, however, considerable doubt as to the proper application of the name, since there are at least six different species or forms offered under the same name.

P. Pissardii Dipp. (cericifera atropurpurea) (273), Japanese Plum. For color there is hardly any more satisfactory small tree to be found 


\section{Cherries, Peaches, Plums}

than this tree, with its soft purple leaves, which retain their color better than most purple trees, especially when properly pruned; a small tree ( $f$ rapid growth and good form. Not hardy in Ottawa.

P. Amygdulus Stokes (274), Flowering Almond, is a tree twenty to thirty feet in height, with several improved varieties, which are most omamental, light rose-colored showy flowers appearing very early in March and April before the leaves arrive. There are also double and white flowering varieties.

P. Persica S. \& Z. (275), the Common Peach, also in various varietics, with double, rose-colored, crimson, red and white (versicolor) delicate flowers. It is rather short-lived, unless closely pruned and fertilized with wood ashes.

P. Armeniaca Linn. (276) and P. Mume S. \&. Z. (277), the Chinese or Armenian and Japanese Apricots, are well worthy of attention for ornamental purposes, not only because of their profusion of pinkish flowers but because of their bright foliage, which, especially in the young shoots, is tinged with red. They are very hardy and adaptive to most soils, but must be kept in good shape by systematic pruning.

Of native plums or sloes, two are attractive by reason of the very early clusters of delicate white flowers and the black and yellow to reddish fruit:

P. spinosa Linn. (278), Black Thorn, the more northern, hardy, and P. angustifolia March. (279) (Chicusa), Yellow or Chickasaw Plum, the more southern, appear in form as shruls more usually than trees, with rather straggling but erect habit and thom-like biunchlets. They are not particular as regards soil, and shade-enduring, and hence useful for under-planting.

P. maritima Wangh. (280), Beach Plum, is also a hardy shrub, valuable as a soil cover and for its usefulness in planting along seabeaches and other inhospitable situations.

The only large tree of this group is our native widely distributed -

$P$. serotina Ehrh. (28I), Black IVild Cherry, native into Canada, a tall, not very spreading tree, with roundish, open crown and often drooping branchlets; is attractive in possessing beautiful white flowers in racemes; is rather thinly foliaged, with a shapely, somewhat leathery glossy leaf, turning deep crimson in autumn, and with a dark almost black fruit, which in its fall renders the tree rather unclean and undesirable. An interesting raggedly-plated, dark bark with slender purplishred branchlets make a good winter effect. It is fit only for lawns of 


\section{Trees for Shade and Ornament}

some extent and near houses, griving a light shate. It is adaptive. to light, deep, sandy soils, such as dunes, but also to more compact soils, and is a very thrifty and rapid grower.

P. Padus Linn. (28.2), English Bird Cherry. A small flat-headed tree or shrub, otherwise similar to the foregoing; blooms earlier (May), but has less pleasing foliage.

P. Pennsylanica Linn. (283), Pin Cherry or Bird Cherry, is an interesting small native tree, often hardly more than a bush, distributed over almost the whole northern part of the continent, springing up) freely after forest fires. Its small white flowers, lively green foliage, but more particularly its cherry-red fruit, the size of a pin or pea, are its attraction. It grows in any dry soil.

P. Mahaleb Linn. (28f), Mahaleb Cherry, a small slender tree (i 5 to 20 feet) from the Caucasus and middle Europe, hardy to Ottawa, is more ornamental than the Bird Cherry, by reason of its apricot-like glossy foliage of pale green color, on slender but abundant sprays, and with as fine flower and fruit as the foregoing, the flowers being fragrant and in umbels (May, June).

\section{OAK}

Quercus. This genus, of not less than two hundred and seventy-five species, over fifty of which are found in North America, represents among the broad-leaf trees what the pine represents among the conifers, in usefulness and in wide distribution, but it excels in number of species and in ornamental value, ranging in size from majestic trees to small shrubs, with a variety of foliage and of form hardly equaled by any other single genus. The oaks are inhabitants of the northern temperate zone, occurring, however, also in the tropics in high altitudes, and are extremely adaptive to soils from the driest to the swamp. The deciduous ones are mostly hardy in the north, the evergreen not north of Washington. They are the embodiment of sturdiness and persistency, holding on to life wherever there is a chance, with remarkable recuperative power. They are light-needing, but will persist in the shade for a long time. Although normally having a tap-root system, they readily adapt themselves, permit any amount of pruning at top and root, so that mere root stumps may be transplanted and grow into trees. They grow at a more rapid rate than they are usually credited, but, to be sure, the majestic, broad-crowned beauties are centenarians. 


\section{White Oaks}

Alhough not entirely immune, they are remarkably free from insect troulle and disease. The foliage of most oaks has a long period and continues to hang on in the dry condition, or, in the case of exotics, green into the winter.

The great variety of outline and of pleasing leaf shapes and leaf colors, with rich tones in autumn, the sturdiness of growth and stateliness of form, the freedom from disease, the easy adaptation to soil, the wide climatic range, the rapidity and persistency of growth, and the ease of repairing damage - all these qualities combine to make the aks, together with the maples, the most useful trees in landscape gardening. Most of them are spreading in habit, with a bold, free, and usually irregular, outline. For best effects they demand large space.

Botanically as well as from the ornamental point of view, the oaks may be divided into four groups. "The "white" oaks, which mature their fruit in one year, receive their name from the light gray color of their bark, and have their foliage with rounded indentations or lobes. The "black" oaks, which mature their fruit in two years, have a darkcolored bark, and their leaves with sharp-comered indentations or lobes, or else entire and bristle-pointed, and a few with entire oblong foliage. In addition to these two botanical classes we may segregate the evergreen or "live" oaks, which botanically belong mostly to the white oaks, although their foliage rescmbles more the black oaks; and the "scrub" oaks, which, mostly with black oak foliage, form spreading shrubs. These latter grow on the prorest, driest soils, and can be used for covering barren, rocky ridges and hillsides.

\section{A. WHITE OAKS}

Q. alba Linn. (285) is the type IThite Oak, a noble tree, of wide distrilution from Maine to Texas, the finest specimen tree where full space is allowed it. Nothing more impressive can be imagined than a fuily developed, broad-crowned specimen of this species. The bright green foliage of narrow, obtusely lobed leaves is quite variable in different individuals, turning violet-purple in the fall. The bark is light gray and flaky. It is a fairly rapid grower, adapted to any soil, but best developed in good loam.

Foliage of similar outline, but longer (five to eight inches), and more lyre-shaped, also whitish beneath, is characteristic of the following three: 


\section{Trees for Shade and Ornament}

Q. macrocarpa Michx. (286), Bur Oak or Mossy ('up Oak (so called from the hairy cup of the acorn), is of more northern distribution, the hardiest of them all, a very picturesque tree of more or less fan-shaped form, the bark darker than the white oak, and corky on the branches;

Q. lyrata Walt. (287), Sieump or ()ier-cup Otk (so called from the cup enclosing the acorn entirely), is of more southern distribution, from New Jersey to Texas, frequenting moist to swampy situations; forms a round-topped head with rather short and somewhat pendulous branches;

Q. stellata Wangh. (288) (obtusiloba or minor), Post Oak, a smaller tree (sixty feet), with a handsome, dense round hearl, or else with open, straggling branch habit, and brownish, fissured bark. It is adapted to dry, rocky, or sandy soil.

Another type of foliage, resembling somewhat the chestnut leaf with short, rounded lobes, and hence called Chestnut Oak, is characteristic of the following three:

Q. Prinus Linn. (289) (montana), Chestmut Oak, Rock Oak, of wide distribution, especially on rocky mountain slopes, and adapted to dry soils; a tree not much larger than the Post Oak, with a somewhat unsymmetrical broad crown and dark ridgy bark;

Q. Michauxi Nutt. (290), Basket Oak, Cow Oak, of more southern range (from Delaware to Texas), is a larger tree with rather dense round head and grows preferably in moist soil; large (four to seven inch) foliage, grayish underneath, and a very light g ay scaly bark;

Q. Muhlenbergi Engelm. (291), Fillow Chestnut Oalk, of southern and western range, is a large tree with a narrow round-topped head, particularly attractive in its handsome foliage, which is glosiy above and silvery white beneath, and with light gray flaky bark.

\section{B. BLACK OAKS}

Q. velutina Lam. (292) (tinctoriu), Black Oak, Cucrcitron Oak, is the type of the black oaks; ranging from Maine to Texals; a tall tree with rather slender branches forming a narrow open hearl, the leaves very large (up to ten inches), very symmetrically cut, clark green above and yellowish brown beneath, turning orange; the lark almost black, and ridgy (the inner bark orange, whence the name Quercitron). It is a very rapid grower, adapted to any soil.

Q. Mubra Linn. (293), Red Oak, of as wide range and of the same dimensions as the preceding, but with its stout spreadine branches 


\section{Black Oaks}

makes a more symmetrical broad crown; a large majestic tree, with beautiful, more deeply cut and large symmetrical foliage, dark green and glossy above, light green beneath and turning dark red. The bark is dark gray, glos:y on the branches. It is a very rapid grower, most adaptive to a variety of seils, and one of the easiest and best to plant.

Q. coccinea Muench. (294), Scarlet Oak, ranging from Maine to I lorida and Missouri, is a less handsome tree as regards form, with a rather open crown, but when the narrow, unsymmetrical, very deeply cut, bright green foliage turns to brilliant scarlet in the fall, there is nothing finer to be seen. This tree is adapted to dry soils.

C. pulustris Linn. (295), Pin Ouk, native of a smaller range than the others, from Massachusetts and Delaware to Wisconsin and Arkansas, alsu to southwestern Canada. The Pin Oak is unique in outline, the rather short, slender branches becoming pendulous, while the handsome, very deeply cut, unsymmetrical foliage, turning bright flaming red in autumn, vies in beauty with the Scarlet Oak. In old age it loses its symmetrical prramidal crown and becomes open and irregular, the lower branches dying but persisting, a defect which can be corrected by pruning. It is a rapid grower; stands swampy conditions as well as dry soils. It transplants readily.

Q. cuncutu Wangh. (296) (digituta or falcula), Spanish Oak, another native species, from New Jersey south and west, is not quite hardy farther north; has a peculiar distinct foliage of subdued tone, but is otherwise without special merits.

An entirely different type of foliage, namely, with entire margins, like a willow leaf, or nearly so, is possessed by four black oak species of more southern range:

Q. Phellos Linn. (297), Willow Oak, is the type, its most northern range being to New York, although it is hardy beyond; a beautiful medium-sized tree, with a conical crown of slender branches and a dense, dark, wlosir, fine, small foliage like that of a willow, remaining green into the fall, finally turning pale yellow. It is a swamp tree, but adaptive to drier soils.

Q. imbricaria Michx. (299), Shingle Oak, and Q. laurifolia Michx. are of more southern distribution, and with larger foliage of the same type as the preceding. Specimens of imbricaria at Ottawa are found quite hardy.

C. nigra Linn. (299), ITater Oak, with the foliage broader and occasionally lobed at the apex is the tree commonly used as a street tree in 


\section{0 \\ Trees for Shade and Ornament}

the South. Like any of the other oaks, it could be used with advantage, at least as far as New York.

The Live Ouks, so called because being evergreen, are confined to the Southern and Southwestern States, and are not hardy north of Washington. The type, one of the most beautiful and characteristic of the world, is -

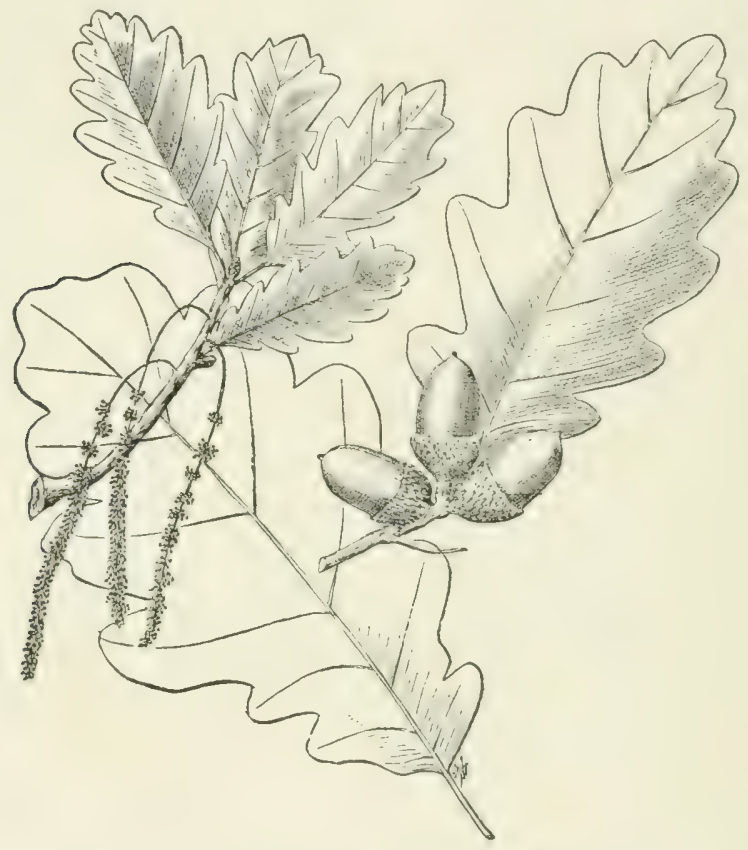

FIg. rro. - English Oak. Quercus Robur Linn.

Q. virginiana Nutt. (300) (zirens), Lize Oak, ranging from Virginia to Mexico, hence not hardy north; a broid spreading tree rarely over seventy feet, with stout, almost horizontal branches, with small entire leaves of bluish hue.

Q. chrysolepis Liebm. (301) California Liz'e Oak, with a golden hue, is the handsomest species of the California oaks; probably never tried in the East. 


\section{Black Oaks}

Of Scruh Oaks at least two may le mentionerl as useful in covering barren and rocky ridges and hillsides, or for low coppice and wind mantle on the outskirts of expused plantation; for they are most hardy and persistent spreading shrubs or small trees.

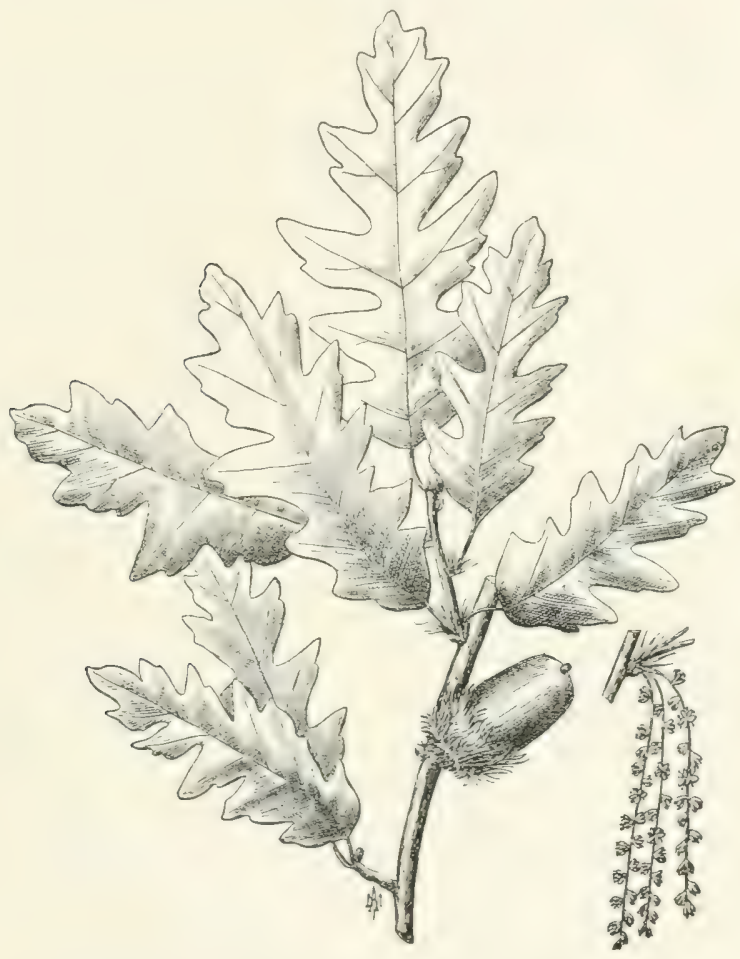

FIG. III. - Turkey Oak. Quercus Cerris Linn.

C. ilicifolia Wangh. (302) (Banisteri or nana), Bear Oak, covers dry mountain soils with dense thickets from Maine to Virginia and west, occasionally growing to tree form (twenty feet), although usually a shrub (ten feet), with foliage of the black oak type, dark green above, but with a grayish shade.

Q. prinoides Willd. (303) (humilis), Chincapin Oak, of even wider range than the precerling, a spreading shrub, usually not over six feet 


\section{I 2

high, with pretty foliage of the white oak type, and of similar hue as the preceding, is useful for the same purposes.

The wealth of American forms is so great that there is hardly any need for introducing foreigners, yet at least three may be mentioned as

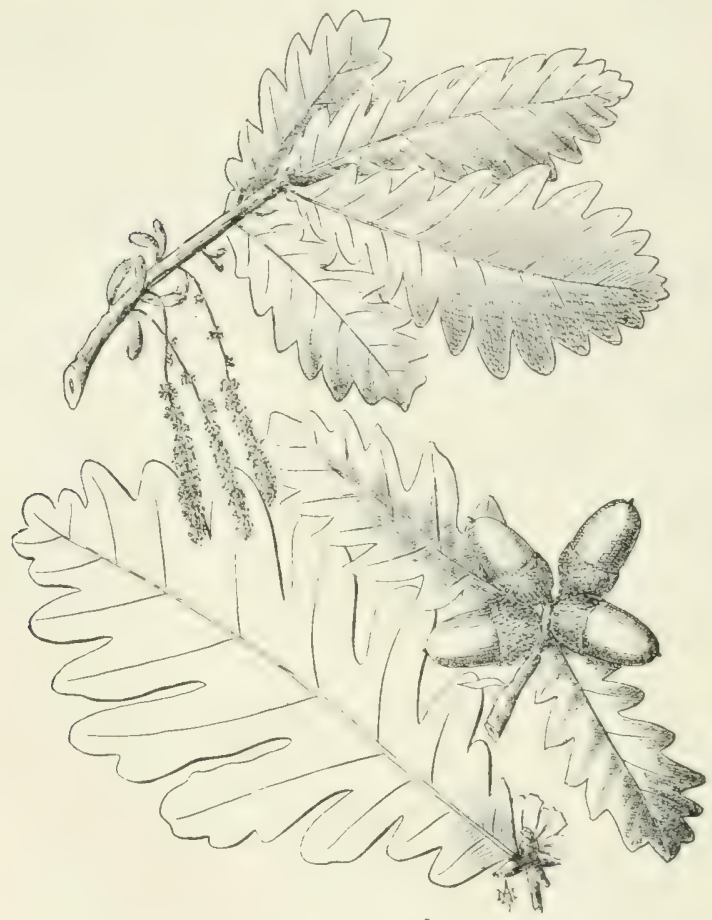

FIG. II2. - Italian Oak. Quercus conferla Kit.

occasionally planted and having merits of their own. Although belonging botanically to the white oaks, their bark is hrown or at least dark and ridgy:

Q. Robur Linn. (30.4), English Ouk, comprising two very similar species, pedunculala and sessiliftora, the principal oak of Eurnpe, nearly hardy to ()ttawa; a large tree forming a broad, round-topied, spreading head, with glosiy leaves, oblong and somewhat more evenly 


\section{Buckthorn}

lober than any of our oaks, except Chestnut Oak. A large number of nurserymen's varicties, cut-leaved (filicifolin $304 a$ ), purple-leaved (purpurescens and atropurpurea, 30.th), weeging (pendula, 30.4C), fastigiate ( fizstiginh, 304d), and many others increase the variety of this much variegated genus.

Q. (Crris Linn. 305 ), Turkey O.lk, a large tree from southern Europe and Asia, with shos spreading branches, forming a broad pyramidal crown, has a handsume dark ereen, deeply-lubed, curled, almost pinnatiliel follage. It has the longest leaf period (green till Christmas). It is probably not hardy far beyond New York.

Q. conferta Kit. (3061 (Pannonicat), a pretty oak from Hungary and Italy, hut hardy in Massachus 1ts, with handsome, very long (four to seven inch) foliage, dark s.cen aluse, whitish beneath, and as deeply cut as the former, is a very distinct form.

\section{BUCKTHORN}

Rhamnus. A genus of some sixty species, mostly native of the temperate zone, mostly shruls, but sometimes growing into small trees, contains a number of omamental value for their pretty, although mostly simple, oval folizer. They are more rarely employert than they might be in shrubleries and as single specimens for which their shapely form fits them, their unally lack berry fruit addling to their interest. Most of them, except the everereen ones, are hardy, several of them succeeding even in the Canadian Northwest. They are not choice as to soil, but most of them prefer a moist one, are easily grown, bear shade well, and can be used as hedges. Of the five native ones three often grow into trees; two from the Pacific Coast, the other is of eastern range.

R. Parshicun I). C. (30\%), ranging from British Columbia to Mexico and from Montana to Texas, is a tree of medium height, from the bark of which the well-known Cascana saspada is derived. If collected from is northeastern range it is hardy in the East, and with its dark green, thiptic foliage with wary margin, and its red fruit turning black, quite a pretty ornament.

R. Carolinium Walt. (.308), Intiun Cherry, of eastern distribution, is quite similar, with a lustrous dark foliage on shorter leaf-stalks, hence somewhat stiffer.

R. alnifoliu L'Iterit (3or,. . Hder-leif Buckthorn, is a low shrub) (four feet) ranging across the continent through Canada and northern United 
States, hence thoroughly hardy; with short oral scalloped foliage, and makes a good hedge plant.

The two best known buckthoms, which, like the above, are either shrubs or small (twelve feet) trecs, are two exotics from Europe and Asia, both entirely hardy, even in Manitoba:

R. cathutica Linn. (3IO), IIartshom, with sharply toothed, small, slightly scalloped leaves, is usually thorny.

R. Fran:zula I,inn. 131 I), with dark green shining foliage of the same size (one to three inch) as the preceding, but entire, forms a handsome lawn shrub or an excellent hedge plant, with its attractive fruit, red, changing $(1)$ black. Its variety $R$. asplenifolia (3I $a$ ) excels in its distinctive feathery foliage.

\section{WILLOWS}

Salix. This is one of the largest genera, with some hundred species and an endle'ss number of varieties of medium to small-sized trees, but mainly shrubs, of wide range in all parts of the world. Their ornamental value is not sufficiently appreciated. The fine, graceful foliage, mostly narrow elliptical, sives to the wilows a place as an omament peculiarly their own, and especially along borders of watercourses or near water scenes, where they are in their natural environment, they produce a translucent, airy efiect which heightens the lucidity of the water. There is enough variety of sharde to be found in the foliage of the various willows to permit most pleasing effects to be produced by the grouping of this tribe alone. The bright yellow catkins of some, the white, silvery "pussies" of others, lend transient interest; while the bright yellow and red branches of some give pleasing winter effects, and the weeping forms of others are useful in their places. Transpiring profusely, they are useful in correcting swampy conditions, and their value in binding embankments and sand dunes is well known. They are rapid growers, but usually short-lived, and light-needing. In nature they are generally found near watercourses, but they are adaptive to dry soils, and most easily grown from mere poles, sprouting readily and responding to pruning. There are unfortunately a number of insects preving on wiliows. Some species of willows form suckers undesirably and are generally ageresise, propagating ly broken twigs sprouting. Althoush their short life reduces their value, their ready sprouting habit and exceeding rapidity of growth permits ready 


\section{Willows}

replacement; thus groups, planted for color effect, can be kept in goor form by coppice treatment.

The largest trees of the genus come from Europe. The handsomest, best known species is -

S. Babylonica Linn. (312), Weeping Willow, than which there is no more beautiful tree, with its long, pendulous branchlets, like flowing tresses of soft feathery green. It is an extremely rapid grower on any soil but a wet one; more liable to suckering than any other. In addition to its particular place by the waterside or spring, it enhances the attractiveness of the rural home.

S. alba Linn. (31,3) and its variety regalis (3r.3a), White Willore, from Europe, is a handsome, round-headed tree of goodly size, resembling the former, but of stilf habit, and the follage silvery-white beneath. A variety of S. aitellina Linn., aurca (3I.4), adis to the pleasure of a winter scene by the golden to orange-yellow color of its branchlets and branches.

Some other willows become ornamental because of the color of their twigs, by a proper combination of which a pleasing color winter garden can be devised; such are:

S. fragilis, Linn. (315) (green); S. candida Flueg. (3I6) (red); S. purpurea Linn. (3I 7) (olive) and its variety Scharfenbergia (3 I 7a) with purple twigs and leaves like rosemary; S. decipiens Hoffm. (3IS) (red and yellow); S. nigra Marsh (3I9) (dark purple); S. nigricans Sm. hirta (320) (soft gray); S. T'oronesh (32I) (bright deep yellow), a very hardy tree.

Several weeping varieties may be used for small yards or lawns if nothing better can be found; such are S. caprea Linn., pendula (322), the Kilmarnock I'illow, one of the most distinctive and graceful, with a close, regular habit, and large, glossy, abundant foliage. This willow is suitable for almost any position.

Japan furnishes one most distinctive, semi-pendulous willow -

S. Niobe (322 bis), the long, lithe rurls of light yellow color beset with silvery-white (underneath) foliage.

Of our native ones, which have been rather neglected, being small trees or shrubs, we may mention as worthy of consideration:

S. discolor Muhl. (323), the commonest, most widely distributed, with upright branches and bright green foliage; and a still smaller, bushy tree (six to fifteen feet) or shrub:

S. lucida Muhl. (324), witl. yellowish-brown, highly polished branches, and dark green, shining leaves. 


\section{3i6 Trees for Shade and Ornament}

Other willows having some desirable points are S. incana, Schrenck. (325), S. rosmarinifolia Willd. (incana), (326), a shrub of very fine foliage, and $S$. argyrocarpa Anders. (327), a native shrub of beautiful satiny luster.

Entirely distinct from all the rest by reason of its larger, broad, dark green, extremely glossy, almost leathery foliage, and its round, compact, dense head, is S. pentandra Linn. (328) (laurifolia), Laurd Leaf IIillow from Europe and Asia, adapted for narrow streets as well as small places, on points which make an accentuation desirable, and for quickly screening out objectionable surroundings, also for hedge work and for seashore planting.

\section{SASSAFRAS}

Sassafras. S. officinale Nees. (Sassafras) (320), a small, native tree, of wide distribution; with roundish outline; among the best ornaments for small places, pleasing and picturesque in its variegated color effects of foliage, fruit, and bark, and its conical to roundish or flat outline, with shelving, horizontally spreading branch habit. The peculiar yellowish-reddish tint of the oddly lobed foliage, turning reddish brown to orange in autumn, is heightened by the reddish basis of the leafstalks, the bright reddish, small fruit, and the greenish to yellow bark of branchlets and gray-brown color of stems and branches; the latter peculiarly furrowed, giving it "an appearance of age and adding antiquity to a new place." Its yellowish flower clusters in early spring, about leafing time, and its long leaf period are additional claims for more extended use. On dry, light, sandy loam, in warm and sunny positions, it develops best. Although with a long tap-root, it is easily transplanted when young. Being dinecious, i.c., male and female trees separate, care should be taken to secure the female trees. Generally free from insects and fungi but liable to sucker. $\quad \mathrm{U}^{\mathrm{s}}$ sed in singleness, or as a filler in woodland planting and large borders.

\section{TAMARISKS}

Tamarix. Of the sixty species found around the Mediterranean, in India and Japan, there are three species worthy of more attention than they have received. They are most exquisite, delicate, shrub-like trees of airy appearance, with minute, pale green foliage, slender, lithe, 


\section{Tamarisks}

swaying branchlets, beset with minute pink or red, ethereal flowers. They are acclimated as far north as Massachusetts. In Ottawa only T. amurensis has proved half hardy. They will grow in almost any soil, and are especially adaptive to seacoasts, thriving in the salt spray down to the very shore; they are rapid growers and free from any trouble. To preserve their beauty, which lies in the branchlets and flowers, frequent, systematic pruning is essential, and this should be done at different times according to the species and its flowering habit, in order to ensure the throwing out of new branches and the flowers appearing on them. Otherwise, the black-barked trunk and the stout, straggling branches are not attractive.

The species, very much alike, vary mainly in the time of flowering, suggesting the grouping of the three first mentioned for continuous flower effect; they also group well with fine-foliaged conifers like cypress and cedars.

T. parviftora D. C. (Africana) (330), from South Europe and Africa, is the finest, with very early (May, June, before leafing), bright pink flowers, covering the

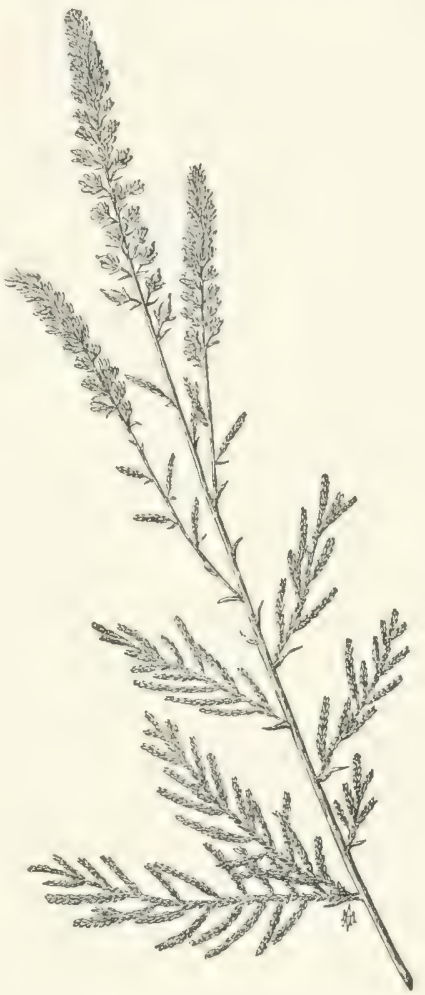

FIG. II3. - German Tamarisk. Tamarix Germanica Linn. somewhat drooping branches. Should be pruned soon after flowering, since the flowers appear on branches formed in the previous year.

T. Germanica Linn. (33 $)$, with terminal red flower spikes, appearing in summer (July), i.e., on wood of the present year, hence pruning should be done in spring; can be trained to any shape.

T. Indica Willd. (333), from India, with terminal flowers 


\section{3i 8 Trees for Shade and Ornament}

appearing on the wood of the year's season in the fall (August, September).

T. Gallica Linn. (332), from France and Spain, is distinguished by its reddish-colored bark.

\section{LINDEN, LIME TREE OR BASSWOOD}

Tilia. A small genus, with three native and several cxotic species, all of northern distribution; is composed of tall and medium trees, of

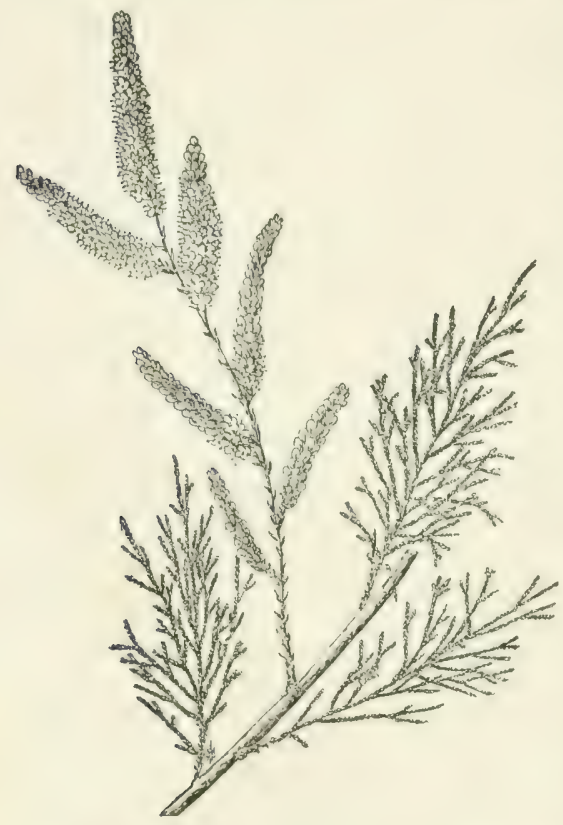

FIG. II4. - French Tamarisk. Tamarix Gallica Linn. rapid growth, which are ornamental in their rich foliage, turning pale yellow, in their upright form and roundish outline, and their graceful flower and fruit. They are commendable in every respect as street and lawn trees, except that they are somewhat late in lcafing out, and are liable to insect depredations. They are adaptive to a variety of soils, not too dry, and even to wet ones; are casily transplanted, and vigorous sprouters from the stump. In winter, the thick, reddish buds and recurved branchlets lend a bright, cheery appearance to the branch system.

T. Americana Linn.

(334), the common Basszeod, the largest of all, with less compact, open habit, and rounded form, with very large but sparse foliage, forms a satisfactory street tree.

T. Europaea Linn. (335) (split up into several species) is superior on account of its smaller, more graceful, and denser foliage, more regular, 


\section{Linden, Lime Tree or Basswood}

compact, conical form, and flowing outline, as well as by its more extended leaf period and its more fragrant flowers. Linfortunately, it is troubled by insects, borers, and leaf blight.

T. pubescens Ait. (336), Downy-leaved Basswovod, of southern distri-

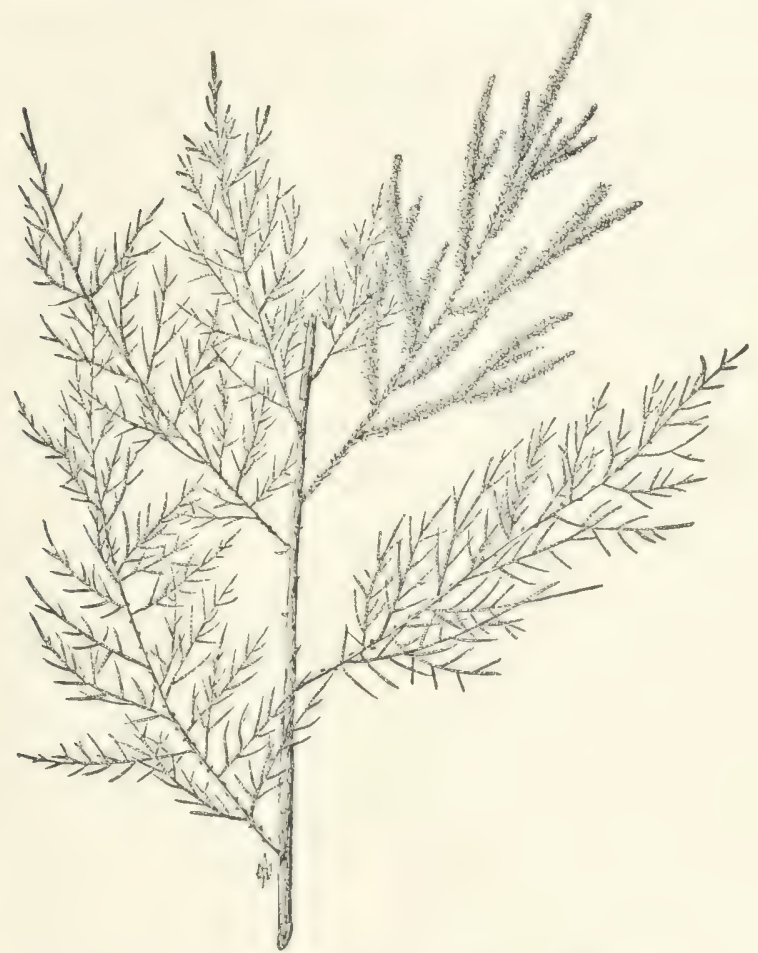

FIG. II5. - Indian Tamarisk Tamarix Indica Willd.

bution, is the one native species, which in size of foliage and other desirable points most nearly resembles the former.

T. heterophylla Vent. (337), White Basswood, a medium-sized tree, also of southern distribution, but hardy as far north as ()ttawa, with somewhat larger, oblong, or somewhat heart-shaped foliage, downy to whitish beneath, mottled yellow and green in autumn, is the most pleasing of the native species, but it is as yet little planted. 
T. argented, D. C. (3.38), the European Silier Linden, with silvery under-side of laves, is of highly ornamental value for color effect.

T. dasystyla Stev. ( $33^{8}$ bis) (euclllora), from the Crimea and other parts of Asia and Eastern Europe, is most distinctive, with tough leathery leaves, dark glossy above, lighter green b.low, fit for planting along dusty roads, as it is not affected by the dust. It is hardy in Ottawa.

There are several varieties, with red and yellow twigs and rariously shaped leaves.

\section{OSAGE ORANGE}

Toxylon. T. pomiferum Raf. (339) (.Maclura anrantiaca), a small round-headed tree, of southeastern range, but acclimated all through the East, and hardy in New England, is, outside of its value for hedges, for which it is admirably adapted, mainly of botanical interest for its shiny, rather coarse, bright geen leaves, its large, orange-shaped, yellowish-green fruit, its yellow tinted bark, and thorny tangle of branches. It might be used arlvantageously for a lawn tree on small plots, where, by proper pruning (annually heading it back), it may be trained into a gigantic, round bush of striking appearance. It is adaptive to various soils, a rapid grower, without insects or other troubles.

\section{ELMS}

Ulmus. A genus with eighteen species of world-wide, mostly northern distribution, and a large number of varieties or forms. Tall to medium-sized trees and shruls, as a rule pleasing in outline and branch habit, with simple but luxuriant foliage of long leaf period, without striking autumn features (pale yellow). 'They are adaptive to various soils, but prefer rich, well-watered soils, even swamps; are moderately shade-enduring and readily transplanted. Aside from the fact that they are subject to many insed troubles, leaf elestroyers, scale, borers, and fungi, they are otherwise amongr the best lawn trees and shade trees, but should always be eriven ample space to permit the develop. ment of their characteristic form.

$L$. Americana Limn. (3+0), IThite $\mathrm{E} / \mathrm{m}$, the finest in form, is the best known and most popular native species, especially when it develops its unique, vase-shaped, broad-toppeel, orer-arching crown with gracefully drooping branchlets. It is, however, often very variable in form, but always vigorous and courtly in appearance, with wide-spreading crown 


\section{Elms}

and an outline which can only be spoiled by pruning. The early flower and fruit, an interesting round green samara, appearing before leafing, mislcarls the uninitiated into the belief that it is an early leafer; it has, however, a long leaf period. It is tolerably shade-enduring, thriving best on leep, moist soils, easily transplanted, and a very rapid and hardy grower. It is best fitted for single positions, and if planted in arenues should le spaced wilely, not less than thirty feet apart, for in thirty to forty years it becomes a large tree.

The American EIm is readily distinguished from the following by its forking habit, each branch dividing into two equally strong branches.

Li. campestris Smith (3+1) (satberosa), English Eim, native of Europe, is, next to the White Elm, most frequently planted; is, however, entirely different and less striking in form, with a stiffer, more compact, and less spreading habit. It is, nevertheless, a noble tree, of large dimensions, with denser foliage than the White Elm, and having the advantage of possessing a much longer leaf period into the fall, and also being less liable to insect troubles. Lately, however, an enemy has developed in the form of a leaf-destroying Aphis, which singles out this European species, leaving the neighboring ones unmolested. This elm is somewhat given to suckering and, at least in Toronto, it fills out its interior with a dense growth of watersprouts. It is best used for grouping and as a street tree.

There are a number of varieties and forms worthy of notice, one of which is suberosc (3+1a), a beautiful, small tree, with vigorous, but small, dark foliage of long duration, and interesting, corky bark.

Of native elms, similar in habit to the European, upright in growth, but smaller and requiring less space, should be mentioned:

U. fulva Michx. (342), Slippery or Red Elm, with a magnificent foliage, larger than that of the IV':ite EIm, and of rough surface, borne on long, somewhat pendulous branches, which usually form an open, flat, and less graceful crown.

$U$. alata Michx. (3+3), If ahoo or I'inged Elm, a small, round-headed tree, of southern distribution, fit only for southern planting.

$L^{r}$. racemose Thomas (334), with corky-winged branches, and foliage whitish beneath, has the advantage of being adapted to drier soils than the others, and is also fairly hardy into Manitoba.

Of the other exotics are to be mentioned the often planted European and Asiatic:

U. scabra Mill. (3+5) (montuna), Wych Elm, a medium-sized tree, 
with oblong or roundish outline, of vigrorous growth, with luxuriant, large, glossy foliage, adaptive to proter soils, and free from insect troubles. Of the many uursery forms, the weeping variety, pendula (345a), Camperderen Elm, with a spreading habit, is one of the best to make arbors.

$U$. parifolia Jacq. (3+6), a small tree to shrub), from China, hardy to Massachusetts; with very attractive foliage, with small leaves, lustrous above, hairy below, and somewhat leathery; with a very long leaf period; is one of the most attractive trees.

\section{A LIST OF SHRUBS}

Originally it had not been the intention of the author to extend the scope of this book beyond discussing the methods of taking care of trees after they are secured.

It was the publisher who caused the addition of the preceding chapter and tree list, and, although the author pleaded comparative ignorance, he was still further inveigled into compiling the following brief enumeration of ornamental shrubs, with notes on their special uses and requirements.

This list of over 200 shrubs covers the majority of species in cultivation, and reference to the best known hybrids.

As we have seen, the distinction between trees and shrubs is not always hard and fast. While the single stem and branching crown are characteristic of a tree, a number of stems from a common root-stock are characteristic of a shrub. Some tree species may, however, be trained to assume the shrub habit, or this may take place naturally under certain climatic or soil conditions, and zice zersa. For the landscape gardener, the general effect of the whole, rather than the species habit, is determinative. Hence in nurserymen's catalogues, the low tree species which are apt to grow in bush-like form are classed as shrubs.

As regards adaptation to climate, situation, and soil, shrubs as a rule prove hardier than trees on account of their low 


\section{List of Shrubs}

stature, which keeps them under the protection of snow, nearer the warming influence of the ground, and more out of reach of searching winds. Their habit of suckering from the root is also of value, replacing more readily the lost stems or parts. Indeed, when dealing with half-hardy shrubs, it is often wisest to cut them down to the ground in the fall, when the roots next spring will reëstablish them. These half-hardy species whose annual shoots are apt to be killed back from one-quarter to one-half require in a northern climate, such as that of New York or New England, or Canada, sheltered situations or artificial protection to enable them to stand the winters. A common methed is to bend them down to the ground, weighting them with stones, when they will be covered by snow, and winter well. Concerning this question of hardiness we refer again to Chapter III.

The low, spreading habit of shrubs furnishes protection to the soil, keeping weeds out, and reducing evaporation, while their shallow root system adapts them to shallower and poorer soils.

Most shrubs are tolerably free from insect and fungus pests, and, if they are attacked, are more readily protected. They are, as a rule, easily propagated, but, to secure the best persistent effects in form, foliage, and flower, the application of the pruning knife is essential. Their more or less ready response to this treatment makes them specially available for hedges or borders.

Besides adaptation to climate, soil, and exposure, shadeendurance is a point of value in many, making them useful as underbrush.

Form is of less moment than in trees, as it can be more or less rearlily corrected, but size is of importance, when grouping is attempted; for while some species may be kept down 
in size to desired proportions, others are too vigorous to be so treated, and the natural habit must be recognized. Ife shall call tall shrubs, those which attain naturally a height of over Io feet; medium-sized, those between 6 and io feet; low or small, those from 3 to 6 feet; and dwarfs those lower than these last dimensions.

In grouping, the smaller linds are, of course, placed in front, the taller toward the center of the group.

From the ornament point of view not only the foliage effect in shape and color during the leafy season, and the color effect of the stems in winter is of importance, but in a large number the flower and fruit is the great attraction.

In regard to flower not only the character, size, color, and profusion, but particularly the time and persistency of the blooming should be taken into consideration in the choice of shrubs.

The great art of the landscape artist is to blend or to contrast foliage in groups or masses, and to secure a succession of harmonious flowers in groups by skilfully combining shrubs, which in habit, size, and character of flower harmonize but differ in the time of blooming.

In some shrubs the flowers appear in early spring either before or with the arrival of the leaves, while in others they do not come until midsummer, and a very few species do not flower until the fall, thereby becoming especially valuable. To assist selection we have, therefore, given the time of flowering, which, of course, varies slightly according to season and latitude. When no statement is made, the usual time, May, June, is understood.

Flowers appear either singly or in bunches and clusters of varying shapes; in flat "cymes" like the common Yarrow and Viburnum; or in elongated pendent "racemes," like the Bleeding Heart; or in long, dense, or loose "spikes," like 


\section{List of Shrubs}

the Mullein or Dragon's Head; or in broad and elongated heads, like the Sunflower and Crimson Clover; or in manybranched "umbel," like the Carrot; or in loose "cymes," like the Apple.

Every shade of color that is wanted may be secured, thanks to the many varieties and hybrids produced by the horticulturists, who are also responsible for the so-called double flowers.

In shape of flowers, several forms can be recognized of which the following may serve as types: flat like the Dogwood; rose-like like the Rose and most of the fruit trees; bell-shape like the Huckleberry; tubular like the Honeysuckle; funnel-shape like the Syringa, and butterfly-shape like the Pea.

In size, we have tiny blossoms which become effective only by being clustered; small, delicate ones, which by their profusion are showy, and large, broad or long, more or less coarse ones, which in their singleness are decorative.

In these points, as elsewhere, similarity is mostly desirable in selecting for groups, contrasts being difficult to devise so that they do not jar.

In managing shrubs, not only for their form, but for their blossom, the pruning knife is most important. As we have seen under Tamarisk (p. 3IO), the annual flowering can be influenced by appropriate pruning practice, based on the recognition of the flowering habit. Iet care is necessary not to overdo the pruning and thereby destroy the character of the shrub; regular annual pruning of moderate extent must be the rulc. It should also be understood that sunlight is inducive of flowering, while shade retards.

It should be kept in mind that many shrubs, like the spiræas, daphnes, and other beautiful species, after a few years blooming, are more easily and severely killed back in severe winters, notwithstending their entire hardiness (as 
species), in healthy condition. They should, therefore, be renewed by layering or else be replaced.

In the following enumeration, the writer has largely depended on the information found in Mr. Lucius D. Davis' volume on "Ornamental Shrubs" as well as on other recognized authorities and nursery men's catalogues, supplementing this by his own personal studies in the field.

An appropriate classification of shrubs from the decorative point of view is difficult, if at all possible, since foliage, flower and fruit combine in making decorative valele. II: have therefore chosen a mixed alphabetical and botanical scheme, grouping together the seven or eight families which furnish the bulk of ornamental shrubs, and following these grour's by a merely alphabetical list of the single genera containing ornamental shrubs. Shrubs which come from genera containing tree species have for the most part been discussel in pag is 213-322. The numbers in parenthesis preceding the species $n \mathrm{~m}$ : coincide with those of the species described in the following pages.

\section{LIST OF SHRUBS}

ABEliA (35) spathulata, (36) rupestris, (36a, grandiflora), (37) serrata, (38) triflora.

ACACIA, see Trees. B.

Acer, see Trees. C.

Esculus, see Trees. B.

Albizzia, see Trees. B.

Alvus, see Trees. C.

Althila, see under Hibiscts.

Amelanchier, see Trees. C.

Amorpha (90) fruticosa, (7I) canescens.

\section{ANDromeda (I) polifolia, arborea.}

Aralia, see Trees. B.
AzaLEA (3) arborescens, (4) calendulacea (lutea), (5) Canadensis (Rhodora), (6) nudiftora, (7) Vaseyi, (8) viscosa, (9) Pontica, (го) mollis (Sinensis), (г I Indica, (г $a, a$ moena), (г $b$, Kampferi).

BACCHARIS (I44) hamilifolia.

Berberis (3+5) Candentisis, ( I 46 ) vulgaris, (I $6 a$, atropurpurea), (I47) Thunbergii, (148) Amurensis, (I48a, Japonica), (149) Japonica, (I50) Wallichiana, (I5I) ilicifolia.

Butneria, see Calycanthus. 


\section{List of Shrubs}

Calluna (12) vulgaris.

Calycanthus (I52) floriduis, (Butreria), (I53) glaucus, (I54) lavigatus, ( 155$)$ occidentalis.

Caragana, see Trees. B.

Carpinus, sec Trees. C.

CASsandra (I3) calyculata (Chamadaphne).

Celastrus (I 55 bis) candens, (I55 tris) orbicularis.

Cercis, see Trees. C.

Chamaedaphne, see CassanDRA.

Chionanthus, see Trees. C.

Cladrastis, see Trees. B.

Clethra (I4) alnifolia, (I5) acuminata, (I6) arborea.

Colutea (92) arborescens, (93) cruenta (orientalis).

Comptonia, see Myrica.

Cornus, see Trees. C.

Corylus (I56) Americana, (I57) Avellana purpurea, (I57a, laciniata).

Cotoneaster (98) horizontalis, (g9) microphylla, (I00) Simoni, (IOI) frigida, (IO2) multiflora, (IO3) mummularia.

Crategus, see Trees. C.

Cytisus (94) scoparius, (95) capitatus (95a, nigricans), (95b, albus), (95c, purpureus).

DAPHNE (I58) Mezereum, (I59) cneorum, (I60) laureola.

Desmodium (96) penduliflorum (Sicboldi), (97) Japonicum.

Deutzia (I26) scabra, (เ26a, flore-pleno),( (126b, candidissima), (I27) crenata purpurea, (I27a,
Watereri), (I28) parviflora, (129) gracilis, (130) Lemoinei.

Diervilla (39) florida (rosea), (39a, nana), (39b, Kosteriana), (39c, alba), (39d, candida), (39e, amabilis), (40) grandiflora arborea, (4I) floribunda (multiflora), (4I bis) Eva Rathke.

EleAGNus (67) argentea (Canadensis), (68) longipes, (69) umbellata, (70) angustifolia (hortensis), (7I) macrophylla, (72) reflexa.

Evonymus (I6I) Americanus, (I62) atropurpureus, ( I63 $_{3}$ Europaus, (I64) Japonicus, (I65) radicans, ( $165 a$, variegata), (I66) alatus.

EXOCHORDA ( $\mathrm{I}_{4}$ ) grandiflora.

Forsythia (73) suspensa Fortunei, (74) viridissima.

Fraxinus, see Trees. B.

Gardenta ( $\mathrm{I}_{7}$ ) jasminoides, (I68) florida (I68a, Fortunei), (I69) radicans, (I70) nitida.

Halesia (Mohrodendron) (I35) tetraplera, (I36) diptera.

Hibiscus (r 7 I) Syriaca (Althea frutex).

Hydrangea (I2I) paniculata, (І21 $a$, grandiflora), (I22) quercifolia, (123) vestita pubescens (124) hortensis, (124a, Otaksa), (I25) Thunbergi (serrata).

HYPERICUM (I72) Kalmianum, (I73) aureum, (I74) Moseriamum, (I75) prolificum, ( 176$)$ densiflorum.

ITEA (I2O) Virginica. 
Kalmia ( ( 7) latifolia, (I8) angustifolia, (I9) glauca (polifolia), (Iga, nana).

Laburnuir, see Trees. B.

LAgerstrema (I77) Indica.

LespedezA, see under DesmoDIUM.

Leucothoe (20) Catesbai, (2I) racemosa, (22) acuminata, (23) axillaris.

Ligustrum (75) vulgare, (76) ovalifolium, (77) Amurense (Ibota), (78) Japonicum, (79) Quihoui, (80) Sinense.

LONICERA (42) ciliata, (43) ccrulea, (44) involucrata, (45) oblongifolia, (46) Hildebrandiana, (47) Tatarica, (48) fragrantissima, (49) Standishi, (50) spinosa (Alberti), (50 bis) periclyminum.

Magnolia, see Trees. C.

Malachodendron, see Stuartia.

Mohrodendron, see Halesia.

Myrica (I78) Carolinensis, (I79) asplenifolia (Comptonia), (I80) Gale.

Neillia, see Spirea.

Opulaster, see Spirea.

Ostrya, see Trees. C.

Paulownia, see Trees. C.

Philadelphus (I3I) coronaria, (132) Gordonianus, (I33) inodorus (grandiflorus), (I34) microphyllus.

Physocarpus, see Spiriea.

Pieris (24) Mariana, (25) ligustrina (Xolisma), (26) floribunda, (27) Japonica, (28) nitida rubra.
Pirus, see Trees. C.

Prunus, see Trees. C.

RHODODENDRON, (29) maximum, (30) Catawbiense, (3I) punctatum, (32) Ponticum, (33) arboreum.

RHODORA, see AzALEA.

RHODOTYPUS (I05) kerrioides.

Rhus, see Trees. B.

RiBES (I8I) alpinus, (I8I $a$, anreum), (I82) aureum, (I82a, tenuifolium), (I83) Americanum (floridum), (I84) speciosum.

Robinia, see Trees. B.

Rosa (106) rugosa, (107) rubiginosa, ( (о8) lucida, (Iо0) setigera, (гіо) multiflora, (I Iоa, Dawsoniana), (III) Wichuraiana.

Sambucus (5I) Canadensis, (52) racemosa, (53) pubens, (54) nigra, (54a, aurea), (54b, laciniata), (54c, variegata).

Sassafras, see Trees. C.

SHEPHERDIA (8I) argentea, (82) Canadensis.

Sophora, see Trees. B.

SPIR EA (II2) opulifolia, (II3) salicifolia, (II4) tomentosa, (II5) Thunbergi, (I I6) prunifolia flore pleno, (I I 7) trilobata, (II8) van Houttei, (I Ig) Bumalda, (I Iga, Anthony Waterer), (IIgb, superba).

StUARTIA (185) pentagyna, (I86) Virginica (Malachodendron).

Styrax (I37) grandiflora, (I38) Americana, (139) pulverulenta, (I40) Japonica, (I4I) Obassia. 


\section{Heath Family}

SYMPHORICARPUS (55) racemosus, (56) vulgaris.

Symplocos (I42) tinctoria, (I 43) cratagoides.

Syringa vulgaris $(83 a, a l b a)$, $(83 b$, grandiflora), (83c, Marie Legraye), (83d, Charles $X)$, (8ze, Charles Joly), (83f, Madame Casimir Perrier), (83g, Congo), (84) Persica, (85) Chinensis (Rothomagensis), oblata, (87) pubescens, Japonica, Lemonei).
Tamarix, see Trees. C.

Viburnuxi (57) lantanoides (almifolium), (58) Lentago, (59) Opulus, (59a, sterile), (60) dentatum, (6I) acerifolium, (62) macrocephalum, tomentosum plicatum, Sieboldi, (65) Tinus, Lantana.

Vitex (I87) Agmus-Castus. Weigelia, see Diervilla. Xolisma, (25) ligustrina. Zenobia (34) speciosa.

\section{HEATH FAMILY (ERICACEAE)}

This large family contains over twenty genera and more than three hundred and fifty species, of which at least some twenty-five, with many hybrids, deserve attention. They make a most attractive flower show, with four- to five-toothed flowers, spreading or bell-shaped (in some cases two-lipped), generally white or pink, varying in size and found in smaller or larger clusters. Well-known examples are azaleas and rhododendron. The fruit is generally an inconspicuous capsule. Many of them are evergreen.

They range from the daintiest small border shrubs with tiniest leaves and flowers, to the robust, large-flowered, and large-foliaged rhododendrons. The low ones are most useful for edging borders, combining well with other evergreen shrubs, and for winter and early spring effect. An arborescent species from Italy furnishes the briarroot pipes. The names of the various genera are often mixed up, being lately split up into the following eleven. Both in formal and in informal naturalistic plantings the different members of the family may be most satisfactorily combined for succession of blossom and color.

Favorable soil conditions and partial protection (during January and Fcbruary) in unfavorable situations are needful for best success, at least with some of those in the list. Indeed, in general the members of this family do not seem to be easily handled.

Andromeda. (Sce also Pieris, Cassandra, Zenobia, Leucothöe, which used to be grouped under Andromeda.) 
"his genus furnishes one excellent ornamental shrub, a dwarf, indigenous to the northem temprate zone and found in the turfy hillocks of northern bogs, from Newfoundland to Nlaski and south.

A. polifolia Linn. (1), W'ild Rosemury, rarely over twelve to fifteen inches in height, with very finc, linear leaves, dark green above and white beneath, and tiny, delicate white to pink flowers in nodding clusters (spring). Most suitable for borders.

A. arborea (2), see Oxydendron, Tree List C.

Azalea. A genus with a large number of species and varieties and endless hybrids, native, from the Mediterranean and from Asia; many only fit for hothouse use; prized for their wealth of early, variously colored, beautiful flowers (April to July). All but one are deciduous, very shade-enduring, hence fit for under-shruls, but they thrive also in sunny and moist places (ravines and borders). Various sizes can be had. For remarks regarding their treatment, see under Rhododendron. Three or four native species and two or three exotics, from which many varieties are derived, are adapted for outdoor use. For best effects, rich soil is desirable, ample moisture, and partial shade.

* A. arborescens Lursh. (3), the native Tree Azalea, from Pennsylvania to North Carolina, is the largest of the family (twelve to twenty fect), with less brilliant (white to reddish) flowers than the others, the latest in blooming. It is the easiest to cultivate in any situation. It fits well in the center of a group of its congeners.

* 1. calcululacea Michx. (4) (lutea), the Flame 1zalea, native of the Atlantic Coast, is next in size (six to fifteen feet), and one of the most showy, with a profusion of yellow to scarlet or orange-red flowers (May, June), which justify its name.

A. Canadensis Kitze. (5) (Rhodora), is probably the hardiest, being native from Newfoundland south, a low shrub (one to two feet), with glaucous foliage and early, rose-purple flowers in variegated shades, appearing before the leaves. No success in Ottawa.

1. mudiflora Linn. (6), the native, common II ood Honeysuckle, or Pinxter, from Maine to Texas, grows to a height of six feet or more, with pink flowers appearing in profusion before and with the leaves, in May, and is perhaps the most adaptive; hardy into Canada.

A. V'aseyi Rehder. (7), from the mountains of North Carolina, only lately introduced into gardens; in cultivation may attain a height of four to six feet. It excels in its delicate pink or rose-colored flowers, * Stars denote the most desirable forms. 


\section{Heath Family}

and is the earliest bloomer (April, May), blossoming before the foliage, which in the fall assumes a rich, vinous red or crimson color.

A. viscosa Linn. (8), the native Swamp Honeysuckle, or Pinxler, from Naine to Texas; with white, fragrant flowers; the latest bloomer of all; is fit for wet spots.

Of exotics there are at least three worthy of attention:

A. Pontica Linn. (9) (gandaiensis?), from Europe, with many varieties, which excels in its large glossy leaves, profusion of larece but delicate, varicolored flowers (1lay, June), which are single and double, and by its pleasing outline, three to five feet high. It is only half hardy. A long line of hybrids with American species gave rise to the so-calle'l Ghent Azaleas.

A. mollis Blume. (Sinensis) (10), the favorite of the Japanese, with its spreading habit, three to eight feet high, most profuse, large, flame-colored, very early fowers (April, May), and pleasing foliage, silvery gray beneath; also with many color varieties.

In addition, a large number of hardy hybrids, giving every choice of color in flowers, have been produced from the one everereen species -

A. Indica Linn. (II), which is itself tender to half hardy.

* A. amœna Lindl. (I $a$ ), one of the choicest, a new introduction, is hardy as far as New York, an low and sprearling as .1. mollis, and as early a bloomer (April, Nay), with a profusion of large rich crimson (to purple) blossoms, and dense foliage of small, ghosy leaves, turniner bronze in winter. It is best used singly, or in hedge line, or in front of rhododendrons and kalmia.

1. Kampfori Rehder ( I b), with pink to orange-ted, early flower: is hardy into New England.

Calluna (Erica). Heath. Of the very large number of species and varieties, mostly of southern climatce, with small, rlainty foliage and flowers, only one is hardy enough with us to be grown in the open, namely:

C. 2ulgaris Salist). (12), the Scolch IIeather, one to three feet high, with handsome, terminal racemes of tiny pink flowers (July to September). It grows in poor, sandy, and peaty soil, and is well adapted to massing in borders.

A number of varietics of this specie:-, with varied color of flower, double blossoms, golden and silver-colored shoots, are worthy of attention. 
Cassandra (Chamædaphne). C. cllyculata Don. (13), Lcatherleaf, is a thoroughly hardy and prety dwarf of the north temperate zone; with leathery foliage, rusty brown beneath, and nearly evergreen, attractive by virtue of its very carly, small white flowers (April, May) covering the branches, in one-sider racemes from the axils of the leaves. It is useful for borders, and arlapted to bogrey land and to watersirles.

Clethra. C. culnifolia Linn. ( I f), Saect Pepperbush (improperly White Alder), so called from the frastance of its flower, is one of the finest native (from Maine to Florida) small shrubs (two to four feet); with slender, straight stems, not much branched, light green, downy bark, becoming purple, with bright, glosisy, large leaves, and lares creamywhite, showy, and fragrant flowers in racemes or spikes, terminal and from the axils of the leaves, which continue blooming from July to ()ctober, when nearly all others have ceasel flowering. Although a plant of the swamps and moist places, it grows well in dry, poor places, and is shade-enduring. It is especially adapted for massing in borders and in semi-refined plantations.

The more southern (Madeira) evergreen species, C. acuminata Michx. (15), which sometimes assumes tree form, has no superior points, nor has the European, C. arborea Ait. (I6).

Kalmia. Laurel. A genus of five species, all American, low to high, shrubs, highly ormamental by reason of their glossy, evergreen foliage and very large, showy flowers. They are especially effective when massed. They are very hardy and frugal, very shade-enduring, and easily propagated. They can be readily secured from the woods.

*K. latifolia Linn. (I 7), Mountain Laurel, Calico Bush, is the largest of the genus (fifteen to twenty feet), although it sometimes grows to a height of forty feet with a diameter of eighteen inches. It thrives from Canada to Georgia. It is the most elegant and attractive of the genus, with dark-tufted, leathery foliage, which is broad and persistent; and beautiful flowers (May, July), of many shades, from pure white to rich rose color, in prolific terminal heads. Sercral varieties vary in color.

$K$. angustifolia Linn. (т8), Sheep Laurel, very hardy, with purple crimson flowers (June, July), and -

K. glauca Ait. (Ig) (polifolia), Szeamp Laurel, with lilac, purple, earlier flowers (May, June), are both dwarfs (one to three feet), and both are like a still lower (six to eight inches) variety of the first, nand, fit for borders and small clumps. 


\section{Heath Family}

Leucothöe. Four species of southern North American heathers, small, graccful shrubs; nearly or entirely eiergren, with small, pinkish to white, bell-shaped flowers in racemes, and appearing early. They require moisture and partial shade.

* L. Cutcstei Gray (20), although found on streams from Virginia to Georgia, it is a harrly dwarf (two to three feet) with long, arching sprays of broad, dark, glosiy foliage on slencler, recurved branches, bronzing in winter, larger than the leaves of the rhododendron, with which it group; well. Its pretty pure white flowers, in racemes from the axils of the leves (. April, May) emit an odor not agreeable to everybody. The purple hue of the buds adds to its beauty. It forms a most excellent ground cover.

* L. racemosa Gray (2I), one of the most desirable of the family, growing in swamps from Massachusetts to Texas, along the coast; is a hardy, low shrub (three to four fert), with rich, glosisy, green, oval, but decidunus foliage; with very fragrant, degant, white, waxy flowers (April, June) in lone terminal racemes, and with a bright red bark which adds to its attractiveness.

L. acuminata Don. (22), the Titi of South Carolina and Florida, and $L$. willaris Don. (2.3), the first a larger, the second a smaller plant than the preceding, with their flowers from the axils of leaves and branches, possess hardly any points of superiority.

Pieris (Andromeda). Of the ten or twelve species distributed over North America and western Asia, three native and one exotic are especially useful for their arry early flowers, as a rule white and bellstaped, of chaste and delicate beauty in dromping racemes. The evergreen foliage of seme species is also ormamental. The natives are very hardy and thrive best in partial sharle. All are to be used like, and in combination with, others of the family.

P. Mariana B. \&. H. (2.4), Stagger Bush, two to four feet; native from Niw England to Florida and Texas; in wet, low ground; is deciduous, with large (two to three inches), oval leaves, and white to pale pink, bell-shaperl thwers in graceful, nodding racemes, appearing (April, May) before the leafing on the old wood.

* P. floribunih Benth \& Hook. (26), Mountain Fefter-bush, another compact and well rounded, but smaller ezergreen (two to six feet); native from the mountains of Virginia to Georgia, and very hardy. Of this species Davis writes: "No one should think of planting any considerable number of ornamental shrubs without including this charming 
plant." Being evergreen, with single stems from the ground densely covered with large, glosiy foliage, it is handsome all the year round. Its terminal flower clusters are pendent and much branched, and the flower buds, which appear prominent above the foliage during winter, add to its interest.

P. Japonica D. Don. (27) is a dwarf similar to the preceding, but more striking with its leaves which come out in bright or red hues, then changine to the dark, normal color, and in winter to rich red and bronze; and profuse with larger, terminal bunches of dronping white flowers (April, May). It is, however, only half hardy. Still more striking in color effects is a variety with white-marked leaves.

$P$. nitida Benth \& Hook var. rubra (28) is the earliest bloomer (March to May), with deep pink flowers and evergreen leaves.

Rhododendron. This enus of large shrubs, of mountain habitat, native and from Asia, furnisher, in some two hundreal species and in various hybrids, all with evergreen foliage and grat variety of showy flowers, a long series of the most striking and satisfactory omamentals. Nothing can take their place for maturalistic planting - in the proper places. Lnfortunately they are not casily propagated. 'They are choice of soil and situation, requiring a cool, light, porous, well-watered, deep, if possible rich loam soil, and thrive best in shady and protected location; although if properly trained or selected and well watered they will do well in sunny spots. Like most of their congeners of the Heath family, lime and heary clay soil, which are poor water conductors, are unsuited to them, unless properly improved. They appear in Canada only half hardy.

The exotic species are only half hardy to tender, and most of the many varieties or hybrids derived from them by European horticulturists share this tenderness. In order to be certain of success, it is necessary to be sure that the mother stock is of the hardy American species, that the planting is carefully done, and that the location is half-shady, or shady at least through the hot part of the day. In hot weather they are grateful for watering and for mulching. They are especially fit for massing on corners, or on borders of driveways, and 1 for underplanting. The seed pods should be remowed in July to favor the flowering in the next season.

R. Muximum Linn. (20), Great Lanurl, is the hardiest native, found from Nova Scotia south; grows to a height of over twenty feet, sometimes even in tree form to forty fect, with dark, glossy, rich green 


\section{Heath Family}

foliage and a profusion of broal ( $\mathrm{I}_{2}^{1}$ to 2 -inch!) pink to white flowers sprinkled with yellowish and orange spots, the latest in blooming (June, July), but persistent. This being the largest, it makes a good background and winter effect for gardens.

* R. Catarbicnse Pursh. (30), Mountain Rose Bay, from the southern mountains, a smaller shrub, three to six feet high (although sometimes reaching a height of twenty feet), with small, oblong leaves, rounded at both ends, and clustered at the tips of the branches; and bright, lilacpurple tlowers (June), as large as those of the preceding; is equally hardy, and adapts itself to adverse situations. It is the one chiefly used in hybridizing for American use.

$R$. punctutum Andr. (3r), so called from the dots on the underside of the foliage, is also a small shrub, from alpine ranges. It is the earliest and most persistent bloomer, bearing dense clusters of funnelshaped, greenish-spotted flowers (May to August).

The species used in Europe, but to be avoided as not hardy with us, are:-

$R$. ponticum Linn. (32), from Asia Minor, recognized by the elliptical leaves, pointed at both ends, and pale underneath; and

$R$. arboreum Smith (33), the largest, twenty to thirty feet, from the Himalayas, recognized by lanceolate leaves, cordate at base and acute at tip.

A very large number of hybrids, with flowers of all shades, are in the market, just as in the case of the related Azaleas; in selecting which the question as to the mother stock used should be carefully looked into.

Xolisma. X. ligustrina Britt (25), Privet Andromeda, also native from Canada to Florida, and west, growing in swamps; is larger, a bushy, compact, deciduous shrub (five to ten feet) and a still earlier bloomer, with a profusion of flower bunches, and with oblong leaves in panicles, assuming a brilliant fall coloring.

Zenobia. Z. speciosa Don. (3+), from the South Atlantic shores, a small (two to four feet) shrub, with upright, arching branches; is one of the latest blooming heathers (July), with a profusion of dainty, waxy, white bells, resembling the lily of the valley, blossoming for a long time on the previous year's branches; its pale green, oval foliage adding to its attractiveness. Its light foliage gives it value as an accent shrub, and it is fine for border work. It thrives well in sandy and peaty soil. 


\section{HONEYSUCKLE FAMILY (CAPRIFOLIACE $\$ )}

Some two hundred and sixty specits in ten genera are known, of which some thirty are more or les commonly planted. With tubular long-necked, or narrow-throated thwers, well known in the climbing Honeysuckle or Caprifulium, or, in much reduced form, or urn-shaped, as in the Elderterry, or lunched in small clusters or heads, as in the Snowball; the fruit a colored berry.

Most honeysuckles are surden shrubs and are used extensively, especially the Asiatic Lonicerds, for this purpuse, in large masses rather than singly, for which they are less adapted in form. Is a rule they make good fillers, and the climbers may be used for soil cover, especially on banks. Most of them are adapted to poor soils.

Abelia. A genus from Asia and from Mexico, affords a number of low, evergreen shrubs, most of which are fit only for southern planting, to be used somewhat like rhodedendron, except that they prefer sunny sites.

A. spathulata S. \& 7. (35), a much-brancher shrub from Japan, is probably the hardiest farthest north; having elliptic leaves with purple edges; the flowers, in pairs and very abundant, white, with light yellow blotches at the throat (early spring).

1. rupestris Lindl. (36), from China, a well-shaped bush, with gracefully arching stems, five to eight fuet high, has small, dark, glossy leaves, tardily deciduous in the nortli; and tuludar flowers, pale rose color without and white within, flowering late (July, dugust), but persisting a long time. A variety, grandiflow $(36 t)$, with larger flowers (one inch), continuously from June to Nosember, is said to be more robust, and hardy to semi-hardy as far north as New York.

A. serrata S. \& Z. (37), is less hardy than the former, with very large, pale red, single terminal flowers (early spring).

1. triflora R. Br. (38), with yellow and pinkish terminal flowers in threes (fall); is one of the best bloomers.

Diervilla (Weigelia). The Bush Honeyuckles or Il igelius, a genus with ten species from Europes, Asia, and native, furnishing a number of vigorous, broad shrubs (ive to eight feet), prized bor their thowers, white, pink, or red, and, wo a less extent, for their bright foliage. In gardens and small places, massed and carefully chosen for their color effect, they may be kept in trim, standing shears well.

* D. florida S. \& 7. (39) (rosea), from China, is one of the most 


\section{Honeysuckle Family}

generally planted, a syringa-like hardy shrub (six feet), of straggling tendency, with numerous slender branches; covered in early spring (May) with a profusion of deep rose-colored flowers gracefully festooned from the axils of leaves and ends of branches. Several dwarf forms adapted to small places, D. nana $(39 a)$, D. Kosteriana (39b), and varieties with white flowers, D. alba (39c) and D. candida (39d), are in existence.

A variety amabilis $(39 c)$, of more robust habit and larger size, excels in its conspicuous red flowers which blossom late when few shrubs are in bloom.

* D. grandiflora S. \& Z., var. arborea (40), from Japan, another late bloomer, with large, pale yellow or rose-colored, honeysuckle-like flowers and large leaves; often achieves tree form.

D. foribunda S. \& Z. (multiflora) (4), also from Japan, perfectly hardy, has rich, dark crimson, small, fuchsia-like flowers and darkcolored foliage.

A group of hybrids of uncertain derivation furnish a long line of more or less distinct ornamental value. Among them the most striking, free bloomer is Ei'a Rathke (4I bis) a very hardy, erect shrub with dark red flowers.

Lonicera, the true Honeysuckle. This is a genus with over one hundred and forty species, not less than sixty of which are under cultivation; of all the honeysuckle family having the most northern distribution on the three continents; is of course entirely hardy. The species of this genus are mainly familiar through the well-known vines or climbers, although they also furnish some ornamental shrubs, decorative in flower and berry. They are shade-enduring and frugal, and invaluable for border and mass planting. Four species of native honeysuckle shrubs are specially hardy.

L. ciliata Muhlenb. (42), Fly Honcysuckle, a Canadian, with spread. ing habit, three to five feet high, with heart-shaped, oblong leaves, is attractive by virtue of its light red berries, which persist long; the greenish-yellow flowers (April, May) are interesting, if not conspicuous.

* L. corrulea Linn. (43), another upright shrub of northern distribution; a dwarf; has blue to purple, persistent fruit; and showy yellow flowers in profusion.

L. involucrata Banks. (44), also a dwarf, from Lake Superior west, has shiny, dark purple to black fruit, and yellow flowers tinged with red (May, to July), and large, bright green leaves. 
L. oblongifolia Hook. (45), a larger shrub (to five feet), is of value in its adaptation to boggy conditions, and ornamental in its very lare: (two to five inches) leaves, and dark purple, long-enduring fruit, following the yellowish-white flowers.

Of exotics some eight or ten species are cultivated.

L. Hildebrandiana Coll. \& Hemsl. (46), from Burma, and therefore perhaps only half hardy, is the largest; a climbing shrub, evergreen in its native country; it excels by reason of its large glosiy leaves (four to six inches), and very large and remarkable (seven inches) crimson flowers. It is as yet little used.

* L. Tatarica Linn. (47), a hardy Russian, with a number of varieties; is one of the best known and most satisfactory shrubs (six to ten feet); with its numerous, slender stems, and a profusion of baatiful, small, yellow flowers, with rose-tinted to crimson base (April to June), followed (July, August) by striking, translucent, and very persistent coral, cherry red, orange, or dark berries.

L. fragrantissima Carr. (48), from China, is only half hardy, but one of the best, most showy species (five to eight feet), having leathery, nearly evergreen leaves, and flowering very early (.March), before or with the foliage, large, white, light yellow, or pink, very fragrant flowers, and scarlet fruit.

L. Standishi Carr. (49), also from China, resembles the preceding, except that the flowers are cream white, opening in late winter and early spring.

* L. spinosa Jacq. (50) (.Alberti), from Siberia (Baikal Sea or Turkestan), very hardy, a dwarf (two feet), with slender, drooping branches, is quite distinct, with long, narrow to linear, bluish-green leaves, and very large and very fragrant, pinkish-purple flowers (May, June), followed by vinous berries. It is well adapted for rock gardens.

One of the best climbers in this group is L. periclyminum ( 50 bis), the Sweet-scented English Honeysuckle.

Sambucus. Lilderberry. There are some twenty species, all of northern distribution and hence hardy shrubs; of a not very attractive, rather coarse, open form, and of stragerling habit, but very hardy and frugal, most satisfactory in exposed and in shaty situations. 'They are very strong sprouters. Although rather coarse in form, they are not without ornamental value, with their compound leaves, small, white flowers in broad clusters, and especially their colored berries. They are most effective when massed, and when used as accent shrubs. 


\section{Honeysuckle Family}

They are particularly useful in waste places, neglected corners, and in seaside planting, for undershrub as well as in damp, shady woods.

Two American and one European species, with a number of varieties, deserve attention:

* S. Canadensis Linn. (5I), the common Elder and the hardiest, deserving more extended use (five to ten feet); of wide distribution from Canada south; with showy, white flowers in flat cymes (early summer), and with dark purple to black fruit (August, September). The fruit is used in pies and in making the elderberry wine.

* S. pubens (53), and its almost exact European counterpart-

* S. racemosa Linn. (52), differs from former only in having red berries, the American species, however, being perhaps the more graceful.

S. nigra. Linn. (5t', the Europaan Bl.lck Elder, so called from the purplish black or dark green berries, is a much larger bush (twenty to twenty-five feet), well rounded and with compound foliage, which keeps very persistently green, like that of most exotics.

Three fine varieties of this species, only half hardy but rapid in recovery, are commendable:

* S. aurea $\left(5 f^{a}\right)$, the best golden-yellow-leaved ornament, especially when kept trimmed to low form and in masses;

* S. laciniala $\left(5 t^{b}\right)$, with a deeply cut, sparsely-leaved foliage, fine for massing and borders;

$S$. variegata $(54 c)$, with white markings, is a curiosity.

Symphoricarpus. There are ten species of which two are native and have great value for covering dry, guvelly binks and heary soils, an 1 for underbrush, being very shade-enduring, their suckering habit ten lin of to keep their growth dense. Their smooth, broad foliaga and their waxy, berry-like fruit, hanging on through winter, are their chicf ornaments. They are largely used in combination with rhododendron and other evergreen shrub:, when the berries set off well against the dark foliage. The two American species are the best, and they are usually planted together.

S. racemosus Michx. (55), Waxberry, a low, graceful shrub, with slender branches, rose-colored tliswers, and white, waxy fruit in clusters;

S. vulgaris Michx. (56), Indian Currant, Coral Berry, a more compact bush, which excels in haring persistent foliage, bright green tinged with reddish-purple, and very showy, dark red berries.

Viburnum. Snowballs. A large genus, over a hundred species of 
small trees or medium-sized shrubs, twenty North American, of which several are very satisfactory and willely planterl ormamentals, being hardy to the Canadian Northwest. They are vigorous growers and attractive in foliage (lobed or otherwise interesting), flower (white heads), and fruit (colored berries), although some specics are somewhat straggling in habit. They thrive in partial shade, and heary, especially peaty soil and swampy ground, lut can adapt themselves to other situations. They are best adapted for rough border work in masses to bring out the foliage effect.

*V. lantanoides Michx. (57) (alnifolium), Hobble Bush, a low to medium-sized bush from the northeastern Lnited States (tive to ten feet), with very large, crinkled, broad (three to eight inches) leaves, and crimson fruit turning black or purple; is one of the most ornamental of the native Viburnums.

V. Lentago Linn. (58), Sheepberry or Nannyberry, a larger shrub (ten to thirty feet), sometimes tree-like, of similar range, with large, ovate, pointed leaves, and large, showy, white, terminal, flat, flower heads (May, June), followed by red-stemmed clusters of dark blue berries, persisting, in striking contrast with the yellowish autumn foliage. A variety with variegated, white and yellow, leaves is one of the better class of curios.

*V. Opulus Linn. (59), Cranberry Bush, is one of the best, a mediumsized, vigorous shrub) (five to ten feet), and a variety, $V$. sterile (59a), the old-fashioned Snowbull, which has its ball-like flower heads all composed of sterile flowers, while the species has the sterile, star-shaped flowers only on the outer rim of the flat cyme. The greatest ornament of the species lies in the bright scarlet-red berries, which persist into winter; but the variety is, of course, without this ornament.

I. dentatum Linn. (60), Arrou'-ieunl, of the same size as the former, sometimes higher, with sharply dentate leaves, is another native swamp shrub, from New Brunswick south; of upricht, complact growth, most adaptable and vigorous, with large, showy flower clusters (.May, June), and dark blue to purple berries, hanging long into winter.

I. acerifolium Linn. (61), Dockmackie, a low (five feet), slender shrub from the Northern States, with handsome purple fall color, is well adapted for ground cover, and under trees.

Of exotics there are at least five worthy of attention.

* I. macrocephalum. Hort. (62), the half-hardy, Chinese Snowbull, its tree form growing to a height of twenty feet, the sterile variety cxcel- 


\section{Olive Family}

ling in its larger flowers (one-inch) in immense balls (eight to ten inches), and its dark green, persistent foliage.

* I. tomentosum var. plicatum Maxim. (63), the Japancse Snowbill, a very compact, vigorous, medium-sized shrub (eight feet), with especially fine, rich, dark green foliage on brown twigs, and very persistent, solid "snowballs," larger than the common (two and a half to three inches).

I'. Sieboldi Miq. (64), another Japanese, stout shrub, with a heary dark green, shiny, semi-evergreen foliage, is well adapted for combination with evergreen shrubs.

* I. Tinus Linn. (65), Laurentinus, from southern Europe (six to nine feet), with oblong, shiny, eiergreen leaves, rose-tinted to white flowers in terminal clusters, appearing very late in autumn, or even in winter (in the greenhouse), and dark blue to black fruit.

V. Lantana Linn. (66), Hobblebush or Rowan Tree, from northern Europe, a tall shrub (ten to twenty f(et); with large, strongly veined, crinkled, darker foliage like lantanides; flat, dense cymes of small, white flowers, and bright red (changing to bluish-black) fruit. Adapted to any, even dry limestone soils.

\section{OLIVE FAMILY (OLEACEAE)}

This contains several genera of high ornamental value; most of which bear small, funnel-shaped flowers (well known in the common lilac), single or in bunches of varying size, followed by a fruit like the familiar olive, generally inconspicuous, but sometimes ornamental. A grayish cast of foliage characterizes a number of the members of this family, and several species are evergreen.

Elæagnus. Oleaster. A genus with about fifteen species of small trees and shrubs from Europe, Asia, and America; mainly of value for color effect because of the gray to silvery cast of their foliage, although some of them are evergreen. They are hardy and frugal, and especially fitted for seacoast planting. The fruit is edible and is used for preserves. They are best employed in border work.

* E. argentea Pursh. (67) (Cinadensis), our native northern Silver Tree, is often only a shrul) of straggling habit (eight to ten feet), with striking, large (two inches), sharp-pointed leaves, silvery-white on both sides, and pretty, yellow, fragrant flowers (May, June), and silvery 
fruit. It is given to suckering, which is, however, prevented or impeded if planted in turf.

* E. longipes Gray (68), the "Goumi" from Japan, is perhaps the best ornamental olive; a small, hardy (?) tree, generally growing in shrub form (five to eight feet), with numerous, slender, reddish-brown branches. The thick leaves are dark green above and silvery-white to brownish beneath, the fragrant flowers are yellowish white, covered with brownish scales, and the cranberry-like, edible fruit (July), bright red with white dots, which hangs for a long time on the long stalks, heightens the color effect. The fruit makes a fine jelly.

E. umbellata Thunb. (69), a spiny, spreading shrub (twelve feet), from Japan; in foliage similar to longipes, but with yellowish to silvery branches, and currant-like, amber-colored, pendent fruit, speckled with white, which ripens in November, making a rare and beautiful show.

E. angustifolia Linn. (hortensis) (70), Russian Olive, a low shrub to small tree, from southern Europe to the interior of Asia, with foliage light green above and silvery-white beneath, and silvery spines, and branches, with yellow flowers and yellow berries. Stock from its southern range is tender, but that secured from northern Russia has proved hardy even in the Dakotas and Manitoba, being deeply rooting and leafing out late. It can be easily grown from cuttings.

E. macrophylla Thunb. (7I), a graceful, medium-sized, spineless shrub from Japan; as yet rare, and untried as to hardiness, is entirely distinct, being evergreen, with large, round leaves, light gray above and pure white beneath, silvery branchlets, clusters of greenish-yellow to creamy-white flowers in autumn, and silvery-white fruit. It is one of the finest species of its genus.

E. reflexa Thunb. (72), also native of Japan, is another eiergreen, with very large (two to four inches) leaves, dark green above and silvery with brownish scales beneath; flowers similar to the preceding; but branches bronze-brown - a fine contrast if combined with the preceding.

Forsythia. Golden Bell. Furnishes two species, both from China; on of the showiest shrubs; early flowering (before the leaves), low ("ight wh ten feet), of fine, pendulous form, with handsome, long, persistent foliage, and a profusion of yellow flowers. 'The blossoms are borne on the previous year's wood, and hence, for best flower effect, the shrub should not be pruned in winter, but immediately after flowering, when new branches will at once form readily. Adapted to all soils, free fro.n 


\section{Olive Family}

diseases, and hardy, it combines all the qualities of an ornament of the first order. The two species are best used together on banks and as ground cover for early flower effect:

* F. suspensa Vahl., especially var. Fortunci (73), with goldenvellow flowers and lustrous dark green and persistent foliage, is the best. Not hardy in Ottawa.

* F. airidissim $a$ Lindl. ( 74 ), more frequently planted, is more erect, less graceful, and with flowers of greenish-yellow color, but foliage brighter green. It is said to be less hardy than the preceding.

Ligustrum. Prizet. Some thiry-five species of small trees and shrubs from Europe, Asia, and Australia, with numerous varieties, are valuable for their frugality and hardiness, as well as for their ornamental features, especially in the foliage, some of them being rergreen. Some four or five species are planted, especially for hedges and screens, although they are apt to thin out at the base. They can be used for formal planting, like $\mathrm{Box}$, and blend well with evergreens. They stand clipping well, and thrive in any soil.

*L. i'ulgare Linn. (75), the Common Prizet from Europe, is well known as a hedge plant, although it also makes a good show in comers and borders with its well-rounded, compact form (six to ten or even fifteen feet high), and upright panicles of small, white, fragrant, tubular flowers in profusion (June, July), followed by black berries. It is the hardiest and most adaptive of its tribe; half-evergreen.

* L. oralifolium Hask. (;6), called California Pricet, although really from Japan, has a larger (two) inches', thicker, more persistent (almost (vergreen), glossier, but less dense half-erergreen foliage than the preceding, and is more rapid, vigorous, and compact in growth. It is hardy into New England, even in exposed (seaside) positions, is shade-enduring, but needs a good soil. It grows taller and more erect than the former (twenty feet), but is readily trimmed. It is useful for hedges, borders, screens, windbreaks, and for binding soil on banks.

* L. 1murense Carr. ( 77$)(I b o t a)$, also from Japan, deciduous, hardier than the preceding, and almost hardy in Manitoba; more slender, graceful, spreading, and curving, and smaller (six to ten feet), and with more fragrant flowers (midsummer), in drooping clusters, is perhaps the best of the genus, both for specimen and mass planting.

The evergreen privets from Japan and China (L. Japonicum) ( 78 ), Quihoui (79), Sincnse (80), not being hardy, are fit only for southern planting. 
Shepherdia. S. argentra, Buffulo Berry. A hardy native, a slender, upright shrub of five to fifteen feet, sometimes in tree form; its silverywhite, delicate foliage and light-colored bark is useful for contrast effects with darker shades. It is rendered still more attractive by its profuse compact clusters of small, yellow flower: (April, May), and its bunches of edible crimson fruit (acid), borne only on f(male shrubs. The female can be told from the buds, which are longer and more slender, the males being short and blunt. It is a good hedge plant.

This, and still more its hardier, rusty-colored congener, S. Canndensis Nutt. (82), which is, however, less showy, with red and yellow berries, are adapted to cover sterile soils, gravelly banks, etc., but they are not quite easily handled.

Syringa. Lilac. A well-known genus, with some fifteen species and very many varieties, from Asia Minor, Persia, Japan, and China, familiar in all gardens. The genus name in this country is unfortunately used as a common name for Philudel phus, the mock orange, thus occasioning confusion. They are vigorous growers, sometimes assuming tree form, hardy (a number of them to the Canadian Northwest), and frugal, adapting themselves anywhere. They are most ready, early bloomers (April, May), with large clusters of variously colored, fragrant flowers, which are their chief attraction. They are planted in groups, hedges, borders, and as single specimens. With proper selection, they may afford a continuous flower show from April to June and even July: The foliage of some species is liable to mildew in late summer. Pruning in winter and spring would destroy the summer's blooming, as the flowers are borne in terminal buds, but when bloomed off the inflorescence should be removed, because they suffer much from seed-bearing, which exhausts the reserve materials.

Six species have served as the basis for the many varieties and hybrids of the horticulturists.

S. vulgaris Linn. (8.3), the common Lilac, a small, rather bushy tree (ten to twelve feet), is familiar to everybody, having been in cultivation for three hundred years. The foliage comes early, and remains green long into the fall, and the fragrant lilac flowers, which are mostly terminal, appear in May.

Among the more than one hundred very ornamental varieties are - alba $\left(8_{3} a\right)$, with white flowers; alba grandiflora $\left(S_{3} 3\right)$, a smaller bush, with large, white flower clusters; Marie Legroye (8.,3), a dwarf, with an abundance of pearl-white blossoms; Charles $\mathrm{X}$ ( $\left.\S_{3} \mathrm{~d}^{2}\right)$, a remarkably 


\section{Pea Family}

free bloomer, with reddish-purple blossoms and glossy foliage; Charles Ioly, with reddish-purple flowers; Congo, a very dark bluish, very distinct boomer; Matame Casimir Perrier, with pure white double flowers. These are all hardy to the Canadian Northwest.

S. Persica Linn. (S+), Persian Lilac, is a smaller and more graceful snrub) (four to cight feet) than the preceding, with smaller, more elegant rich green foliage and smaller, pale lilac flower clusters (May, June) all along the branches. A white variety is also often planted.

S. Chinensis Willd. (85), (Rolhomagensis), Rouen Lilac, a large (eight to ten feet) Chinese shrub, excels in the profusion of very large clusters of very fragrant violet flowers, and has smaller, more graceful foliage than vulgaris.

S. oblata Lindl. (86), als from China, is similar to the common lilac, with larger, purplish llowers, apprearing two weeks carlier (the earliest, May) and with the foliag variesated in brilliant, vinous red fall shades.

S. pubescens Turcz $\left(8_{7}\right)$ (rill'osi ). a dwarf from China or Himalayas, is useful for its late and very piofuse bhoming (end of May), with almost scentless flowers of purplish or bluish rose turning into white, and for its rery large, striking bright green foliage. Fine for hedges.

S. Japonial Decne (88), Japan Tree Lilac, a larger tree (over twenty fect), with uprig!t branches, spreading crown, large, elliptic leaves, and very showy, unusually large flower clusters (often a foot long) of creamywhite blosssoms which are not very fragrant, but come the latest in the season (end of June to July), and this prolong the lilac season. Quite hardy.

S. Josikea Jacq. $(89)$, a large (twelve feet), rigid, rery hardy shrub from Hungary with large, glossy, deep green, laurel-like foliage and scentless violet flowers in namm panicles, is less handsome, but it is useful because of its late flowering (the latest colored one, June, July). It is well adapted for hedge work.

An endless number of hybrids have been produced, mostly of vulgaris, some of which are cited above, to which constant additions are make, most of which increase the size or vary the shade of the flowers, while some form double flowers. Of the latter, S. lemoni $(89 a)$ is said to be the best.

\section{PEA FAMILY (LEGUMINOSAE)}

This family with the familiar, two-lipped or winged flowers, podlike fruit of the common pea, and compound leaves, contains a large 


\section{List of Shrubs}

number of ormamentals, both trees and shrubs, distributed through many genera.

Acacia, see Trees [List B].

Albizzia, see Trees [List B].

Amorpha. A. fructicose Linn. (0o), False Indigo, a native of southern United States, but hardy north to ()ttawa, is a spreading shrub (six to eight feet and more), with many shoots, beset with oblong, pinnate leaves of many bright green leaflets, aml unusual, dark violet, purplish small flowers, appearing in terminal spikes or racemes, bunched in twos and threes (Jume). It is arlapted to dry situations and fit for borders and massing on rocky slopes and banks.

A. cancscens Nutt. (or) or Lead Plant, a native dwarf of the Midelle West, is useful for color effects because of its generally whitish-silvery or lead-colored hues in foliage and stems, and its late, deep purple to light blue flower spikes (June to August). It is also fit for dry soils, especially in rock gardens, and hardy.

Caragana, Pea Tree, see Trees [List B].

Cercis, Redbud, see Trees [List C].

Cladrastis, Yellow-wood, see Trees [List B].

Colutea. C. arboresens Linn. (02), Bladder. Senna, a native of Italy, is the hardiest and most arlaptive of this otherwise not quite hardy genus, a medium-sized (six to ten feet), slender shrub, decorative by reason of its glaucous green foliage of compound leaves, holding their color into late fall, and of its vellow to brownish-red flowers, continuing through the summer, followed by an interesting, balloon-like fruit, green to reddish, which gives it its name. It makes a well-rounded head, and thrives best in sumy situations and well-drained soil, but is only half hardy, and rarely used.

C. cruenta Ait. (93) (orientalis), a smaller shrub, from southern Europe, with pale rerl to orange tlowers, and a few other species and varieties are also useful.

Cytisus, the well-known Bromm, is a genus with some forty-five species from Europe, Africa, and . lisia. It is noted for its frec flowering hahit, with yellow, white, and purple racemes in early spring and summer. 'These shrulss grow in almost any soil, even a dry gravelly one, and are mostly hardy. They are well adapted for borders of shrubberies.

C. scoparius Link. (94), the Scolch Broom, a low (six to ten feet) shrub, has become naturalized in many places. It is uscful in cover- 
ing rough, unsightly places, and being a persistent sprouter it maintains itself readily. It prefers sunny situations.

Most of the other species are smaller, more compact shrubs. The dwarf forms are especially handsome for rockeries, and some make fine tub plants.

C. capitatus, Scop. (05), from Europe, excels in its large flowers in summer; C. nigricans Linn. (95a) in its blooming twice a year; C. albus Linn. $\left(95^{b)}\right.$, in its white flowers; $C$. purpureus Scop. $\left(95^{c}\right)$, in its purple blood flowers and its prostrate form.

Desmodium (Lespedeza). Tick Trefoil or Bush Cloier. For late flowering shrubs (September, October), nothing finer can be found than the two species of this genus from Japan, both of which are hardy, and easily grown; with pinnate leaves of three leaflets and small purple or white flowers. For best effect they should be cut back to the root every winter, when they throw out many stems in the spring.

* D. penduliftorum Oudem. (Sicboldi) (96) is a gracefully pendulous bush, native of Japan, with rather large, deep rose to purple flowers, continuing to bloom until winter.

* D. Japonicum Hort. (97), from Japan and China, is a lower shrub (two to four feet), with similar pendulous branches, but pure white blossoms and lighter foliage.

Laburnum, Golden Chain, see Trees (List B).

Lespedeza, see Desmodium.

Robinia, Locust, see Trees (List B).

Sophora, see Trees (List B).

\section{ROSE FAMILY (ROSECEAE)}

This is one of the largest, to which, besides the roses, belong most of our common fruit trees - apples, paars, cherries, and hawthorns, which all have the familiar rose flower, usually small and single, but sometimes double and in heads, and the colored fruit various, hips, apples, or berries.

Amelanchier, Shadbush, Juneberry, see Trees (List C).

Cratægus, Hawthorn, see Trees [List C].

Cotoneaster, a genus of some twenty-five species from Europe, Asia, and Africa, furnishes a few very hardy, handsome shrubs, some of them evergreen, with ornamental fruit, which hangs on through the 


\section{List of Shrubs}

winter. They thrive in any except a very wet soil, and prefer light, but can stand half shade.

C. horizontalis Decne (98), from China, a half-hardy, low shrub, with almost horizontal branches; is one of the most effective shrubs for rockeries, with half evergreen, roundish foliage, and single, pinkishwhite flowers and bright red fruit.

C. microphylla Wall. (99), a dense, prostrate shrub from the Himalayas, has similar features, but oblong, glossy, evergreen foliage.

C. Simonsi Bak. (roo), and C. frigida Wall. (ror), the former less hardy, are large, beautiful shrubs, both in flower and fruit.

Besides these evergreen species there are two deciduous ones, bearing their white flowers in showy, flat-topped clusters: C. multiflora Bonge. (IO2), a large (five to eight feet) shrub from China, with slender, curving branches, a very rapid grower, and attractive with its red berries;

C. nummularia Fisch. \& Mey. (IO3), native of the Himalayas, hardy, smaller, and more upright than the preceding, flowering later and more profusely, the red berries persisting into winter.

* Exochorda. E. grandiflora Lindl. (IO4), Pearl Bush, a tall (eight to ten feet), hardy (not in Ottawa), Chinese shrub, growing sometimes into tree form, can only by proper pruning be kept in good form; is prized for the profusion of graceful festoons of pearl-white, early flowers (April, May), a floral gem for refined plantations. Unfortunately, the flowers are of short duration, and as they furnish the chicf ornamental value of the shrub, it should be planted only in the interior of groups. It requires a moist, fertile soil.

Pirus and Prunus (Almond, Apple, Cherry, Peach, Pear, Plum, Quince), see under Trees [List C].

\section{Physocarpus, see Spiræa.}

Rhodotypus. R. kerrioides S. \& Z. (I05), a small shrub from Japan, hardy to Massachusetts, half hardy in Ottawa, has few equals in graceful, delicate, slender-pointed green foliage, borne on a multiplicity of branches, tipped in spring with conspicuous, large, white, solitary, rose-like flowers, followed by a dry, somewhat shiny, black, apple-like fruit, hanging into winter. It requires a well-drained, fertile snil.

Rosa. Rose. Rose culture is an art by itself, and an endless variety of flowers have been produced by hybridization, besides the hundred or more species. For ornamental use outside the flower garden, and for hedges and ground cover, at least three species deserve attention, to be 


\section{Rose Family}

always used in masses. They fit into almost any soil and are easily handled.

R. mgosa Thunb. (Iо6), from Japan, is one of the most desirahle low shrubs (five to ten feet), a vigorous sprouter, and most hardy, fit for exposed places and seasirle planting. Its dense, thick, shining, dark green foliage makes it a desirable plant in lawn and border even without the flowers, but the latter, large (three to four inches), deep red, blossoming abundantly in clust:ri from June into fall, and the scarletcrimson, crab-apple-like hips add greatly to its beauty. It stands shearing well, and makes excellent, informal hedges, but for best effect it should be kept trimmed, as it rapidly reëstablishes itsclf. It is free from insects and fungus.

R. rubiginosu Linn. (107), English Suectbriur or Eglantine, from Europe, is another small, dense shrublet, but with lighter foliage and with a profusion of delicate pink blossoms (June). It fits well into rugged corners and between rocks, and makes a pleasing hedge p'ant. It is somewhat less hardy than the preceding.

R. lacida Ehrh. (I08), Tatize II ild Rose, six feet in height, with handsome, dark, glossy foliage and solitary, bright pink flowers, followed by persistent red hips and brownish-red stems, is effectively massed to cover wild comers, rough embankments, and exposed situations, as well as for hedges; rather improving under the shears.

Besides these standard hedge and cover plants, there are three others, one native and two Japanese, with a number of hybrids of the same - to be used similarly:

R. setigera Michx. (109), Prairie Rose, of a wide range from Ontario to Texas and Florida, and one of the hardiest, excels by virtue of its large foliage and long, slender, recurved or climbing branches (six feet), and profuse, deep rose, many-flowered corymbs.

R. multiflora Thunb. (110), from Japan, is a very pretty mediumsized shrub, and especially its hybrid Dawsoniana (I IOa), is one of the best climbing roses, with large clusters of crimson flowers.

R. Wichuraiana Crepian. (III), Ifemorial Kose, from Japan, a half erergreen with prostrate and creeping branches, and with large white, fragrant flowers, and remarkably lustrous foliage, is a handsome cover for banks and rockeries, thriving in any soil. A great number of hybrids adapted for training on pillars and trellis work are derived from this rose.

Sorbus. Service-Tree, see Trees [List B]. 
Spiræa. This well-known genus of the rose family, with over fifty species and very numerous varieties, permitting a wide choice as to time of flowering (from early spring to late fall), and size, has representatives in all continents among herbs, as well as low to tall shrubs. Delicate, white and rose-colored flowers, freely produced in showy clusters, and fine, mostly small foliage are their ornamental features, while hardiness, frugality, case of propagation, and vigor, though full of grace, recommend them for use everywhere, especially as borders, along walls, facings, etc., or in masses of one variety. Some of them, to be sure, lack in outline, being weedy of appearance, which defect must be overcome by proper grouping. They prefer sunny exposures, but a moist soil.

Of the native ones, at least three late flowering species deserve attention:

S. opulifolia Linn. (II2) (Physocarpus, Neillia, Opulaster), Ninebark (because easily peeling), is the best known, a shrub of our eastern swamps, and into the Canadian Northwest, thriving in all soils. A rugged, rather coarse, spreading bush, of six to ten feet in height, with relatively large, three-lobed, serrate, bright green, lustrous leaves, and white flowers (early summer) in numerous clusters along the branches, followed by bright red pods, contrasting well with the foliage. A variety, $S$. aurea, with bright yellow leaves and double flowers (June), is one of the best plants for color effect. Both are fine specimens and good for massing.

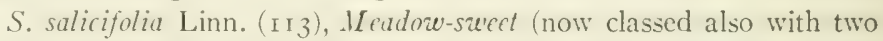
other species, alba and latifolia), so called from the fact that it is found bordering meadows and swamps, from Manitoba south, is a low bush (two to five feet), with reddish-brown branches and long, willow-like leaves. The terminal panicles of fine, white to pink flowers in July, persisting into August, are its chief attraction.

S. tomentosa Linn. (II4), Steeplebush, Hardhack, also quite low, with oblong leaves, dark green above and yellowish or whitish beneath, and dense spikes of rose-colored or deep pink flowers (July to September).

Of exotic species, several from Japan and China, quite as hardy and frugal, are more elegant than the natives and some are earlier bloomers.

* S. Thunbergi Sieb. (II5) is one of the most popular, the carliest bloomer (April, May), with small, white flowers covering the low, round, 
arching bush (three to four fe'et), like snow, before the appearance of the small leaves; the feathery, bright green foliage in graceful sprays turning to golden bronze. It is most fit for rounding off groups of shrubbery.

$S$. argula, a garden variety of the former and similar to it, excels in its more vigorous development, earlier and more profuse, feathery, pure white, larger flowers, and in its perfect hardiness.

S. prunifolia flore pleno S. \& Z. (I I6), Bridul-Wreath, the doubleflowering, plum-leaved Spirca, is only half hardy at Ottawa, a taller shrub (five to seven feet), with arching brancises, beset with tiny white double flowers in early spring before the appea rance of the leaves, which are glossy green, turning brilliant orange.

S. sorbifolia Linn. (Sorbaria sorbifolia A. Braun), from the Ural to Japan, is one of the tallest Spircas (ten feet), with large pinnate elegant foliage, and long terminal tassels of pure white, late flowers (June, July).

S. trilobata Linn. ( I I ), only two to four feet high, with similar wealth of flowers in May; but more striking on account of size and pinkish color.

* S. Van Houttci Zabel. (1 8 ), the most profuse, hardy bloomer, covering the gracefully spreading branches from end to end (four to six feet), with blossoms in dense umbels in May. A smooth, trifoliate, dark green foliage, with pale underside and rounded form, adds to its usefulness for border planting.

S. bracteata Zabel (media rotundifolia), a garden variety, comes next to the foregoing in time, with its showy umbels of white flowers, and excels in its fine, red-brown color of twigs, and dark green handsome foliage, remaining fresh until late in fall.

Of the pink-flowering ones, three recommend themselves:

S. Bumalda Burv. (I I g), the Eierblooming Spirea, a tlat-topped but upright dwarf, with a profusion of rose-pink flowers (throughout summer and fall), with serrate foliage, of rare beauty;

S. Anthony Waterer (II $a$ ), a variety of the former, with larger, pink to crimson flower heads (July, August), which continue throughout the summer.

S. superba Zabel (I g b), a low shrub with striped dark brown branches, large leaves, and light pink, rather large flowers (June, July). 


\section{STONEBREAK FAMILY (SAXIFRAGACEAE)}

This very large family (some six hundred species) of mostly herbaceous plants, with smaller or larger, white, star-shaped flowers in racemes or heads, familiar in the Hỵlangea, contains at least four genera with about a dozen omamental shrubs, attractive in foliage (large) and flowers.

Itea. I. virginica Limn. (I20), improperly caller I'irginiz W'illone', a native species from New Jersey south, tender in Ottawa, of a genus widely distributed; is an upright shrub, three to eight fect high, somewhat coarse in form, but attractive by bright, lustrous foliage, turning scarlet-crimson in summer or early fall, as well as by the dense, terminal racemes of small, white, fragrant flowers (June, July). It is adaptive to any situation, wet and dry, sunny and shady; a rapid grower; useful in grouping with other coarser shrubs in large plantations and at water-sides. It may be secured from the woods.

Hydrangea. A genus of thirty to forty species, native and from Asia, and a long line of varieties and hybrids, some evergreen and mostly only semi-hardy, ornamental, with their large, showy rather than beautiful, broadly ovate leaves, and large clusters of beautiful, variously hued, late flowers. Forms with the enlarged sterile flowers are most generally planted. 'They require rich soil and partial shade, though producing best flower effects in sunny sites. For best flower effect they should be pruned severely if large panicles are desired, less so (to two or three buds) if smaller but more numerous panicles are the object. They are admirable for specimens, border planting, or massing.

* $H$. paniculata Sieb), from Japan, is the hardiest, a large shrub, sometimes grown in tree form with ghobular head. The variety grandifolid (121) is most generally planted, producing immense terminal heads (five by ten inches) of creamy-white, entircly sterile flowers (August, September), changing to purplish-red or bronze, and continuing till frost. For best flower effect and form it should be cut back to the ground annually in early spring, the new shoots producing flowers the same year; and something clse should be planted in front, to relieve its coarseness and to form a foreground.

H. quercifolia Bartr. (122), a native of the Alleghanies, a hardy shrub, four to six feet high, with spreading branches, is much more satisfactory than the preceding, and is especially valuable for its large 


\section{Stonebreak Family}

oak-leaf-like foliage (four to eight inches), with rich autumn tints, and pinkish-white flowers (June) turning purple.

H. restita pubescens Maxim. (I2.3), a shrub from China, with slender branches (four to five feet), is recommended for its hardiness (half hardy in (ttawa), and its early blooming (June) in broad cymes of flowers, white changing to pink, and large leaves (four to cight inches).

Among the less hardy ones, which require protection in winter, are:

H. hortensis Smith (124), and a number of varieties, especially H. Otaksa Maxim (124a), from China, with variable color of flowers, which appear in July in large balls, and change hues (white to blue and pink) during the season; are good tub plants on piazzas and in formal gardens.

H. Thunbergi S. \& Z. (serrata) (I25), a dwarf, from Japan, with blue or rose-colored flowers in cymes.

Deutzia. A genus from Asia, of tall, medium, and low, sturdy shrubs of rather stiff habit; more or less hardy, and very ornamental, with dense, luxuriant foliage, and showy, white to purplish flowers in bunches, mostly from the axils of the leaves. They thrive in almost any soil and are easily cultivated.

D. scabra Thunb. ( $\mathrm{I}=6$ ), a native from China and Japan (six to eight feet), with rough, stiff, rigid foliage; forms the basis of a number of varieties, which are superior to the type in their flowers, of which the best, D. flore plenu (124a), Pride of Rochester (sometimes referred to crenata), is also the largest as well as the best in form, with large, double, pure white, rather early flowers (Мay, June). D. candidissima (126b), has the double white flowers in rosettes.

D. crenata S. \& Z. purpurea (I27) and D. Watereri (127a) have flowers of a pink shade, the first single, the second double.

D. purviflora Bonge. ( 28 ), the hardiest, from China (four to six feet), is the earliest blonmer (April), with creamy-white, lilac-like bunches of flowers, and rather roughened foliage, of better form than the preceding.

D. gracilis Sicb. \& Zucc (129), from Japan, a dwarf (one to four feet) of rounded form, with slender, arching branches and early (May), very luxuriant inflorescence of delicate, small, white flowers in graceful, nodding racemes; is the best for borders, for facings, and small places.

$D$. Lemoinei Hort. (I 30 ), cross between D. gracilis and D. pari iflora, another dwarf, with large foliage (two or three inches), is said to excel the foregoing in vigor and showiness. 
Philadelphus. Mock Orange, misnamed Syringa and Jasmine, a genus with some thirty species and a large number of varieties and hybrids of tall to medium-sized shrubs, from Europe, Asia, and native; hardy and easily propagated, vigorous growers, and apt to assume rather coarse form, with broad, ornamental foliage and medium to large flowers. For best form and flowering, severe cutting back after flowering is essential, the flowers forming on the wood of last year. They are adaptive and shade-enduring.

P. coronarius Linn. ( 131 ), from southern Europe, a shrub) of twelve to fifteen feet, of upright habit, with creamy-white, strongly fragrant (objectionable to some), medium to large, orange-like flowers (May), in racemes, and sharply-pointed, bright green foliage. Varieties with double flowers and variegated foliage, and of lower stature, exist; the species is, however, best used for border planting.

P. Gordonianus Lindl. (I32), a native of our northwest, with scentless flowers in racemes, blooms in July.

P. inodorus Linn. (grandiflorus) (I33), of southern habitat, hence not quite hardy, has round leaves and much larger, scentless flowers (May).

P. microphyllus Gray ( 134 ), from the Rocky Mountains, is a dwarf, with slender, rigid branches, dense foliage of small leaves, and large terminal, very fragrant flowers in threes. It is adapted for sunny, dry sites, and excellent for rock gardens.

\section{STORAX FA MILY}

This family with small, open, bell-like, delicate flowers, as a rule white, blooming early, contains seren genera, consisting mostly of tropical species, three of which, however, furnish ornamental values for northern use.

Halesia (Mohrodendron). Snowdrop or Silver Bell Tree. Is a genus of six or eight species, of which two are native through the South, in nature growing into tree form. These are among the finest ornaments, with their profusion of early clusters of delicate white, "silver-bell" flowers two to four in a cluster, on long stalks, appearing with the foliage; and their graceful form, with many long, slender branches, and with rather large, light green foliage, making a pleasing round bush, which is best used singly. They are adaptive to soils, prefer shade, and are easily handled, but are only half hardy north of Philadelphia. 
The two native species are as good or better than any of the exotic introductions.

* H. letraptera Linn. (I35) (1/ohrodendron carolinum), the Fourwinged Silver Bell, so called from the four-winged fruit; is a large shrul, growing to twenty feet, often in tree form, with a bewildering, cloudy mass of snowy white; carly flowers (May); it is hardicr than its congener -

* H. diptera Ellis. ( 136 ), the Two-Itinged Silder Bell, which is smaller (ten feet), but has even more showy, larger blossoms and leaves; it needs protection in the north.

Styrax and Symplocus. Storax. Two closidy allied senera of over two hundred and thirty species, furnish, mainly for southern planting, a few small trees and shrubs, which, because of their delicate, white flowers and somewhat tropical-looking, leathery folliags, and graceful nabit, have ornamental value. They are best planted singly, are adapted to light soils, but only half hardy.

Styrax grandiftora Ait. (I37), a shrub of five to ten feet, with large, pointed leaves (two to six inche's and more), S. americana Lam. (1 38 ), and $S$. pulverulenta (139), the three native species, are of southern range, and hence not very hardy, and are outdone in beauty by the Japanese Storax.

S. Japonica S. \& Z. (I 40 ) is a small to medium-sized tree or shrub (thirty feet), with horizontal branch hathit; is precieralsy kept in shrub) form to secure the best flower show, the pendulous racemes of fragrant, pure white flowers, with yellow stamens, covering the entire length of the branchlets in early summer. The leaves are small (one to three inch), pointed, light green. It is hardy as far as New York City, and a splendid specimen plant.

S. Obassia S. \& Z. ( $\left.\mathrm{I}_{\mathrm{H}} \mathrm{I}\right)$, sometimes growing into a small tree, also from Japan, with catalpa-like leaves (six to ten inch) is less effective.

Symplocos tinctoria L'Hert., Suecutleaf, so called from the fragrance 1: its foliage, a pretty, low shrub, sometimes tree, from the Southern States, is almost an evergreen, with long narrow, somewhat leathery itaves, and clusters of fragrant yellow flowers.

S. cratcgoides Buch-Ham ( 143 ), from Japan, is the most hardy wi this group, a shrub (five to eight feet), sometimes assuming tree form (thirty feet), resembling the hawthorn in outline, forming an irregular open head with long, thick, rough leaves and panicles of frat- 
grant, white, small flowers (May, June), followed by bright blue berries in September, which form its chief attraction.

\section{VARIOUS SHRUBS (Alphabetically Arranged)}

Acer, Maple, see Trees [List C].

Aesculus, Buckeye or Ho se-chestnut. See Trees [List B].

Aralia, Angelica Tree, Hercules Club, see Trees [List B.]

Alnus, Alder, see Trees [List C].

Althea, see Hibiscus.

Ash (Fraxinus), see Trees [List B].

Baccharis. B. hamilifolia Linn. (144), Groundsel, a tall to medium shrub (twelve feet or less), belonging to the Thistle family, native from New England south, is most useful for its adaptation to the seashore and salt marshes and almost any other situation. It is ornamental in somedegree, by virtue of the dark, lustrous, persistent foliage, the terminal, dense panicles of small yellow flowers on the male specimens, and the very showy, snow-white, long hairy pappus on the females, the sexes appearing on different individuals. It is also adapted to dry, rocky places as well as to the seashore, and to give woodsy effect. It prefers sunny situations.

Berberis (Mahonia). Barberry. Some hundred species and several varieties of low shrubs, natives of Europe, Asia, and America; foliage, flower, and fruit being decorative. The leaf stems are more or less beset with small spines, making them hard to handle. The leaves in the Mahonia group are often fluted or crinkly, holly-like, holding their color well, some of them evergreen, and all retaining their leaves long, and assuming various gorgeous autumn hues. The early flowers are small, and of yellow hues. The fruit, scarlet or crimson, blue or black, hangs on long into winter, and, being acid, makes an excellent preserve. They are very adaptive to soils, in fact thrive better in dry than in moist soils, endure shade well, and are hardy to semi-hardy. A rust fungus (wheat rust) makes them the host plant for one phase of its existence, but is not destructive. They are excellent for low hedges, and as filler and accent shrubs.

B. Canadensis Mill. (r45), the native dwarf (one to three feet) from the southern Alleghanies, and -

B. aulgaris Linn. (r46), the European Barberry (six to ten feet), show few differences, except that the latter is larger and more pronounced in all its characteristics, - bristly leaves, bright flowers, and 


\section{Baccharis - Calycanthus}

conspicuous red fruit, - but the former is distinguished in possessing reddish branches. It is apt to run wild. Both plants are hardy or almost so in Manitoba. A very unique variety of the same, atropurpurea ( $146 a$ ), with richly colored, permanent, purple foliage, and bright red shoots, is most useful for color effects.

*B. Thunbergi, D C. (I47), from Japan, is the best exotic and altogether most attractive, a low bush (two to four feet), of varying form, with small, dark, glossy, smooth foliage down to the ground, turning scarlet, orange, and bronze; following the single, pale yellow flowers are coral-berries, pendent from the under side of branches, and persisting in good form into and through the winter. It is thoroughly hardy (half hardy in Manitoba), and frugal. It is excellent used by itself, for borders of walks and drives, as well as on the lawn in masses, or for edging other shrubbery.

B. Amurensis Rupr. (I 48 ), and especially a variety, Japonica (I $8 a$ ), a sturdy, low bush (two to five feet), growing without branches, with very large (five to ten inches), compound, dark green, holly-like leaves, prominently veined below, turning into brilliant bronze and purple shades; with terminal spikes of large flowers (May), and larger berries than vulgaris, is hardy into Manitoba and stands drouth well. It is not to be confounded with the species B. Japonica Spreng. (I 49), a larger shrub, five to ten feet, having larger foliage with spiny teeth, which is also very effective. This is hardy north of New York only in sheltered positions and, like the others, prefers shade.

B. Wallichiana D C. (Hookeri) (I50), a very showy and distinct evergreen from the Himalayas; a compact little bush with large leaves; entirely hardy in Massachusetts.

B. ilicifolia Forst. (151), from 'Terra del Fuego, with simple, hollylike leaves, evergreen, or nearly so, seems not to be hardy north of Philadelphia.

Calycanthus (Butneria). C. floridus Linn. ( $\left.1_{52} 2\right)$, Allspice or Strawberry-bush, so called from the fragrance of the flowers, leaves, and wood, and from the dark strawberry-colored flowers, is a well-known native from the Carolina mountains, quite hardy to Ottawa; a small, compact, attractive bush (four to six feet and more), with large, deep green, somewhat leathery foliage, and large (one to two inches), deep blue to purple, or chocolate-brown flowers, appearing in early spring, and blooming all summer. Requires well-watered soil; is shade-enduring, and makes a good filler in border planting. 


\section{List of Shrubs}

Three other species, C. glancus Willd. (153), C. lavigatus Willd. (154), and C. occidentalis look and Arn. (155), are scarcely as hardy and have few superior points, except perhaps difference in color intensity.

Caragana, see Trees [List B].

Carpinus, see Trees [List C].

Chionanthus, see Trees [List C].

Comptonia, see Myrica.

Celastrus. Bitter-sweet. This genus of some twenty-five species, native from Asia and Australia, furnishes several low shrubs of a trailing or climbing habit which makes them invaluable for effective covering of rocks, trellis, or posts. Their bright varicolored fruit, hanging on through the winter, makes them even attractive at that monotone season. They are most adaptive, filling any soil and situation, sun or shade. Suckering freely, they can be readily propagated or renovated.

C. scandens Linn. ( ${ }_{55}$ bis) is our native species, common from Canada to New Mexico, climbing to twenty feet, the crimson seeds in the opening orange-yellow capsules continuing through the winter.

C. orbiculatus Thunb. (articulatus) ( 55 tres), from Japan and China, does not differ much from the former, but appears more prolific in foliage and fruit, which latter, however, is hidden under the foliage until the fall.

Corylus. Hazelnut. C. Americana Walt. (156), the American species, has but little ornamental value, yet is picturesque and is useful for planting along watercourses and other wet or moist, but also in dry places.

C. Avellana Linn. purpurea (157), a variety of the European species, four to six feet high, fit for dry as well as moist situations, excels by its large, round, dark purple, almost black foliage, preserving its color even better than the blood beech, changing to lighter hues in the fall. There is also a very ornamental variety, laciniuta ( $55 a l$ ), with deeply cut leaves. Neither of them are more than half hardy at Ottawa.

\section{Crape Myrtle, see Lagerstrœmia.}

Currant, see Ribes.

Daphne. Of the forty or more species and varieties, widely distributed throughout the south temperate zone, at least three deserve notice as being among the finest low shrubs for use in borders, massing for color effect by foliage, flower, and fruit, and especially in rock work and for refined planting. They are adaptive and shade-enduring.

* D. Mezereum Linn. ( $\left.5_{5} 8\right)$ Lady Laurel, Paradise Plant, from 


\section{Celastrus - Euonymus}

Europe, is one of the hardiest, most frugal, early bloomers, rarely over two feet, and spreading; with dark green leaves, a profusion of fragrant, lilac-purple flowers in threes, arriving with the very earliest breath of spring (February to April), long before the coming of the leaves, followed in June by large, bright red berries (very poisonous), which remain until fall. This is one of the most satisfactory ornaments for a small garden. Although thoroughly hardy, and not particular as to soil, exposure, and surroundings when once estab.ished, it requires care to propagate.

* D. cneorum Linn. (159), Garland Flower, is another dainty dwarf, also from Europe, as satisfactory as the foregoing, if not better, from which it differs in being evergreen, with dark, glossy leaves and trailing branches, resembling the Trailing Arbutus, and producing its fragrant lilac flowers not only early (April, May), but continuing to blossom into the summer, and often repeating a full flower show in the fall.

D. laureola Linn. (I60), Spurge Laurel, another bushy evergreen dwarf from Europe, less hardy than the preceding, with attractive, laurel-like leaves, but without showy or fragrant flowers, is exceedingly shade-enduring, hence well adapted for underplanting.

Euonymus. Of the forty of this genus, some seven species, American, European, and Asiatic, recommend themselves especially by reason of their pretty fruit, and their interesting corky, green, and gray bark, and well-shaped outline, though somewhat stiff in habit. Their shadeendurance fits them for underplanting; they are hardy and frugal, growing in almost any but thriving best in well-watered soil. They are, as a rule, hardy into Canada. Some of them grow into small trees, others are climbers, some are evergreen. They are best adapted to shrubberies, but also make pleasing individuals in small places.

E. Americanus Linn. (16r), Strawberry Tree, ranging from New York south, is really only a small, straggling bush, five to eight feet high, with very showy, crimson, or scarlet fruit.

E. atropurpurea Jacq. ( 162 ), Burning Bush, or Wahoo, also of American habitat from Canada to Florida, a shrub or tree (six to fifteen feet high), has dark purple flowers, followed by the showiest scarlet fruit, hanging long into winter.

E. Europaus Linn. (163), Spindletree, or Pope's Hat, the latter name from its pale red to orange fruit in the shape of a cardinal's hat, resembles the former, the fruit being, however, more orange in color. Grows into tree form. 
E. Japonicus Linn. ( 164$)$, the best in form, with its gracefully drooping branches (although sometimes upright), six to ten feet in height, is an evergreen, with pink fruit and very dark, glossy leaves, holding their brilliancy into winter; half hardy, but adapted to seashore planting as far north as New Jersey. A variety, E. microphyllus, is valuable for low hedges.

E. radicans Sicb. (165), also from Japan, is a low, prostrate shrub or climber, trailing along the ground, evergreen, with small, myrtlelike leaves, bright green in color, and pink and scarlet fruit; perfectly hardy (not in Ottawa), and may be substituted with great satisfaction for the less hardy English ivy, as a wall vine and for ground cover, especially in shady locations. A variety, varicgata ( $165^{a}$ ), has the foliage touched with silvery white.

E. alatus. Maxim. ( 166 ), a new introduction from Japan, quite hardy, is a large shrub (six to eight feet), of most desirable character, with corky, winged branches, brilliant scarlet berries, fine foliage, turning gorgeously into pink to dark red, and peculiarly pinkish-hued buds. It is especially valuable for a specimen plant and accent work.

Fraxinus (Ash), see Trees [List B].

Fringetree (Chionanthus), see Trees [List C].

Gardenia. Cape Jessumine. All the sixty species of this genus are from the southern latitudes of China, India, South Africa, and hence only fit for southern planting as far north as Virginia; but make excellent house plants in the north. They are evergreen, with deliciously fragrant, large, white, waxy, funnel-shaped flowers, in constant succession. They are most readily grown, but are very subject to insects.

The best known are:

G. jasminoides Ellis ( ${ }^{6} 6_{7}$ ), the true Capc Jessamine, the bushy species coming from China, which nurserymen split up into distinct forms, namely:

G. florida, (I68), with double, solitary; terminal flowers, beginning in midsummer; also an earlier flowering variety, Fortunei (I68a);

G. radicans ( 169 ), the tree form from Japan, the earliest bloomer (June), with salver-shaped flowers;

G. nitida (I 70), a low, compact (two to three feet), still later flowering bush (October to November), with attractive glossy, oblong foliage.

Hibiscus (Althea). Mallow. Some hundred species of shrubs and herbs and a large number of varieties, mostly of tropical and sub- 


\section{Gardenia - Hypericum}

tropical range, of which, besides several small plants, at least one shrub has become a popular ornament.

H. Syriacus Linn. (I I I) (Althea frutex), Rose of Sharon, from Asia, but quite hardy into southern Ontario, is a shrub) (ten to twelve feet), sometimes in tree form, with a rather stiff, stragrgling hahit unless properly pruned; with large, hollyhock-like flowers (August, September), which, in varietics, vary from white (alba) to pink (corrulea), and red (boule de feut), double and single. It lends itself to informal hedge use, standing shears well, and then flowering freely, also useful as accents and in small gardens, and is very adaptive as regards soil.

Hazelnut, see Corylus.

Hercules Club, see Aralia.

Holly, see Trees [List C].

Hornbeam, see Trees, List C (under Carpinus).

Hop Hornbeam, see Trees, List C (under Ostrya).

Hypericum. St. John's W'ort. A very large genus (two hundred species) of composite, herbaceous plants, shrubs, and trees, from Europe, Asia, and America, not all hardy. Several small to very small shrubs are attractive because of their small, or at least narrow, foliage. The large, showy, yellow flowers, appearing late in summer or fall, are persisting, which is their special recommendation. They are useful in small gardens and lawns for edging, and as a substitute for turf. Although they are capable of thriving in poor soils and in partial shade, they are short-lived.

* H. Kalmianum Linn. ( I 72), the native St. John's Wort, from the Great Lake region, is a low (two to four feet), sprearling bush, with dense foliage, of linear, long (two inches), bluish-green leaves, and glossy, yellow, dandelion-like flowers in clusters, appearing in August and continuing long. It is shade-enduring, and perhaps the hardiest and best, very distinct and attractive.

H. aureum Bart. (I73), is a lower (two to three feet), not so hardy, shrub, of southern range, with larger (two inches), showier flowers than the preceding, and as late and persistent.

* H. Moserianum André (I74), Gold Flower, is still lower, almost diminutive, semi-hardy into New England, wich immense (two to two and a half inches), rich golden flowers, with crimson stamens, blooming all the season; it is perhaps the most graceful, with long, slender stems, drooping at the tips and densely foliaged. It is splendid for rockeries, like the others. 
IT. prolificum Linn. ( $\mathrm{I} 75$ ) and $I T$. densiftorum Pursh. ( $\mathrm{r} 76$ ), with smaller flowers, are larger in stature (four to six feet), and usually earlier bloomers.

Ilex, see Holly.

Laburnum, see Trees [List B].

Lagerstrœmia. L. Indica Linn. (177), Crape Ifyrtle or Fringed . Iyrtle, from China, a shrub (twenty to twenty-five feet), and L. flosregince, from India, a tree (up to sixty feet), are hardy only in the South, half hardy in the Middle States; with large, beautiful panicles of unique bright pink and rose-color flowers, blooming from spring to midsummer, found planted in every dooryard in the South, and may be used in protected places as far north as Baltimore.

Maple, see Trees [List B] (under Acer).

Magnolia, see Trees [List C].

Myrica. Wax. Myrtle. A large genus, of many species, three of which from America are most useful, especially where infertile, barren, and exposed, hopeless spots are to be quickly and permanently covered with low shrubbery, for they are indifferent to the soil and to the sun, hardy from north to south, especially in the ocean breezes, and have a most tenacious root system. Although of small ornamental value, their rich, dark green foliage and rounded form is pleasing, and their bluish, waxy berries interesting.

M. Carolinensis Mill. (178), Wax Myrtle, the most common, from Nova Scotia to Alabama, is also the best for the purposes stated; growing from one to four feet, and on favorable sites to ten feet high, with dark green, lustrous, fragrant foliage, and very waxy, bluish-white berries hanging into winter.

11. (Comptonia) asplenifolia Linn. (179), the Suect Fern, of even wider distribution and of lower stature, excels the former by reason of its fern-like foliage, and beautiful, delicate flowers, which render it attractive. It is at the same time singularly adaptive.

1I. Gale Linn. ( 180 ), Sweet Gale, of northern range, also has a pleasing, partly toothed foliage, and fragrant flowers, appearing before the leaves; an interesting plant in the foreground of taller shrubs.

Osage Orange, see Trees [List C] (under Toxylon).

Ostrya, see Trees [List C].

Paulownia, see Trees [List C].

Rhus, see Trees [List B].

Ribes. Flowering Currants. Of the sixty or seventy species, indige- 


\section{Lagerstrœmia - Vitex}

nous to all continents, mostly of mountain habitat, there are at least three that have ornamental value, besides those cultivated for their fruit, and, since they are very easy of cultivation, and frugal in their demands on the soil, they may be used to advantage for their foliage, flower, and fruit. They are rather liable to mildew and various insects, which can be prevented, the former by spraying, the latter by hellebore and sulphur.

R. alpinum Linn. (18I), the European 1Fountain Currant, a compact, shapely bush, two to three feet, and very hardy, has pale yellow flowers in erect clusters (May), and very showy, scarlet, tasteless fruit. A variety, aureum ( $18 \mathrm{r} a)$, has yellow foliage.

R. aureum Pursh. (182), the western native Buffalo Currant (four to eight feet), sprearling, with fine, three-lobed, shiny leaves, bright yellow flowers (.May) and dark bluish fruit, is perhaps the best, being hardy everywhere. A cut-leaved variety, tchuifolium (ISza), is less hardy.

R. Americanmm Mill. (floridum) ( $8_{3}$ ), the Bluck Currant, also native, and of wide distribution, has greenish-white flowers in large racemes, dark fruit and fine lobed foliage.

R. speciosum Pursh. $\left(\mathrm{I}_{4}\right)$, from California, the most showy bright red fuchsia-flowered gooseberry, is unfortunately not hardy in the north.

\section{Sassafras, see Trees [List C].}

Stuartia. Two species, native of the mountains of the southeastern United States, are desirable for their large, creamy-white, camellialike flowers and their rich bright green foliage of large leaves, which assumes most brilliant autumn shades. They are only half hardy in New England, and require a rich soil.

S. pentagyna, eight to twelve feet, very large flowers (July, August), creamy-white, fluted sepals, with orange-colored anthers and oval leaves.

S. virginica Car. (186) (1Falachodendron), six to eight feet, flowers (May, June, July, August in the north), with purple filaments and oblong leaves, has the largest and showiest flowers.

Sumach, see Trees [List B], (under Rhus).

Tamarix, sce Trees [List C].

Vitex. V. Agnus-castus Linn. (187), Chuste Tree, one of some sixty species of the Verbena family, is a small, neat shrub (three to six feet) from southern Europe, sometimes growing into tree form. It is only half hardy north of Pennsylvania, with terminal panicles of light lilac 
flowers (August, September), which in some varieties are changed to white or bluc, and aromatic, compound foliage, with long, narrowpointed leaflets.

\section{SELECTED LISTS FOR SPECIAL PURPOSES}

The following lists may aid in suggesting the selection of plant material for special situations, and special purposes. It must be understood that they are only suggestions calling for more detailed incluiry in each case. Endurance of untoward conditions of soil or climate, for instance, is not an absolute but a relative characteristic, and usually form and character of growth are more or less influenced by the environment. Hence while a species may endure in a given climate or in a dry or wet soil, it may not thrive and develop its characteristic form. Altogether soil conditions and climate are so variable and exhibit so many gradations that it is not always easy to judge how far a given species may be suited.

Where all species of a genus cited in the preceding lists show the same characteristics, only the genus name is given.

\section{DESIRABLE STREET TREES}

The width of the street, besides the points discussed on page 200 , should be taken into consideration in selecting trees, and the size which different trees ultimately attain should also be borne in mind; the narrower streets, if planted at all, calling for smaller to medium-sized material. The sequence indicates somewhat the relative values.

Large-sized trees: Quercus rubra, coccinea; Platanus occidentalis, orientalis; Ulmus Americana, campestris; Acer saccharinum, nigrum, pseudo-platanus; Eseculus Hippocastanum; Tilia Americana, Europæa, 


\section{Trees and Shrubs with Colored Foliage 365}

daststyla; Liriorlendron tulipifera; Gymnocladus Canarlensis; Liquidambar styraciflua.

Ifedium-sized tres: (Quercus imbricaria, Phelios; Ulmus fulva, montana; Acer platanoides, rubrum; Esculus glabra, octandra; Celtis occidentalis; Sophora jajonica, Populus monilifera; Gleditsia triacanthus, inermis; Robinia pseudacacia.

Small-sized trees: Acer campestre; Esculus Pavia; Salix pentandra (laurifolia); Fraxinus viridis; Cladrastis tinctoria; Ostrya virginica; Sorbus Americana, aucuparia.

\section{TREES AND SHRUBS IITTH COLORED FOLIAGE}

There is a great range of color variation in green foliage, which makes possible most pleasing and artistic effects, ranging from the dark, lustrous, evergreen foliage of the evergreen magnolia and holly, or the dark, equally lustrous, but not evergreen Red Oak and the less lustrous Black Oak, or among shrubs, Kalmia and Rhododrendon, through all gradations and shades of lighter hues, as represented by Basswood, Tulip-tree, Ash, to the almost silvery whiteness of the foliage of Silver Maple, of the olive family and of some of the willows. Through the seasons, these shades vary, but each species retains characteristic colors, varied to some extent, it is true, by situation (dry or humid) and weather conditions, until the final fall coloring bursts out into glory. These variations can hardly be described, but must be studied in Nature.

In addition to these color variations common in Nature, there are special creations, mainly of nurserymen's production, which exhibit abnormal coloration of foliage, namely purple to red of varying hues, yellow or golden, white or silvery, or variegated. Some have the underside of their leaves so colored (white) as to change the whole tone of the 
foliage. If used with discretion, this colored foliage imparts interest, variety, and artistic effects.

RED HUES:

Acer Schweidleri, Reitenbachi,

Worlei, polymorphum forms;

Berberis vulgaris alropurpurea;

Betula atropurpurea;

Corylus Avellana purpurea;

Pirus Sinensis foliis rubris, and

Niedzivetskyana;

Prunus Pissardii;

Quercus robur purpurescens, atropurpurea.

Yellow or Golden Hues:

Buxus sempervirens aurea;

Chamacyparis (Retinispora) aurea;

Sambucus nigra aurea;

Spirca opulifolia aurea;

Viburnum lentago aurea.
White and Silvery Hues, or VARIEGATED:

Abies concolor;

Cedrus Atlantica glauca;

Picea pungens, Kosteriana, Parryana;

Populus alba;

Quercus ilicifolia, prinoides;

Tilia argentea;

Amorpha canescens;

Azalea mollis;

Buxus sempervirens argentea;

Cornus Siberica variegata, Spathi;

Elaagnus argentea;

Evonymus variegata;

Salix, various;

Sambucus nigra variegata;

Shepherdia argentea.

\section{EVERGREEN BROAD-LEAVED TREES AND SHRUBS}

Buxus sempervirens;

Berberis (Mahonia) Amurensis, Wallichiana, ilicifolia;

Cassandra calycu!ata (nearly evergreen);

Clethra alnifolia;

Cotoneaster horizontalis, microphyllum, Simoni;

Cratagus pyracantha;

Daphne cneorum, laureola;

Elaagnus macrophylla, reflexa;

Erica;

Evonymus Japonica, radicans;
Gardenia;

Ilex opaca, aquifolium;

Kalmia;

Lencothoë Catesbai;

Ligustrum Sinense, Japonicum.

Lonicera fragrantissima;

Magnolia fotida;

Osmanthus;

Pieris floribunda, Japonica;

Quercus virginiana, clirysolepis; Symphoricarpus vulgaris;

Viburnum Tinus. 


\section{Trees and Shrubs with Colored Twigs 367}

\section{TREES AND SHRLBS WITH SPECIALLY COLORED TWIGS}

OR STEMS

RED:

Berberis canadensis, atropur. purea;

Cormus sanguinea, stolonifera, alba;

Salix candida, decipiens;

Tilia;

Leucothoë racemosa;

Berberis canadensis, atropurpurea;

Pirus Niedzivetzkyana.

Brown, Rev Brown, Brownish RED:

Betula alba, papyrifera young stems and twigs);

Elaagnus longipes, reflexa (bronze);

Evonymus (green to brown); Ostrya virginica;

Rosa lucida;

Salix lucida;

Spirca salicifolia, bracteata, superba;

Viburnum tomentosum.
PURPLE:

Cornus amomum;

Salix nigra, Scharfenbergi.

YELLOW:

Elaagmus (shading to white);

Salix vitellina, aurea, decipiens (shading to red), Voronesh (deep yellow), Niobe (light yellow);

Sassafras (shading to green).

Green:

Acer negundo;

Cornus alternifolia;

Salix fragilis, purpurea (olive);

Evonymus.

WHTE:

Betula alba, papyrifera (stems), lutea (yellowish silvery); Elaagnus macrophyilum (silvery), umbellata (yellowish); Salix hirta (soft gray).

BLACK:

Cercis Canadensis.

\section{SHRUBS WITH COLORED FLOWERS}

Pink, Rose, Red Hues:

Abelia serrata;

Andromeda polifolia;

Asalea, various.

Calluna vulgaris;

Colutea cruenta;
Cratagus Crus-galli;

Desmodium pendulifolium;

Diervilla florida;

Evonymus atropurpureus (dark purple);

Hibiscus Syriacus; 
Hydrangea quercifolia;

Kalmia;

Lagerstromia;

Lonicera Hildebrandiana, spinosa (purple);

Magnolia, various;

Pieris, various;

Pirus, various;

Prunus Japonica, Amygdalus, Armeniaca;

Rosa, various;

Rhododendron Catawbiense;

Sambucus racemosa;

Spircea, various;

Symphoricarpus racemosus;

Syringa Charles X, Charles Joly;

Tamarix, various;

Yellow to Brownish Hues:

Abelia trifiora;

Azalea, various;

Berberis, various;

Carragana;
Colutea;

Cytisus;

Diervilla grandiflora;

Elaagnus angustifolia;

Forsythia;

Hypericum;

Laburnum;

Lonicera fragrantissima;

Magnolia Kobus;

Shepherdia;

Symplocos tinctoria.

Bluish Hues, ANd VARIED:

Amorpha;

Calycanthus;

Daphne;

Hydrangea paniculata, Otaska, Thunbergi;

Magnolia obovata, gracilis (purple);

Rhododendron;

Syringa, various.

\section{SHRUBS WITH STRIKING COLORED FRUIT}

\section{RED HUES:}

Berberis vulgaris, Thunbergi;

Celastrus scandens;

Cotoneaster;

Cratagus, various;

Elaagnus longipes;

Evonymus alatus, Americamus, atropurpureus, radicans;

Ilex;

Lonicera fragrantissima, tartarica, clc.;

Magnolia, various;

Pirus, various;
Prunus Pennsylvanica;

Rhammus frangula (turning black);

Rhus hirta, glabra, semialata, Europea (orange), Japonica;

Ribes alpinum;

Rosa, various:

Sambucus pubens, racemosa;

Shepherdia argentea;

Symphoricarpus vulgaris;

Viburnum lantanoides, Lantana, Opulus. 


\section{Trees and Shrubs with Colored Fruit 369}

Blue, Purple to Black Hues:

Cormus, various;

Ligustrum vulgare;

Lonicera involucrata, oblongifolia, cornilea;

Myrica;

Rhammus frangula, Purshiana;

Ribes aureum;

Sambucus canadensis, nigra;

Symplocos cratcegoides;

Viburnum lentago, dentata, Tinus.
Whitish and Yellow Hurs:

Elcagnus argentea, umbellata (amber), macrophylla, angustifolia;

Myrica;

Pirus coronaria, prunifolia;

Prunus angustifolia;

Sambucus racemosa;

Symphoricarpus racemosa.

\section{SHRUBS BLOOMING OUT OF REGULAR SEASON}

Early Bloomers (March, April): Abelia spathulata, serrata; Amelanchier Canadensis; Azalea amœna, mollis;

Cassandra;

Cornus;

Cratcegus;

Daphne mezereum, cneorum;

Deutzia parviflora;

Exochorda;

Forsythia;

Halesia;

Lonicera fragrantissima, Standishi;

Miagnolia, various, especially stellata;

Pieris ligustrina, Mariana, Japonica, nitida;

Pirus;

Prunus;

Shepherdia;

Spircea Thumbergi, pariifolia, prunifolia, etc.;

Sorbus;
Syringa oblata.

Midsumer Bloomers (July,

August):

Abelia rupestris, triflora;

Esculus macrostachya;

Amorpha;

Azalea calendulacea, arborescens, viscosa;

Colutea;

Diervilla;

Deutzia Lemonei;

Diervilla florida, nana, Kosteriana;

Evonymus microphyllus;

Hydrangea Thumbergi;

Kalmia angustifolia, glauca, nana;

Leucothoë Catesbai;

Elaagnus Canadensis;

Erica;

Hibiscus;

Hydrangea;

Hypericum; 
Kelreuteria;

Lagerstrimia;

Ligustrum Ibota;

Lonicera tartarica, Alberta;

Rhus semilaata;

Rosa rugosa;

Spirca ariafolia, Anthony Waterer, salicifolia, tomentosa;

Stuartia pentagyna;

Zenobia speciosa.
Late Bloomers (September, October):

Clethra alnifolia;

Desmodium;

Diervilla amabilis, arborea, grandiflora;

Gardenia nitida;

Hibiscus Syriacus;

Viburnum Tinus;

Vitex.

\section{DIVARF SHRUBS}

Andromeda polifolia;

Berberis canadensis;

Chamcecyparis pygmaa;

Caragana pygmea;

Cotoneaster horizontalis, microphylla;

Cytisus purpureus;

Daphne laureola;
Lonicera carulea, involucrata:

Myrica asplenifolia;

Philadelphus microphyllus;

Pieris Japonica, nitida;

Rhus copallina;

Syringa Chinensis, pubescens, Marie Legrave.

\section{SHADE-ENDURING SHRUBS SUTTABLE FOR USE IN UNDER-PLAN'TING}

Usually all the species of a genus possess the same characteristics as to need of light.

Azalea, Berberis, Buxus, Calycanthus, Clethra, Cornus, Cotoneaster, Cytisus, Daphne, Eronymus, Halesia, Hypericum, Ilex, Kalmia, Ligustrum, Leucothö̈, Lonicera, ()smanthus, Philadelphus, Rhododendron, Sambucus, Symphoricarpus, Taxus, Viburnum.

TREES AND SHRLBS COMPAR.ITIVELY RESISTANT TO SMOKE

Of conifers, Pinus austriaca appears to suffer least. Of broadleaved trees, species of Asculus, Amelanchicr, Betula, Cornus, Cratxgus, Eronymus, Fraxinus, Ilex, Laburnum, Liriodendron, Platanus, Populus, Salix. 


\section{Trees and Shrubs for Various Sites 37 I}

Of shrubs, most of the Heath family, Berberis, Buxus, Cotoneaster, Cytisus, Deutzia, Hibiscus, Iypericum, Ligustrum, Philadelphus, Ribes, Rhus, Syringa, Viburnum.

TREES AND SHRLBS FOR SEASHORE AND EXPOSED SITES

Abies Cephalonica, Hookeriana, concolor;

Cupressus macrocarpa;

Juniperus virginiana;

Pinus austriaca, laricio, cembra, insignis, pinaster, pumilio;

Thuja;

Thuyopsis;

Ilex;

Platanus;

Populus;

Quercus, several species;

Prunus maritima;

Rhammus;

Salix pentandra, and others;

Tamarix;
Tilia;

Alnus;

Baccharis;

Berberis;

Buxus;

Cytisus;

Eloagnus;

Erica;

Evonymus;

Leucothoë;

Ligustrum ovalifolium;

Myrica Gale;

Ribes;

Rosa rugosa;

Sambucus:

Spirca.

TREES AND SHRCBS FOR SWAMPY AND IIET SOILS

Abies balsamea;

Chamacyparis;

Cupressus;

Larix Americana;

Picea nigra, alba;

Pinus divaricata;

Betula alba, nigra;

Corylus avellana;

Fraxinus nigra;

Hicoria laciniosa;

Nyssa sylvatica;

Populus, most species;

Salix, most species;
Taxodium distichum;

Thuja;

Acer rubum, saccharinum;

Almus glutinosa, maritima;

Aralia Chinensis;

Aznlea viscosa;

Quercus alba, bicolor, palustris, Phellos, aquatica;

Cassandra calyculata;

Leucolhoë racemosa;

Lonicera oblongifolia;

Pieris:

Viburnum. 
TREES AND SHRUBS FOR S.NIYY AND DRY SOILS

Many of these are also fit for wet soils.

Amelanchier;

Betula;

Cratagus;

Ilex;

Juniperus;

Pinus divaricata, sylvestris;

Prumus;

Quercus;

Sorbus;

Tamarix;

Amorpha;

Arbutus;

Baccharis;

Berberis;

Caragana;
Clethra;

Cormus circinata;

Cytisus;

Deutia;

Erica;

Ligustrum;

Myrica;

Philadelphus microphyllus;

Rhus;

Rosa rugosa;

Salix;

Sassafras;

Shepherdia;

Symphoricarpus;

Zenobia.

TREES AND SHRLBS FOR CALCAREOLS OR LIMESTONE SOILS

Abies nobilis, Nordmanniana, Pinsapo;

Amelanchier;

Berberis;

Buxus;

Chamacyparis;

Cornus;

Cotoneaster;

Cratagus;

Daphne;

Fagus;

Hibiscus;

Hypericum;

Juniperus;
Ilex;

Kalmia;

Larix;

Ligustrum;

Pinus austriaca, laricio, sylvesiris;

Populus;

Prumus;

Rhododendron;

Ribes;

Symphoricarpus;

Taxus;

Viburmum lantana. 


\section{Trees and Shrubs for Various Sites 373}

TREES AND SHRUBS FOR PEATY AND BOGGY SOILS

Most of the Heath family;

Larix;

Betula;

Lonicera oblongifolia,

Myrica;

Picea;

Tsuga;
Thuja;

Viburmum;

and the perennial herbs, Epi-

gœa, Gaultheria, Ledum, Men-

ziesia, Vaccinium.

\section{SHRUBS FIT FOR ROCK GARDENS}

Amorpha;

Baccharis;

Celastrus;

Cotoneaster;

Cupressus thuyoides, pilifera, obtusa;
Cryptomeria elegans;

Lonicera spinosa;

Ilex;

Juniperus communis, nana, Sabina;

Philadelphus microphyllus. 



\section{BRIEF LIST OF BOOKS ON COGNATE SUB JECTS}

I. L. H. Bailey. Cyclopedia of American Horticulture. igoo. 4 vols. The best reference book for species and varieties of trees and shrubs.

2. N. L. Britton. North American Trees. ig08. To be consulted for the native arborescent flora.

3. R. B. Hough. Handbook of the Trees of the Northern United States And Canada. 1907. Excels in fine photographic illustrations.

4. Saunders \& Macoun. Catalogue of Trees and Shrubs. Bulletin 2. Central Experimental Farm, Ottawa, 1899. To be consulted as to hardiness of trees and shrubs.

5. F. E. Clements. Plant Physiology and Ecology, igo7. Will be found of interest by those who wish to expand their knowledge on the points raised in Chapter II.

6. L. H. Balley. The Pruning Book, I898. Refers especially to the pruning for fruit.

7. Tree Surgery. Fiftieth Annual Report of Massachusetts State Board of Agriculture. I902.

8. E. G. Lodeman. The Spraying of Plants, I908. The most comprehensive volume on the subject.

9. Spraying Mixtures and Machinery; Where and How to Spray. Bulletin 193. North Carolina Agricultural Experiment Station. I906.

ro. Fungicides, Insecticides, and Spraying Directions. Bulletin i23. Massachusetts Agricultural Experiment Station. 1908.

II. Shade Trees. Bulletin 125. Massachusetts Agricultural Experiment Station. I908.

I2. Shade Trees. Bulletin 205. Cornell Agricultural Experiment Station. I902.

I3. Street Trees, their Care and Preservation. Bulletin 256, Cornell College of Agriculture. I908.

14. Felt, E. P. Insects Affecting Park and Woodland Trees. Albany, volume I, I905; volume II, I906. 


\section{Brief List of Books on Cognate Subjects}

15. Packard, A. S. Insects Injurious to Forest and Shade Trees. Washington, I890.

I6. Smith, J. B. OUR Ixsect Friends and Enemes. Philadelphia, I909.

77. Ixsect Pests ANd Pl.int I)ise.isfs. Bulletin 252. Cormell Agricultural Experiment Station. 1908.

I8. The More Important Insects Affecting Ohio Shade Trees. Bulletin 194. Ohio Agricultural Experiment Station.

I9. The Pests of Shade and Orvamental Trees. Bulletin 47. Kentucky Agricultural Experiment Station. I893.

20. Diseases of Deciduous Forest Trees. Von Schrexck \& Perley Spalding. Bulletin I49. Bureau of Plant Industry, Washington, D. C. 1909 .

21. Studies of Some Shade Tree and Tmber Destroying Fungi. Bulletin I93. Cornell University Agricultural Experiment Station, IgOr.

22. Injury to Vegetation by Sielter Fumes. Bulletin 89. Bureau of Chemistry, Washington, D. C. I905.

23. Injuries to Shade Trees from Electricity. Bulletin 9i. Hatch Experiment Station of Massachusetts Agricultural College. Igo3.

24. The Elis and their Diseases. Bulletin 84. Kentucky Agricultural Experiment Station. I899.

25. The Bronze Birch Borer. Bulletin 234. Cornell Agricultural Experiment Station. I906.

26. The Brown-tall Moth. Bulletin I22. New Hampshire Agricultural Experiment Station. Ig06.

27. Of books on landscape gardening may be mentioned: Downing's LANDSCAPE GARDENING, which, although old, contains still much of value; Parsons' Landscape Gardening and How to Plan the Home Grounds, which are written on the basis of long experience in the parks of New York. Maynard's LANDSC.ApE G.ARdening AS APPLIED To Home Decoration gives much common-sense advice. 


\section{INDEX}

Illustrations are indicated by an asterisk after the page reference.

Abele, Populus, 301

Abelia, Honeysuckle, $326,336,367-$ 360; sec also Lonicera

Abies, Firs, 209, 2I 5, 224, 228, 240, $366,371,372$

Acacia, 210; Albizzia, 247, 249; Glcditschia, 210, 247, 249, 365; Robinia, 2II, 247, 248, 365; Rose, Robinia, 248; Threc-thorned, Gledilschia, 249, 365

Acer, Maples, 2 I I, 264, 36t-367, 37 I

Adaptation, process of, 20-22, I98, 200,323

Adirondack Forest P'reserve, I 37

Adolescence, 205

Aeration of roots, 20, 24, 28, 57-6o, $77^{-80}, 82,142$

Esculus, Horse Chestnuts, I I I, 2 I0, $250,364,365,369,370$

Ailanthus, Tree of Heaven, $210,25 \mathrm{I}, *$ 256,262

Air, need of, 20, 2I, 28; supply limited by pavements, etc., 33, So; also 53,82

Albizzia, Acacia, 247,240

Alcoholic fermentation of cells, 58

Alder, Almus, 6I, 60, 158, 2 I I, 37 I ; Black, 272, 273*; Italian, 272, $274 *$; Japanese, 275

Alder-leaf Buckthorn, Rhammus, 3 I3 Alfalfa, as fertilizer, 80

Allspice, Calycanthus, 327, 357, 368, 370

Almond, Prumus, 212; Flowering, 305; Japanese, 303, 304

Alnus, Alders, 2II, 272-275, 37 I

Althea, see Hibiscus

Amelanchier, Shadbush or Juneberry, II I, 2 II , 273, 369, 370, 372 Amorpha, False Indigo, 326,346 , $366,368,369,372,373$

Andromeda, 326, 333, 367, 370; see also Cassandra; Lencothoe; Pieris; Zenobia
Angelica Tree, Aralia, 210, 252, 37 I

"Annual ring," 7, 8, I7

Antiopa, see Spiny Elm Caterpillar

Antiseptic dressing for wounds, 80, 96, I 24, I67; see also Bordeaux mixture

Ants, I3I

Antwerp, tree guards in, IIS

Aphis, Leaf-destroying, $32 \mathrm{I}$

Apple, Pirus, 68, I54, 2I 2, 204,* $295,{ }^{*} 296,{ }^{*} 297,{ }^{*} 298, * 325,347$, 366-369

Apple-borers, 284

Apple-family, attacked by fireblight, 56

Apple-tent caterpillar, I6o

Apricot, 305

Aralia, Angelica Tree, Hercules (lub), 210, 252, 37 I

Araucaria, 223

Arborvitæ, Libocedrus, 209, 2 I 5, 22 I ; Thuja, 210, 215, 219, 371, 373; Japanese or Tom Thumb, Thuyopsis, 210, 215, 219, * 37I; Pacific Coast or Incense Cedar, Libocedrus, $22 \mathrm{I}$

Arbutus, 359, 372

Army-worms, I64

Arrow-wood, Viburnum, 340

Arsenate of copper, see Paris Green

Arsenate of lead, I35-137, I62, I63, I05

Arsenite, formula, I6o; also I 56

Ash, Fraxinus, I6, 68, 69, 85, I02, I $22, I 54$, I 6 I $, 210,253,365,370$, 37I; Black, 255; Blue, 256; English, 254, ${ }^{*} 256$; Flowering, 255,* 256; Green, 255, 365; White, 255

Asparagus-beetle, ${ }_{5} 6$

Aspen, 25, I93; Large-toothed, Populus, zor

Assimilation, process of, I 7, I 8, 21

Atmosphere, effect on growth, 63

Azalea, 192, 326, 330, 331, 335, 366371 ; Flame, 330, 369; Tree, 330 
Baccharis, Groundsel, 37, 326, 356, $371-37.3$

Bacterial disease, 56, 89

Bag-worm, I6I

Baiting for insect pests, I44, I95

Balm of Gilead, Populus, 212, 301

Banding trees for trapping insects, I 45, I 59, I62, I65

Barberry, Berberis, 37, 326, 356, 357 , 366-368, 370-372

Bark, method of renewal, 7, I7; use in life of tree, 8; protection, 34; longitudinal cut to relieve water-pressure, 59; also 203

Bark-beetles, 45, 48, 55, 128 , 146I $48,152,154$

"Bark-bound," 8

Bark-lice, I50

Basswood. Tilia, 58, 68, 85, I54, I59, I6I, I63, I7 I, 2I3 318,364 , 365, 37I; Downy-leaved, 319; White, 319

Bean Tree, Catalpa, 211, 278

Beech, Carpinus, Blue, I92, $21 \mathrm{I}$, 277; Water, 211, 277; Fagus, 16, $25,59,07,6,5,102,122,154,172$, 192, I93, 212, 285, 372; Copper, 203 , 286; American, 286; European, $286^{*}$; Purple-leaved, sec Beech, Copper

Beecher, Henry Ward, quotcd, 275

Beetle-borers, 152-158; see also Insect pests

Berberis, Barberry, 37, 326, 356, 357 , 366-368, 370-372

Berlin, tree guards in, 83 , .II 8 , I 2 I

Betula, Birches, 211, 220, 275, 276, $366,367,37 \mathrm{I}-373$

Bilsted, Liquidambar, 21 2, 288, 365

Biota, Arborvita or White Cedar, 215,218

Birch, 16, 25, 68, 91, 158, 163, $21 \mathrm{I}$, $275,370,372,373$; Cherry, 276; European, 275, 367, 371; White, 193, 229, 276, 366; Yellow, 193, 276; Black, see Birch, Cherry; Gray, see Birch, Yellow; Sweet, see Birch, Cherry

Birds, Insectivorous; 128, 130; see also English Sparrow

Bisulphide, 163
Bitternut, Hicoria, 257

Bitter-sweet, Celastrus, 327, 358, 368,373

Black Elder, see Elderberry

Black-knot, 38, I 25

Bladder Senna, Colutea, 327, 346, $367-360$

Bleeding Heart, 324

Blue stone, I 25, I 26

Bole, branchless, I4, I 82 ; breathing pores, 20; improper treatment of, $8 \mathrm{I}$; mutilations, II 2 ; also 5

Bonn, tree guards in, I I

Bordeaux mixture, II 2, II3, I25, I 27, I28, I35; see also Antiseptic dressing; Insecticides

Bordeaux nozzle, I39

Borers, 49, I4I, I46, I47, I53; scC also Insect pests

Boston, Metropolitan Park System, I86, I94; also 249

Bowker Fertilizer Company, 135 nole; 145 note

Box, Buxus, 60, 2 I I, 276, 343, 366, 370-372; Minorca or Japanese, 277

Box-elder, Acer, I6I, 266

Bran, Poisoned, I64

Branch system, skeleton of, 203

Branches, II-14, I8, 20; sec also Crown

Branchless boles, I4, I 82

Branchlets, $65,83,107$, I08; see also Bole; Branches

Breathing pores, 20, 44

Briarwood pipes, material for, 329

Bridal-wreath, Spirca, 351

Bridging, II 3

Broad-leaved trees, I04, 203, 207, 209-2 I I, 229, 247, 264; also List, p. 366

Bronx Park, N. Y. City, 186

Broom, Cytisus, 327, 346, 368, 370372

Brooklyn, N. Y., English Sparrow's introduced into, I30; also 140,141

Brussels, old elms in, 148

Buch-Ham, Symplocos, 329, 355, 368

Buckeye, Esculus, I59, 250, 365; see also Horse Chestnut

Buckthorn, Rhamnus, 2I3, 3I3, 3I4, $368,369,371$ 
Buds, concentration of living cells, 7 ; place in growth of tree, $8,10-13$, 26 ; assimilation, 17 ; annual rejuvenation, 29

Buds, Dormant, possible development into branch, I4; pruning for crown, 26; forming sprouts to replace lost bole, 27 ; also 59

Buffalo Berry, Shepherdia, 328, 344, $366,368,369,372$

Burbank, Luther, referred to, 260

Burlap, Band of, for trapping insects, I45; see also Banding trees

Burning Bush, Evonymus, 359, 367

Bush Clover, Desmodium, 327, 347, 367,370

Bush Honeysuckle, Diervilla, 336 , $367-370$

Butneria, see Calycanthus

Butterflies and moths, I57

Butternut, 66, 257; see also Walnut

Buttonwood, Platanus, 299, 364

Buxus, Box, 2I I, 276, 343, 366, 370$37^{2}$

Calico Bush, 332

California Nutmeg tree, Torreya, 210,247

California Privet, Ligustrum, 343, 371

Calluna, Heath, 327, 331, 367

Callus, 88, 92, 95, 96, I I 2, I 25

Callusing, process of, $36,40,91$

Calycanthus, Allspice or Strawberrybush, $327,357,368,370$

Cambium cells, growth at margin of wound, 92; division of, 93; relation to healing of wounds, 98 ; also $7,8, \mathrm{I}_{5}, \mathbf{1} 7,27$

Cambium layer, annual rejuvenation, 29; parasitic roots in, 43; larvæ of bark-beetles feeding in, $45,49,147$; injuries to, $52,55,74$; functions impeded, 58; activity of, 59, 95; winter-killing, 67 ; insect injury to, 52-54; also 88 , II 3

Canadian Experiment Farms, Bulletin on tests of hardiness, 200

Canker, 40, 67; see also Black-knot; Fungi

Canker-worm, Spring, I65
Cape Jessamine, Gardenia, 327, 360, 366,370

Capillaries, 79

CAPRIFOLIACAE, Honeysuckle family, 336

Carabidæ, see Ground-beetles

Caragana, Siberian Pea Tree, 210, $252,368,370,372$

Carbolic acid, I46, I48

Carbolineum, I24

Carbon, 79

Carbon bisulphide, I 46

Carbonic acid, $\mathbf{1 7}, \mathbf{1} 26$

Carpenter moth, $16_{3}$

Carpinus, Hornbeam, Water Beech, Blue Beech, I92, 21 I, 277

Carrot, 325

Cascara sagrada, $3 \mathbf{I} 3$

Cassandra, Leatherleaf, 327, 332, $366,369,37 \mathrm{I}$

Castanea, Chestnut, 2 I I, 277

Castanopsis, Pacific Coast Chinquapin, 278

Catalpa, II I I 7 I, 2 I I, 278

Caterpillars, sce Insect pests

Cedar, Ccdrus, 209, ${ }^{*} 215,216,{ }^{*} 217{ }^{*}$ 366; Alaska Yellow, Chamacyparis, 209, 218; Cedar of Lebanon, Cedrus, 216 *; Deodar, Cedrus, 209, $2 I_{7}^{*}$; Incense, Libocedrus, 209, 2I5, 22I; Pencil, Jumiperus, 209, 2I5, 2I9, 220, 37I-373; Red, 38; Silver, Cedrus, 2I6, ${ }^{*} 366$; White, Chamacyparis, 209, 2I5, 2 I $8,366,370-372$

Cedrus, Cedars, 209, 215, 216, * 21 \%, * $218-221,366,370-372$

Celastrus, Bitter-sweet, 327, 358, 368,373

Cells, alcoholic fermentation of, 58 ; see also Cambium cells

Celtis, Hackberry, Nettle Tree, 2 I I, 279,365

Central Park, N. Y. city, I86

Cephalotaxus, Yew, 209, 246, 247; see also Podocarpus; Taxus; Torreya

Cercidiphyllum, 2II, 279, 280*

Cercis, Red Bud or Judas Tree, I II, $211,280,367$

Chamadaphne, see Cassandra

Chamacyparis, Cedar, 209, 2I5, 218 , $366,370-372$ 
Cherry, Prumus, 102, 154, I61, I64, 212, 302, 347; Bird or Pin, 306, 366; Black Wild, 305; English Bird, 306; Flowering, 302, * 304; Mahaleb, 306

Chestnut, Castanca, 68, 85, I 54, 2 II, 277

Chickadees, I 30

Chinaberry, Ifelia, 210, 260, ${ }^{*} 261$

Chinch-bugs, I4I, I 50

Chinquapin, Pacific Coast, Castanopsis, 278

Chionanthus, Fringe Tree, 2II, 28I

Chlorine gas, 70

Chlorophyl, 17

Cicadas, 150,152

Cicindelidx, see Tiger-beetles

Cladrastis, Yellow-wood, 210, 253 , 365

Classification, with regard to light and shade, 192; foliage, 207; decorative qualities, 326

Clethra, Sweet Pepperbush, 327, 332, $366,370,372$

Clicking-beetles, I48, I52, I 55

Climate, adaptation of species to, $2 \mathrm{I}, 22,24,34,202$; soil in relation to, 199

"Clothes Tree," 299

Clover, 80, 325

Coal-tar, 89

Coal-tar oils, I 12

Coccinellidæ, see Lady-bugs

Cockchafers, I 52 , I 55

Collecting as means of combating insect pests, I95

Cologne, tree guards in, is 8

Colorado potato-beetle, I32

Colutea, Bladder Senna, 327, 346, $367-369$

Comptonia, see Myrica

Conical outline, 204

Conifer type, I03, 104

Coniferous trees, 7, 14, 34, 92, IOI, I50, I53, I55, I62, I64, I67, I70, I 72,177, I 78, I 89 , I91, I94, 203 , 205, 209, 2I3, 228, 229, 23I, 245, 306

Copper hydrate, I 26

Copper salt, . I 26

Coppice, I93

Coral Berry, Symploricarpus, 329, $339,366,368-370,372$
Cornelian Cherry, Cornus, 283

Cornus, Dogwoods, $211,281,366$, $367,369,370,37^{2}$

Corylus, Hazelnut, $327,358,366$, 371

Cotoneaster, $347,366,368,370-373$

Cotton batting for trapping insects, I44; see also Banding trees

Cottonwood, Populus, 212, 300, 365

Cottony cushion scale, I5 I, 234

Cottony maple scale, I5I

Crab-apple, 294

Cranberry Bush, Viburnum, 340

Crape Myrtle, Lagerstramia, 328 , $362,368,370$

Cratagus, Thorn Trees, Hawthorn, I I I, 2 I $2,28_{3}, 366-370,372$

Creepers, 44

Creosote oil, I 59, I62

Crown, definition, 5; development, 8 , II, I3, I5-I7, 59, I02; relation to root system, r9, 32; affected by light, 25, 26; indications of disease, 52; winter-killing, 66; balance with root system necessary, 99; height from ground, IOI; transplanting, I69; value of nursery stock, I70; changes of form with age, 205; also 200, 203

Crude petroleum, 145

Cryptomeria, 373

Cuckoos, I 30

Cucumber-beetle, I 56

Cucumber Tree, Magnolia, 212, 289

Cunninghamia, 209, 223, 221 *

Cupressus, Cypress, 209, 215, 217 , 371,373

Currant, Flowering, Ribes, 328,362 , 371,372 ; also 59, I5 1 ; Black, 363 ; Buffalo, 363,369 ; Mountain, 363 , 368

Cutworms, 148

Cydonia, see Pirus, 294

Cymes, 324, 325

Cypress, Cupressus, 200, 215, 217 , 37 I, 373; Bald, Taxodium, 61, 65, I 77, 2IO, 2I 3, 2I5, 22I, 37I; Lawson's Chamacyparis, 218 ; Monterey, Cupressus, $2 \mathbf{I} 7$

Cytisus, Broom, Laburnum, 210 , $259{ }^{*} 261,327,346,368,370-$ 372 
Daphne, 192, 325, 327, 358, 366, 368370,372

Davis, L. D., "Ornamental Shrubs" quoted, 326, 333

Death of trees, $29,30, \mathbf{I} 21$

Deciduous trees, I54, I55; 162,164 , I66, I76, I9I, I93, 203, 214, 229, $234,288,300,3,30,335,348$

Defoliation, 20, 45; see also Assimilation; Insect injury

Dendrolene, I45, I47, I 54, I 58

Dendroscope, ro5

Des Cars, A., Treatise on Pruning Forest and Ornamental Trees, 105 and note

Desmodium, Tick Trefoil, Bush Clover, $327,347,367,370$

Destruction by storm, 3I

Development of trees, requirements for, 29

Deut 2 ia $, 327,353,369,371,372$

Diagnosis, difficulty of, 32

Dichopodial type, 203

Diervilla, Bush Honeysuckle, 336, $367-370$

Diœecious trees, $287,316,356$

Diospyrus, Persimmon, I72, 212, 285

Disease, 29, 51, 2I5; see also Bacterial disease; Physiological dissease; Spot diseases

Disinfectants, I26; see also Antiseptic dressing; Bordeaux mixture

Disparene, I35, and note

Dockmackie, Viburnum, 340

Dogwood, Cormus, I50, I92, 2 II, $325,366,369,370,372$; Alternate leaf, 282,367 ; Flowering, $28 \mathrm{I}$

Douglas Fir, Pseudotsuga, 24, 228, 229

Dragon Trees on Island of Teneriffe, I 2 I

Dragon's Head, 325

Drainage, 79, I99

Drooping trees, 203

Dropsy, 58

Drouth, effects of, $59,60,64,215$

Dwarf forms, 203, 208, 2I 8, 250, 252 , $253,262,271,277,291,298,324$, $330,332,334,337,338,345,347$, 35 I, 353, 354, 356, 359; also List, p. 370
Ebony, Diospyrus, 212, 285

Economic tree-planting, 198

Eglantine, 349

Elaagnus, 327, 341, 342, 366-369, 37 I

Elderberry, Sambacus, 328, 336, 338, $339,366,368-37$ I

Electricity, dangers of, 33, 62, 7I, 72

Elliptical outline, 204

Elm, Ulmus, 16, 58, 65, 69, II 5, I56, I59, I6I-I65, I97, 204, 213, 364, 365; Camperdown, 322; English, 32 I ; European, 205; Slippery, 32 I Wahoo or Winged, 32I; White, 320; Wych, 32I; Red, see Elm, Slippery

Elm-leaf beetles, 54, I 56, I97

Endurance of trees, 201

England, forestry in, 186

English Ivy, substitute for, 360

English Sparrow, I30, I52; see also Birds

English Sweetbriar, 349

Epidermis, 36

Epiphyte, 44

ERICACEAE, Heath family, 293, $329,334,366,369,371,372$

Essential points of tree life, 27, 28

Etiolation of leaves, 53, 62, 73

Europe, baiting of bark-beetles in, I48; gypsy moth imported from, I62; forestry in, 186; exotics from, 26I, 264, 277, 301, 312, 316, $317,320,335,336,34 I-343,346$, $347,354,359,361,363$

European flora in California, 22

Evaporation, 18, 21, 58, 60, 79

Evergreens, 228, 276, 277, 287, 306, $307,332-334,336,342,343,347$, 349, 359, 360; also List, p. 366

Evomymus, Burning Bush, etc., 327 , $359,360,366,371$

Exochorda, Pearl Bush, 327, 348, 369

Exotics, 22, 24, 63, 65, 205, 244, 298

Fagus, Beech, 2I 2, 285, 286, 372

Fall web-worm, I6o

False Indigo, Amorpha, 326, 346 $366,368,369,372,373$

Fastigiate forms, 203, 208, 245, 279, 313

Fertilizers, 62, 80, I73 
Fibrils, 7, 99, r68; sec also Root system

Fields of distribution, 21, 22; see also Adaptation, process of

Fir, Abies, I6, 26, I66, I93, 203, 209, $215,224,228,240,366,371,372$; see also Douglas Fir; Gingko

Fire-blight, 56

"Fire-pine," 239

"Five, five, fifty" formula, I25; see also "Two, two, fifty"

Flooding, dangers of, 20

Flowers, pruning for, I10; varying shapes, 324,325 ; types, 325 ; also Io

Foliage, effect of light upon, 18, I9, 25; dependent on root system, I8, 27; gives first indication of disease, 5I; approach of winter, 65; poisoned by sulphurous acid, 69 ; effects of leakage of illuminating gas, 70; development by pruning, 76 ; ornamental trees, 207; also 200; sce also Crown; Defoliation; Leaves

Fontainebleau, primitive tree guards in, II 7

Food materials, I4, 17; assimilation, I 7; elaboration, I9, 20, 26, 96; increased by trimming, $6 \mathrm{I}$; growth of callus, 97

Forest, Pleasure, versus Pleasure Park, I88

Forest Park, St. Louis, I 86

Forest planting, I 70

Forest tent-caterpilar, 159

Forestry as an art, 185,187

Form (in trimming), types, I03; A. Des Cars's book on, 105 nole; rules 107; corected in transplanting, I69; affected by soil, 205; inheritance in, 208; see also Outlines

Forsythia, Golden Bell, 327, 342, 368,369

Four winged Silver Bell Tree, 355

France, vineyards of, 148

Frankfurt, tree guards in, irs, 120

Fraxinus, Ash, I6, 68, 69, 85, 102, I 22 , I 54, I6 I, $210,253,254$, * $255 * 256,365,370,37$ I

Fringe Tree, Chionanthus, 2II, 28I
Fringed Myrtle, Lagerstramia, 328 , $362,368,370$

Frost, differing effects, 64-66; pre ventive, 67 ; worst form of injury 67; enemy to insect pests, I29; also 215

Frost-heaving, I 77

Frost splits, 68

Fruit and fruit trees, $60,84,1_{50}$, 207,325

Fungi, entering through dead twigs, 30 ; cause of disease, 32 ; result of mechanical injuries, $32,36,42$; attacks affected by season, 34; life history, 37; various forms, 38 , 40; spraying for, 55 ; frost injuries, 67; fundamental principle in combating, I 24, I25; also 7, I5, 86, 89, 96; see also Canker; Parasites; Root Rot; Saprophytes

Fungicides, see Bordeaux mixture; Disinfectants

Fungus diseases, 197, 201, 206, 21 5, $229,250,278,279,28 \mathrm{I}, 285,286$, 294,307

Galls, 46, 48; see also Insect pests

Gardenia, Cape Jessamine, 327,360 , 366,370

Garland Flower, Daphne, 359

Gas, Illuminating, effects of leakage, 33,70

Gasoline torch, 144 note

Geometridx, see Inchworms

Germany, forestry in, 54, I87; laws against insect pests, 132

Ghent Azalea, 33 I

"Giant Tree," 288

Gingko, 209, 213, 226

Girdling, I9 note

Gleditschia, Honey Locust, 2 ro, 247, 249,365

Globular outline, 204

Goethe, Johann Wolfgang, quoted, I 85

Gold Flower, Hypericum, 361

Golden Bell, Forsythia, 327, 342, 368,369

Golden Chain, Cytisus, 259, ${ }^{*} 26 \mathrm{I}$

Goldenrod, I54

Gooseberry, Fuschia-flowered, 363

"Goumi," The, 342

Grading, improper forms of, 80, 8I 


\section{Index}

Grafted stock, 205

Grapevines, $15 \mathrm{~S}$

Grass crops, I 55

Grasshoppers, I50, I 5 I

Great Laurel, Rhododendron, 334

Grills around trees, 83 ; see also Guards

Ground-beetles, I3I

Groundsel, Baccharis, 37, 326, 356, $37 \mathrm{I}-373$

Group planting, light intensity for, 25 ; also $\times 82$

Grouping of trees, important points in, 201

Growth, impeded, 3I, 32; rapidity of, 20I; affected by soil, 205

Guards, Tree, 83 , I I 7, II 8 , I 20, I 2 I

Gypsum, 78

Gypsy moth, I62

Hackberry, Celtis, 2I I, 279, 365

Hailstones, injury by, 36

Hairs, see Root-hairs

Halesia, Snowdrop, Silver Bell Tree, I I I, 327, 354, 369, 370

Hardhack, Spircea, 328, 350, 370

Hardiness of trees, I99, 200, 323

Hardwood ashes as fertilizer, so

Hardwood forest, Igo

Hardwood trees, 193

Hartshorn, 3I4

Hawk-moths, I 57

Hawthorn, Crategus, 56, I 5I, 2 I 2, 283,284 ; Paul's Double Scarlet, 285 ; Siberian, 284

Hazelnut, Corylus, 327, 358, 366, 37 I

Heading in, 87

Healing, see Callusing

Heart-root, I 99; see also Root system

Heath family, ERICACEAE, 293, $329,334,366,369,37 \mathbf{I}, 372$; see also Calluna

Heather, North American, Leucothöe, 333, 366, 367, 369-37I; see also Zenobia

Hedges, suitable forms for, 219,228 , $24 \mathrm{I}, 276,284,287,297,320,33 \mathrm{I}$, $343,344,348,349,356,36$ r

Heeling, 170

Height, gradations of, 209

Height growth, classification according to, 192

Hellebore, 363
Hemlock, 26, I89, I93, 227; Alpine, Tsuga, 210, 227, 228, 373; Bastard, Pseudotsuga, 210,228

Hercules Club, Aralia, 210,252 , $37 \mathrm{I}$ Hibiscus, Mallow, 327, 360, 367, $360-372$

Hickory, Hicoria, I6, I54, I 7 I, I72, 210, 256, 37I; Bitternut, 257; Mockernut, 257; Nutmeg, 257; Pecan, 257; Shagbark, 257; Shellbark, 257

Hicoria, Hickories, 2 Io, 256, 257, 37 I

Hobble Bush, Viburmum, 340, 341

Holly, Ilex, 25, 102, 192, I93, 212 , $366,368,370-373$; Deciduous, native, 288; English, 287

Honey Locust, Gleditschia, 210,247 , 249,365

Honey Mushroom, 43

Honeysuckle, Abelia, 326, 336, 367369; Lonicera, 325, 328, 336338, 366, 368-37 I, 373; Fly, 337

Honeysuckle family, CAPRIFOLIACEAE, 336

Hop Hornbeam, Ostrya, 212, 293, 365,367

Hornbeam, Carpinus, I92, 2I I, 277

Horse Chestnut, Esculus, 59, 67, 68, III, $118,122,159,210,304,305$, 369,370 ; Dwarf, 250

Host-plants, $37,43, \mathbf{I 9 7}, 356$

Huckleberry, 325

Humic acids, 6 I

Humus, I73

Hydrangea, 327, 352, 353, 368, 369

Hydrocyanic gas, I 34

Hypericum, St. John's Wort, 327, 361, 368-372

Ice-pressure, damage from, 3 I

Ichneumons, I 30

Inchworms, plague of, subdued by English Sparrow, I30

Ilex, Holly, 21 2, 287, 288, 366, 368, 370-373

Indian Cherry, Rlıammis, $3 \mathbf{I} 3$

Indian Currant, Symphoricarpus, $339,366,368-370,372$

Infections, see Fungus diseases; Insect pests

Ingrafting, I I 6

Inheritance in form, 208

Insect hosts, I 30 


\section{4}

Insect injury, IS, 26, 36, 49, 52; see also Insect pests

Insect lime, see Dendrolene

Insect pests, periodic development, 45; various groups, 46; character of damage inflicted, 46 ; precautions against, 54; combating in cities, 54, I3I-I33; natural enemies, 129 ; methods, 133 ; mechanical destruction of, 144; in parks, I95; also 197, 206, 2 I 5

Insecticides, I25, I 34, I46; see also Bordeaux mixture; Soap solution; Tobacco

Insects, biting, 134, I35; sucking, I34, I42; obnoxious to tree growth, I 49

Iron, deficiency in soil, 62

Ironwood, Ostrya, I92, 2 I 2, 293, 365, 367

Itea, $35^{2}$

Ithaca, N. Y., trees killed in, 142 note

Japanese Quince, Pirus, 297; sec also Strawberry-bush

Japanese Storax, 355

Japonica, Pirus, 297; see also Strawberry-bush

Jasmine, Philadelphus, 354

Judas Tree, Cercis, III, 2 I I, 2 So, 367

Juglans, Walnut, 210, 257, 259, 260

June bug, I 55

Juneberry, Amelanclier, III, 2 II, $273,369,370,372$

Juniper apple, 38 ; sec also Rusts

Juniperus, Pencil Cedar, 209, 2 I5, 2I9, 220, 371-373

Kainit, see Potash fertilizers

Kalmia, Laurel, 293, 331, 332, 365, $366,369,370,372$

Kentucky Coffee Tree, 256

Kerosene emulsion, 50, I34, I4I, I42, I50, I5 I, I 55 I 56,160

Kinnikimik, Cornus, 282

Kirkland, A. H., quoted, I4I

Knapsack pumps, I 38 note, 147

Knots, their causes, $\mathrm{I}_{4}$

Kolreuteria, Varnish Tree, 210,258 , 261,370
Laburnum, Cytisus, 210, 259, ${ }^{*}{ }_{26} \overline{1}_{\text {, }}$ 368,370

Lady-bugs, coccinellidx, I3 I

Lady Laurel, Daphne, $35^{8}$

Lagerstramia, Crape Myrtle, Fringed Myrtle, 328, 362, 368, 370

Larch, I70, 177, I95, 209, 215 ; American, Larix, 230, 37I; Golden, Pseudolarix, $210,213,229$, 230*; Japanese, Larix, 230; Western, Larix, 230

Larch-moth, 166

Larix, Larches, 209, 21 5, 220, 230 , 371-373; see also Pseudolarix

Larvæ, see Insect pests

Laurel, Kalmia, 277, 332, 366, 369, 370, 372; Mountain, 332; Sheep, 332, 369; Swamp, 332

Lawn trees, treatment of soil for, 77 , conditions for planting, I73, I76; size, I78; contrasted with forest trees, I89; also I98

Lead plant, Amorpha, 326, 346, 366

Leaf-beetles, 152,155

Leaf-eaters, $46,54,55$

Leaf-miners, $47,165,167,229,272$, 284

Leaf-rollers, 47, I65, I66

Leaf-suckers, 47

Leatherleaf, Cassandra, 327, 332, $366,369,37$ I

Leaves, development, 7, 10; part in evaporation and assimilation, I 7-I9; breathing pores, 20 ; etiolation, $53,58,60,62,73$; period of, 204; color and form, 208; see also Foliage

LEGUMINOSAE, Pea family, 345

Lepidoptera, see Butterflies and moths

Lespedeza, see Desmodium

Leucolhöe. North American Heathers $333,366,367,369-371$; see also Zenobia

Libocedrus, Arborvitæ, Incense Cedar, 209, 2I 5, 22 I

Lichens, excessive development on bark, 44 ; relation to disease, 53

Life of tree, definition of term, 30; comparison with animal life, 30 , $3 \mathrm{I}$; causes contributing to length of, 3 I 
Light, necessity of, r8, 2I; degrees of intensity, 25, 26; uneven distribution, 73 ; as means of combating insect pests, I44; requirements in grouping, $20 \mathrm{I}$

Light-needing forms, I92, 215, 23I, $235,275,300,306,314$

Light requirements, scale of, 25,26

Ligustrum, Privet, 192, 328, 343, 366, 369-372

Lilac, Syringa, 329, 344, 368, 37 I; Japan Tree, 345; Persian, 345; Rouen 345,370

Lime, in soil, 62,78 ; as medicine, I23; as insecticide, $125, \mathbf{1} 63$

Lime Tree, Tilia, 213, 3 I 8

Lime wash, I46-I 48 , I 54 , I 58

Linden, Tilia, I6, 65, 205, 213, 318; Silver, 320, 366

Liquidambar, Red Gum, Sweet Gum, Bilsted, 2I 2, 288, 365

Liriodendron, Tulip Tree, Whitewood, Yellow Poplar, 212, 288, 365,370

Locust, Black, Robinia, 65, I I I, I54, 163, I93, 2II, 248, 263, 365; Clammy, Robinia, 2II, 248; Honey, Gleditschia, 249, 365

Locust-borer, I 54

London, tree guards in, 83 , II 8 , I 2 I

Longevity, 201

Lonicera, Honeysuckle, 328, 336$338,366,368-37$ I, 373

Lost parts, ability to replace, see Recuperative power

Lowell, James Russell, quoted, 86

Lupine, as fertilizer, 80

McGovern nozzle, I39

Magnesium, deficiency in soil, 62

Magnolia, III, I72, 2 I2, 288-290, 366-369

Maidenhair Tree, 226

Malachodendron, see Stuartia

Mallow, Hibiscus, 327, 360, 367 , $369-372$

Mantis, see Walking-stick

Manure, see Fertilizers

Maple, Acer, I6, 69, 91, I02, I58I60, I62, I65, I7I, 205, 2II, 364367,371 ; Ash-leaved, 266; Black, 264; Eagle-claw, 271; English, 269; Japanese, $270,{ }^{*} 271{ }^{*}$ 272;
Maple, Acer - continued

Mediterranean, 268,* 269; Mountain, 265; Norway, 266, ${ }^{*} 268$, 27I; Pacific coast, 267; Red, 66, 265; Rock, 60; Silver, 59, 84, 103, II $, 265,365$; Soft, 85, I93; Striped, 265; Sugar, 25, 193, 264; Sycamore $267,{ }^{*} 268,27 \mathrm{I}$; Tartarian, 269, ${ }^{*}$ 270; Oregon Maple. see Maple, Pacific coast.

Maple-worm, see Forest tent-caterpillar

Marl, 78

Massachusetts, gas companies of, 70 ; efforts to exterminate gypsy moth in, I62

Meadow-sweet, 350

Mealy bugs, I 50

Measuring-worm, see Inchworms

Mechanical destruction of insect pests in woodland parks, 195

Mechanical injuries, in city streets, 32,33 , II7; cause of disease, 34, 36 ; results of, 74 ; also 59

Mechanism of tree compared with system of water works, is

Medlar, 294

Melia, Chinaberry, Umbrella Tree, 210,260 * $26 \mathrm{I}$

Mengel, William, Son, N. Y., I45 note

Metal protector for trapping insects, I 45

Mildews, 38, 363; see also Spot diseases

Minerals, requisite for tree life, I7, I 8, 2I, 28; results of deficiency of, I9, 79; also 62

Mist Tree, 262

Mistletoe, 43

Mites, I34

Mock Orange, Philadelphus, 192, $328,344,354,370,372,373$

Mockernut, Hicoria, 257

Mohrodendron, see Halesia

Monopodial type, 203

Moosewood, 265

Morus, Mulberry, 212, 29I

Mosses, excessive development on bark, 44; relation to disease, 53

Moth, Household, I66

Mountain Ash, Sorbus, 56, I50, I92, III, 263, 264, 365, 369, 372 
Mountain Fetter-bush, Picris, 328, 333

Mountain Rose Bay, Rhododendron, 335

Mourning Cloak, $\mathrm{I}_{3}$

Mulberry, Morus, 21 2, 29I

Mulching, 67,77 , So, $175,177,334$

Mullein, 325

Murrill, A. W., on "Shade Trees," I 7 nole

Muriate of potash, I 49

Mycelium, 4I-43, 56, I1 2, I2.4; set also Fungi

Myrica, Wax Myrtle, 328, 362, 369-373

Nannyberry, Viburmum, 340, 366

Nason, Prof. F. L., referred to, J.45 note

National parks, I86

Needle-shaped leaves, see Coniferous trees

Neillia, see Spirca

Nettle Tree, Celtis, 2 I I, 279, 365

New York State, winter of I903-04, 66; Forest Preserve of, 186

Nitrogen, deficiency in soil, 62, 79

Nomenclature, 207, 208

North American species, number of, 202

Nozzles, I39, I47

Nursery stock, I69, 200

Nuthatches, I30

Nyssa, Tupelo, 2I2, 29I, 37I

Oak, Quercus, I6, 59, 65, 85, II2, I54, I56, I62-164, I 7 I, I92, I93, 213, 228, 306, 371, 372; Basket, 308; Black, 307-309, 365; Bur- or Mossy-cup, 308; California, 310, 366; Chestnut, 308; Chincapin, 3I I, 366; Cow, 308; English, 310,* 31 2, 366; Italian, 3 I 2, * 313; Live, 307; Over-cup, 308; Pin, 309, 37I; Post, 308; Quercitron, Red, 308, 364, 365; Rock, 308; Scarlet, 309, 364; Scrub, Bear, 3 I I , 366; Shingle, 309, 365; Spanish, Willow, 309, 371; Swamp, 6r, 308; Turkey, 3II, 3I3; Water, 309; White, 307, 371; Yellow Chestnut, 308

Oak-carpenter, $\mathrm{I}_{3}$

Oak-pruner, I54
Old age in trees, I2I

Olea, see Osmanlhus

OLEACEAE, Olive family, 34T, 365

Olive family, OLEACE $\backslash \mathrm{E}, 34 \mathrm{I}$

Opulaster, see Spircea

Orange trees, I5I

Oregon I'ine, 228

Ornamental planting, 198

"Ornamental Shrubs," by L. D. Davis, quoled, 326, 333

Ornamental trees, values, 200, 202; in Washington, 206; foliage, 207; classification, 207; see also Lawn trees; Shade trees; Street trees; and Lists, pp. 365-373

Orthoptera, 150

Osage Orange, Toxylon, 213, 320

Osmanthus, 212, 291, 366, 370

Osmosis, 18 note

Ostrya, Hop Hornbeam, Ironwood, $212,293,365,367$

Outlines of trees, 204

Oxydendron, Sorrel Tree, 212, 293

Oxygen, see Air

Pagoda Tree, Sophora, 263

Palm trees, 8

Paradise Apple, Pirus, 295

Paradise Plant, Daphne, $35^{8}$

Parasites, causes of disease, 32, 37, 44; see also Fungi; Insect pests; Mistletoe

Paris, tree guards in, 83 , II 8 , II 9 , I 2 I

Paris Green, I 27, I35, I37, I47, I48, I 53, I 55, I64

Park, Woodland, versus pleasure park I8S; location, outline, composition, I90; classification of species in, 192; permanency, 193; selection of materials, 194, 198; dealing with insect pests, I95

Park planting, degrees of light intensity needed, 25

Parks, see Adirondack Forest Preserve; Bronx Park, N. Y. City; Forest Park, St. Louis; Soldiers' Home, Washington

Parry, nurseryman, 243

Paulozunia, 212, 293

Paul's Double Scarlet Hawthorn, 285

Pea, type-shape, 325

Pea family, LEGUMINOSAE, 345 


\section{Index}

Peach, Prumus, II I, 21 2, 302, 305

Peach-borer, ${ }^{8} 8$

Pear, effect of sun-scald, 68; time for pruning, I I I

Pearl Bush, Exochorda, 327, 348, 369

Pecan, Hicoria, 256

Pendulous (form), 208

Pepperidge, Nyssa, 2I2, 29I, 37 I

Perennial herbs, 373

Persimmon, Diospyrus, I 72, 2I 2, 285

Philadelphus, Mock Orange, I92, $328,344,354,370,372,373$

Phosphoric acid in soil, 62

Phylloxera, I 48

Physiological disease, 56

Physocarpus, see Spiraa

Picea, Spruces, 209, $215,228,240$, $242,243,{ }^{*} 244,{ }^{*} 366,371,373$

Pieris, 328, 333, 334, 366, 368-37I ; see also Andromeda; Xolisma

Pine, Pinus, 25, I56, I65, I7 I, I89, 193, I95, 203, 2IO, 2I4, 23I; Bhutan, 234; Black, 237, * 238, 240, 259; 37I, 372; Bull, 240; Calabrian, 238, * 239; Cluster, 240; Corean, 232,* 234; Dwarf, 240; Greek, 233, *234; Jack, 239, 37 I, 372; Longleaf, 239; Mexican White, 234, 235; Northern Pitch, 239; Red, 239; Scotch, 236,* 259, 372; Shortleaf, 240; Silver, 234; Spruce, 240; Sugar, 234; Swiss Stone, 234; Table Mountain, 239; White, 37, 60, 66, 23I, 233; Yellow, 234; Australian, Corsican, see Pine, Black; Gray, see Pine, Jack; Norway, see Pine, Red

Pine-apple, 48; see also Galls

Pine-bud worm, I66

Pine-twister, I66

Pinetum, 2 I4

Pinus, Pines, 210, 2I4, 23I, 232, * $233,{ }^{*} 234,235,{ }^{*} 236,{ }^{*} 237,238,{ }^{*}$ $239,240,{ }^{*} 259,371,372$

Pinxter, $33 \mathrm{I}$

Pirus, Apple, 2 I 2, 294, * 295, $296,{ }^{*}$ $297,{ }^{*} 298, * 366-369$

Pith rays, 14,17

Plane-tree, Platanus, 68, 212, 298, 300

Plant-lice, I34, I4I, I48, I 50

Planting too deep, consequence of, 58
Platanis, Sycamore, Plane-tree, 2 I2, 298, 299, 364, 370, 371

Plum, Prunus, I51, 158, 21 2, 302; Beach, 305; Japanese, 304, * 366, 368; Yellow, 305; Chickasaw, see Plum, Yellow

Podocarpus, Yew, 2 10, 247

Poisons, for combating fungi and insect pests, 125, 133; injurious to plants as well as to animals, 134 ; for biting-insects, I35; see also Arsenate of lead; Bran; Insecticides; Paris Green; Soap solution

Poisonous trees, 26I

Polypodial type, 204

Pope's Hat, Evonymous, 359

Poplar, Populus, I6, 25, 58, 65, 69, I03, I50, I5I, I54-156, I58, I6I, I63, I65, I7 I, 2 I $2,300,365,366$, 370-372; Balsam, 30I; Lombardy, 3or; Silver-leaf, 301

Poplar, Yellow, Liriodendron, 212, 288, 370

Poppelsdorf Allee, Bonn, tree guards in, 1 I 8

Populus, Poplars, 21 2, 300, 301, 365, $366,370-372$

Potash, deficiency in soil, 62

Potash fertilizers, 149

Potato-beetle, I 56

Praying-mantis, I5 I

Pride of Rochester, Deutzia, 353

Privet, Ligustrum, 192, 328, 343, 366, $369-372$

Privet Andromeda, Xolisma, 335

Protective coloration, I3I

Pruning, natural, 13,83 ; in relation to light intensity, 25, 26; to replace lost parts, 27 ; for frostkilling, 65, 67; in late summer, 66; to establish equilibrium between root and crown, 82 , IoI; to prevent location of fungus spores, 86 , I 24; outfit and method, 87,88 ; distinguished from trimming and heading in, 87; dressing of wounds, 89; healing process, 9I ; depending on food elaboration, 98 ; most difficult task, IO2; varieties of form, I03; A. Des Cars's book on, I05 note; rules for form, I07; tools, I08; for flowers or fruit, I 10; effect of severe, III; repairing of 


\section{Pruning - continued}

neglected wounds, III; time for, III; for scales, I5I, I53, 155; while transplanting, I60, I 7I; for form out of place in forest, 189; shrubs, 325

Prunus, Cherries, Peaches, Plums, $212,302-306,366,368,369,371$, 372

Pseudolarix, Golden Larch, 2 I 0, 213, 229, 230*; see also Larix

Pseudolsuga, Bastard Hemlock, 2 1о, 228; see also Douglas Fir; Tsuga

Pulse family, Acacia, 2 10, 247, 249; Albizzia, 247, 249; Gleditschia, 2 10, 247, 249, 365; Robinia, 21 1, 247, 248,365

Purple Fringe, Rhus, 262

Pyrus, time for pruning, III

Prussiate of potash, I 26

Pumps, see Spraying machinery

Pyrenees, 240

Quercus, Oak, 213, 228, 306-309, 3 IO $^{*}$ 3II, * 3I $2,{ }^{*}$ 313, 364-366, 371,372

Quick lime, see Lime

Quince, 294

Quince, Japanese, Pirus, 297

Racemes, 324

Ragweed, 37

Raupenleim, I45

Rear-horse, see VValking-stick

Recuperative power, 26-28, 32, 36, I 7 I, I 72, 20I, 306

Red Bud, Cercis, III, 2II, 280, 367

Red Gum, Liquidambar, 2I2, 288, 365

Red Osier, 283

Redwood, Sequoia, 2 IO, 2I5, 222

Resin, covering a wound, 91, 92, I66

Respiration, importance of, 20; affected by season, 34

Retiuspora, see Chamacyparis

Reversion to type, 208

Rhamnus, Buckthorn, 2I3, 3I3, 3I4, $368,369,37$ r

Rhododendron, 60, I75, 192, 228, $277,293,328,331,334-336,365$, $368,370,372$

Rhodora, 330

Rhodolypus, 328, 348
Rluts, Sumach, 211, 261, 262, 368, $370-372$

Ribes, Flowering Currants, 328,362 , $363,368,369,37$ I, 372

Road system of the forester, 187

Rock gardens, shrubs for, 373

Root-hairs, I7, I68, I72

Root-lice, $\mathrm{I}_{5} \mathrm{I}$

Root pests, see Cutworms; Wireworms; Clicking-beetles; Phylloxera

Root rot, 43,56, I $_{2} 8$

Root stock, how to kill, 50

Root system, development, I5; types and characteristics, I6; root-hairs, 17; relation to foliage, I8, 19, 27; respiration, 20; adaptation to change, 20; requisites for life, $2 x$; annual rejuvenation of rootlets, 29; conditions in city streets, 33 ; insect injury to, 49 ; conditions causing disease, 52; loss by winter-killing, 66 ; effects of gas leakage, 70; injury by grading, 8o; equilibriüm between root and crown necessary, 82; pruning crown to balance with, 99 ; injury in transplanting, 168, 169; advantage of nursery stock, I 70 ; shrubs, 323

Rosa, Rose, $325,328,348,349,367$, $368,370-372$

Rose, Rosa, 325, 328, 348, 367, 368, 370-372; Memorial, 349; Native Wild, 349; Prairie, 349

Rose family, ROSACEAE, 347; see also Spircea

Rose of Sharon, Hibiscus, $36 \mathrm{I}$

Rosemary, Wild, Andromeda, 330

Rot, 3I, 37, 5I, 86, II2; see also Root rot

Rot fungi, 40, 55

Rowan Tree, Sorbus, 263

Rowan Tree, Virburnum, 34 I

Russian Olive, Elcagnus, 342

Rusts, 37

St. John's Wort, Hypericum, 327 $361,368-372$

St. Louis, smoke nuisance in, 70; Forest Park, I 86

Salix, Willows, 2I3, 3I4-316, 365 . $37 \mathrm{I}$ 


\section{Index}

Sambacus, Elderberry, 328, 336, 338, $339,366,368-371$

San José scale, I5I

Sandy soil, trees suitable for, 372

Sap-lifters, Io8

Sap-wood trees, I7I

Saprophytes, 36, 4I, 43

Saratoga, cost of spraying in, I I I

Sargent, Prof. C. S., definition of tree adopted by, 209

Sascatoon Berry, Almus, 275

Sassafras, $213,316,367,372$

Saunders, Dr. William, on tests of hardiness in trees, 200

Saw-flies, 48, 230; see also Insect pests

SAXIFRAGACEAE, Stonebreak family, 352

Scale-insects, I34, I4I, I50; see also Insect pests

Scheele's Green, 137

Scotch Broom, Cytisus, 346

Scotch Heather, Calluna, 33 I

Seashore planting, trees suitable for, $242,249,284,=317,339,34 \mathrm{I}$, $343,349,356,362,37 \mathrm{r}$; also List, p. 371

Seasons, influence of, on disease, 34

Sced, preserving characteristics of mother plant, 24; inheritance of adaptability, 34

Senecio, 37

Sequoia, 210, 215, 222

Service-berry, 56

Service-tree, Sorbus, 192, 263, 264

Sesias, ${ }_{5} 8$

Seventeen-year locust, see Cicada

Shadbush, Amelanchier, III, 2II, $273,369,370,372$

Shade, effect on weak trees, 25; value of, 200 ; affected by soil 205 , see also Light

Shade-enduring trees, 215, 21 8,232 , $234,264,267,276-278,281,284$, $287,288,323,330,332,337,354$, 359, 36r; also List, p. 370

Shade trees, adverse conditions in streets, 33; treatment of soil for, 77; reasons for pruning, 98 ; height of crown from ground, Ior

Shagbark, Hicoria, 257

Shapes of trees, see Typpes of trees
Sheepberry, Viburnum, 340, 366

Shellbark, Hicoria, 256, 257

Shepherdia, Buffalo Berry, 328, 344, $366,368,369,372$

Shoulder, 88

Shrubs, adaptability, 322 ; hardiness, 323,325 ; freedom from pests, 323; grouping, 324; pruning, 325; classification, 326

Shrubs and trees, confusion between, 208, 322

Siberian Crab-apple, 295

Siberian Pea Tree, Caragana, 210 , $25^{2}, 368,370,372$

Silkworm, 158, 29 I

Silver Bell Tree, Malesia, II 1327 , $354,369,370$

Silver Tree, Elceagnus, 327, 341, 342 . 366,360

Slacked lime, see Lime

Smith, Prof. J. B., referred to, I49

Smoke, cause of disease, 68; symptoms of poison by, 69; suppression of nuisance, 70

Smoke-resistant trees, 69; also List. p. 370

Smoke Tree, Rhus, 262

Snout-beetles, $\mathbf{r}_{52}$

Snow-pressure damage from, 3 I

Snowball, Viburnum, 192, 324, 329, 336, 339-34I, 366-373; Chinese, 340

Snowdrop, Halesia, I I I, 327, 354, 369,370

Soap, Soft, $16_{3}$

Soap solution, I4I, I42, I48, I50, I 53, I 54, I60; see also Insecticides

Soil, relation to root system, ${ }_{5}$, 16; respiration, 20; adaptation to species, 24, 198; important factor in city streets, 33; symptoms of unfavorable conditions, 53; changes in, 57, 58; physically wet, physiologically dry, 6r; chemical constituents, 62, 79; treatment of for shade and lawn trees, 77; composition of versus physical conditions, I98, I99; needed depth, r99; for transplanting, 172; influence on form, 204, 205; conditions for coniferous trees, 2 I 4

Soldiers' Home, Washington, I 86 
Sophora, 2II, 263

Sorbus, Mountain Ash, 211, 263, $264,365,369,372$

Sorrel Tree, Oxydendron, 21 2, 293

Sour Gum, Nyssa, 212, 291, 37 I

Spacing of trees, I80, 321

Span-worms, see Inchworms

Species, number of, 202, 206; description of those in Washington, compiled by B. E. Fernow, 206

Specimen trees, planting of, $\mathrm{I}_{3}$, I98, 208, 216, 218, 355

Sphinxes, I 57

Spiders, I3I

Spikes (flower shapes), 325

Spindletree, Evonymous, I92, 359

Spiny EIm caterpillar, 163

Spinners (moths), ${ }_{5} 8$

Spiraa, I5I, 325, 328, 350, 35I, 366-37I

Spot diseases, 37

Spraying, 55, I 27, I35, I40, I4I

Spraying machinery, I38; discussion of in Yearbook of U. S. Dept. of Agriculture, I40; dealers in, I40 note

Springfield, Mass., cost of spraying in, $I 4 I$

Spruce, Picea, 16, 25, I66, I78, 189, I93, 203, 209, 2r5, 228, 373; Blue, 242, 366; Caucasian, 243, 244; Japanese, 244, ${ }^{*}$ Norway, I 78, 240, 242; Red, 242; White, $2+2,371$

Spruce-bud tortrix, I66

Spruce-bud worm, I66

Spruce forests in Europe, $1_{4} 8$

Spurge Laurel, Daphne, 359

Squash-bug, I 50

Stagger Bush, Pieris, 328, 338

Staghead, 53, 61, 62, 72

Steeplebush, Spirca, 328, 350, $37^{\circ}$

Stomach of the plant, I 8

Stonebreak family, Saxifragacea, $35^{2}$

Stool shoots, I93

Storax family, 354

Strawberry-bush, Calycanthus, 327 , $357,368,370$

Strawberry-bush, Pirlls, 212, 297, 299 *

Strawberry Tree, Evonymus, 359, 368
Street trees, degrees of light intensity needed, 25 ; aëration, 82 ; height of crown from ground, ror; pruning while young, 109; spacing, II6, I80; mechanical injuries, II7; guards for, II 7 ; conditions for planting, 173, 176, 364; size, I 78, 364 ; adverse conditions, 199 ; considerations in choice, 201; inappropriate species, 203; also 198 , 214, 226, and List, pp. 364-365

Stuartia, 328, 363, 370

Styrax, 328, 355

Suckers, see WVater-sprouts

Suffocation, see Respiration

Sugar Plum, see Juneberry

Sulphur, 363

Sulphur, Flowers of, formula, ${ }_{4} 6$ note

Sumach, Rhus, 21 I, 26r, 368, 370372; Dwarf, 262; Osbeck, 262; Smooth, 262; Staghorn, 262; Venetian, 262

Sun-scald, $36,56,59,68$, I 75, 250, 286

Sunflower, 325

Surgery, 27, 32

Swamp Honeysuckle, Azalea, 33 I

Swamps, and root respiration, 20

Swampy soil, trees suitable for, 37 I

Sweet Fern, Myrica, 328, 362

Sweet Gum, Liquidambar, 2I 2, 288, 365

Sweet Gale, Myrica, 328, 362

Sweet Pepperbush, Clethra, 327, 332, $366,370,37^{2}$

Sweetbriar, English, 349

Sweetleaf, Symplocos, 329, 355, 368

Swift's arsenate of lead, I35 note

Sycamore, Platanus, 65, 69, 84, 103, 21 2, 298, 299, 364, 370, 37 I

Symphoricarpus, Waxberry, Indian Currant, Coral Berry, 329, 339, $366,368-370,372$

Symplocos, Buch-Ham, Sweetleaf, $329,355,368$

Syringa, Lilac, 325, 329, 344, 345 , $354,368,370,37$ I

Tachina flies, I 30

Tamarack, I66, 230

Tamarisk, Tamarix, 213, 316, 325, 37 I, 37.2; French, 318*; German, $317^{*}$; Indian, 319 * 
Tamarix, 213, 3I6, 317, * 318, 3 I9, * $325,371,372$

Tap-root, I7I, I78, 199, 284, 285, 306; see also Root system

Tarred Paper, Band of, for trapping insects, 145

Taste, standards of, 202

Taxodium, Bald Cypress, 210, 213 , $215,221,37$ I

Taxus, Yews, 192, $210,245,370$, 372

Temperature, and evaporation, $2 \mathrm{I}$

Teneriffe, Island of, Dragon Trees on, I 2 I

Tennyson, Alfred, Lord, quoted, 275

Thistle family, $35^{6}$

Thorn Tree, Cratcgus, I I I, 2 I 2, 283 , 366-370, 372; Cockspur, 282, ${ }^{*}$ 284; Scarlet, 284; White, I92, 284

Thrushes, I 30

Thuja, Arborvitæ or White Cedar, 210, 215, 219, 371, 373

Thuyopsis, Tom Thumb or Japanese Arborvitx, 210, 215, 219, 37I

Tick Trefoil, Desmodium, 327, 347, 367,370

Tiger-beetles, I3I

Tilia, Linden, Lime Tree or Basswood, 213, 318, 319, 364, 366, 367, 371

Tinea, see Leaf-miners

Tissues, dead, 6; living, 7, I7, I9; mechanical injuries to, 36 ; healing process of injured, 92 ; leaf-miners inside of, 167

Titi, Leucothöe, 333

Toadstool, 42

Tobacco, as an insecticide, I42, I49, I 5 O, I 55

Tom Thumb or Japanese Arborvitæ, Thuyopsis, 210, 215, 219, * 371

Top dressing, formula, 8o; see also Fertilizers

Torreya, California Nutmeg Tree, 210,247

Tortrix, see Leaf-rollers

Toxylon, Osage Orange, 21 3,320

Tracing-root, I6; see also Root system

Transpiration, see Evaporation

Transplanted trees, difference in derivation, 34 ; value of, I70
Transplanting, replacing of lost roots by, 27; adaptation to new conditions, 6r, 63; favorable conditions for, I 72 ; proper depth, $\mathbf{I} 73$; time, I76; size, I 77 ; spacing, I80

Trapping, as means of combating insect pests, I44

Tree-hoppers, I 50

Tree-life, essential points of, 27 , 28

Tree of Heaven, Ailanthus, 210 , $25 \mathrm{I},{ }^{*} 256,262$

Tree-planting, objects of, 198

Tree-tanglefoot, I 45

Trees and shrubs, confusion between, 208

Trimming, distinguished from pruning, 87

Trunk, see Bole

Tsuga, Hemlock, 2 10, 227, 228, 373; see also Pscudotsuga

Tulip Tree, Liriodendron, I02, I93, $203,212,288,365,370$

Tupelo, Nyssa, 2I 2, 29I, 37 I

Tussock moth, I50

'Twigs, breathing pores in, 20; dying of, in old trees, 30; trees and shrubs with colored, 367

"Two, two, fifty," formula, I27; see also "Five, five, fifty"

Two Winged Silver Bell 'Tree, 355

Types of flower shapes 325 ; of trees, 203, 204

Ulmus, Elms, 213, 320-322, 364, 365

Umbel, 325

Umbrella Tree, Melia, 210, 260, 26 I

U. S. Div. of Forestry, Bulletin no. I 7 , referred to, 208

Varnish Tree, Kolreuteria, 210, 258,* 261,370

Verbena family, 363

Vermorel nozzle, I39, I47

Viburnum, Snowballs, I92, 324, 329, $339,340,34 \mathrm{I}, 366,373$

Vireos, I30

Virgilia, see Cladrastis

Virginia Willow, Itea, 352

Vitex, Chaste Tree, $329,363,370$

Vreeland Chemical Company, I35 note 
Wahoo, Evonymous, 359, 367

Wahoo, Ulmus, 32 I

Walking-stick, Mantidæ, I3I, I5I

Walnut, Juglans, I6, 102, I54, I 7 I, 210, 259, 26r; Black, 257; English, 260; White, 257

WTarblers, I30

Water, taken up by rootlets, I7, I9, 21, 28; even supply favorable, 24 ; use of in transplanting, 174

Water-sprouts, 53, 59, roo

Water-supply, deficiency cause of death, 30,31 ; reduced by pavements, 33 ; and winter-killing, 66 ; surplus at root, 58, 59; various demands upon, 60; necessary to growth, 77,78 ; regulation by drainage, 79 ; excluded by grading, 80; in old age, I2I, I23; also $53,57,62,64,169,198,199,201$, 206

Water-works, mechanism of tree compared with system of, I8

Wattle, Acacia; Black, 249; Hairy, 249

Wax, covering a wound, 95 ; formula for, II 3 nole; used in bridging, I15; also 167

Wax Myrtle, Myrica, 328, 362, 369373

Waxberry, Symphoricarpus, 329, $339,366,368-370,372$

Weather, affecting disease, 53, 57, 64 ; a consideration in transplanting, 176

Weevils, 48, I52, 284; see also Insect pests

Weigelia, see Diervilla

Whale-oil soap, see Soap solution
White Alder, Clethra, $327,332,366$, 370,372

White Beam, Sorbus, 264

White Pine pest from Germany, 37

White Pine scale, I5I

White Pine weevil, 153

Whitewash, sec Lime wash

Whitewood, Liriodendron, 21 2, 288, 370

Wild Service Tree, Sorbus, 264

Willow, Salix, 16, 25, 58, 65, 68, I54-156, I58, I6I, I63, I7 I, 213, 365; Kilmarnock, 315; Laurel leaf, 316, 365, 37I; Weeping, 315; White, 3I5

Willow-rosette, 48; see also Galls

Wind, damage from, 31

Wireworms, I48, 155

Witch's broom, 38

Wood-borers, 49, 152-I54, 158, 275

Wood Honeysuckle, Azalea, 330

Wood-wasps, 49; see also Insect pests

Wounds, dressing of, 89 ; healing, 9I-94; treatment for fresh, II3

Wrens, I30

Xolisma, Privet Andromeda, 335

Yarrow, 324

Yellow-wood, Cladrastis, 210, 253 , 365

Yew, Cephalotaxis, 200, 246, ${ }^{*} 247$; Podocarpus, 210, 247; Taxus, 192, $210,245,{ }^{*} 370,372 ;$ Torreya, 210 , 247; English, Taxus, 210, $2455^{*}$ 246; Japanese, Taxus, 210,246

Zenobia, 335,372 




\section{THE AMERICAN NATURE SERIES}

In the hope of doing something toward furnishing a series where the nature-lover can surely find a readable book of high authority, the publishers of the American sicience Series have berun the publication of the American Nature Series. It is the intention that in its own way, the new series shall stand on a par with its famous uredecessor.

The primary object of the new series is to answer questions which the contemplation of Nature is constantly arousing in the mind of the unscientific intelligent person. But a collateral object will be to give some intelligent notion of the "causes of things."

While the coöperation of foreign scholars will not be declined, the books wiil be under the gruarantee of American experts, and generally from the American point of view; and where material crowds space, preference will be given to American facts over others of not more than equal interest.

The series will be in six divisions:

\section{NATURAL HISTORY}

This division will consist of two sections.

Section A. A large popular Natural History in several volumes, with the topies treated in due proportion, by authors of unquestioned authority. 8vo, $7 \frac{1}{2} \times 10 \frac{1}{4}$.

\section{The books so far publisht in this section are:}

FISHES, by Davin Star Jordax, President of the Leland Stanford Junior University. $\$ 6.00$ net; carriage extra.

AMERICAN INSECTS, by Yanson L. Kellogg, Professor in the Leland Stanford Junior University. $\$ 5.00$ net; carriage extra.

BIRDS OF THE WORLD. A popular account by Fraxk H. Knowltow, M.S., Ph.D., Nember American Ornithologists Union, President Biological Society of Washington, etc.. etc., with Chapter on Anatomy of Birds by Freneric A. Lucas, Chief Curator BrookIyn Museum of Arts and Sciences, and edited by Robert Ringway, Curator of Birds, U. S. National Museum. $\$ 7.00$ net; carriage extra.

\section{Arranged for are:}

SEEDLESS PLANTS, by Georgf, T. Moone, Head of Lepartment of Botany, Marine Biological Laboratory, assisted by other specialists.

WILD MAMMALS OF NORTH AMERICA, by C. HART MERruas, Chief of the United States Biological Survey.

REPTILES AND BATRACHIANS, by Leonhari) STEJNeger, Curator of Reptiles, U. S. National Miuseum. 


\section{NATURAL HISTORY (Continued)}

Section B. A Shorter Natural History, mainly by the Authors of Section A, preserving its popular character, its proportional treatment, and its authority so far as that can be preserved without its fullness, Size not yet determined.

\section{CLASSIFICATION OF NATURE}

\section{Library Series, very full descriptions, 8 vo. $7 \frac{1}{2} \times 10 \frac{1}{\mathrm{in}}$.}

\section{Already publisht:}

NORTII AMERICAN TREFS, by N. L. Britros, Director of the New York Botanical Garden. \$i.00 net; carriage extra.

FERNS, by Canprez.t. E. Watros, of Johns Hopkins Lniversity, $\$ 3.00$ net; by mail, $\$ 3.30$.

2. Pocket Series, Identification Books - " How to Know," brief and in portable shape.

\section{FUNCTIONS OF NATURE}

These books will treat of the relation of facts to causes and effects - of heredity and the relations of organism to environment. 8 vo. $658 \times 8 \frac{7}{8}$ in.

\section{Already publisht:}

THE BIRD : ITS FORMI AND FUNCTION, by C. W. BEEBE, Curator of Birds in the New York Zoological Park. \$3.50 net; by mail, $\$ 3.80$.

Arranged for:

THE INSECT: ITS FORII AND FUNCTION, by Vernon L. Keiloge, Professor in the Leland Stanford Junior University.

THE FISH : ITS FORM AND FUNCTION, by H. MI. SnITH, of the U. S. Bureau of Fisheries.

\section{WORKING WITH NATURE}

How to propagate, develop, care for and depict the plants and animals. The volumes in this group cover such a range of subjects that it is impracticable to make them of uniform size.

\section{Already publisht:}

NATLRF, AND HEALTH, by Enwan Cirtis, Professor Emeritus in the College of Physicians and Surgeons. 12mo. \$1.25 net; by mail, $\$ 1.37$.

THE FRESHWATER AQUARIUM AND ITS INHABITANTS. A Guide for the Amateur Aquarist, by Otro Egenisg and Frederick Ehrexberg. Large 12mo. \$2.00 net; by mail, \$2.19 
A MER I C A N N T URE SER I ES (Continued)

\section{WORKING WITH NATURE (Continued)}

THE LIFE OF A FOSSIL HUNTER, by Charres H. Sternizir. Large $12 \mathrm{mo}$. $\$ 1.60$ net: by mail, $\$ 1.72$.

SHELL-FISH INI)USTRies, by Janes L. Ketmog, Professor in Williams College. \$1.75 net; by mail, \$1.93.

THE CARE OF TREES IN LAWN, STREET AND PARK, by B. E. Fernow, Professor of Forestry, University of Toronto.

\section{Arranged for:}

PHOTOGRAPHING NATURE, by E. R. SANmon, Photographer of the New York Zoological Park.

CHEMISTRY OF DAILY LIFE, by Henry P. Talizot, Professor of Chemistry in the Massachusetts Institute of Technology.

DOMESTIC ANIMALS, by William H. Brewer, Professor Emeritus in Yale University.

INSECTS AND DISFASE, by Renxie W. Doaxe, Assistant Professor in the Leland Stanford Junior University.

\section{DIVERSIONS FROM NATURE}

This division will include a wide range of writings not rigidly systematic or formal, but written only by authorities of standing. Large $12 \mathrm{mo} . \quad 5 \frac{1}{4} \times 8 \frac{1}{8} \mathrm{in}$.

\section{Already publisht:}

INSFCT STORIES, by Veray L. Keilosi(. \$1.50 net; by mail, $\$ 1.62$.

FISH STORIES, by Charifs F. Holden and David Starr Jordpax, $\$ 1.75$ net; by mail, $\$ 1.87$.

\section{Arranged for.}

HORSE TALK, by WILIAM H. BREWER.

BIRD NOTES, by C. W. BEEBE.

\section{THE PHILOSOPHY OF NATURE}

A Series of volumes by President Jondan, of Stanford University, and Professors Brooks of Johns Hopkins, Lut of Yale, Tномson of Aberdeen, Pizibram of Austria, zur Strassen of Germany, and others. Edited by Professor KeLLOGg of Leland Stanford. I mo. $5 \frac{1}{8} \times 7 \frac{1}{2} 1 \mathrm{n}$.

Arranged for:

THE Stability OF TRUTh, by David Starr Jordan.

HENRY HOLT AND COMPANY, NEW YORK JANEARY, ' 10 , 


\section{BRITTON'S NORTH AMERICAN TREES}

By Nathaxiel Lond Britrox, Director-in-Chief of the N. Y. Botanical Garden, assisted by J. \. Shafer, Custodian of the Museums of the N. Y. Botanical Garden, 775 illustrations, 894 pp., $\$ 7.00$ net.

The most comprehensive and profusely illustrated single volume on the trees known to grow independently of cultivation in North America north of the West Indies and Mexico. Wrth a minimum of technical terms, a glossary of the botanical terms, keys for identification and a 29-page index.

"This splendid book."-7he Dial.

"It is a most thoroly admirable book, and one which I shall find personally of the greatest use. There is nothing of the kind better in any language either in method or appearance of text."-President DAvID STARR JORDAN, Leland Stanford University.

"This superb volume. . . Seldom does one find a book which merits more enthusiastic enconiums than this. No slightest aspect of the subject untouched; yet there is not a superfluous phrase, scarcely a superfluous word. . Invaluable to all serious students. . . Excellent paper, admirable type and abundant illustrations."-Frovidence Journal.

\section{KERNER AND OLIVER'S NATURAL HISTORY OF PLANTS.}

From the German of Axton Kerner von MArilaun, Professor of Botany in the University of Vienna, by F. W. Oliver, Quain Professur of Botany in University College, London, with the assistance of MARIAN Bush and MARY E. EWART. 4to. 2 vols. The set, \$I I. OO net.

A work for reference or continuous reading, at once popular and, in the modern sense, thoroly scientific. The new edition is practically identical with the former four-volume edition except that the colored plates in the latter have been omitted. The wood engravings, over two thousand in number. have been retained.

"Professor Kerner has honught the most recent researches within reach of the intelligent reader, and in a style so clarming that even the professiona! teacher may learn a lesson in the art of presentation."-Prof. JoHN M. Coulter, in Tha Dial.

\section{Prospectuses of the above on request.}

H E N R H O L T A D COMPANY
if WEST 33D ST. 


\section{Ferns of the Northeastern States}

By Campbell E. Waters. 302 pp. Square 8vo, with 200 illustrations, mostly from photographs. Boxed, \$3.00, net; by mail, $\$ 3 \cdot 34$.

Thoroughly authoritative, yet popular in style, it covers all the ferns in the region embraced either in Britton's or in Gray's Manuals. Contains Analytical Keys based both on the Stalks and on the Fructification.

"This book is likely to prove the leading popular work on ferns. No finer examples of fern photography have ever been froducen. Dr. Waters brings to his work fifteen years of experience in field and herbarium study, and the book may be expected to prove of permanent scientific value as well as to satisfy a want which existing treatises have but imperfertly filled."-Plant World.

\section{Mushrooms}

By George F. Atrinson. With 230 illustrations from photographs, including 15 colored plates. 320 pp. 8 vo. \$3.00, net; by mail, \$3.23.

Mushrooms, edible, poisonous, etc. With recipes for cooking by Mrs S. T. Rorer, and the chemistry and toxicology of mushrooms by J. F. Clark.

"It would be difficult to conccive of a more attractive and useful rook."-Educational Reviez.

\section{Atkinson's College Botany}

By George F. Atkinson, Professor in Cornell University. $\mathrm{xvi}+737$ pp. Svo. \$2,00.

This book is the result of a revision and elaboration of the author's "Elementary Botany." The general plan of the parts on physiology and general morphology remains unchanged. Considerable new matter his been added, however, in the physiological part, especially on the subjects of nutrition and digestion, and the subject of the morphology of fertilization in the gymnosperms and angiosperms has been revised to bring this abreast of the discoveries of the past few years. The greatest improvement has been in the complete reorganization, rewriting, and elaboration of the part dealing with ecology, which has been made possible by studies of recent years, so that the subject can be presented in a more logical and coherent form.

\section{HENRY HOLT \& CO. 34 west 33d Street, New York vi11, '05}




\section{Kellogg's Darwinism Today}

By Versox L. Kellogi, Professor in the I.cland Stanford University. 395 pp. 8vo. $\$ 2.00$, net. Postage 15 cents.

A simple and concise discussion for the educated layman of present-day scientific criticism of the Darwinian selection theories, together with concise accounts of the other more important proposed auxiliary and alternative theories of speciesforming.

President Darid Starr Jordan in The Dial:-Its value cannot be over-estimated. A book the student must have at hand at all times, and it takes the place of a whole library. No other writer has attempted to gather together the scattered literature of this vast subject, and none has subjected this literature to such uniformly trenchant and uniformly kindly criticism. An investigator of the first rank, and master of a clear and forceful literary style.

New York Sun:-Can write in English as brightly and as clearly as the old-time Frenchmen.... In his text he explains the controversy so that the plain man may understand it, while in the notes he adduces the evidence that the specialist requires. . . A brilliant book that deserves general attention.

\section{Locy's Biology and Its Makers}

By Willax A. Locy, Professor in Northwestern University. 460 pp. 8ro. \$2.75, net. By mail, \$2.88.

An untechnical account of the rise and progress of biology; written around the lives of the great leaders, with bibliograpliy and index. The 123 illustrations include portraits, many of them rare, of nearly all the founders of biology. The book is divided into two parts: Part I dealing with the sources of biological ideas except those of Organic Evolution, and Part II devoting itself wholly to Evolution.

The Dial:- It is entertainingly written, and, better than any other existing single work in any language, gives the layman a clear idea of the scope and development of the broad science of biology.

The Nation:- Whether the reader be layman, or a college student, or a biologist whone life work is nearing completion, this summary of achievements will be an inspiration. Introduces us in a charming way to the human side of the scientists. A well chosen reading list, an excellent index.

\section{HE NRY HOL'T A ND COMPAN Y PUBLISHERS




\section{E. RAY LANKESTER'S EXTINCT ANIMALS}

By Prof. E. Ray Lankester, F.R.S., Keeper of the Natural History Department of the British Museum, Author of "The Advancement of Science" and "A Treatise of Zoölogy." With numerous illustrations. \$1.75 net; by mail, \$I.93.

An interesting book by a high authority, based on a course of his successful, popular lectures. His narrative is well unified and developed, and his style so simple that children as well as older folk may enjoy the work. The illustrations are unusually effective.

N. Y. Sun:-A charming book . . showing that the greatest learnıng can be combined with the utmost simplicity of expression . . . a book of intense interest... the pictures are skilfully arranged to elucidate the text.

N. Y. Globe:-A great deal more lively than it sounds. . . Huxley himself could not have talked more instructively in such simple language.

N. Y. Tribune:-Opens up a world of new interest, popular rather than technical.

\section{E. RAY LANKESTER'S THE KINGDOM OF MAN}

"Nature's Insurgent Son"; "The Advance of Science188I-I906"; “Nature's Revenges-The Sleeping Sickness." \$I.40 net; by mail, \$I 52 .

A readable and pictorial survey, brief but nevertheless accurate, of the recent progress in the many branches of science-all leading towards the realization of man's king dom-the conquest and control of nature.

H. I. Brock in a three-column notice in the New York Times Saturday Review.-An impressive statement of human progress in knowledge and power by a conservative scientist who believes man soon able to eliminate disease... exceedingly interesting... it gathers into a very small compass and presents sharply to the layman an immensely impressive set of facts and ideas.

*** If the reader will send his name and address. the publishers wilk send, from time to time, information regarding their new books.

\section{HENRY HOI.T AND COMPANY}



SD Fernow, Bermhard Eduard

391 The care of trees in lawn,

F3 street and park.

cop. 3

BiolMed

\author{
PLEASE DO NOT REMOVE \\ CARDS OR SLIPS FROM THIS POCKET
}

UNIVERSITY OF TORONTO LIBRARY 
